Data de Depósito:

Assinatura:

\title{
Uma abordagem para projeto de aplicações com interação multimodal na Web
}

\author{
Americo Talarico Neto \\ Orientadora: Profa. Dra. Renata Pontin de Mattos Fortes \\ Tese apresentada ao Instituto de Ciências Matemáticas e de \\ Computação - ICMC-USP, como parte dos requisitos para \\ obtenção do título de Doutor em Ciências - Ciências de \\ Computação e Matemática Computacional. VERSÃO \\ REVISADA.
}


Ficha catalográfica elaborada pela Biblioteca Prof. Achille Bassi e Seção Técnica de Informática, ICMC/USP, com os dados fornecidos pelo(a) autor(a)

Talarico Neto, Americo

Uma abordagem para projeto de aplicações com interação multimodal na Web / Americo Talarico Neto; orientador Renata Pontin de Mattos Fortes -- São Carlos, 2011.

$199 \mathrm{p}$.

Tese (Doutorado - Programa de Pós-Graduação em Ciências de Computação e Matemática Computacional) -Instituto de Ciências Matemáticas e de Computação, Universidade de São Paulo, 2011.

1. INTERAÇÃO HOMEM-MÁQUINA. 2. PROJETO DE SOFTWARE. 3. INTERFACES DE VOZ. 4. INTERFACES MULTIMODAIS. 5. ENGENHARIA DE SOFTWARE. I. Pontin de Mattos Fortes, Renata, orient. II. Título. 
"Embora ninguém possa voltar atrás e fazer um novo começo, qualquer um pode começar agora e fazer um novo fim"

- Chico Xavier 
A Deus.

Aos meus familiares, Alina, Clarissa, Rosa Maria, Rosa Aparecida e Wladimir pelo apoio em todos os momentos.

A orientadora, professora Renata, pela amizade, ajuda e confiança.

Aos colegas do laboratório Intermídia e da empresa Nuance Communications Inc pelo incentivo e colaboração. 
O principal objetivo do desenvolvimento de aplicações multimodais é possibilitar uma maneira mais natural dos seres humanos se comunicarem com as máquinas, por meio de interfaces mais eficientes, intuitivas, fáceis de usar e, de certa forma, mais inteligentes.

No entanto, a literatura da área mostra que a reutilização, tanto de conhecimento como de código fonte, ainda apresenta problemas, dados a complexidade do código em sistemas multimodais, a falta de mecanismos eficientes de testes de usabilidade e a dificuldade em se gerenciar a captura, o armazenamento e a recuperação de conhecimento de projeto.

Nesta tese argumenta-se que a utilização de uma abordagem sistemática, centrada no usuário, apoiada por uma ferramenta computacional e com um modelo bem definido que permita o desenvolvimento de interfaces multimodais com a reutilização de Design Rationale, aumenta e melhora os níveis de usabilidade, promove a identificação e utilização de padrões de projeto e o reúso de componentes.

Para demonstrar esta tese, apresenta-se neste texto a abordagem para o desenvolvimento de interfaces multimodais Web, MMWA, e o seu ambiente de autoria, o MMWA-ae, ambos compostos por atividades que auxiliam a equipe de projeto durante as fases de projeto, desenvolvimento e avaliações de usabilidade.

São discutidos também os resultados obtidos com a execução de três estudos de caso, realizados no ambiente acadêmico, nos quais se buscou determinar a viabilidade da abordagem e os benefícios que podem ser alcançados com a combinação de diferentes técnicas, a saber: design rationale, padrões de projeto, modelagem de tarefas, componentes de software, princípios de usabilidade, avaliações heurísticas, testes com usuários, regras de associação, entre outras.

Os resultados evidenciam que a abordagem e seu ambiente de autoria podem proporcionar diferentes benefícios para organizações que desenvolvem sistemas multimodais, incluindo o aumento da usabilidade e consequentemente da qualidade do produto, bem como a diminuição de custos e da complexidade do desenvolvimento com a reutilização de código e de conhecimento capturado em projetos anteriores.

Palavras-chave: Interfaces multimodais, usabilidade, projeto de interfaces, Design Rationale, reúso. 
The main goal of developing multimodal applications is to enable a more natural way of communication between human beings and machines through interfaces that are more efficient, intuitive, easier to use and, in a certain way, more intelligent.

However, the literature shows that the reuse of both knowledge and source code still presents problems, given the complexity of the code in multimodal systems, the lack of efficient mechanisms to test the usability and the difficulty in managing the capture, the storage and the recovery of design knowledge.

In this thesis it is discussed that the use of a systematic approach, usercentered, supported by a computer tool and with a well defined model that allows the development of multimodal interfaces with the reuse of DR, increases and improves the usability levels, promotes the identification and the use of design patterns and the reuse of components.

To demonstrate this thesis, it is shown in this text an approach to develop Web multimodal interfaces (MMWA) and its authoring environment (MMWA-ae), both composed of activities that help the design team during the different project phases: design, development and usability evaluation.

We also discuss in this thesis the results obtained with the execution of three case studies, executed in the academic environment, which aimed to determine the feasibility of the approach and the benefits that can be achieved with the combination of different techniques, such as: design rationale, design patterns, tasks model, software components, usability principles, heuristic evaluations, user testing, association rules, among others.

The results show clearly that the approach and its author environment can provide different benefits to organizations that develop multimodal systems, including the usability improvement and, consequently, the quality of the product, as well as the decrease of costs and complexity since it encompasses the development with reused code and design knowledge captured in previous projects.

Keywords: Multimodal Interfaces, usability, interface design, Design Rationale, reuse. 


\section{Glossário}

Gramática: é um arquivo que contém todas as palavras, sentenças ou frases que o sistema Reconhecedor de Voz deve entender. Uma gramática retorna para a aplicação um significado semântico em resposta a uma entrada do usuário.

Log: é uma expressão utilizada para descrever o processo de registro de eventos relevantes que ocorrem na execução de um software.

Nomatch: tipo de erro que ocorre nas interfaces de voz, no qual a fala do usuário não confere com os dados presentes na gramática.

NoInput: tipo de erro que ocorre nas interfaces de voz, no qual o usuário não fala nada em resposta a um prompt.

Prompt: define uma mensagem falada da interface de voz para o usuário, com o objetivo de obter uma entrada de informação.

Widget: um termo genérico para referenciar um componente de interface gráfica.

Wiki: uma palavra do idioma havaiano que significa "rápido". Na computação é utilizada para referir-se a um sistema colaborativo na Web para a criação e edição de hiperdocumentos. 
AS - Análise de Soluções

AU - Avaliação de Usabilidade

API - Application Programming Interface

DOM - Document Object Model

DR - Design Rationale

DTD - Document Type Definition

DTMF - Dual-Tone Multi-Frequency

EC - Estudo de caso

EMMA - Extensible MultiModal Annotation

GUI - Graphical User Interface

IBIS - Issue-Based Information System

IT - Identificação de Tarefas

ISO - International Organization for Standardization

IHC - Interação Humano-Computador

JSGF - Java Speech Grammar Format

JSP - Java Server Pages

HTML - HyperText Markup Language

LOC - Lines of Code ou Linhas de Código

MVC - Modelo-Visão-Controlador

MMWA - MultiModal Web Approach

MMWA-ae - MultiModal Web Approach authoring environment

MMLOG - MultiModal Log Analysis

MMHE - Multimodal Heuristic Evaluation

MCI - Modelo Comportamental Inicial

RT - Representação de Tarefas

SAAS - Software As A Service 
SALT - Speech Application Language Tags

SAX - Simple API for XML

SDK - Software Development Kit

TTS - Text To Speech

UML - Unified Modeling Language

UsiXML - User Interface eXtensible Markup Language

VUI - Voice User Interface

VXML - Voice eXtensible Markup Language

W3C - World Wide Web Consortium.

WIMP - Window, Icon, Menu, Pointing

$\mathrm{X}+\mathrm{V}$ - eXtensible HyperText Markup Language + Voice

XHTML - eXtensible HyperText Markup Language 


\section{Índice de Quadros}

Quadro 1 - Definição de usabilidade em diferentes fontes .................................................................13

Quadro 2 - Principais elementos da linguagem VXML organizados por escopo …...............................32

Quadro 3 - Sincronização das interfaces de voz e gráfica do segundo estudo de caso ..........................56

Quadro 4 - Trecho do documento de projeto do segundo estudo de caso............................................60

Quadro 5 - Trecho do formulário de avaliação heurística................................................................... 70

Quadro 6 - Exemplo de utilização de DR em um estudo de caso com a MMWA ..................................78

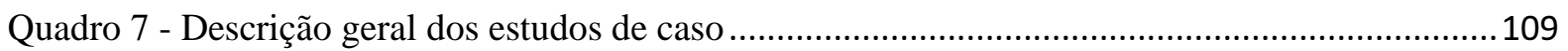

Quadro 8 - Uso de design rationale no estudo de caso 1 ............................................................... 112

Quadro 9 - Dados gerais das avaliações de usabilidade nos Estudos de Caso executados com a

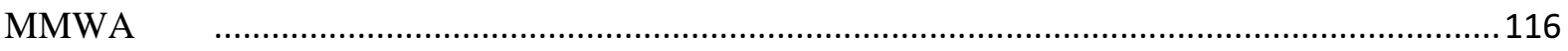

Quadro 10 - Sincronização das interfaces do sistema de localização de rotas do EC2 ........................123

Quadro 11 - Dados gerais dos Estudos de Caso executados com a MMWA.......................................132

Quadro 12 - Utilização de comandos universais nos estudos de caso ...............................................141

Quadro 13 - Trecho do MMLOG que apresenta mudança de modalidade após um erro ....................142

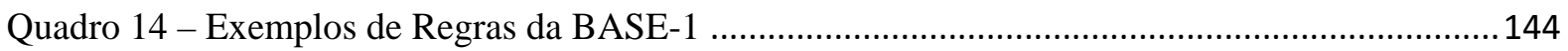

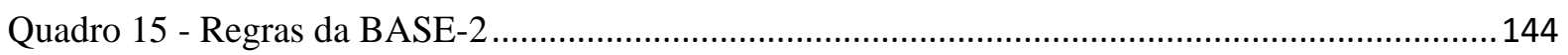

Quadro 16 - Exemplo de erro que pode ser corrigido com o uso das propriedades CARE ................146

Quadro 17 - Tempo de desenvolvimento das interfaces geradas no EC1 e EC3 ................................152 


\section{Índice de Figuras}

Figura 1 - Usuário interagindo com o sistema Put That There (BOLT, 1980) ….................................. 2

Figura 2 - Mapa de Leitura da Tese ……...................................................................................... 10

Figura 3 - Modelo em camadas para usabilidade, traduzido de (VEER; WELIE, 2000). ....................18

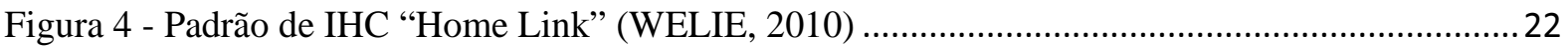

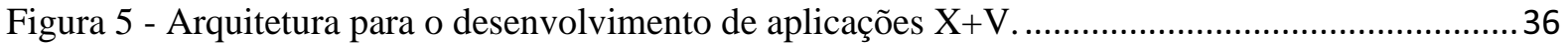

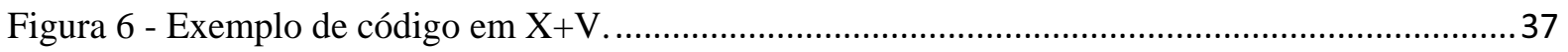

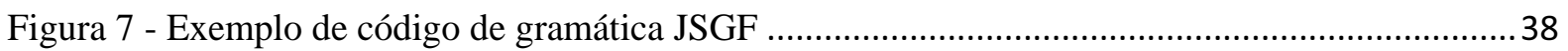

Figura 8 - Componentes básicos do Framework para Interação Multimodal do W3C (LARSON, 2003)

Figura 9 - As atividades da MMWA: 1-Modelo Comportamental Inicial (MCI); 2-Identificação de

Tarefas (IT); 3- Representação de Tarefas (RT); 4- Análise das Soluções (AS); 5-Avaliação de

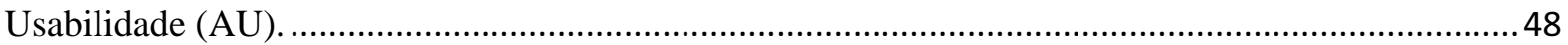

Figura 10 - MMWA: Modelo Comportamental Inicial ..................................................................... 51

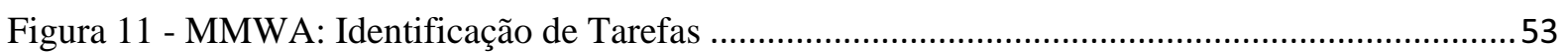

Figura 12 - Diagrama de transição de estados utilizado no estudo de caso 2 ......................................54

Figura 13 - Diagrama de atividades utilizado no estudo de caso 2 ....................................................54

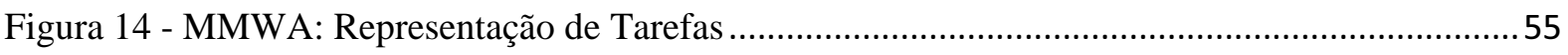

Figura 15 - MMWA: Análise de Soluções........................................................................................ 58

Figura 16 - Trecho do Documento de Projeto obtido com a MMWA ……...........................................59

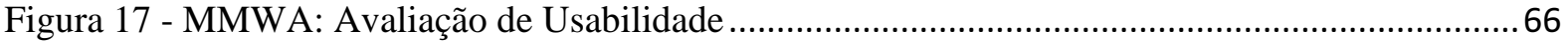

Figura 18 - MMHE: Formulário de avaliação heurística ......................................................................69

Figura 19 - Fluxo de interação do MMLOG .................................................................................. 71

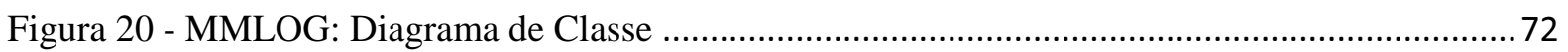

Figura 21 - MMLOG: gráfico que mostra o número e o tipo dos erros na interface de voz para uma

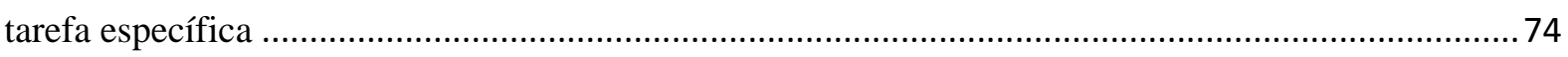

Figura 22 - MMLOG: gráfico que compara o uso de dois tipos de modalidade para uma tarefa.........75

Figura 23 - Relacionamentos do Modelo IBIS adaptado de (KUNZ; RITTEL, 1970) .........................77

Figura 24 - Exemplo de DR capturado durante o preenchimento da checklist ..................................... 78

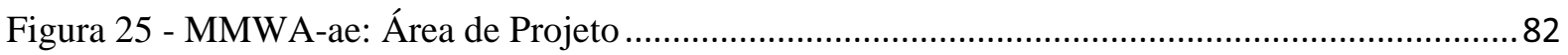

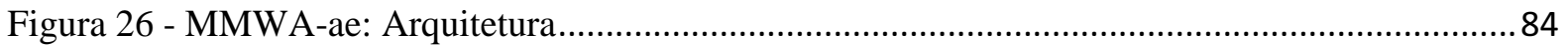

Figura 27 - Captura de DR usando o MMWA-ae e a DokuWiki........................................................92

Figura 28 - Trecho de código de interface de voz gerado pelo MMWA-ae ..........................................93

Figura 29 - Trecho de código de interface gráfica gerado pelo MMWA-ae..........................................94 
Figura 30 - Trecho de código de sincronização gerado pelo MMWA-ae

Figura 31 - Trecho da função que captura eventos de erro .................................................................94

Figura 32 - Tempo médio de interação na tarefa ChooseService para GUI e VUI................................95

Figura 33 - MMLOG: Criação do protocolo de testes ......................................................................95

Figura 34 - Protocolo de testes em execução .....................................................................................96

Figura 35 - Cenário de uso criado pelo MMLOG …….........................................................................96

Figura 36 - Elementos do Modelo de Tarefas da MMWA e o DR recuperado .....................................99

Figura 37 - Sugestão automática de padrão de projeto multimodal para corrigir um problema de usabilidade

Figura 38 - Trecho do modelo que mostra dois erros na interface de voz e uma interação gráfica

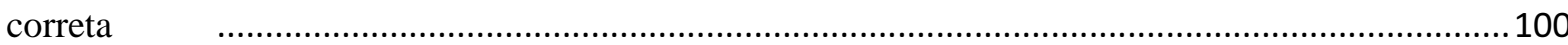

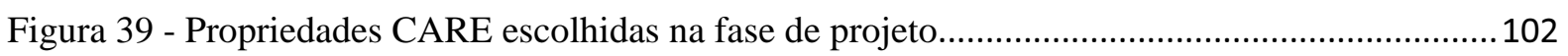

Figura 40 - Propriedades CARE utilizadas nos Testes com Usuários ................................................. 102

Figura 41 - Trecho do modelo que permite a identificação de um problema de usabilidade ..............103

Figura 42 - MMWA-ae sugerindo uma correção, fundamentado em um problema de usabilidade

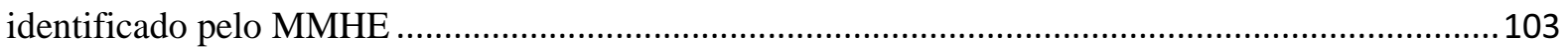

Figura 43 - Linha do tempo das atividades realizadas no doutorado ................................................110

Figura 44 - Disposição dos elementos gráficos no sistema de localização de rotas. ...........................119

Figura 45 - Diagrama das camadas da aplicação de localização de rotas do EC2..............................119

Figura 46 - Elementos X+V da aplicação de localização de rotas do EC2 ........................................121

Figura 47 - Métodos JavaScript da aplicação de localização de rotas do EC2. ....................................122

Figura 48 - Métodos ActionScript da aplicação de localização de rotas do EC2. …............................123

Figura 49 - Interface desenvolvida no EC1, sem o auxílio do MMWA-ae .........................................126

Figura 50 - Interface do EC3, projetada com o MMWA-ae, sendo executada em uma plataforma de

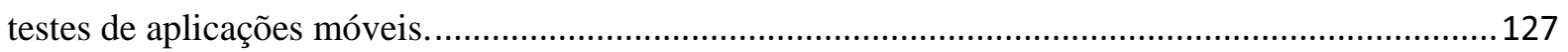

Figura 51 - Sistema de apresentações de palestras desenvolvido no EC3 ……................................127

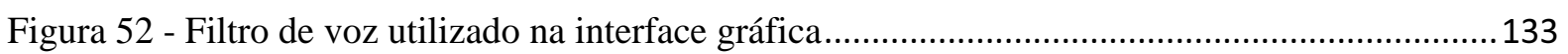

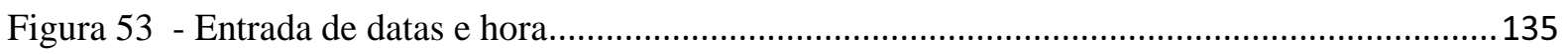

Figura 54 - Tipos de erro identificados na interface de voz.......................................................... 137

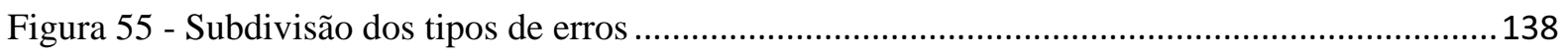

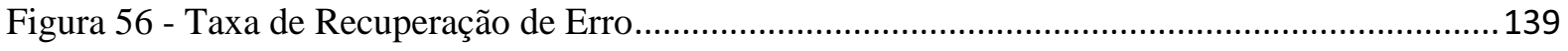

Figura 57 - Taxa de Recuperação de Erros em relação ao total de interações analisadas....................139

Figura 58 - Estrutura para identificação de padrões de projeto ...........................................................148

Figura 59 - Linha do tempo das atividades realizadas no doutorado e publicações ...........................157 
Capítulo 1. Introdução 1

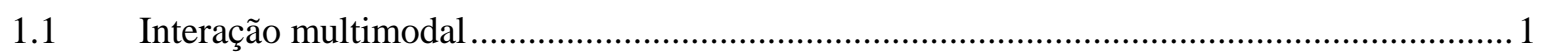

1.2 Motivações para a pesquisa com interação multimodal ..................................................... 4

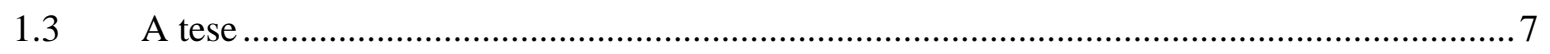

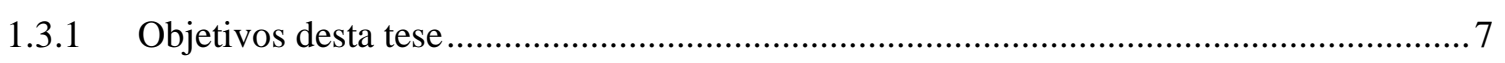

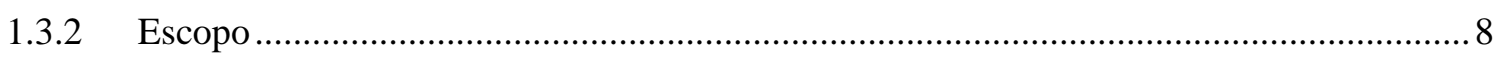

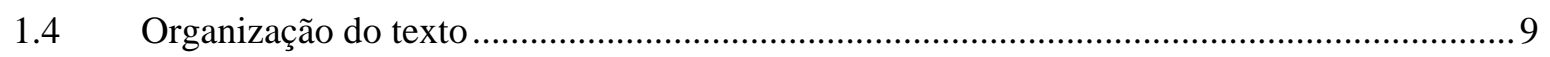

Capítulo 2. A usabilidade no projeto de interfaces multimodais centrado no usuário.........................11

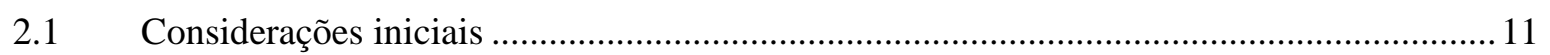

2.2 Definições de usabilidade e acessibilidade ........................................................................ 12

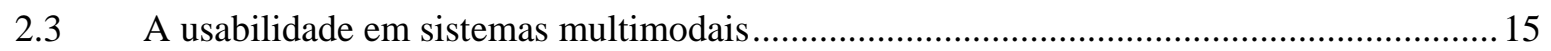

2.4 Um modelo em camadas para obtenção de requisitos considerando usabilidade................... 17

2.5 Princípios e guidelines para o projeto de interfaces multimodais Web ................................ 18

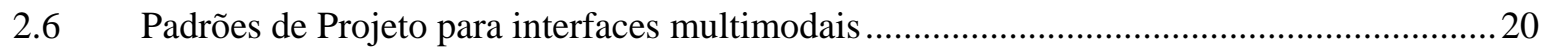

2.7 Avaliação de usabilidade em interfaces multimodais.........................................................22

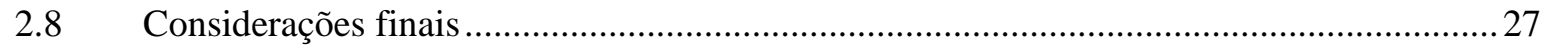

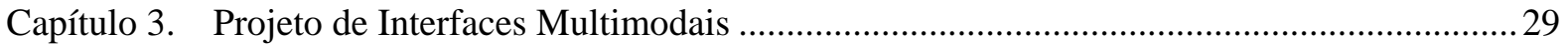

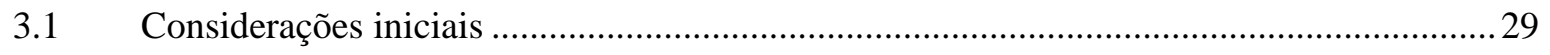

3.2 O uso de interação por voz em sistemas multimodais .......................................................... 30

3.3 Tecnologias para o desenvolvimento de interfaces multimodais para a Web ......................31

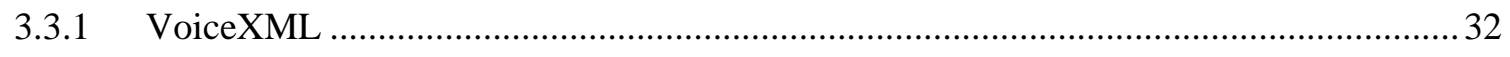

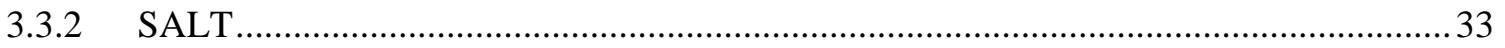

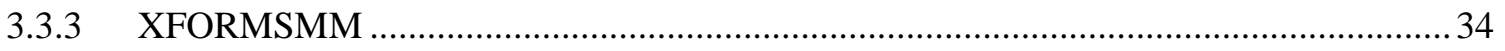

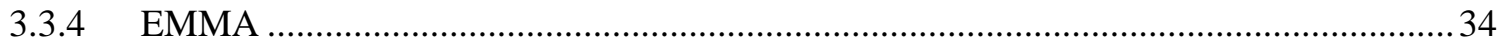

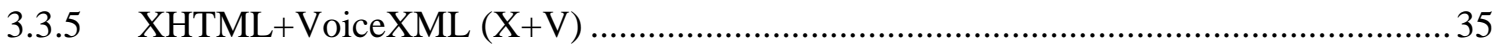

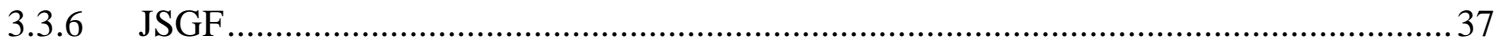

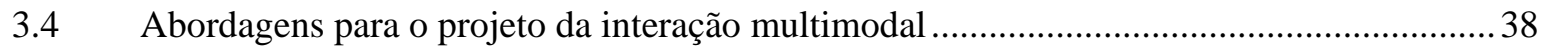

3.4.1 Estado da arte das abordagens para projeto de interfaces multimodais ............................39

3.4.2 Frameworks conceituais para desenvolvimento de sistemas multimodais Web..............42

3.4.2.1 Framework ICARE (Interação, Complementaridade, Associação, Redundância e

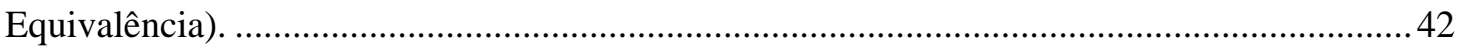

3.4.2.2 Framework para interação multimodal do W3C ...................................................... 44

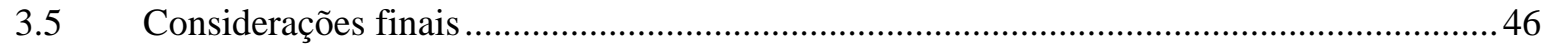

Capítulo 4. Abordagem para o Desenvolvimento de Interfaces Multimodais Web (MMWA) ..........47 


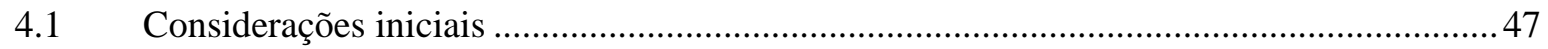

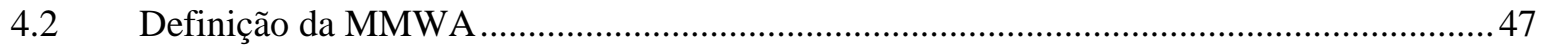

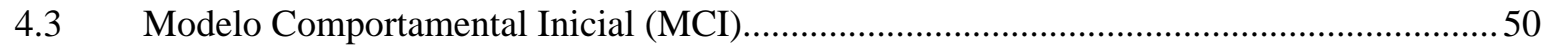

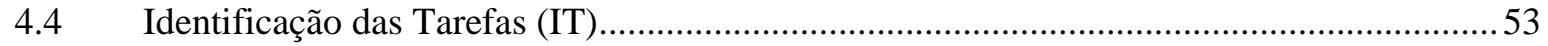

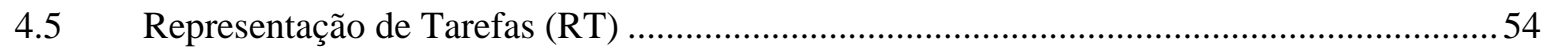

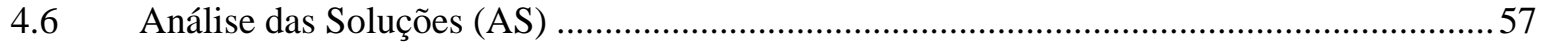

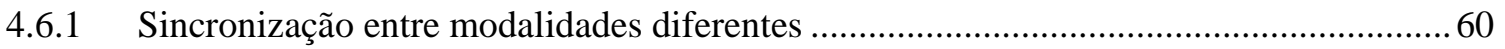

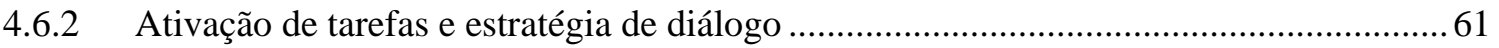

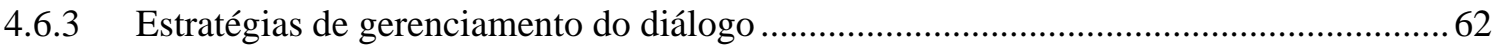

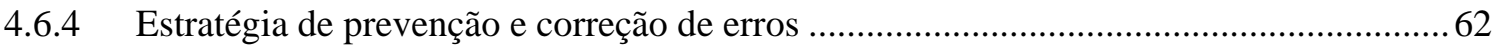

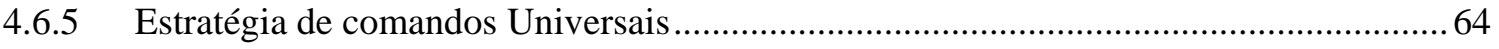

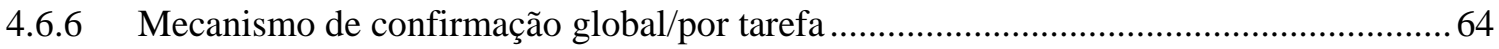

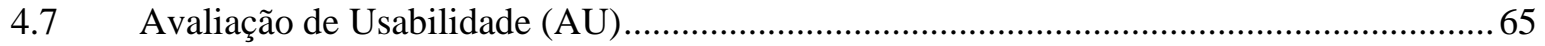

4.7.1 Mecanismo de avaliação heurística em interações multimodais Web (MMHE) .............66

4.7.2 Mecanismo de geração e análise automática de log em interações multimodais Web

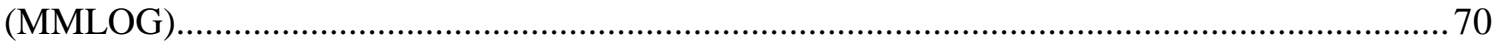

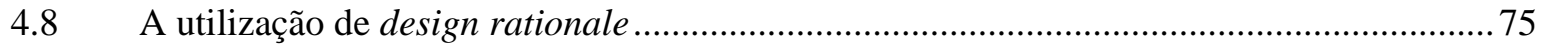

4.9 Uma comparação com as abordagens pesquisadas .............................................................79

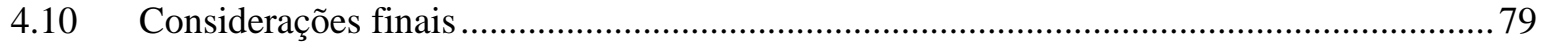

Capítulo 5. Ambiente de autoria para o projeto de interfaces multimodais Web (MMWA-ae) .........81

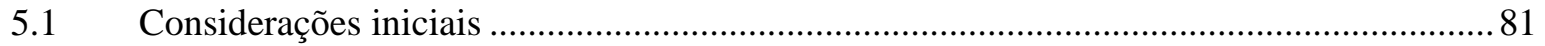

5.2 Arquitetura de implementação do ambiente de autoria ........................................................ 81

5.3 Arquitetura de integração das interfaces, módulos e base de dados ..................................... 84

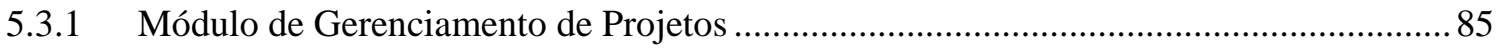

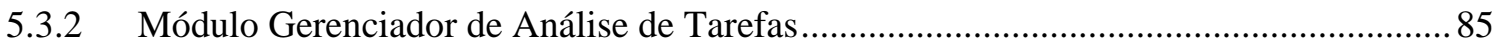

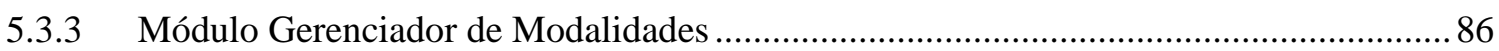

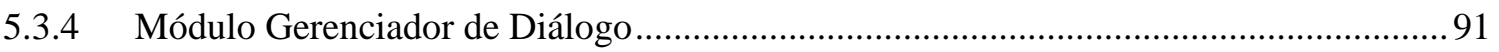

5.3.5 Módulo de Gerenciamento de Avaliação de Usabilidade ................................................93

5.4 Desenvolvimento de interfaces multimodais orientado a modelos com o MMWA-ae ........96

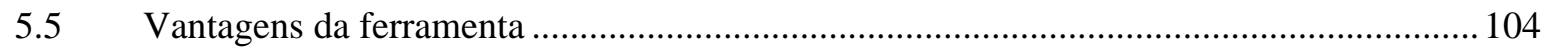

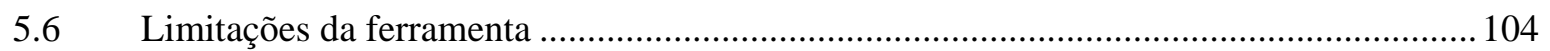

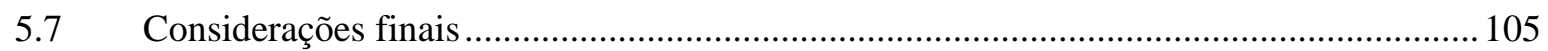

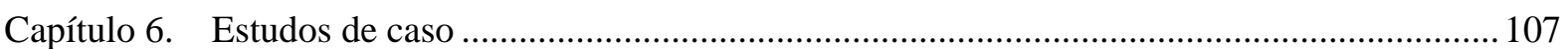

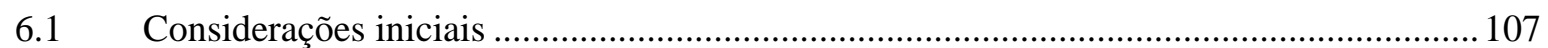

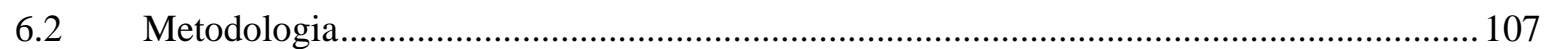

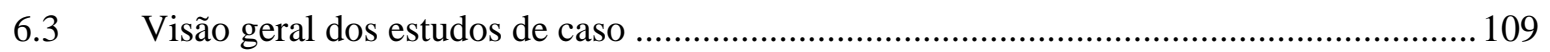




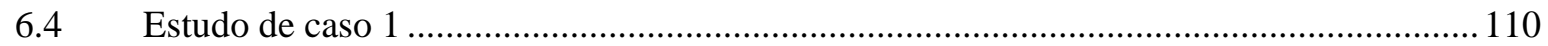

6.4.1 Definição do estudo de caso ...................................................................................... 111

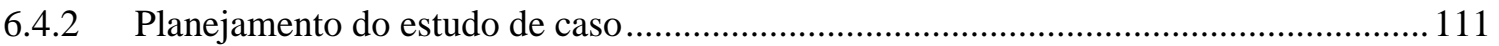

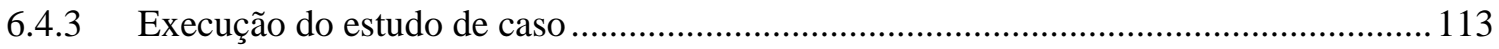

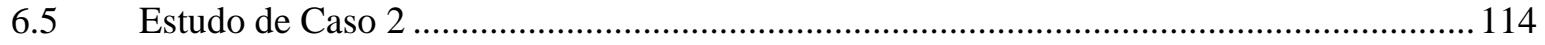

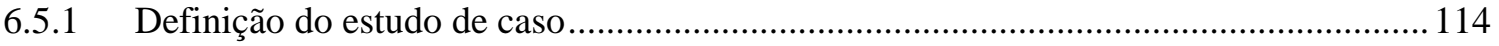

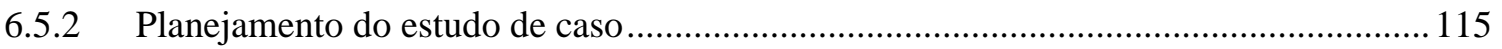

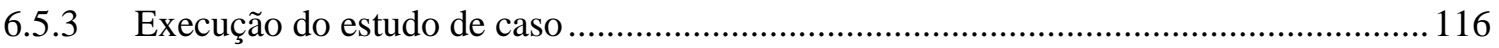

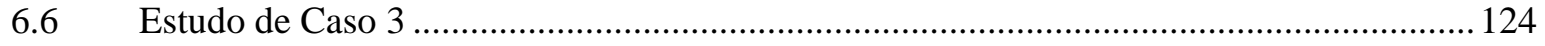

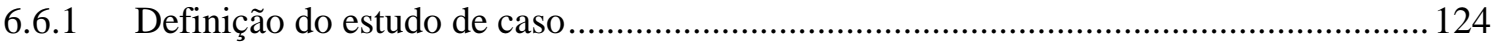

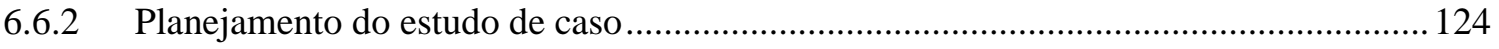

6.6.3 Execução do estudo de caso ……............................................................................ 125

6.7 Considerações finais sobre os estudos de caso ................................................................ 128

Capítulo 7. Análise dos Resultados dos Estudos de Caso................................................................ 131

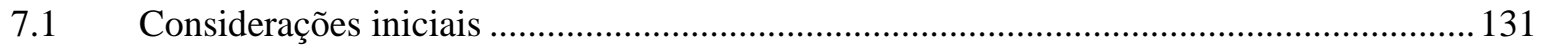

7.2 Usabilidade das interfaces geradas pelo MMWA-ae....................................................... 131

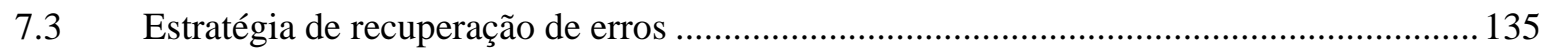

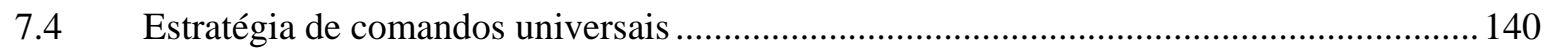

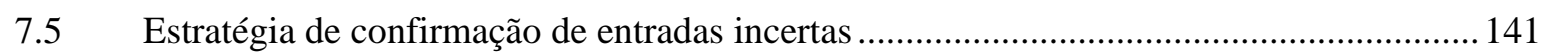

7.6 Regras de associação para a identificação de padrões de interação .................................... 142

7.7 Identificação das propriedades CARE nos logs gerados pela técnica MMLOG................. 145

7.8 Documentação e processo de captura, armazenamento e recuperação de DR ....................146

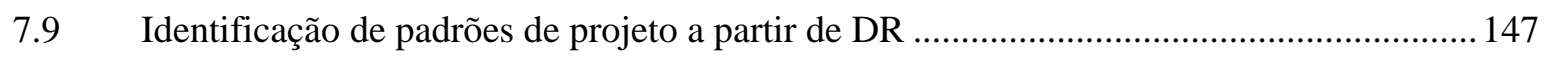

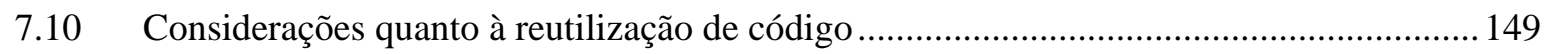

7.11 Tempo gasto para projetar a interface e para obter o protótipo de interface para testes com

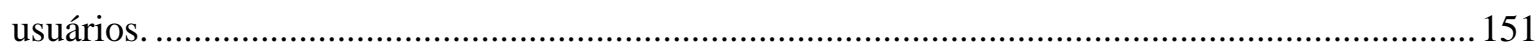

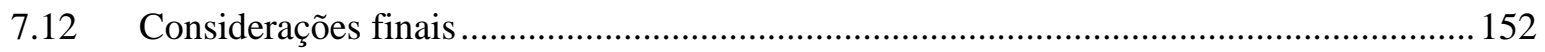

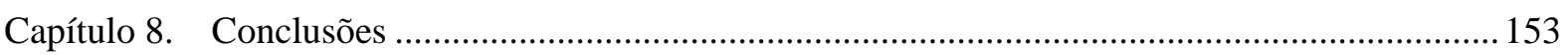

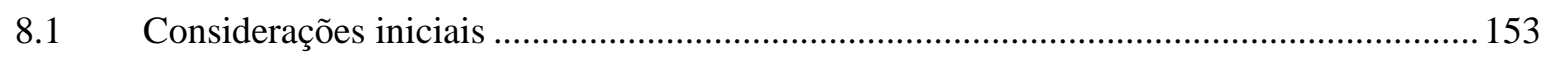

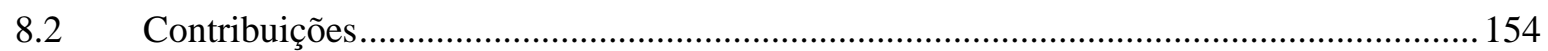

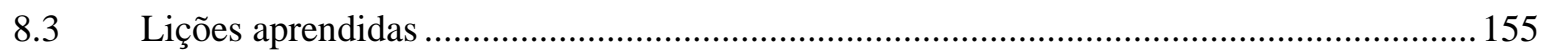

8.4 Publicações resultantes do trabalho realizado nesta tese ...................................................... 156

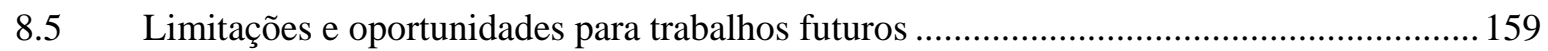

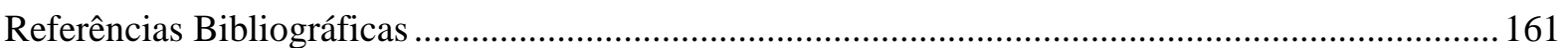

Apêndice A. Padrões de projeto multimodal referenciados nesta Tese …..................................... 175

Apêndice B. Relacionamentos entre heurísticas, checklists, guidelines e princípios ..................... 179 
Apêndice C. Exemplo de DR identificado em um estudo de caso ............................................... 185

Apêndice D. Questionário aplicado a um desenvolvedor que utilizou o MMWA-ae......................187

Apêndice E. Trechos de artefatos desenvolvidos no EC1 …........................................................ 189 


\section{Capítulo 1. Introdução}

Neste capítulo são apresentadas as principais motivações que nortearam esta pesquisa sobre interfaces multimodais Web com o uso das modalidades gráfica (GUI) e de voz (VUI), bem como os significados e definições de termos que serão usados no contexto deste trabalho. Também serão abordados os objetivos, as contribuições e o escopo da tese e, no final, será apresentado um resumo dos próximos capítulos.

\subsection{Interação multimodal}

No mundo real as pessoas estabelecem entre si interações multimodais, ou seja, elas fazem uso de diversos modos de comunicação para executar suas tarefas cotidianas. Imagine a seguinte situação, dois amigos estão conversando em uma festa. Enquanto um deles fala, o outro está concentrado no assunto, mas não deixa de perceber também a linguagem corporal de seu amigo, os gestos e a expressão facial que acompanham as suas palavras. Durante a conversa, o interlocutor irá adaptar seu tom de voz ao ambiente em questão para que o receptor possa não apenas ouvi-lo como também compreendê-lo. Assim, caso haja música, será preciso que os amigos falem mais alto. Eles podem também seguir o ritmo da música, falando mais rápido ou mais devagar, permitindo um melhor entendimento do que está sendo dito e a continuidade do diálogo entre os dois amigos.

Já a Interação Humano-Computador (IHC) não apresenta até o momento esse aspecto multimodal, pois poucas das interfaces gráficas desenvolvidas nos últimos 20 anos permitem que os usuários se comuniquem da mesma maneira que eles naturalmente se comunicam quando estão se movimentando, usando as mãos para realizar outras tarefas, olhando para outro lugar ou interagindo com outra pessoa (KLEMMER et al., 2000). Uma razão para isso é o grande dispêndio de recursos e tempo para desenvolver uma interface multimodal e o fato dos processos ainda estarem se estabelecendo (FLIPPO; KREBS; MARSIC, 2003).

No entanto, nos últimos anos, o progresso tecnológico no projeto de novos dispositivos e o crescimento científico no campo da Interação Humano-Computador têm possibilitado novas formas de interação que estão migrando da pesquisa para produtos comerciais. Desde o aparecimento do sistema "Put That There" de Bolt (1980), Figura 1, que processa objetos gráficos em uma tela com o uso de reconhecimento de voz e dispositivos de apontamento em paralelo, uma diversidade de pesquisas no campo multimodal tornaram-se conhecidas, incluindo: combinações de modalidades, tais como voz, gráfico e gestos 
(JOHNSTON, 2009), estratégias de fusão e fissão de modalidades (DUMAS; INGOLD; LALANNE, 2009), o gerenciamento de diálogo (MCGEE; COHEN; OVIATT, 1998), adaptação de interfaces e dispositivos (BERTI; PATERNO, 2005) pesquisas em acessibilidade e usabilidade (HUBERT, 2006).

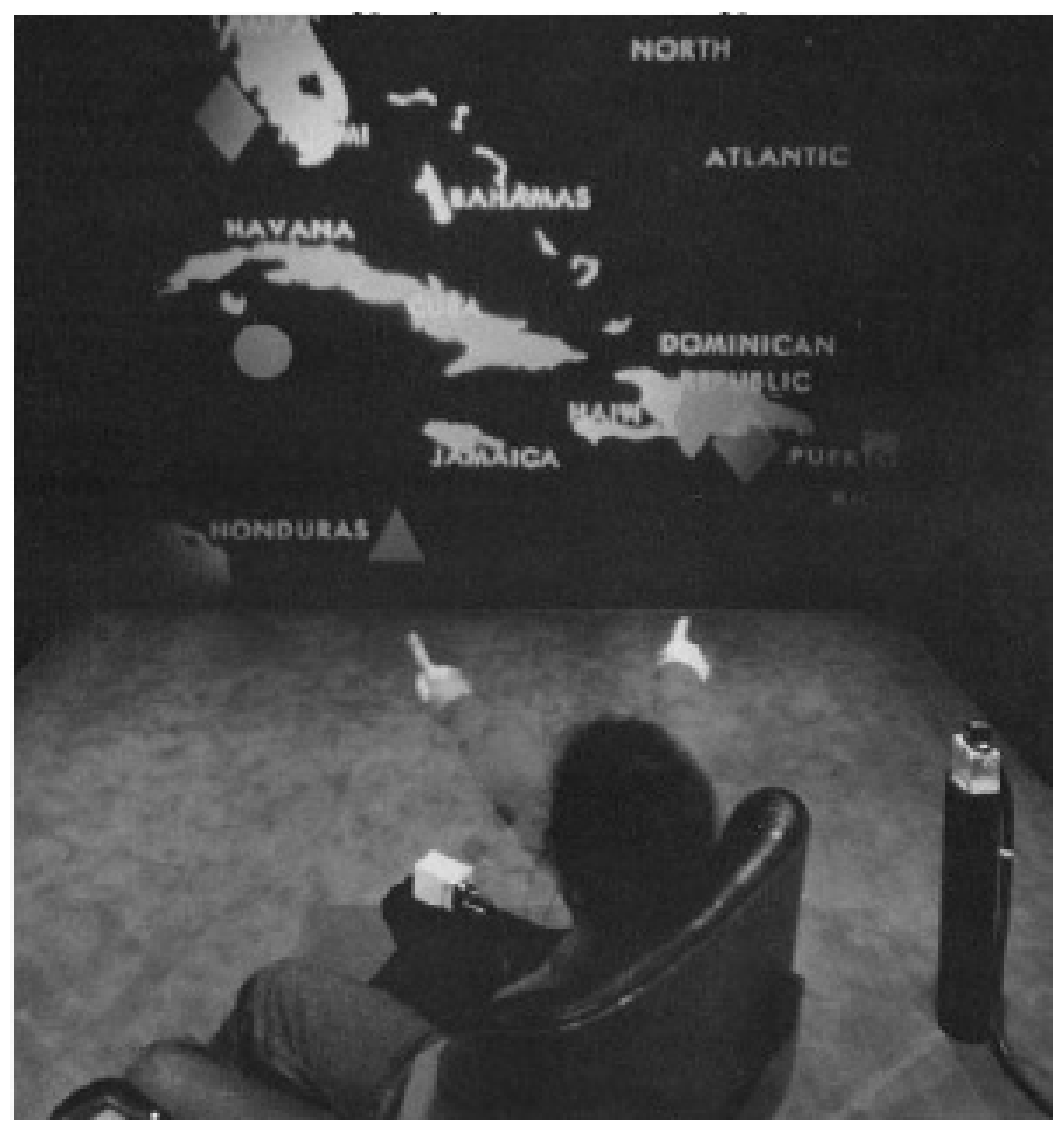

Figura 1 - Usuário interagindo com o sistema Put That There (BOLT, 1980)

Dispositivos que permitem o uso de novas modalidades de interação como o IPhone e o IPad da Apple, Inc e o Wii da Nintendo ${ }^{\circledR}$, ganharam rapidamente a atenção e a preferência dos usuários e são sucessos de venda e crítica.

Portanto, o apoio a diversas modalidades de interação tornou-se um requisito essencial para a próxima geração de interfaces com a crescente proliferação de dispositivos de interação, a crescente disponibilidade de serviços na Web para a população mundial e, devido ao grande poder expressivo, a naturalidade e a portabilidade que interfaces multimodais oferecem aos usuários para executar suas tarefas diárias (OVIATT; LUNSFORD; COULSTON, 2005).

No entanto, a utilização de modalidades combinadas, como a fala, o toque, gestos e gráfico, eleva o número de problemas de usabilidade e questões de interação que os projetistas e desenvolvedores enfrentam, como requisitos de sincronização e integração, bem 
como restrições que devem ser consideradas nas fases de projeto (COHEN; GIANGOLA; BALOGH, 2004). Negligenciar estes temas ao projetar interfaces multimodais pode acarretar uma série de problemas, porque os usuários acham difícil entender as novas interfaces e também porque o desempenho das tarefas será menos eficiente (BOLT, 1980).

Consequentemente, os projetistas estão expostos a um desafio cada vez maior: além de terem que aprender diferentes linguagens de programação e tecnologias acessíveis e aplicá-las para obter o código da aplicação multimodal, eles precisam entender quais são as melhores práticas neste campo de pesquisa e como testar as interfaces projetadas com usuários reais, com diferentes comportamentos, de uma forma eficiente antes do lançamento do produto.

Além disso, a equipe do projeto deve se preocupar em como promover a reutilização do código de aplicação e do design rationale (DR), ou seja, os porquês das decisões e as lições aprendidas a fim de obter um bom equilíbrio entre o custo e o esforço de implementação de interfaces multimodais.

Nesta tese de doutorado, consideram-se as particularidades da interação multimodal e concentra-se em resolver os principais problemas mencionados na literatura, expostos nos parágrafos anteriores, com o uso da MultiModal Web Approach (MMWA), que se fundamenta na experiência teórica e empírica adquirida pelos projetistas durante o processo de projeto da interação multimodal.

Essa experiência é documentada na forma de DR, princípios e padrões de projeto que podem ser compartilhados e aplicados, não só pela equipe de projeto de uma única aplicação multimodal, durante várias iterações para refinar esse mesmo sistema, mas também por projetistas de diferentes aplicações.

Além disso, fundamentado na experiência adquirida na aplicação da MMWA em projetos reais (NETO; FORTES, 2009), e com base nas observações do fluxo de trabalho da MMWA, foi desenvolvida uma ferramenta de autoria que orienta os projetistas, desenvolvedores e testadores de usabilidade, ou seja, a equipe do projeto, através das etapas e atividades da MMWA.

A vantagem dessa ferramenta de autoria, chamada MMWA-ae, é que ela sugere alternativas de projeto com base na coleta prévia de DR (NETO et al., 2009) e dos conhecidos padrões de projeto (GAMMA et al., 1995) e padrões de interação (BORCHERS, 2001; RATZKA; WOLFF, 2006). Esses padrões foram estendidos para apoiar a teoria multimodal. 
O MMWA-ae também implementa os princípios e checklists (listas de verificação) identificados neste trabalho para que os projetistas possam utilizar as soluções bem sucedidas para problemas recorrentes nesse contexto, juntamente com seu DR.

Embora a abordagem tenha sido originalmente concebida para o domínio da Web, acredita-se que ela possa ser útil para a concepção e avaliação das aplicações com interação multimodal em outros contextos, como dispositivos móveis, por exemplo.

\subsection{Motivações para a pesquisa com interação multimodal}

A Interação Humano-Computador Multimodal permite ao usuário utilizar vários modos de comunicação para interagir com um sistema, tais como voz, toque, gestos e movimentos.

Os modos podem ser utilizados simultaneamente ou em sequiência e em combinação ou independentemente, além da tradicional entrada via teclado e mouse, e saída através de uma interface gráfica. A relação entre um dispositivo de entrada ou saída (microfone, teclado, tela sensível ao toque) e uma linguagem de interação (linguagem natural, manipulação direta) é chamada modalidade. Consequentemente, a interação multimodal pode ser definida também como a utilização de duas ou mais modalidades para interagir com um sistema.

$\mathrm{O}$ advento dos sistemas multimodais representa uma mudança de pesquisas com o paradigma das interfaces convencionais do tipo Janelas, Ícones, Menus, Ponteiros (WIMP em inglês) para pesquisas com um novo paradigma que tem como objetivo fornecer aos usuários: maior poder de expressão, naturalidade, flexibilidade e portabilidade (SCHAPIRA; SHARMA, 2001). Sistemas WIMP são determinísticos, uma vez que eles se concentram sobre a posição do cursor em uma tela, já os sistemas multimodais são probabilísticos, uma vez que utilizam identificadores de modalidades que trabalham com a incerteza (DUMAS; INGOLD; LALANNE, 2009).

As pesquisas atuais sobre a interação multimodal são constantemente interdisciplinares, incluindo tópicos que vão da Engenharia de Software à Psicologia. Além disso, há um desejo de estender a Web para permitir aos usuários selecionar dinamicamente o modo mais adequado de interação para as suas necessidades momentâneas, através do desenvolvimento de interfaces mais eficientes, que possam ser ativadas de acordo com o modo escolhido pelos usuários (OVIATT, 1999b). 
Estudos mostram que as tarefas novas e complexas são executadas de forma mais rápida com o uso de múltiplas modalidades de interação (COHEN; MCGEE; CLOW, 2000; RATZKA, 2008)

Como descrito em Narayan et. al. (2004), “o uso de múltiplos modos de interação aumenta a quantidade de informação em um diálogo, melhora o conhecimento mútuo entre o sistema e o usuário, reduz a ambigüidade e simplifica o diálogo". A idéia para um projeto que respeite e considere as diferenças de forma indiscriminada é que os objetivos estabelecidos na interação com um sistema computacional sejam alcançados com eficácia, eficiência e satisfação por um amplo conjunto de usuários.

A interação multimodal oferece benefícios em termos de facilidade de uso e pode aumentar a usabilidade das interfaces, pois um ponto fraco de uma modalidade pode ser superado com o uso de um ponto forte de outra modalidade (OVIATT, 1999a). Além disso, permite a compensação mútua de erros de reconhecimento das tecnologias probabilísticas (OVIATT, SHARON, 2003). Há muitas vantagens no uso das interfaces multimodais, incluindo:

- Aumento na facilidade de uso dos dispositivos pequenos e complexos permitindo uma interação mais natural na execução das tarefas. As interfaces multimodais podem oferecer aos usuários a habilidade de usar o modo de interação que melhor se adapta a uma situação particular, aumentar a taxa de tarefas que o usuário consegue completar, reduzir o tempo e o esforço do usuário para completar uma tarefa, proporcionar maior satisfação do usuário através da prevenção e recuperação rápida de erros de maneira mais intuitiva (OVIATT et al., 2000).

- Flexibilidade, pois os sistemas multimodais permitem aos usuários selecionar e alternar entre os modos de entrada evitando sobrecarga física ou mental na utilização de uma modalidade.

- A interface pode acomodar uma ampla gama de usuários, tarefas e ambientes, inclusive os usuários temporariamente ou permanentemente impossibilitados, e outros casos em que uma modalidade pode não ser suficiente ou adequada para completar uma tarefa.

- Acessibilidade, quando mais de um tipo de interação está disponível, os usuários com dificuldades ou restrições à utilização de um dispositivo podem fazê-lo de outra forma, garantindo o acesso à informação (BOUILLON; VANDERDONCKT; CHOW, 2004). 
Por outro lado, projetar interfaces que se beneficiam dos avanços em tecnologias de reconhecimento como o reconhecimento de voz e os dispositivos novos de interação ainda é uma atividade complexa, mas têm permitido novas possibilidades de pesquisa no campo de interfaces multimodais (CHANG; BOURGUET, 2008).

Embora as vantagens das interfaces multimodais sejam evidentes, o desenvolvimento de projetos multimodal é ainda um desafio (OVIATT; COULSTON; LUNSFORD, 2004), devido à falta de ferramentas que apropriadamente orientam o projetista, no projeto, implementação e avaliação das interfaces multimodais. Além disso, há a necessidade de processar entradas de grupos de usuários heterogêneos e integrar várias modalidades de entrada de saída que podem operar em paralelo ou simultaneamente e de lidar com erros de reconhecimento e de sincronização para a geração de interfaces multimodais eficientes.

A falta de entendimento sobre a melhor forma de combinar os diferentes modos de interação nas interfaces muitas vezes leva a projetos de interface com pouca usabilidade (CHANG; BOURGUET, 2008).

Os princípios e técnicas de usabilidade utilizados para as interfaces gráficas tradicionais (GUI) não se aplicam necessariamente aos sistemas multimodais (OVIATT, SHARON, 2003), para os quais alguns tópicos importantes como o projeto das entradas e saídas de informações, da adaptabilidade, da consistência e do tratamento de erros, além de tópicos como dependências culturais, comportamentais e de personalidade individual devem ser considerados (REEVES et al., 2004).

Isto significa que o projeto bem sucedido da interação multimodal requer o apoio da ciência cognitiva na coordenação da percepção humana e no desenvolvimento de interfaces utilizando modalidades mais naturais.

Dessa forma, o contexto deste trabalho se orienta na investigação de um suporte conceitual e ferramental necessário para a confecção de um projeto de interação multimodal, por meio de uma abordagem com etapas fundamentadas em um ferramental teórico para apoiar a geração automática de protótipo de interface multimodal nas modalidades gráfica, toque e voz para a Web, considerando-se para isso as questões relacionadas à acessibilidade, usabilidade e experiência do usuário. O diferencial deste trabalho está na:

- Utilização de um mecanismo automático para captura e recuperação de DR que facilita a identificação de padrões de projeto. 
- Utilização de avaliação de usabilidade por meio de interações com usuários reais que considera dados obtidos da interação desses usuários para a melhoria das interfaces antes do projeto final ser entregue e colocado em uso.

Nos próximos capítulos desta tese serão apresentados os métodos, técnicas e frameworks para o projeto de interfaces multimodais Web e será discutido que eles pouco consideram tópicos relacionados, como usabilidade. Como solução para este problema, será apresentada a abordagem proposta e os resultados obtidos utilizando-a em estudos de caso.

\subsection{A tese}

Nesta tese argumenta-se que o projeto, desenvolvimento e teste de usabilidade das interfaces multimodais são atividades que se beneficiam da aplicação de uma abordagem sistemática, ou seja, uma metodologia composta por um modelo de tarefas bem definido, um método para manipular esse modelo e para promover a reutilização de conhecimento e uma ferramenta que implemente o método definido e que efetivamente auxilie a equipe de projeto a desenvolver interfaces multimodais Web.

Dados:

- Potencial do uso de várias modalidades de interação para resolver problemas de usabilidade e acessibilidade, promover o Design Universal e agilizar a execução de tarefas.

- Benefícios do uso de padrões de projeto e DR no desenvolvimento.

- Necessidade de um processo completo e sistemático para o projeto, desenvolvimento e testes de interfaces multimodais centrado no usuário.

- Necessidade de um mecanismo para reutilização de conhecimento e código fonte.

- Necessidade de se realizar avaliações de usabilidade em estágios iniciais do desenvolvimento de software.

A tese sendo defendida é a de que "uma abordagem sistemática, centrada no usuário, apoiada por uma ferramenta computacional, com um modelo bem definido que permita o desenvolvimento de interfaces multimodais com a reutilização de DR aumenta e melhora os níveis de usabilidade, promove a identificação e utilização de padrões de projeto e o reuso de componentes".

\subsubsection{Objetivos desta tese}

Para validar esta tese foram definidos os objetivos a seguir que serão aprofundados durante a leitura deste texto: 
- Propor uma abordagem para o projeto de interfaces multimodais Web (MMWA).

- Identificar e implementar um mecanismo não intrusivo que proporcione a captura, o armazenamento e a recuperação de DR, de forma que se obtenha uma base de dados da qual será possível extrair padrões de projeto.

- Prover um mecanismo ao projetista e ao desenvolvedor para facilitar a consulta de DR e utilizar padrões de projeto de forma que possa ocorrer geração de código fonte fundamentado em componentes, promovendo reúso e diminuindo o tempo de projeto, desenvolvimento e testes.

- Validar o uso da abordagem proposta em estudos de caso (ECs) comparando com métodos existentes.

- Desenvolver um ambiente de autoria que permita a utilização da abordagem proposta em projetos multimodais Web.

\subsubsection{Escopo}

As modalidades pesquisadas nesta tese são:

- Gráfica:

○ Dispositivos: vídeo, teclado e mouse, Tablet PC (toque);

○ Linguagem de Interação: manipulação direta.

- Voz:

○ Dispositivos: Microfone e caixa de som ou headset;

○ Linguagem de Interação: reconhecimento e síntese de voz.

A escolha por estas modalidades se deve ao fato do doutorando possuir vínculo empregatício com a empresa Nuance Communications Inc, empresa líder no ramo de reconhecimento e síntese de voz, que apoiou este projeto e incentivou a pesquisa na área multimodal. Além disso, estudos apontam que $80 \%$ dos usuários preferem uma mistura de interfaces baseadas em comando e em diálogo ao invés de uma interface totalmente em linguagem natural (NICHOLS et al., 2002).

Observa-se também que atualmente não é possível obter um desempenho perfeito na interação utilizando-se somente reconhecimento de voz, pois as entradas de voz podem ser corrompidas por barulho, o reconhecimento é probabilístico e o significado pode ser ambíguo. As outras modalidades existentes não fizeram parte do escopo desta pesquisa.

A mesma motivação do trabalho na empresa Nuance Communications influenciou a escolha do ambiente Web para o desenvolvimento da pesquisa, pois a empresa é membro da W3C e participa ativamente nos grupos de trabalho de linguagens que envolvem o uso de voz 
e multimodalidade tais como VXML, X+V, EMMA (Extensible MultiModal Annotation) (BAGGIA et al., 2007), entre outras.

A abordagem considera o desenvolvimento de interfaces multimodais convencionais, portanto, estão fora do escopo a pesquisa por interfaces 3D, tangíveis, imersivas; a pesquisa de arquiteturas e notações formais e a transformação ou adaptação de interfaces.

Além disso, foi priorizada a definição de uma abordagem prática sem a cobertura extensa do ciclo de vida do software para que a sua utilização e avaliação em projetos acadêmicos fossem realizadas com maior controle.

O público alvo desta tese é a comunidade de pesquisa de IHC, os profissionais envolvidos no projeto, implementação e testes de interfaces multimodais Web, além de estudantes em nível de graduação e pós-graduação.

\subsection{Organização do texto}

Esta tese está organizada em 8 capítulos descritos a seguir e resumidos no mapa de leitura da Figura 2.

No Capítulo 2 são discutidos os conceitos de usabilidade para o projeto, desenvolvimento e avaliação de interfaces multimodais. No Capítulo 3 são apresentadas as tecnologias, as abordagens e frameworks pesquisados na literatura com o objetivo de formar a base para o desenvolvimento deste trabalho. Nesses dois capítulos é apresentado, portanto, o Estado da Arte.

No Capítulo 4 é proposta a Abordagem para o Desenvolvimento de Interfaces Multimodais Web (MMWA), uma ferramenta conceitual composta por atividades e técnicas, utilizada para o projeto de interfaces multimodais Web. No Capítulo 5, são apresentadas as arquiteturas de implementação e de integração do ambiente de autoria desenvolvido para facilitar o uso da MMWA em projetos multimodais Web, bem como as principais características do modelo de tarefas desenvolvido neste contexto. Nesses dois capítulos é descrito o trabalho que foi desenvolvido no período do doutorado.

No Capítulo 6 é apresentada a metodologia usada neste trabalho e uma descrição dos estudos de caso executados e no Capítulo 7 são apresentados e discutidos os resultados mais significantes obtidos aplicando-se a metodologia proposta com as ferramentas criadas. Nesses dois capítulos é apresentado o mecanismo de validação da ferramenta e da abordagem proposta.

Por último, no Capítulo 8 são discutidas as conclusões. 
Introdução

-Interação Multimodal

-Motivações para a pesquisa com interfaces multimodais

- Tese

\section{Estado da Arte}

-A usabilidade no projeto de interfaces multimodais centrado no usuário

-Projeto de Interfaces Multimodais

\section{Proposta da Tese}

-MultiModal Web Approach

-MultiModal Web Approach - authoring environment

\section{Validação}

-Estudos de Caso

-Resultados

\section{Conclusões}

Figura 2 - Mapa de Leitura da Tese 


\section{Capítulo 2. A usabilidade no projeto de interfaces multimodais centrado no usuário}

\subsection{Considerações iniciais}

No transcorrer desta década, inúmeras pesquisas em diversas áreas da computação mostraram a preocupação em considerar o usuário como um importante participante no processo de projeto de software com usabilidade (HOLZINGER, 2005; HUBERT, 2006; NIELSEN, 2006; SEFFAH et al., 2006; KAMEL; AIT AMEUR, 2007; RAJANEN; IIVARI, 2007; BERNHAUPT, 2008; BERNHAUPT et al., 2008; CHANG; BOURGUET, 2008; NETO; FORTES, 2009), pelo fato de que o software automatiza as tarefas cotidianas do usuário e o usuário tem necessidades que devem ser atendidas pelo produto. Essas necessidades são expressas por algumas palavras que são usadas como métricas na avaliação de usabilidade do software: aprendizagem, eficácia, eficiência, satisfação, intuitividade, entre outras.

Portanto os métodos de projeto centrados no usuário compartilham o raciocínio que os sistemas devem ser desenvolvidos para as pessoas que irão utilizá-lo, considerando as suas necessidades e o ambiente no qual as tarefas serão executadas, ou seja, são consideradas as perspectivas humanas (ou contexto de uso físico, representando todas as situações que influenciam o uso do sistema), da interação (ou contexto tecnológico, considerando a tecnologia disponível ao usuário como rede e dispositivos de entrada e saída) e do trabalho (ou contexto social, representando todas as situações que influenciam o uso do sistema) (WELIE; VAN DER VEER; ELIËNS, 1999).

Os sistemas e suas interfaces são desenvolvidos para os humanos, então faz-se necessário entender as suas habilidades e limitações, especialmente as habilidades cognitivas, perceptivas, sensoriais e motoras, e a relação entre as métricas de usabilidade e as características dos seres humanos. Por exemplo, o conhecimento das pesquisas sobre a memória de trabalho pode melhorar a facilidade de aprendizado dos sistemas, enquanto que o conhecimento da memória de longa duração e suas relações com o modelo mental do usuário podem ajudar na correção de problemas de usabilidade que são causados pela inconsistência entre esse modelo mental e a estrutura das interfaces (OVIATT, S., 2003). 
No tocante à interação, é necessário entender o tipo de solução que funciona para uma determinada tarefa. Esse conhecimento do porque algumas interfaces "funcionam" melhor do que outras pode ser obtido tanto da experiência prática do projetista como do conhecimento capturado nas técnicas descritas neste capítulo, como guidelines, princípios, design rationale, padrões de projeto, etc. Por isso faz-se necessário pesquisar formas para capturar e estruturar o raciocínio de projeto, bem como criar modos eficientes de busca e apresentação desse raciocínio, incluindo a criação de uma linguagem comum de comunicação, para que novos projetistas se capacitem mais rápida e eficientemente.

De igual importância, a perspectiva do trabalho deve ser considerada durante o projeto da interação, pois o humano interage com o sistema para desempenhar um trabalho, ou uma série de tarefas. Tópicos como a tecnologia disponível e o contexto de uso devem ser considerados.

Existem muitas definições sobre usabilidade e diversos autores criaram ao longo dos anos diferentes técnicas para ajudar na melhoria da usabilidade, tais como: guidelines, padrões, normas, heurísticas e checklists. Mas é necessário esclarecer como certas escolhas de projeto influenciam na usabilidade.

Para os projetistas e desenvolvedores de software é difícil ou trabalhoso escolher qual dessas técnicas deve ser escolhida e quando deve ser utilizada. Portanto, é necessário estudar essas diferentes técnicas para que seja possível identificar seus pontos fracos e fortes com o objetivo de utilizar o que há de melhor no projeto de interfaces multimodais.

Nesse sentido, o objetivo com este capítulo é apresentar as definições de usabilidade e acessibilidade (Seções 2.2 e 2.3), bem como discutir os principais tópicos de pesquisa para a obtenção de requisitos (Seção 2.4), projeto (Seções 2.5 e 2.6) e avaliação de usabilidade (Seção 2.7) para interfaces multimodais. Essa discussão faz-se necessária para a proposta da abordagem tema desta tese que será apresentada no Capítulo 4.

\subsection{Definições de usabilidade e acessibilidade}

Na literatura são encontradas diferentes definições para usabilidade, pois ela não pode ser expressa em uma medida objetiva.

Usabilidade é, na maioria das vezes, definida como a facilidade de uso e a aceitabilidade de um sistema para uma classe particular de usuários executando tarefas específicas em um ambiente específico. A facilidade de uso afeta o desempenho e a satisfação dos usuários, enquanto que a aceitabilidade afeta o uso ou não do produto 
(HOLZINGER, 2005). Assim, é de grande importância que todo projetista de software não esteja apenas ciente dos vários métodos de usabilidade, mas também esteja apto a determinar rapidamente qual método é mais apropriado para cada situação em um projeto de software.

Há ainda outras definições para usabilidade como a descrita no padrão ISO 9241-11: "A efetividade, eficiência e satisfação com que usuários específicos atingem objetivos especificados num ambiente particular".

Seffah et al. (2006) sugerem que a efetividade pode ser medida pela exatidão, a eficiência pelo tempo e a satisfação pelos parâmetros subjetivos da carga de trabalho.

Para Preece (1993) usabilidade é definida como uma medida da facilidade com que um sistema pode ser aprendido ou usado, a sua segurança, eficácia e eficiência, e a atitude de seus usuários para com ele. Esta definição não faz uma referência explícita ao contexto de utilização ou de objetivos do usuário especificados e sugere que a usabilidade é uma "propriedade" de um sistema.

Essas definições consideram a usabilidade do ponto de vista teórico.

Nielsen (1993) e Shneiderman (1998) têm uma definição mais prática que está descrita por meio de elementos mais específicos, sendo que a definição Shneiderman é essencialmente parecida com a de Nielsen divergindo na terminologia, como pode ser observado no Quadro 1. Tanto Nielsen como Shneiderman não mencionam qualquer aspecto relativo a utilidade (por exemplo, informações sobre conclusão de tarefas).

Dix (1998), por sua vez, define três grandes grupos como fatores de usabilidade: facilidade de aprendizado, flexibilidade e robustez. Os grupos são especificados por fatores que influenciam o conceito a que pertencem. Por exemplo, a consistência influencia na facilidade de aprendizado, que subdivide-se em aspectos que são de natureza cognitiva. Assim, mais controle é dado sobre as habilidades cognitivas dos usuários.

Quadro 1 - Definição de usabilidade em diferentes fontes

\begin{tabular}{|l|c|c|}
\hline ISO 9241-11 & Shneiderman & Nielsen \\
\hline \multirow{2}{*}{ Eficiência } & Velocidade de desempenho & Eficiência \\
\cline { 2 - 3 } & Tempo de aprendizado & Facilidade de aprendizado \\
\cline { 2 - 3 } & Retenção por tempo & Facilidade de memorização \\
\hline Eficácia & Taxa de erros & Taxa de erros \\
\hline Satisfação & Satisfação & Satisfação \\
\hline
\end{tabular}

Em geral, concorda-se que cinco características essenciais de usabilidade devem fazer parte de qualquer projeto de software: 
Capítulo 2 - A usabilidade no projeto de interfaces multimodais centrado no usuário

- Capacidade de aprendizado, para que o usuário possa rapidamente começar a trabalhar com o sistema;

- Eficiência, permitindo ao usuário que aprendeu a usar o sistema alcançar um alto nível de produtividade;

- Capacidade de memorizar, possibilitando que o usuário casual retorne ao sistema depois de um período de não uso sem ter que reaprender tudo;

- Baixa taxa de erros, que leva os usuários a cometerem menos erros enquanto usam o sistema e os erros cometidos são facilmente retificados, ou seja, não ocorrem erros catastróficos;

- Satisfação, que compreende o conforto e a aceitabilidade, entendidos pelo usuário como um sistema agradável de usar.

Alguns desses critérios podem ser considerados mais importantes do que outros, dependendo da situação a que forem aplicados. Em alguns casos, a eficiência em longo prazo pode ter um grau de importância suficientemente alto para que os desenvolvedores se disponham a sacrificar a rápida capacidade de aprendizado (HOLZINGER, 2005).

Defensores desta abordagem engajam-se na análise de tarefas e depois fazem protótipos dos projetos da interface e conduzem testes de usabilidade com eles. No fundamento desses testes, a tecnologia é (idealmente) re-projetada ou (ocasionalmente) as metas operacionais para o desempenho do usuário são revisadas (DILLON, 2000).

Já o termo Engenharia de Usabilidade, em contraste com outros nomes de disciplinas como Projeto da Interação (Interaction Design) ou Projeto Centrado no Usuário (User Centered Design), visa descrever uma abordagem pragmática para o projeto de interface do usuário, a qual enfatiza métodos empíricos e definições operacionais dos requisitos do usuário.

As vantagens da utilização do projeto centrado no usuário trazem benefícios tanto para o usuário como para o cliente: maior eficiência, maior produtividade, redução de erros, aumento de satisfação, menos treinamento, menos manutenção corretiva, maior aceitação, menos custo de desenvolvimento e aumento nas vendas (RAJANEN; IIVARI, 2007).

A acessibilidade, por sua vez, significa não apenas permitir que pessoas com necessidades especiais participem de atividades que incluem o uso de produtos, serviços e informação, mas a inclusão e extensão do uso destes por todas as parcelas presentes em uma determinada população, com as mínimas restrições possíveis (MELO et al., 2006). 
Em (FREIRE; RUSSO; FORTES, 2008), os autores afirmam que mesmo existindo várias guidelines e leis federais relacionadas à acessibilidade, muitas páginas Web ainda têm problemas de acessibilidade devido à falta de conhecimento dos desenvolvedores sobre como as pessoas com necessidades especiais usam a Web e devido à falta de treinamento dos mesmos desenvolvedores sobre os potenciais problemas de acessibilidade.

Com o objetivo de promover a acessibilidade no desenvolvimento de sistemas Web e torná-los acessíveis para um número maior de usuários foi criado o modelo WAI pelo W3C que consiste em um conjunto de documentos compostos por guidelines para pessoas que acessam a Web em condições especiais (ambientes, equipamentos) (LARA et al., 2010)

O termo acessibilidade utilizado neste trabalho envolve três noções. A primeira noção, o usuário, significa que nenhum obstáculo deve ser imposto ao usuário face às suas capacidades sensoriais e funcionais. A segunda, a situação, quer dizer que o sistema é acessível e utilizável em diversas situações, independentemente do software, das comunicações ou dos equipamentos. E a terceira, o ambiente, implica em um acesso nãocondicionado pelo ambiente físico.

Uma motivação para o desenvolvimento de sistemas multimodais tem sido o seu potencial para expandir a acessibilidade dos computadores para usuários não especialistas, de diferentes idades e níveis de conhecimento, com dificuldades sensoriais e motoras, além de disponibilizar novas formas de interação não disponíveis no passado (GRUENSTEIN; MCGRAW; BADR, 2008).

Uma interface multimodal pode ainda ser projetada para melhorar a acessibilidade e o desempenho de usuários que tendem a ter dificuldades com interfaces de voz, por exemplo, um usuário que não é nativo em língua inglesa interagindo com sotaque e tendo problemas com os sistemas de reconhecimento de voz (JURAFSKY; MARTIN, 2000).

Interfaces multimodais podem ser projetadas para aumentar o desempenho em circunstâncias não ideais de interação, por meio da sugestão do uso de uma modalidade de interação em resposta, por exemplo, ao aumento do nível de ruído em um ambiente em que está ocorrendo a interação por voz.

\subsection{A usabilidade em sistemas multimodais}

No ciclo do desenvolvimento de qualquer software, inclusive o multimodal, diversas atividades de avaliação de usabilidade são realizadas durante as fases de projeto e desenvolvimento com o intuito de melhorar a qualidade final do produto. 
Componentes como os reconhecedores de voz e reconhecedores de gestos são avaliados exaustivamente para verificar se o desempenho é suficiente para a liberação do produto. Um problema simples de reconhecimento, ou a falta de um requisito no produto final pode acarretar um grande prejuízo para empresas que lidam com grandes quantidades de usuários. Por exemplo, o Decreto $n^{\circ}$ 6523, mais conhecido como a Lei do SAC (DECRETO $\mathrm{N}^{\circ}$ 6.523, DE 31 DE JULHO DE 2008.) diz que a opção de falar com atendente deve ser apresentada no início da interação em uma interface de voz. Se esse requisito não for considerado ou se o reconhecedor de voz não entender a solicitação do usuário, as empresas podem ser multadas.

Para que os testes sejam realizados, protótipos e versões preliminares de sistemas são gerados e simulações são executadas por avaliadores de usabilidade (OVIATT, S., 2003). Porém, muitas vezes o protocolo de testes e as métricas estabelecidas são desenvolvidos sob demanda e com recursos limitados, diferentes aspectos de qualidade são avaliados com diferentes critérios de avaliação.

Uma das soluções é considerar o uso de Design Rationale (DR) na fase de avaliação de usabilidade e estabelecer o protocolo de testes na fase de obtenção de requisitos.

A taxonomia para avaliar a qualidade de serviço e a qualidade da experiência proposta em (MOLLER et al., 2009) pode ser utilizada durante essas duas fases para viabilizar a coleta de informação necessária no contexto do projeto de interfaces multimodais, pois considera aspectos importantes de qualidade e de acordo com o padrão ISO 9126, a usabilidade é um dos seis aspectos de qualidade de software (BHATTI, 2005).

$\mathrm{Na}$ abordagem proposta nesta tese, o projeto para a usabilidade é o foco central nas fases de projeto, desenvolvimento e testes. No entanto, muitas empresas e muitos métodos encontrados na literatura não consideram e não incorporam a usabilidade em seus processos.

Quando um teste apresenta indicações de que existe a necessidade de melhoria da usabilidade, é necessário localizar o que precisa ser corrigido e como corrigir. A correção de um problema pode ter um impacto positivo em um indicador de usabilidade e negativo em outro, portanto é necessário que o projetista utilize o raciocínio capturado e armazenado em projetos anteriores para julgar porque e como o problema deve ser corrigido.

A eficiência do uso de técnicas como guidelines, princípios, etc, está diretamente relacionada com o tipo de avaliação que vai ser conduzida, como será discutido mais adiante neste capítulo. 
Capítulo 2 - A usabilidade no projeto de interfaces multimodais centrado no usuário

\subsection{Um modelo em camadas para obtenção de requisitos considerando usabilidade}

As diferentes técnicas, definições e princípios tornam a usabilidade um conceito de difícil interpretação, tanto no projeto de um novo sistema como na realização de manutenções ou na criação de novos projetos num mesmo domínio já conhecido e explorado.

Normalmente, os autores despendem muito esforço para identificar qual é o melhor conjunto de princípios ou para definir um conjunto completo de heurísticas. Apesar desse conjunto importante de técnicas, como guidelines, princípios e padrões de projeto estarem disponíveis, ainda não está claro como elas se relacionam e como escolher uma técnica para melhorar a usabilidade.

A Figura 3 mostra um modelo de camadas de usabilidade (VEER; WELIE, 2000) (WELIE; VAN DER VEER; ELIËNS, 1999) que ajuda a compreender os diferentes conceitos durante a fase de análise de requisitos.

No mais alto nível, está a definição ISO de usabilidade que é dividida em três aspectos: eficiência, eficácia e satisfação. Este nível é uma maneira abstrata de interpretar a usabilidade e não é diretamente aplicável na prática. No entanto, fornece três pilares que são fundamentados em uma teoria bem definida para a usabilidade (BHATTI, 2005).

O próximo nível contém uma série de indicadores de utilização, que são indicadores do nível de usabilidade que pode realmente ser observado na prática quando os usuários estão no ambiente de trabalho. Cada um desses indicadores contribui para os aspectos abstratos do nível superior. Por exemplo, uma baixa taxa de erro contribui para uma maior eficácia e rapidez e um bom desempenho indica uma boa eficiência. O nível desejado para cada um dos indicadores de utilização depende da natureza do sistema. Para um sistema em produção, eficiência pode ser a meta principal, mas para um site multimodal a satisfação pode ser muito mais importante do que a eficiência.

O terceiro é o nível dos meios que são utilizados nas heurísticas para melhorar um ou mais dos indicadores de utilização. Por exemplo, a consistência pode ter um efeito positivo sobre a facilidade de aprendizado. Por outro lado, alta adaptabilidade pode ter um efeito negativo de memorização, tendo um efeito positivo no desempenho. Assim, cada meio pode ter um efeito positivo ou negativo sobre alguns dos indicadores. Cabe ao projetista encontrar os melhores níveis para cada meio. Para fazer isso, o projetista deve usar os três domínios do conhecimento (seres humanos, interação e trabalho) para determinar os níveis adequados dos indicadores, e o conhecimento de projeto deve incorporar o raciocínio de como as mudanças na utilização dos meios afetam os indicadores de utilização. 
O último nível é usado para determinar o domínio de conhecimento que o projetista pretende trabalhar em um determinado momento do projeto (usuário, interação ou trabalho).

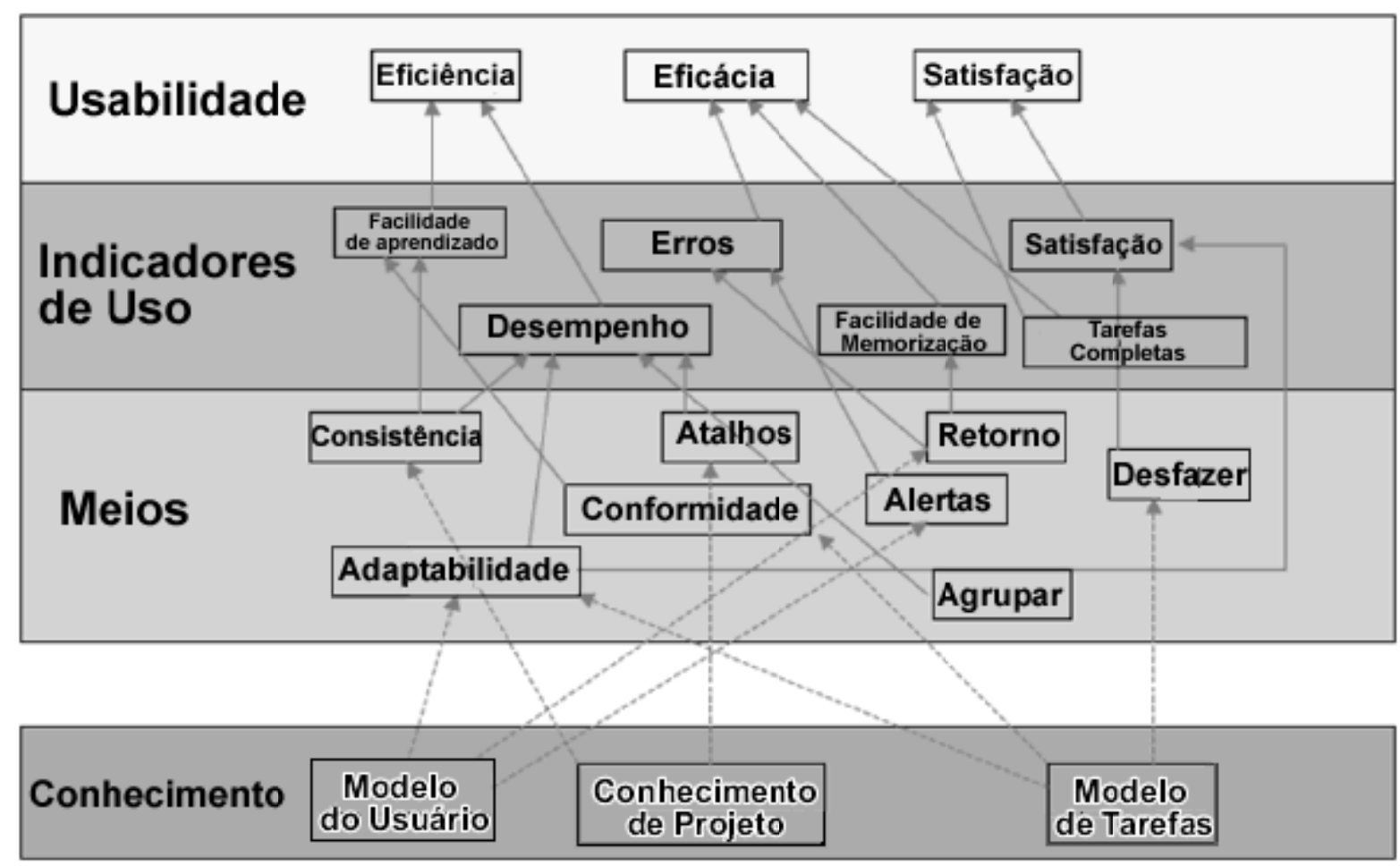

$\rightarrow$ Tem impácto sobre ...

Melhora ...

Figura 3 - Modelo em camadas para usabilidade, traduzido de (VEER; WELIE, 2000).

\subsection{Princípios e guidelines para o projeto de interfaces multimodais Web}

Os paradigmas de interface que são bem sucedidos atualmente, por exemplo, o Janelas, Ícones, Menus, Ponteiros (WIMP em inglês) e o arrastar e soltar (drag and drop), foram estabelecidos com base na consistência percebida pelo usuário com a interação entre projetos diferentes e na interpretação de um comportamento intuitivo, resultando em padrões de projeto bem entendidos e metáforas que podem ser aplicadas independentemente do sistema (SERRANO et al., 2008).

Essas metáforas permitem que o usuário aplique o conhecimento adquirido em sua interação com a aplicação em diversas outras tarefas em sistemas diferentes.

Por trás desses paradigmas foram estabelecidos alguns princípios de bons projetos de interface com o objetivo de pautar o projeto e permitir a descoberta de problemas de usabilidade. Os quatro princípios, segundo (NORMAN, 1995) são:

- Visibilidade e propriedades percebidas de um objeto (affordance),

- Bom modelo conceitual (entendimento do funcionamento do sistema), 
Capítulo 2 - A usabilidade no projeto de interfaces multimodais centrado no usuário

- Bons mapeamentos (relacionamento entre as entradas e saídas de uma interface)

- Retorno ou feedback (retornar ao usuário informação sobre as ações que foram feitas).

Com base nessa particularidade presume-se que as interfaces multimodais também necessitam estar fundamentadas em um conjunto de princípios, para facilitar o projeto de sistemas multimodais e porque elas integram várias modalidades de interação com o usuário.

Dessa forma, novas metáforas poderão se manifestar nas aplicações e nas interfaces nas quais elas desempenharão o papel de integrar as entradas do usuário, que podem ocorrer de diversos modos, e na síntese de saída de dados na forma de múltiplas mídias.

Um desafio para desenvolver uma aplicação de qualidade que contenha interação por voz é usar o tempo de maneira eficiente e não obrigar o usuário a ouvir mais do que ele precisa ouvir para entender a mensagem, responder de forma sucinta e conseguir interagir com o sistema.

De acordo com (RAMAN, 2003) existem cinco princípios que devem ser considerados durante o projeto das interfaces multimodais: sincronização, transição, compartilhamento do estado de interação, previsibilidade e adaptatividade.

Guidelines (diretrizes) também são importantes no projeto de interfaces, pois orientam os projetistas na tomada de decisões consistentes através dos elementos que constituem o produto. Em (REEVES et al., 2004) os autores propõem a utilização de cinco guidelines para o projeto de interfaces multimodais: projeto da entrada e saída multimodal, adaptatividade, consistência na interação, retorno (feedback) e tratamento e prevenção de erros.

Em geral, os princípios e guidelines costumam ser genéricos e não triviais. A experiência é fundamental para que o projetista ou o avaliador saiba distinguir quando aplicar e quando ignorar um princípio em determinado projeto.

Por essa razão, no Capítulo 4 será proposta a utilização de dez princípios definidos com base na teoria pesquisada nesta seção, como uma forma de facilitar a identificação de problemas de usabilidade na interação multimodal e também visando explicitar boas práticas em nível de projeto que sejam identificados por seus projetistas. 


\subsection{Padrões de Projeto para interfaces multimodais}

Além dos princípios e das guidelines, existe uma técnica utilizada para representar e comunicar o conhecimento de projeto em IHC, os padrões de projeto (JOHN W. STAMEY; HONEYCUTT, 2004).

Padrões de projeto (Design Patterns) foram utilizados primeiramente no domínio da arquitetura (ALEXANDER; ISHIKAWA; SILVERSTEIN, 1977) para representar soluções de sucesso para problemas recorrentes encontrados nesse contexto.

Um padrão pode ser entendido como uma abordagem para capturar e apresentar conhecimento de projeto na resolução de problemas, atuando como um meio de divulgação de conhecimento entre projetistas especialistas e novatos e de comunicação entre os elementos da equipe.

(BARFIELD et al., 1994), (BORCHERS, 2001) e (TIDWELL, 2005) afirmam em seus trabalhos que os padrões para interação diferem dos propostos por Alexander (1977) em um tópico importante: o tempo. Os padrões de Alexander lidam exclusivamente com configurações espaciais. A IHC, por outro lado, deve levar em consideração que a interface com o usuário em um sistema computacional interativo é um ambiente dinâmico que freqüentemente muda de aparência e comportamento durante o processo da interação (BORCHERS, 2001).

Um dos desafios para o domínio de IHC encontra-se no desenvolvimento de técnicas eficientes para documentar e comunicar o conhecimento que os projetistas adquiriram e aplicaram em determinadas circunstâncias (TIDWELL, 2005).

Segundo Borchers (2001), esse conhecimento precisa ser aplicado em diversos contextos, tais como:

- Durante o processo, quando o projetista procura uma solução para um problema.

- Durante a formação de equipes para o projeto.

- Durante a inclusão de novos membros na equipe do projeto.

- Na comunicação entre as equipes multidisciplinares e com os usuários.

- Na disseminação da solução.

Tidwell (2005) argumenta que os padrões são as melhores alternativas para se expressar as guidelines e princípios disponíveis no domínio da IHC. As guidelines para o projeto de uma interface gráfica (GUI) são exemplos típicos que são utilizados para assegurar um visual comum a todas as interfaces geradas através de uma ferramenta computacional, mas que tornam o projeto dependente da tecnologia disponível no momento, perdendo a 
aplicabilidade caso haja alguma mudança tecnológica, por exemplo, a migração de interfaces entre diferentes sistemas operacionais, ou até mesmo a inclusão de uma nova modalidade de interação.

A utilização de padrões ao invés das guidelines é motivo de muita discussão na comunidade de IHC. O que se verificou durante essa pesquisa foi que a proposta das guidelines é capturar conhecimento de projeto em regras pequenas, que podem ser usadas depois, no projeto de novas interfaces. A proposta dos padrões é capturar conhecimento (valores e idéias) de projeto validado cientificamente e descrevê-lo em problema, contexto, solução e raciocínio.

A utilização dos padrões implica em uma ênfase no processo de desenvolvimento e o uso de guidelines no produto (uma lista de diretivas imperativas). Um bom padrão tem que ser evoluído da experiência tanto do sucesso quanto da falha e observações de um conjunto de desenvolvedores ao invés de gravar muitos exemplos, deve ser feito um refinamento para garantir a invariância.

Uma linguagem de padrões (BORCHERS, 2001) através da sua organização interrelacionada permite um caminho de navegação entre as diversas guidelines com segurança e a possibilidade de envolver os usuários de interfaces no projeto e modificação desses artefatos, servindo como uma linguagem de comunicação entre os participantes do projeto.

Quando se fala de ponto de vista do usuário, é importante dar ênfase à argumentação de como e porque a usabilidade pode ser melhorada. Sem esse raciocínio é impossível ver quando e porque a solução é realmente boa e aceitável.

Algumas soluções resolvem os problemas dos projetistas, mas não necessariamente os do usuário. De acordo com Welie (2000), não é difícil identificar padrões na interface com o usuário, mas é difícil identificar os padrões que realmente beneficiam o usuário e explicam os aspectos de usabilidade do sistema em questão através de indicadores como: aprendizagem, memorização, desempenho, taxa de erro, satisfação e finalização da tarefa.

Na Figura 4, é mostrado o padrão de IHC “Home Link" (WELIE, 2010) que mostra a importância de ter um logotipo direcionando o usuário para a página principal do site.

O trabalho descrito em (RATZKA; WOLFF, 2006) propõe uma metodologia de projeto que utiliza padrões de projeto para o desenvolvimento de sistemas multimodais interativos, destacando questões de projeto relacionadas ao contexto de fatores de utilização e como um meio de orientar o processo de análise e projeto. Os padrões de projeto são discutidos como uma ferramenta de modelagem em geral, bem como uma possível abordagem para a criação de sistemas multimodais. A concepção dos sistemas multimodais 
reúne uma ampla variedade de métodos de análise (tarefa, contexto, dados do usuário). Os autores afirmam que a combinação de modalidades, bem como os novos dispositivos de interação implicam um elevado grau de liberdade e são tópicos que devem ser considerados em padrões multimodais.

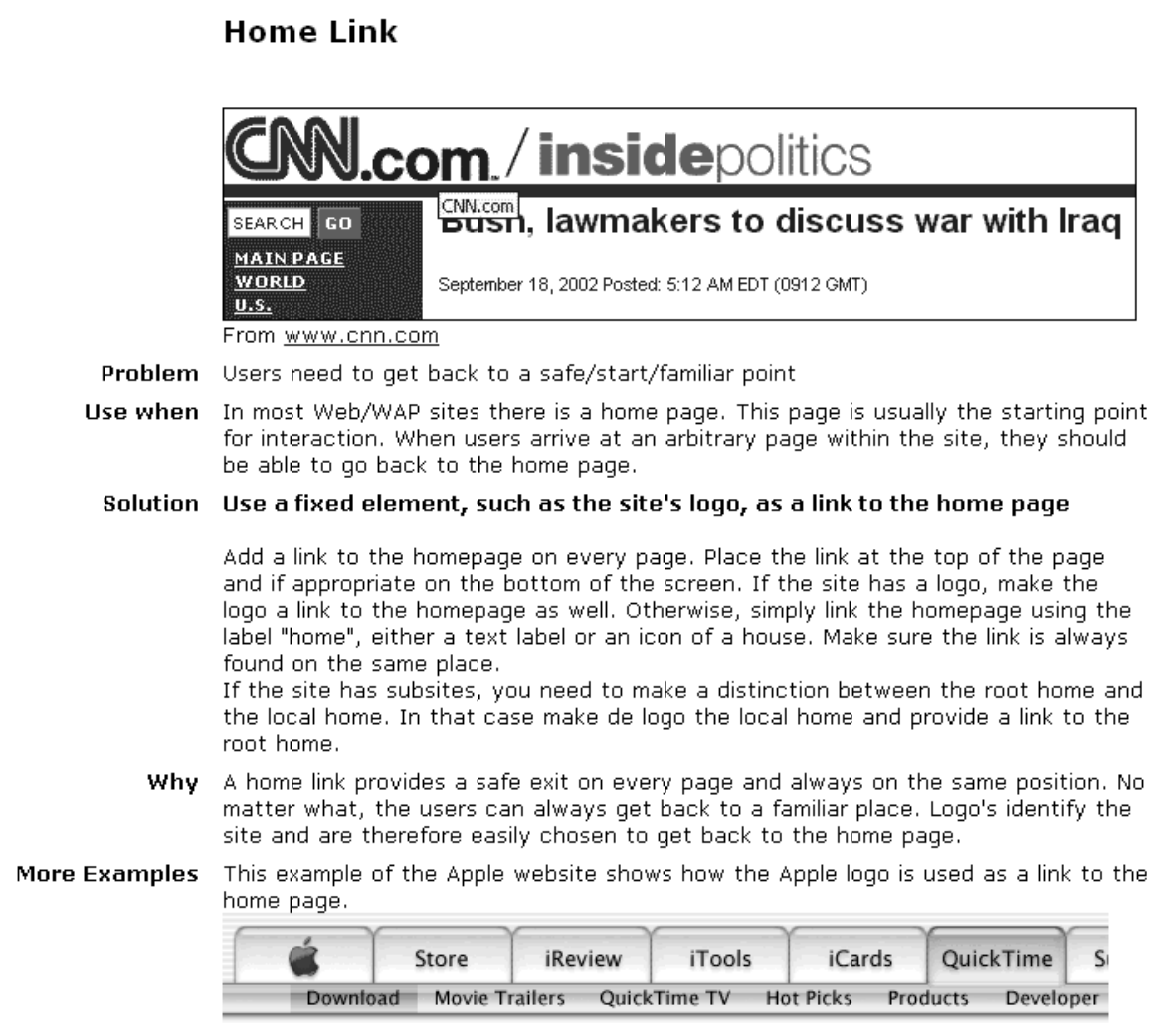

Figura 4 - Padrão de IHC “Home Link” (WELIE, 2010)

Neste trabalho propõe-se a identificação de padrões de projeto para a interação multimodal como forma de documentar e divulgar as soluções bem sucedidas para os problemas recorrentes de projeto no contexto da interação em sistemas multimodais. Exemplos de padrões multimodais identificados nesta pesquisa podem ser encontrados no Apêndice A.

\subsection{Avaliação de usabilidade em interfaces multimodais}

Um dos conceitos fundamentais da Interação Humano-Computador é que a usabilidade deve ser considerada em etapas anteriores ao início do desenvolvimento, pois quando os métodos de inspeção ou de testes são iniciados no final do ciclo do projeto, as mudanças nas interfaces podem ser caras e difíceis de implementar e gerenciar. Quanto mais cedo os erros forem detectados, mais fácil será corrigi-los (MARCUS, 2002).

Durante as etapas de um projeto de software diversas formas de avaliações podem ser usadas com o objetivo principal de corrigir problemas técnicos e informar ao projetista 
Capítulo 2 - A usabilidade no projeto de interfaces multimodais centrado no usuário

problemas de interação e usabilidade que podem afetar a experiência do usuário e diminuir sua satisfação no uso do produto.

Os métodos clássicos de avaliação de usabilidade foram estabelecidos no século passado, principalmente na década de 80 , quando o principal objetivo era avaliar e melhorar a usabilidade de aplicações desktop que eram utilizadas em ambientes semelhantes, geralmente o ambiente de trabalho, na sua maioria por usuários com o mesmo perfil de uso. O objetivo principal das avaliações era aumentar a produtividade com a realização rápida, eficiente e fácil das tarefas.

Os métodos para a avaliação de interfaces convencionais podem ser divididos em 2 grupos:

- Os analíticos, fundamentados na teoria e que não necessitam de um sistema funcional nem de usuários reais;

- Os empíricos, fundamentados em dados reais obtidos da interação entre um usuário e um protótipo do sistema.

Exemplos de métodos analíticos incluem a avaliação heurística baseada na lista de dez heurísticas definidas por Jacob Nielsen (NIELSEN; MOLICH, 1990; NIELSEN, 1993), o GOMS (CARD; NEWELL; MORAN, 1983) e o método Cognitive Walkthrough (LEWIS et al., 1990).

O principal benefício é permitir a avaliação de uma interface nos estados iniciais de projeto e desenvolvimento. No entanto, o fato de depender de dados hipotéticos e de teorias faz com que esses métodos sejam pouco precisos ou limitados quando o escopo de estudo é interação multimodal, que ainda não é apoiada por uma base teórica consolidada. Além disso, a configuração de experimentos e a interpretação dos dados desses métodos são tarefas complexas e consomem muito tempo e recursos, muitas vezes inviabilizando a avaliação.

Em contraste, os métodos empíricos usam dados obtidos da observação de usuários reais executando tarefas e interagindo com um sistema, geralmente protótipo do sistema final, mock-ups ou cenários.

Um exemplo é o "Teste com Usuários”. Esse método de avaliação de usabilidade é realizado com a participação de usuários, executando-se tarefas definidas pelos avaliadores e projetistas de interface, que observam as atitudes dos usuários diante da interface analisada (NIELSEN, 1993).

Hoje em dia, com o grande número de dispositivos existentes aliado ao avanço exponencial do acesso à Internet por diferentes perfis de usuários que executam diferentes 
tipos de tarefas em diferentes ambientes (PATERNO; GIAMMARINO, 2006; PATERNÒ; SANTOS, 2007), faz-se necessária a pesquisa por diferentes formas de avaliações de usabilidade que proporcionem a identificação de problemas tanto para tarefas rotineiras e simples como também para tarefas complexas e de alto risco.

Essa característica de um cenário variado de utilização das interfaces por diferentes perfis de usuários em diferentes ambientes com novos dispositivos fortalece a tese de que as interfaces multimodais são uma boa escolha para aumentar a satisfação do usuário e sua experiência geral de uso devido a sua característica de proporcionar uma interação mais natural, flexível e eficiente de uma maneira mais próxima ao modo como as pessoas se comunicam naturalmente.

Os métodos de avaliação de usabilidade devem também considerar, investigar e proporcionar formas de resolução para os problemas que podem ocorrer devido ao local onde o usuário está interagindo e sua situação momentânea, por exemplo, estar distraído em um ambiente ruidoso ou estar executando múltiplas tarefas ao mesmo tempo.

Outro fator interessante levantado por (KJELDSKOV; GRAHAM, 2003) em um estudo que compara os métodos usados em pesquisas de IHC em ambientes multimodais, aponta que a maioria dos estudos (55\%) são pesquisas aplicadas e 33\% são pesquisas de laboratório, mas apenas 3\% são estudos de campo, o que sugere que existe uma tendência de não se considerar o ambiente em que o usuário comumente interage durante as avaliações, fator esse que pode prejudicá-las. Esse fato pode ser justificado pelo alto custo e necessidade de um alto número de recursos inerentes aos métodos de pesquisa de campo.

Portanto, os três fatores relacionados ao contexto de uso, que foram apresentados neste capítulo, devem ser levados em consideração durante o processo de avaliação, pois podem influenciar na usabilidade final do produto:

- o contexto físico, ou o lugar onde o usuário interage.

- o contexto tecnológico, tecnologia disponível ao usuário (rede, dispositivos de $\mathrm{IO})$.

- o contexto social, representando todas as situações que influenciam o uso do sistema.

Nesta tese, descrevem-se os métodos mais apropriados para a avaliação de interfaces multimodais, categorizando-os segundo a definição de (BERNHAUPT, 2008), bem como as modificações e extensões que se sugere para uma maior eficiência dos mesmos, levando-se 
em consideração a premissa de Desurvire (1994) que os pontos fracos de alguns métodos são superados com o uso de outros métodos.

A avaliação em interfaces multimodais pode ser realizada com qualquer dos métodos citados a seguir, levando-se em consideração as características dessas interfaces. O objetivo das avaliações de usabilidade não é somente identificar problemas de usabilidade, mas também fornecer um mecanismo eficiente para se reportar os erros à equipe de projeto e até mesmo fornecer sugestões de alteração de projeto ou implementação.

\section{Testes com usuários:}

Os testes com usuários são conduzidos geralmente em laboratório e envolvem usuários que executam tarefas típicas e são orientados a "pensar alto", ou seja, falar o que pensam quando interagem com o sistema.

O sistema alvo do teste pode ser o sistema real totalmente funcional, um protótipo executável ou uma configuração Wizard of $O z$ (TAIB; RUIZ, 2007), na qual as funcionalidades multimodais são simuladas por uma pessoa. O desempenho dos usuários é observado e medido em termos de solução de problemas, tarefas completadas, erros observados, número de clicks e teclas pressionadas.

As observações podem ser realizadas pelos pesquisadores, por câmeras ou por meio da análise dos $\log s$ das ações executadas no sistema. Essa avaliação de aplicações multimodais em laboratório pode não ser suficiente, pois para se investigar o real contexto de uso, testes de campo ou em situações reais são necessários para se verificar possíveis problemas no uso das interfaces em diferentes contextos, como em ambientes com ruído ou usando dispositivos móveis.

A maioria dos estudos de usabilidade para interfaces multimodais encontrados na literatura adota como método preferido os testes com usuários (BERNHAUPT, 2008; CHANG; BOURGUET, 2008; NETO; FORTES, 2009) no qual as tarefas executadas por usuários reais são observadas ou gravadas, pois permite a observação e a investigação de como os usuários interagem com as interfaces multimodais fornecendo informações úteis sobre usabilidade e experiência de uso.

Mais adiante nesta tese será apresentado um estudo de caso utilizando testes com usuários com análise de $\log s$ e uso de questionário que foi projetado para considerar as necessidades inerentes às interfaces multimodais.

\section{Métodos de inspeção:}

Os métodos de inspeção envolvem especialistas no domínio e em avaliações de usabilidade com métodos analíticos que conhecem e utilizam guidelines ou recomendações 
específicas para identificar e julgar problemas de usabilidade fundamentado em sua experiência em outros projetos e até mesmo no desenvolvimento de interfaces.

Os métodos analíticos são conhecidos por serem fáceis, rápidos e baratos, mas requerem pessoas especialistas e treinadas, pois os resultados dependem do conhecimento e da experiência de tais especialistas (NIELSEN, 1995). Métodos desta categoria incluem: avaliação heurística, revisão de guidelines, percurso pluralístico, inspeções de consistência, percurso cognitivo, entre outros.

Métodos de inspeção podem ser aplicados nas primeiras etapas do processo de desenvolvimento com a análise de mock-ups, cenários e protótipos. A falta de experiência e conhecimento específico dos especialistas no domínio multimodal e a falta de guidelines que considerem as modalidades e suas combinações durante a interação podem explicar porque esses métodos têm sido usados menos frequentemente em projetos multimodais.

A avaliação heurística (NIELSEN, 1995) é utilizada para realizar inspeções sistemáticas da interface que está sendo desenvolvida com relação à sua usabilidade. Basicamente avaliadores experientes interagem com a interface e julgam a sua adequação comparando-a com princípios de usabilidade reconhecidos: as heurísticas. Mais adiante será apresentado como esse método pode ser adaptado para ser utilizado com as peculiaridades das interfaces multimodais, por meio do uso de guidelines específicas que foram obtidas em estudos de caso utilizando-se DR.

A modificação dos Métodos de Inspeção para incluir guidelines e conhecimento específico do domínio multimodal ajudam os avaliadores a aproveitarem as vantagens desses métodos e a reduzirem seus pontos fracos.

\section{Pesquisas e questionários:}

É um método bastante conhecido e extensivamente empregado para obtenção de feedback qualitativo dos usuários (satisfação de uso, preferências de modalidade, etc), mas pouco usado até então para avaliações em interfaces multimodais, porém são muito úteis para investigar o contexto de uso dos dispositivos e das interfaces em sistemas multimodais. $\mathrm{O}$ usuário interage com os dispositivos em tarefas cotidianas e ao mesmo tempo reporta suas experiências, problemas e sugestões para a melhoria das interfaces e da interação. Frequentemente questionários são usados em conjunto com outros métodos de avaliação de usabilidade para apresentar melhores resultados.

\section{Métodos de modelagem:}

Em complemento aos métodos centrados em usuários, especialistas e pesquisas existem os métodos de modelagem tradicionalmente aplicados no domínio de engenharia de 
Capítulo 2 - A usabilidade no projeto de interfaces multimodais centrado no usuário

software como testes automáticos, descrições formais, análise de incidentes e modelos de tarefa.

Os métodos de modelagem complementam os tradicionais métodos de avaliação, fornecendo informações da especificação formal do software e são úteis no contexto multimodal, pois as diferentes modalidades e suas combinações de uso podem ser testadas automaticamente, por meio de seleções no modelo.

Mais recentemente, as simulações (OVIATT, S., 2003) e os métodos de modelagem para checagem de especificações de sistemas (CHANG; BOURGUET, 2008) têm sido utilizados para prever problemas de usabilidade, tais como, estados que não são alcançados, detecção de conflitos de modalidades, eventos necessários para fusão e fissão de modalidades.

Paternò e Santos (PATERNÒ; SANTOS, 2007) propõem combinar análise de tarefas no modelo com gravações de vídeo e eye tracking para melhor entender a interação.

Bernhaupt (2008) e Chang (2008) usam técnicas de especificação formal em combinação com os métodos tradicionais de avaliação de usabilidade, como testes com usuários e cognitive walkthrough para uma detalhada verificação e análise de problemas de usabilidade relacionados aos eventos necessários para fusão e fissão de modalidades.

\subsection{Considerações finais}

Neste capítulo foram apresentados os referenciais teóricos que serão utilizados para a proposta da abordagem para projeto, desenvolvimento e testes de interfaces multimodais Web, que será introduzida no Capítulo 4 .

A seguir, no Capítulo 3, serão discutidos o estado da arte na área de interação multimodal e as diversas abordagens e frameworks que têm sido propostos para realizar a atividade de projeto, os quais servirão como base para a proposta do ambiente de autoria de interfaces multimodais Web apresentados nesta tese. 



\section{Capítulo 3. Projeto de Interfaces Multimodais}

\subsection{Considerações iniciais}

$\mathrm{O}$ advento dos sistemas multimodais representa um movimento de pesquisas do paradigma de interação convencional do tipo janela, ícone, menu e dispositivo de apontamento (tradução para Window Icon Menu Pointing - WIMP), para pesquisas com um novo paradigma que tem como objetivo fornecer aos usuários: maior poder de expressão, naturalidade, flexibilidade e portabilidade no uso de interfaces mais intuitivas e naturais (SCHAPIRA; SHARMA, 2001).

Os requisitos de integração e de sincronização para combinar estrategicamente as diferentes modalidades em sistemas completos constituem um novo tema de pesquisa para os sistemas multimodais que começaram a se definir no final da década de 90 (OVIATT; DEANGELI; KUHN, 1997).

Isto significa que o projeto bem sucedido de um sistema multimodal requer a orientação da ciência cognitiva na coordenação da percepção humana e na produção de interfaces que utilizem modalidades naturais ao usuário (OVIATT; COULSTON; LUNSFORD, 2004).

Sabe-se que os usuários apreciam poder interagir de maneira multimodal com os sistemas, mas não o fazem sempre assim (OVIATT; COULSTON; LUNSFORD, 2004). Seus padrões naturais de comunicação envolvem misturar expressões de uma modalidade e expressões previsíveis de outras modalidades baseadas no tipo de ação que está sendo executada.

Resultados empíricos (OVIATT, 1997; OVIATT; DEANGELI; KUHN, 1997) enfatizam que os sistemas multimodais necessitam distinguir entre quando os usuários estão e não estão se comunicando de maneira multimodal, de forma que as decisões corretas possam ser feitas no momento em que as entradas de informação paralelas forem interpretadas conjuntamente ou individualmente.

Estes dados também sugerem que o conhecimento do tipo de ações a serem incluídas em uma aplicação deve influenciar a decisão sobre construir um sistema multimodal ou não. 
Neste capítulo são apresentados: o estado da arte na área de interação multimodal e as diversas abordagens que têm sido propostas para realizar a atividade de projeto de aplicações que incorporem interação multimodal.

Na Seção 3.2 são feitas algumas considerações sobre o uso de interação por voz em sistemas multimodais e na Seção 3.3 apresentam-se as características das linguagens de programação que habilitam o desenvolvimento de sistemas multimodais. Na Seção 3.4 são mostradas as abordagens e frameworks existentes na literatura para o projeto de interfaces multimodais. Conclui-se o capítulo na Seção 3.5, com as considerações finais.

\subsection{O uso de interação por voz em sistemas multimodais}

É importante considerar que embora as interações por interfaces de voz e por interfaces gráficas com manipulação direta possam ser sincronizadas durante a interação multimodal, sincronismo não implica em simultaneidade (DUMAS; LALANNE; OVIATT, 2009).

Quando a interação por voz é utilizada, uma segunda modalidade é considerada útil se o sinal de fala está degradado em um ambiente ruidoso, por exemplo. Nesse caso ela pode fornecer a informação necessária quando a confiança associada ao reconhecimento de voz é baixa.

As entradas baseadas em apontamento ou caneta precedem as entradas por fala em 90\% dos comandos multimodais seqüenciais, e na maioria das simultâneas também (COHEN et al., 1997). Portanto, a fala não é nem a portadora exclusiva de conteúdo importante, nem tem a precedência temporal sobre outras modalidades de entrada.

O oferecimento adiantado de entrada manual pode ser considerado como um fornecedor de contexto, e também pode dar assistência aos usuários enquanto planejam sua fala. Quando livres para interagir de forma multimodal, os usuários eliminam seletivamente muitas complexidades da fala, por exemplo, quando um usuário diz: “Adicione um quadrado no canto superior esquerdo da tela" ou de maneira mais simplificada, quando o usuário aponta o local desejado na tela e diz "Adicione um quadrado".

A linguagem multimodal é diferente da forma tradicional da linguagem natural, e em muitos casos ela é simplificada substancialmente. Uma implicação é que a linguagem multimodal pode ser mais fácil de processar e poderia suportar sistemas mais robustos no futuro. 
Em uma comunicação humana, linguistas verificaram que a fala espontânea e gesticular não envolve informação duplicada (OVIATT, 1999a), destacando a importância da complementaridade como um tema importante durante uma comunicação multimodal. Os projetistas de sistemas multimodais não devem conseqüentemente confiar na suposição de que uma informação é duplicada ao processar um comando multimodal.

É um erro pensar que todos os usuários interagem com um sistema multimodal de maneira uniforme, sempre utilizando os mesmos comandos e modalidades em um determinado momento (OVIATT, 1999b). Tais sistemas devem ser projetados para detectar e se adaptar ao padrão de interação de cada usuário e, conseqüentemente, melhorar consideravelmente as taxas de erro de reconhecimento.

Há outras vantagens na utilização dos sistemas multimodais com o uso de voz do que simplesmente a velocidade de interação, pois esses sistemas permitem evitar erros substanciais e uma recuperação de erro mais fácil, como discutido previamente. Por exemplo, os erros críticos de tarefa e os erros de linguagem não fluente podem diminuir de $36 \%$ a $50 \%$ durante a interação multimodal (OVIATT, 1997).

Uma vantagem mais significativa é a flexibilidade que os sistemas multimodais permitem aos usuários em selecionar e em alternar entre modalidades de entrada. Tal flexibilidade torna possível aos usuários alternarem modalidades de modo que a sobrecarga física seja evitada na utilização de uma delas (PATERNÒ; SANTOS, 2007). As interfaces multimodais com interação por voz podem acomodar uma grande gama de usuários, tarefas, e ambientes incluindo os usuários que estão com algum sentido temporariamente ou permanentemente comprometido, ou quando estão usando um dispositivo móvel, e outros casos em que uma modalidade pode não ser suficiente (HUBERT, 2006; PATERNO; GIAMMARINO, 2006).

\subsection{Tecnologias para o desenvolvimento de interfaces multimodais para a Web}

O World Wide Web Consortium (W3C) fundado em 1994 tem se mostrado ativo na pesquisa e desenvolvimento de linguagens para o desenvolvimento baseado na Web. Dois de seus grupos, o Voice Browser e o Multimodal Interaction, são responsáveis pela padronização de linguagens para o desenvolvimento de aplicações de voz e multimodais (JOHNSTON, 2009). 
A vantagem das linguagens padronizadas, além do reúso e da portabilidade, é que o desenvolvedor não precisa conhecer os detalhes tecnológicos de como os sistemas de reconhecimento funcionam, economizando tempo e esforço.

$\mathrm{O}$ W3C vem padronizando linguagens para o desenvolvimento de aplicações multimodais como o SALT e o XHTML + Voice $(X+V)$ e também publicou recentemente a linguagem EMMA para a representação de informações semânticas fornecidas pelo usuário através de teclado, mouse, microfone, etc.

$\mathrm{Na}$ seção a seguir será apresentada a linguagem VoiceXML que impulsionou as pesquisas pelas linguagens multimodais apresentadas na seqüência.

\subsubsection{VoiceXML}

VoiceXML (2007) é uma linguagem de marcação cujo objetivo é fornecer aos desenvolvedores de aplicações com interação por voz a possibilidade de descrever os elementos de diálogo e minimizar as requisições entre o cliente e o servidor por meio da especificação de múltiplas requisições por documento XML (W3C, 1996). A linguagem VXML inclui elementos para permitir a saída de voz sintetizada (TTS) ou a saída por meio de arquivos de áudio, além de permitir o reconhecimento de entrada por voz, por DTMF ou entrada previamente gravada. Inclui também as características dos sistemas de telefonia como transferência de chamada e desconexão. O Quadro 2 resume os elementos da linguagem VXML, alocando-os ao escopo de seus respectivos objetivos.

Quadro 2 - Principais elementos da linguagem VXML organizados por escopo

\begin{tabular}{|c|c|}
\hline Escopo & Elementos (Tags) VXML \\
\hline Variáveis e propriedades & $\begin{array}{l}\text { <assign>, <meta>, <param>, <property>, <script>, <value>, <var>, } \\
\text { <clear> }\end{array}$ \\
\hline Síntese de fala e saída de áudio & $\langle$ audio $\rangle,\langle$ block $\rangle,\langle$ enumerate $\rangle,\langle$ reprompt $\rangle$, , sayas $\rangle,\langle$ break $\rangle$ \\
\hline Tratamento de erros & $\langle$ <atch $\rangle,\langle$ throw $\rangle$, <error $\rangle,\langle$ help $\rangle,\langle$ noinput $\rangle,\langle$ nomatch $\rangle$ \\
\hline Fluxo do diálogo & 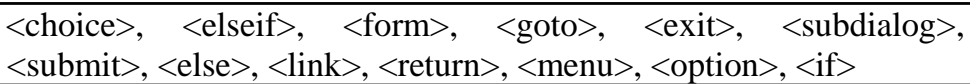 \\
\hline Entradas de usuários e gramáticas & $\langle$ field $>,\langle$ dtmf $>,\langle$ record $>,<$ filled $>,<$ grammar $>$ \\
\hline Integração com sistemas de telefonia & $\langle$ transfer $>,<$ disconnect $>$ \\
\hline Definição de documento & <vxml $>,<$ initial $>,<$ object $>$ \\
\hline
\end{tabular}

Existem diversas ferramentas para desenvolvimento de aplicações em VoiceXML como, o WebSphere Voice Toolkit da IBM e o Nuance Development Framework da Nuance Communications Inc, que oferecem os componentes necessários para o desenvolvimento de aplicações complexas sem a necessidade de conhecer a tecnologia de voz por completo. Essas 
ferramentas oferecem características essenciais para o desenvolvimento de aplicações de voz como:

- Suporte para o projeto gráfico do fluxo de comunicação.

- Auxílio no desenvolvimento de código VXML e verificação de erros em código.

- Auxílio no desenvolvimento de gramáticas e verificação de erros.

\subsubsection{SALT}

SALT (Speech Application Language Tags) é uma linguagem de marcação desenvolvida pelo Salt Forum, originalmente formado por Cisco, Comverse, Intel, Microsoft, Philips, e ScanSoft, para o desenvolvimento de aplicações multimodais que usam a entrada e a saída de voz (reconhecimento e síntese de voz), reconhecendo e gerando falas humanas (SWADE; REUSCH, 2007).

Como linguagem de marcação, SALT fornece tags que especificam o que o software de reconhecimento de voz deve escutar e o que o software de síntese deve dizer. Enquanto o $\mathrm{X}+\mathrm{V}$, que será apresentado mais adiante, combina XHTML, VoiceXML e XML Events para criar aplicações multimodais, o SALT é um conjunto de tags de baixo nível para especificar a interação por voz que pode ser inserida em qualquer ambiente. Ou seja, SALT requer um ambiente para ser executado, mas não define esse ambiente, fazendo com que o desenvolvedor tenha que gerar diferentes versões da aplicação para cada ambiente de execução. Em contraste, $\mathrm{X}+\mathrm{V}$ define todos os aspectos do ambiente da aplicação e assegura consistência e portabilidade entre diferentes ambientes.

A necessidade desse ambiente externo torna necessário gerar diferentes versões de aplicações para diferentes dispositivos.

Os principais elementos (tags) SALT são:

- 〈prompt>, apresenta ao usuário gravações de áudio ou fala sintetizada;

- <listen>, reconhece palavras e frases ditas pelo usuário;

- <grammar>, especifica as palavras e frases que o usuário pode falar;

- $\quad\langle\mathrm{dtmf}>$, reconhece DTMF (teclas de telefone);

- <record>, captura fala e outros sons;

- <bind>, integra palavras e frases reconhecidas com a lógica da aplicação;

- $\langle$ smex $>$, comunica-se com outros componentes da plataforma. 


\subsubsection{XFORMSMM}

Outra linguagem para criação de interfaces multimodais é apresentada por Honkala e Pohja (2006). Os autores propõem o XFormsMM, para autoria de aplicações multimodal, utilizando XForms como linguagem de descrição de interface com o usuário que permite o uso de uma aplicação de várias maneiras, focando no uso de interfaces gráficas e de voz. A utilização do XFormsMM permite preencher e submeter qualquer formulário escrito em XForms, utilizando entradas de texto e voz simultaneamente.

O modelo separa as interfaces dependentes da modalidade (voz ou visual) das interfaces independentes da modalidade, permitindo mudanças flexíveis de modalidade e que o usuário escolha que modalidade usar e quando usar.

A principal vantagem, segundo seus autores, é que o XForms possui um conjunto amplo de tipos de dados, maior acessibilidade devido ao alto nível semântico de seus elementos e pouca necessidade de se utilizar scripts, comuns nas tecnologias X+V e SALT.

\subsubsection{EMMA}

EMMA (Extensible MultiModal Annotation markup language) (BAGGIA et al., 2007) é uma linguagem de marcação usada para representar informação extraída da entrada dos usuários que interagem com uma aplicação multimodal. Essa linguagem possibilita atribuir significado para diferentes tipos de entrada como: texto, fala, escrita e combinações dessas entradas.

EMMA considera os seguintes tipos de entradas:

- Entrada por uma única modalidade.

- Entradas por modalidades seqüenciais.

- Entradas por modalidades simultâneas, ou seja, a entrada pelas diferentes modalidades é interpretada uma após a outra na ordem em que foram recebidas ao invés de serem combinadas antes de ocorrer a interpretação.

- Entradas por modalidades compostas, ou seja, as entradas são recebidas ao mesmo tempo por meio das múltiplas modalidades, e tratadas individualmente.

A linguagem EMMA está sendo utilizada primeiramente como um formato padrão para troca de dados entre sistemas multimodais e o objetivo é que ela seja gerada automaticamente por componentes de software (e não por desenvolvedores) responsáveis pela interpretação e usados para representar a semântica das entradas dos usuários. 
A linguagem EMMA não representa uma linguagem de especificação e não contém nenhuma abordagem transformacional para permitir desenvolvimento de aplicações usando diferentes modelos.

EMMA pode ser considerada uma linguagem complementar a SALT e $\mathrm{X}+\mathrm{V}$, funcionando como uma camada intermediária entre os componentes da aplicação multimodal, ou seja, entre a entrada do usuário e o interpretador SALT ou $\mathrm{X}+\mathrm{V}$. Isso permite que o desenvolvedor não precise se preocupar em escrever código para interpretar a entrada do usuário, pois EMMA traduz a entrada em um formato interpretado pela linguagem de desenvolvimento da aplicação multimodal, simplificando o processo de se adicionar várias modalidades a ela.

\subsubsection{XHTML+VoiceXML $(\mathbf{X}+\mathrm{V})$}

O X+V (CROSS et al., 2003) é um padrão proposto pelo W3C para o desenvolvimento de aplicações com interface multimodal (visual e voz), que combina um subconjunto de elementos XHTML, uma linguagem de marcação para criar aplicações visuais, e VXML. Ambas as linguagens são integradas por XML que disparam eventos DOM (Document Object Model) para possibilitar a interação por voz.

DOM é uma API proposta pelo W3C para estruturar documentos na Web em forma de árvore. O objetivo do DOM é permitir que os programadores acessem de maneira fácil os elementos e atributos de documentos escritos em XML por meio de qualquer linguagem de programação, utilizando as operações conhecidas de manipulação de árvores.

As aplicações criadas com o padrão $\mathrm{X}+\mathrm{V}$ podem conter estilos visuais fundamentados em folhas de estilo e podem ser visualizadas por navegadores que contêm um plugin para reconhecimento de voz, como o Opera ${ }^{1}$, por exemplo.

Como pode ser observado na Figura 5, as aplicações multimodais usando o padrão $\mathrm{X}+\mathrm{V}$ permitem uma migração natural das aplicações de voz baseadas em VXML, geralmente utilizadas em aplicações para telefonia, e das aplicações visuais em XHTML para uma aplicação simples que pode ser executada em ambos os ambientes isoladamente e também em conjunto.

As vantagens ao se usar $\mathrm{X}+\mathrm{V}$ como linguagem de desenvolvimento são: a existência de uma comunidade de desenvolvedores altamente treinada em VXML, bem como materiais de estudo, infra-estrutura e ferramentas disponíveis dessa linguagem padronizada.

\footnotetext{
${ }^{1}$ www.opera.com/
} 


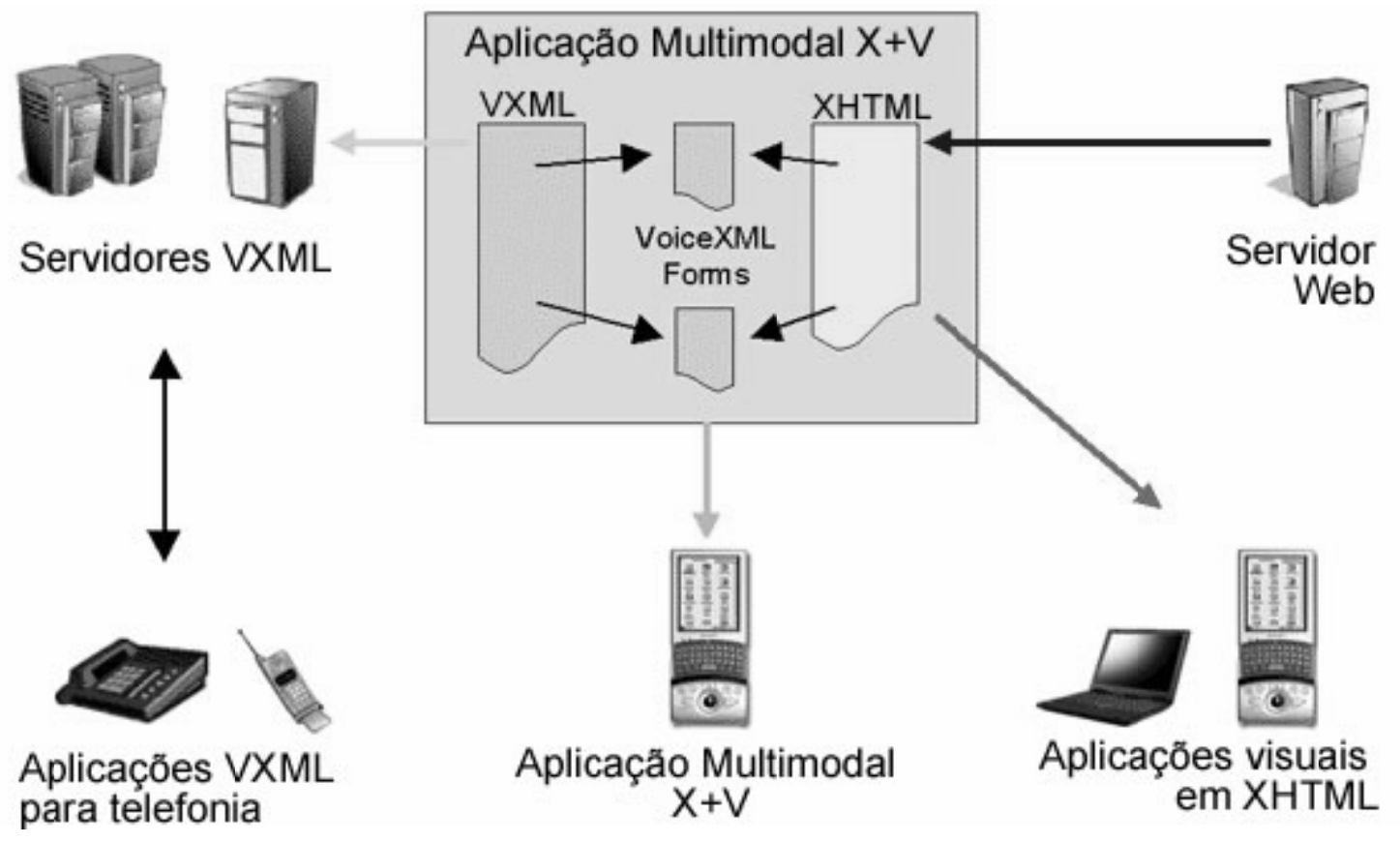

Figura 5 - Arquitetura para o desenvolvimento de aplicações $\mathrm{X}+\mathrm{V}$.

Uma aplicação básica de $\mathrm{X}+\mathrm{V}$ permite que o usuário interaja por meio de comandos de voz além dos com campos de dados tradicionais (checkboxes, input fields e assim por diante) e receba mensagens de voz bem como visuais. Este tipo simples de interação por voz é chamado uma interação dirigida por diálogo.

Os arquivos $\mathrm{X}+\mathrm{V}$ são divididos em três partes. O cabeçalho indica a versão XML, o DOCTYPE e a DTD da linguagem. O elemento <html > é aberto para indicar os módulos usados e contém os elementos $\langle$ head $\rangle$ e $\langle$ body $\rangle$. A segunda parte é o $\langle$ head $\rangle$, que inclui todas as funções de voz, e define o título da página e indica que folha de estilo usar. As funções de voz estão contidas no elemento 〈vxml:form>, que especifica todos os elementos de voz correspondentes aos elementos que compõem a interface visual. A terceira parte é o <body>, que contém todos os elementos gráficos HTML. Adicionalmente, possui uma referência no formulário que contém o elemento que trata os eventos para o elemento $<$ vxml:form>, responsável por gerenciar a parte de voz.

A arquitetura modular do $\mathrm{X}+\mathrm{V}$ permite que a programação do código de voz seja realizada independentemente da programação visual. Trechos de código de VXML usados nas aplicações $\mathrm{X}+\mathrm{V}$ podem ser reusados em aplicações VXML.

$\mathrm{X}+\mathrm{V}$ é a linguagem escolhida para este trabalho, porque: suporta multimodalidade na Web, que é o ambiente mais comum da interação, é um padrão W3C e atualmente navegadores publicamente disponíveis (tais como o Opera) suportam-na, permitindo, assim, que os desenvolvedores testem imediatamente as interfaces produzidas. 
Na Figura 6 é mostrado um exemplo de código em $\mathrm{X}+\mathrm{V}$.

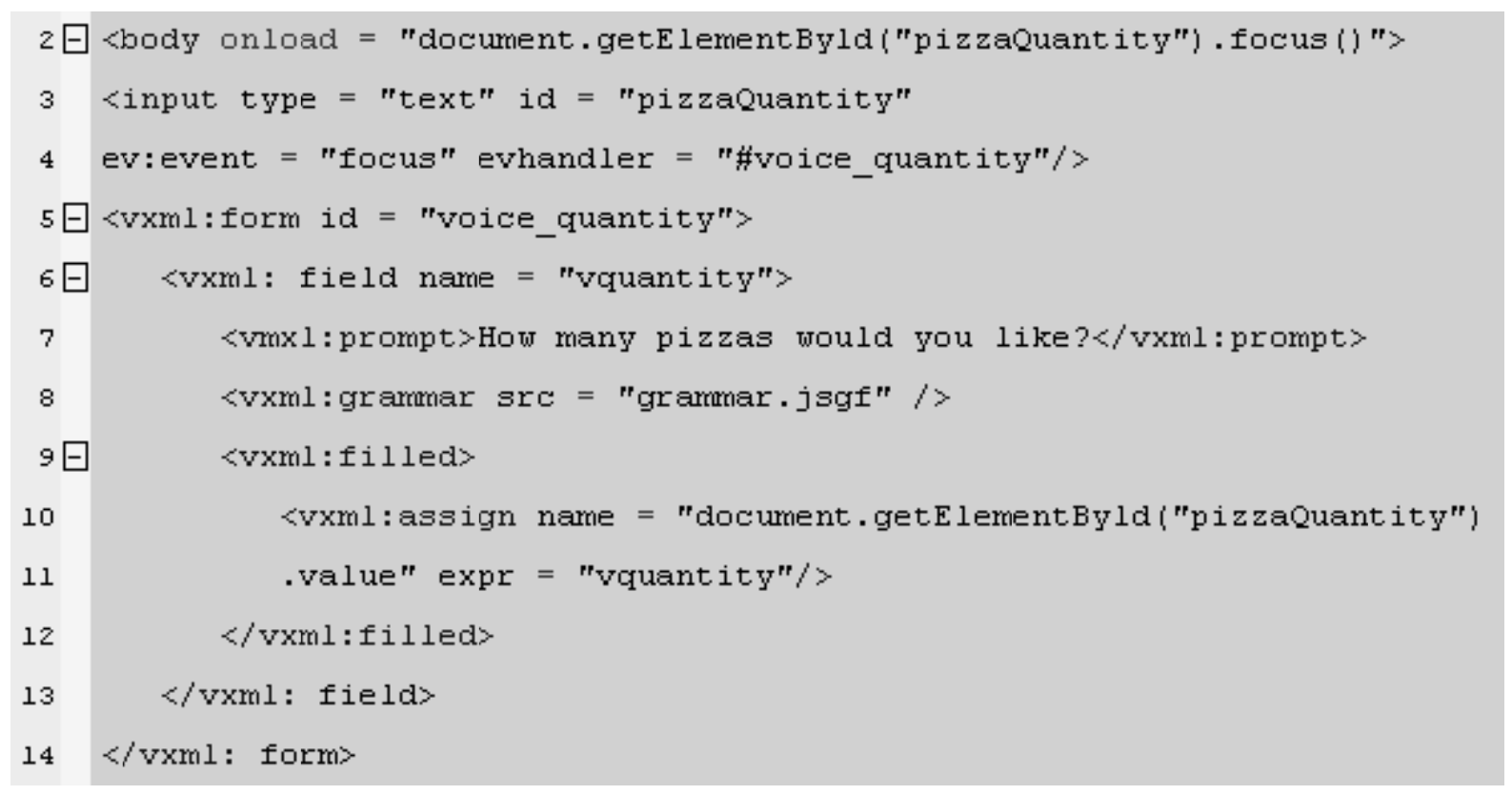

Figura 6 - Exemplo de código em $\mathrm{X}+\mathrm{V}$.

Nesse exemplo, quando o arquivo é carregado, foco é colocado no campo de texto HTML com o objetivo de obter a quantidade de pizza desejada. No mesmo momento o formulário VXML representado pelo “id=voice_quantity” é requisitado e um prompt sonoro é emitido para o usuário perguntando: "How many pizzas would you like?". O usuário pode responder por meio de fala ou digitando o número no campo de texto. Se ele optar pela fala, o elemento <assign> copiará o número falado pelo usuário para o campo de texto de forma que ele fique atualizado.

\subsubsection{JSGF}

A tecnologia utilizada para reconhecer a fala em aplicações $\mathrm{X}+\mathrm{V}$ não suporta $\mathrm{o}$ reconhecimento de voz sem restrições, ou seja, não é possível para a aplicação converter a fala para alguma outra representação, por exemplo, traduzir uma entrada de voz para texto. Para se reconhecer uma entrada de voz é necessária uma gramática de regras. O JSGF (Java Speech Grammar Format) é um formato utilizado para representação de gramáticas independente de plataforma. Por meio dele é possível definir textualmente as palavras que serão reconhecidas pela aplicação (GRUENSTEIN; MCGRAW; BADR, 2008).

Na Figura 7 é apresentado um exemplo da forma de um arquivo de gramática JSGF. No exemplo pode ser observada uma gramática identificada como "food_drink". Essa gramática identifica os seguintes tokens: "orange juice", "rice" e "steak", sendo que o token "orange juice" é interpretado como "drink" e os tokens "rice" e "steak" são interpretados como "food". Isso é muito útil quando é necessário atribuir a mesma interpretação para 
diferentes entradas de voz. Por exemplo, quando espera-se que a entrada de voz seja "yes", mas o usuário pode falar "yeah", "ok" ou "sure".

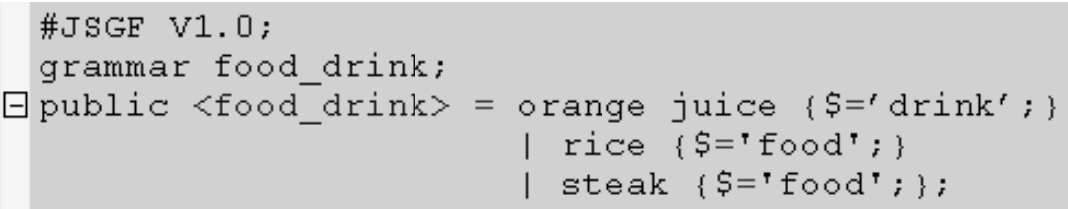

Figura 7 - Exemplo de código de gramática JSGF

A definição da gramática reconhecedora de voz é inserida no formulário de voz de uma aplicação VXML ou X+V, por exemplo.

\subsection{Abordagens para o projeto da interação multimodal}

O projeto de interfaces multimodais é importante porque os princípios e técnicas utilizados para as interfaces gráficas tradicionais (GUI) não se aplicam necessariamente aos sistemas multimodais, para os quais alguns tópicos importantes como o projeto das entradas e saídas de informações, da adaptabilidade, da consistência e do tratamento de erros, além de tópicos como dependências culturais, comportamentais e de personalidade individual devem ser considerados (REEVES et al., 2004).

Basicamente, o projeto de tais sistemas tem sido inspirado e organizado de duas maneiras (OVIATT, SHARON, 2003).

Primeiramente, seguindo as propostas encontradas na ciência cognitiva que fornece informações básicas sobre modelagem para usuários, o que os sistemas devem reconhecer e como as arquiteturas multimodais devem ser organizadas.

A habilidade em se desenvolver sistemas multimodais depende do conhecimento da tecnologia de linguagem natural e do modo como as pessoas combinam o uso de diferentes modos de entrada em uma interação.

O projeto de novos sistemas multimodais depende também do conhecimento das propriedades inerentes aos diferentes modos, da informação que carregam e das características de integração e sincronização.

É necessário também considerar quando os usuários querem interagir de forma multimodal e como são os padrões de interação multimodal de diferentes usuários.

A literatura da ciência cognitiva é bastante ampla nesse sentido especialmente quando o foco é a percepção sensorial e capacidades de interação inerentes às diferentes modalidades de entrada incorporadas em um sistema multimodal. 
A segunda forma de organização de um projeto multimodal são as simulações automáticas e desenvolvimento de protótipos, que também vêm desempenhando um papel fundamental para auxiliar os desenvolvedores nos estágios iniciais de planejamento e desenvolvimento de sistemas multimodais. Essas simulações têm como objetivo visualizar o sistema, suas funcionalidades e validar o fluxo da interação humano-computador, além de propiciar a obtenção de dados com uma população real e significativa de usuários.

A vantagem do uso de simulações está no fato de que nelas as mudanças são fáceis e de baixo custo comparando-se com um sistema completo já construído. Simulações também permitem que os pesquisadores alterem as características de um sistema planejado e estudem o impacto de diferentes características de interfaces de uma maneira sistemática, além de permitir tomada de decisões sobre projetos alternativos.

Nesta revisão identificou-se a necessidade da pesquisa e criação de ferramentas para apoiar o projeto, desenvolvimento e avaliações de usabilidade de sistemas multimodais, e vislumbra-se a seguinte infra-estrutura para o projeto de doutorado:

- ferramentas de simulação para construção e configuração rápida de interfaces multimodais;

- ferramentas de automação para coleta e análise de dados que melhorem a usabilidade das interfaces;

- ferramentas de autoria para sistemas multimodais.

A seguir serão apresentadas as abordagens identificadas na literatura e que são usadas para o projeto de interfaces multimodais Web atualmente.

\subsubsection{Estado da arte das abordagens para projeto de interfaces multimodais}

O trabalho realizado por Stanciulescu et al. (2005) apresenta uma abordagem baseada em transformações para o desenvolvimento de interfaces multimodais para Web. Em tal abordagem é utilizado um framework de referência, o Cameleon (LIMBOURG et al., 2005), que decompõe o ciclo de vida de uma interface em quatro níveis: modelo de tarefas, modelo de domínio, interface abstrata e interface concreta. Cada um deles realizando transformações do passo anterior para o seguinte até a obtenção da interface multimodal final.

Os passos para a obtenção da interface multimodal são: obter uma ou várias interfaces abstratas de um modelo da tarefa e de um modelo do domínio, derivando uma ou várias interfaces concretas de cada interface abstrata, e produzir o código das interfaces finais correspondentes. 
Todos os elementos, modelos e transformações entre os níveis são especificados uniformemente por meio de uma única linguagem de descrição de interface, a UsiXML (User Interface eXtensible Markup Language) (LIMBOURG et al., 2005), que permite aplicar regras de transformações no modelo de entrada e produzir o modelo gráfico de saída resultante. Dessa forma, todo o conhecimento de projeto necessário para conduzir as transformações está explicitamente contido nas regras de transformações e a execução dessas regras é garantida por um mecanismo de transformação que está separado da lógica de transformação, possibilitando que o projetista explore muitas alternativas e obtenha diversos tipos de interfaces sem precisar reiniciar o processo.

Todas as interfaces resultantes são consistentes entre si, pois o mecanismo de transformação tem como base o mesmo modelo de tarefas e de domínio. A interface final é multimodal e atualmente envolve interação gráfica convencional (teclado e mouse) e interação por voz, podendo ser estendida no futuro.

Fabio Paternò e seu grupo de pesquisa fundamentam seus trabalhos no problema de que desenvolver interfaces multimodais é ainda uma tarefa difícil para os projetistas e desenvolvedores e há falta de ferramentas de autoria para esta finalidade, especialmente quando são considerados os ambientes multi-dispositivos, como: desktop gráfico, desktop com suporte de voz e celular. Em (PATERNO; GIAMMARINO, 2006) os autores apresentam uma método e um instrumento de apoio para auxiliar no desenvolvimento de várias versões de interfaces e várias maneiras para combinar gráficos e voz em ambientes multi-dispositivos que podem se adaptar aos recursos de interação disponíveis e evitar confundir o projetista com muitos detalhes relacionados aos dispositivos e linguagens de programação.

A idéia é ter algumas descrições lógicas próximas da visão do usuário e ambientes inteligentes capazes de transformar interfaces a fim de obter adaptações para os dispositivos alvos.

Esse grupo de pesquisa trabalha com um método que deriva interfaces multimodais a partir das descrições lógicas das tarefas e das interfaces do usuário obtidas por meio das notações gerais, independentes de plataforma. Há ainda a possibilidade de combinar as modalidades de várias maneiras, mas em níveis diferentes de granularidade (dentro de um único objeto de interação e entre diversos objetos de interação).

Uma descrição lógica (PATERNO, 1999) é composta por: 
- Níveis de tarefa e de objeto, que refletem a visão do usuário sobre o sistema interativo em termos das atividades lógicas e dos objetos que devem ser manipulados para realizá-las.

- Interfaces abstratas, que fornecem uma descrição independente da modalidade da interface com o usuário (por exemplo, uma interação por gesto ou um comando de voz ou uma interação gráfica).

- Interfaces concretas, que fornecem uma descrição dependente da modalidade e uma descrição independente da linguagem de implementação da interface (por exemplo, seleção pode ser feita por radio-button ou uma lista ou um menu dropdown). O nível concreto é um refinamento da interface abstrata dependendo da plataforma associada.

- Implementação final, em uma linguagem de implementação de interface.

Existe também uma ferramenta chamada Teresa que funciona em um ambiente fundamentado em transformações de interfaces multimodais para diversos dispositivos utilizando a TeresaXML (MORI; PATERNO; SANTORO, 2004) e utilizando a descrição lógica descrita anteriormente.

Os autores comparam o método proposto ao método do trabalho de Stanciulescu (2005), que aplica transformações às descrições lógicas para derivar interfaces multimodais. Segundo os autores, a diferença é que o trabalho atual pôde fornecer um ambiente de autoria que pode sugerir soluções para identificar como combinar várias modalidades e permite que os desenvolvedores as modifiquem facilmente a fim de adequar a geração da interface às suas necessidades específicas.

A vantagem deste tipo de abordagem é que permite que os desenvolvedores focalizem em aspectos lógicos e considerem a visão do usuário nos estágios mais iniciais do processo do projeto. No caso das interfaces que podem ser alcançadas através dos tipos diferentes de dispositivos a abordagem tem vantagens adicionais, pois a tarefa e o nível abstrato podem ser descritos com a mesma linguagem para qualquer plataforma de destino. Portanto, há uma linguagem de interface concreta para cada plataforma destino.

Existem também outras propostas baseadas em XML, mas que não consideram explicitamente multimodalidade como, XIML (PUERTA; EISENSTEIN, 2002) e UIML (ABRAMS et al., 1999).

O projeto MONA (Mobile multimOdal Next generation Applications) (ANEGG et al., 2004) fornece um ambiente para se desenvolver aplicações multimodais Web. Tal ambiente é 
composto por um servidor de apresentação, que permite o desenvolvimento de aplicações móveis flexíveis, disponível para um grande número de dispositivos móveis. Esse servidor de apresentação transforma uma especificação de interface multimodal em uma combinação de interface gráfica e de voz e a adapta dinamicamente para diversos tipos de dispositivos: WAP Phones, Smart Phones, PocketPC e PDAs. O método de desenvolvimento da aplicação multimodal é fundamentado em casos de uso, que permitem o refinamento e a validação do projeto por meio de protótipos de interface para cada tipo de dispositivo. Os idealizadores do projeto MONA recomendam que esses protótipos gerados sejam submetidos a avaliações heurísticas executadas por avaliadores experientes.

$\mathrm{Na}$ revisão bibliográfica percebeu-se que esses métodos não consideram princípios, guidelines ou padrões de projeto para facilitar o projeto de interfaces multimodais Web. Tais conceitos são fundamentais, pois orientam os projetistas na tomada de decisões consistentes através dos elementos que constituem o produto e são técnicas eficientes para capturar, documentar e comunicar o conhecimento adquirido, aplicado e validado cientificamente em determinadas circunstâncias.

A seguir serão apresentados os frameworks identificados na literatura e que são usados para o projeto de interfaces multimodais Web.

\subsubsection{Frameworks conceituais para desenvolvimento de sistemas multimodais Web}

Durante a pesquisa bibliográfica sobre o estado da arte para projetos de sistemas multimodais foram encontrados frameworks para apoiar o desenvolvimento de tais sistemas. Os dois principais frameworks usados pela comunidade de projetistas de sistemas multimodais são apresentados a seguir.

3.4.2.1 Framework ICARE (Interação, Complementaridade, Associação, Redundância e Equivalência).

As propriedades CARE (Complementaridade, Associação, Redundância e Equivalência) representam uma forma de caracterizar as relações que podem ocorrer entre diferentes modalidades de interação disponíveis nas interfaces multimodais. Como apresentado no primeiro Capítulo, uma modalidade é descrita como uma relação entre um dispositivo físico e uma linguagem de interação. Coutaz e seus colegas em (COUTAZ et al., 1995) propuseram termos para definir objetivamente as propriedades CARE:

- Estado: é um conjunto de propriedades que podem ser medidas em um determinado momento para caracterizar uma situação. 
- Objetivo: é um estado passível de ser alcançado por um agente.

- Agente: é uma entidade capaz de executar ações.

- Modalidade: é um método de interação que um agente pode usar para atingir um objetivo.

- Relações Temporais: caracterizam o uso das modalidades que podem ocorrer simultaneamente ou em seqüência em um intervalo de tempo.

As propriedades CARE foram definidas baseadas nas noções mostradas anteriormente e são descritas a seguir:

Complementaridade: duas ou mais modalidades devem ser usadas de forma complementar para se atingir um determinado estado. É caracterizada por um modo dominante que requer o uso de outros modos. Por exemplo, considere a situação na qual uma interface multimodal tem um campo de texto não preenchido que permite ao usuário fornecer seu nome como entrada (Estado inicial). Este campo de texto deve ser preenchido (Estado final) por um agente que fornece entrada por fala usando microfone e linguagem natural com vocabulário restrito para falar a primeira parte de seu nome e entrada gráfica usando mouse e manipulação direta para completar a tarefa.

Associação: expressa a atribuição de uma modalidade específica em um determinado estado de origem para se atingir um estado destino. Expressa a ausência de escolha de um outro modo. Por exemplo, considere a situação na qual uma interface multimodal tem um campo de texto que não está preenchido (Estado inicial). Este campo de texto deve ser preenchido (Estado final) por um agente que pode utilizar uma única modalidade para isso, entrada por linguagem natural escrita utilizando teclado.

Redundância: expressa a utilização de duas ou mais modalidades ao mesmo tempo para se atingir um estado destino. Por exemplo, considere a situação na qual uma interface multimodal tem uma caixa de seleção que pode ser selecionada por um agente usando duas modalidades, entrada por fala usando microfone e linguagem natural com vocabulário restrito e entrada gráfica usando mouse e manipulação direta, em paralelo ou seqüencialmente, mas no mesmo intervalo de tempo.

Equivalência: expressa a disponibilidade de escolha entre múltiplas modalidades, mas não impõe nenhuma restrição temporal. Por exemplo, considere a situação na qual uma interface multimodal tem um campo de texto que não está preenchido (Estado inicial). Este campo de texto deve ser preenchido (Estado final) por um agente que pode utilizar duas 
modalidades para isso, entrada por fala usando microfone e linguagem natural com vocabulário restrito e linguagem natural escrita utilizando teclado.

Bouchet, Nigay e Ganille (2004) propuseram o framework ICARE (Interaction CARE), uma abordagem baseada em componentes que permite projeto e desenvolvimento rápidos de interfaces multimodais. Existem dois tipos de componentes, os básicos, que descrevem uma modalidade simples (dispositivo em conjunto com linguagem de interação) e os componentes compostos, que descrevem o uso combinado de modalidades (propriedades CARE). A plataforma permite ao projetista manipular graficamente os componentes para especificar uma interação multimodal, além de gerar o código da interface automaticamente.

\subsubsection{Framework para interação multimodal do W3C}

A proposta do Framework para Interação Multimodal do W3C (LARSON, 2003), é identificar os componentes básicos dos sistemas multimodais, as linguagens de marcação definidas pelo $\mathrm{W} 3 \mathrm{C}$ e utilizadas para descrever a informação requerida pelos componentes e o fluxo de dados entre esses componentes.

O framework descreve os modos de entrada e saída mais utilizados atualmente e pode ser estendido para incluir novos modos.

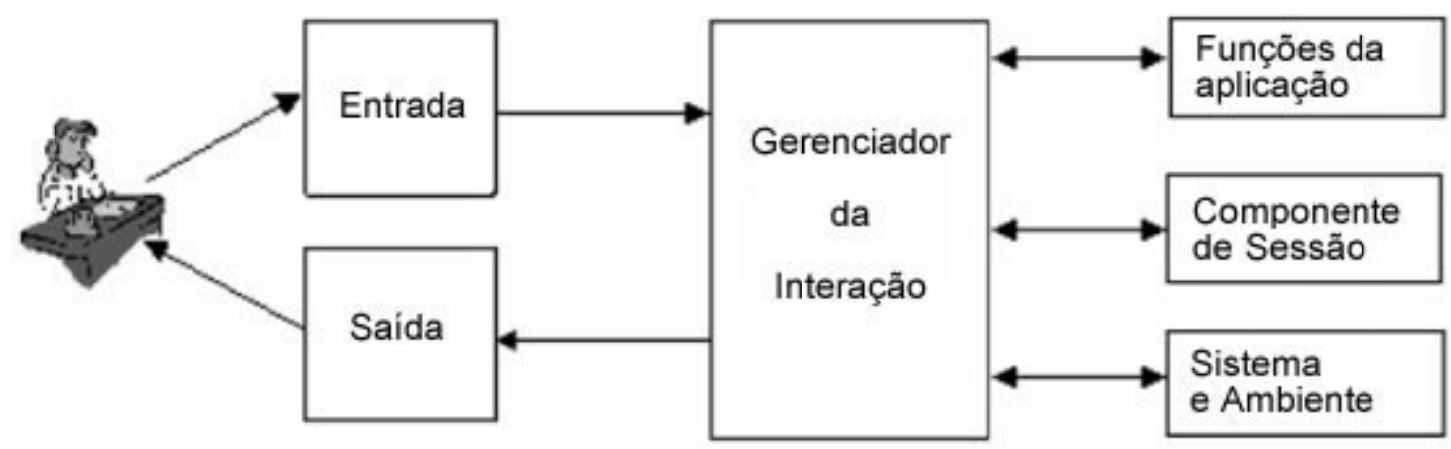

Figura 8 - Componentes básicos do Framework para Interação Multimodal do W3C (LARSON, 2003)

Na Figura 8 são ilustrados os componentes básicos do Framework para Interação Multimodal do W3C:

- Usuário: fornece entrada de informação para o sistema, observa e ouve a informação de saída apresentada pelo sistema.

- Componente de Entrada de Informação: contém várias modalidades de entrada como áudio, fala, escrita, teclado. A linguagem de marcação EMMA pode ser usada para identificar a semântica dos dados que representam a entrada do usuário. 
- Componentes de Saída Informação: considera as várias mídias de saída como voz, texto, gráfico, arquivos de áudio e animação. O componente de saída pode ser projetado nas seguintes linguagens: SSML (Speech Synthesis Markup Language) usada para descrever como as palavras devem ser pronunciadas, XHTML ou SVG usado para descrever como os gráficos devem ser tratados e SMIL que pode ser usado para coordenar saída multimídia.

- Gerenciador da Interação: é o componente lógico que coordena os dados e gerencia o fluxo de execução das várias modalidades de entrada e saída. Ele mantém o estado da interação, o contexto da aplicação e responde às entradas dos objetos de interface e às mudanças no sistema e no ambiente.

- Componente de Sessão: fornece uma interface para o gerenciador da interação para apoiar o gerenciamento dos estados e sessões temporárias e persistentes para aplicações multimodais.

- Componentes de Sistema e Ambiente: permite que o gerenciador da interação procure e responda às alterações nos dispositivos, preferências do usuário e condições do ambiente, por exemplo, qual dos modos disponíveis o usuário deseja utilizar, a resolução do vídeo, se suporta cor ou não.

Os requisitos para a especificação da interação multimodal e gerenciamento da entrada de informações estão descritos em (MAES; SARASWAT, 2003). De acordo com o Framework para Interação Multimodal do W3C, existem três níveis para o gerenciamento da interação:

- Entrada multimodal sequencial: é aquela que é fornecida com o uso de uma única modalidade em um espaço de tempo. É possível especificar qual modalidade ou dispositivo usar para fornecer a entrada além de fornecer dicas para troca de modalidade em um determinado momento da interação.

- Entrada multimodal simultânea: as entradas utilizando diferentes modalidades são interpretadas uma após a outra de acordo com a ordem de ocorrência.

- Entrada multimodal composta: é a entrada recebida com o uso de várias modalidades ao mesmo tempo e interpretada em conjunto.

Como pode-se perceber existe uma semelhança entre esses níveis de gerenciamento e as propriedades CARE apresentadas anteriormente.

A diferença entre os frameworks é a forma como eles definem e consideram a noção de modalidade. Enquanto uma modalidade, para as propriedades CARE, é descrita como uma 
relação entre um dispositivo físico e uma linguagem de interação, para o W3C Multimodal Interaction Framework uma modalidade é um tipo de canal de comunicação usado para a interação e considera a forma como uma idéia é expressa ou percebida, ou ainda a maneira como uma ação é executada.

Existem algumas semelhanças entre as propriedades CARE e os requisitos especificados no W3C Multimodal Interaction. A propriedade Redundância poderia ser expressa usando as modalidades seqüencialmente ou em paralelo, que corresponde respectivamente aos requisitos de entrada multimodal seqüencial e simultâneo identificados pelo W3C Multimodal Interaction Working Group.

Da mesma forma, a propriedade Complementaridade prevê o uso individual de modalidades em sequiência ou em paralelo e que corresponde aos requisitos seqüencial e composto do $\mathrm{W} 3 \mathrm{C}$, respectivamente.

\subsection{Considerações finais}

Neste capítulo foi apresentada uma ampla visão de como o projeto de um sistema multimodal pode ser organizado, as tecnologias, as abordagens, os métodos e os frameworks existentes para viabilizar o desenvolvimento de tais sistemas.

Percebe-se que as novas linguagens de marcação como o $\mathrm{X}+\mathrm{V}$, o SALT e o EMMA possibilitam o desenvolvimento de interfaces Web e aplicações multimodais de forma semelhante ao desenvolvimento Web tradicional e os frameworks apresentados apóiam o desenvolvimento organizado de tais sistemas.

Esses dados pesquisados foram utilizados durante o desenvolvimento do projeto de doutorado, com o objetivo de servir como uma lista de requisitos e as correspondentes motivações para o projeto e desenvolvimento de interfaces multimodais Web.

No Capítulo 4 será apresentada a abordagem que será utilizada para a continuação desta pesquisa e no Capítulo 5 será apresentado o ambiente de autoria que foi criado para facilitar as atividades de projeto de interfaces multimodais Web. 


\section{Capítulo 4. Abordagem para o Desenvolvimento de Interfaces Multimodais Web (MMWA)}

\subsection{Considerações iniciais}

Neste capítulo é apresentada a abordagem para o projeto, desenvolvimento e avaliação de usabilidade de interfaces multimodais Web proposta nesta tese, bem como os seus objetivos, sua estrutura e a descrição de suas atividades. A abordagem é definida na Seção 4.2 e suas cinco atividades são detalhadas entre as Seções 4.3 e 4.7. Na Seção 4.8 apresenta-se as considerações sobre o uso de design rationale (DR) na abordagem proposta. No final do capítulo, na Seção 4.9, é feita uma breve comparação com as abordagens, linguagens e frameworks existentes na literatura e as considerações finais são apresentadas na Seção 4.10.

\subsection{Definição da MMWA}

A abordagem para o desenvolvimento de interfaces multimodais Web (MultiModal Web Approach - MMWA) foi criada com objetivo de propiciar à equipe de projetistas, desenvolvedores e testadores de interfaces multimodais uma estrutura prática composta por atividades e técnicas para serem utilizadas em suas tarefas cotidianas de forma otimizada, ou seja, reusando artefatos e conhecimento de projetos anteriores de forma a maximizar a comunicação entre a equipe.

A abordagem segue um modelo em espiral, centrado no usuário, representado na Figura 9, composto por cinco atividades (MCI, IT, RT, AS e AU) e um conjunto de técnicas que serão descritas neste capítulo. Esse ferramental permite armazenar, capturar e utilizar DR em todas as atividades com o objetivo de prover soluções de sucesso para problemas recorrentes no contexto da interação multimodal por meio de registro de discussão de decisões, justificativas, alternativas e argumentos que culminam com a documentação e o projeto final para reutilização futura.

A MMWA promove a reutilização sistemática de software de forma controlável, gerenciável e repetível (ROMBACH, 2000) durante as fases de projeto e desenvolvimento, pois tanto os artefatos gerados em projetos anteriores quanto o conhecimento capturado na 
forma de DR são reaproveitados, em contraste com uma abordagem ad hoc, que é dependente da criatividade e do conhecimento individual dos projetistas.

Para promover essa reutilização, aproveitando a similaridade entre aplicações dentro de um mesmo contexto bem definido, utiliza-se a técnica de DR e o conceito de padrões de projeto (GAMMA et al., 1995). Neste trabalho, também generaliza-se uma técnica para a identificação de padrões de projeto que será apresentada mais adiante no Capítulo 7. Destaca-se que a reutilização é realizada em nível de modelo de tarefas, evitando os problemas que ocorrem quando reutiliza-se somente o código fonte, por exemplo, a extração de DR.

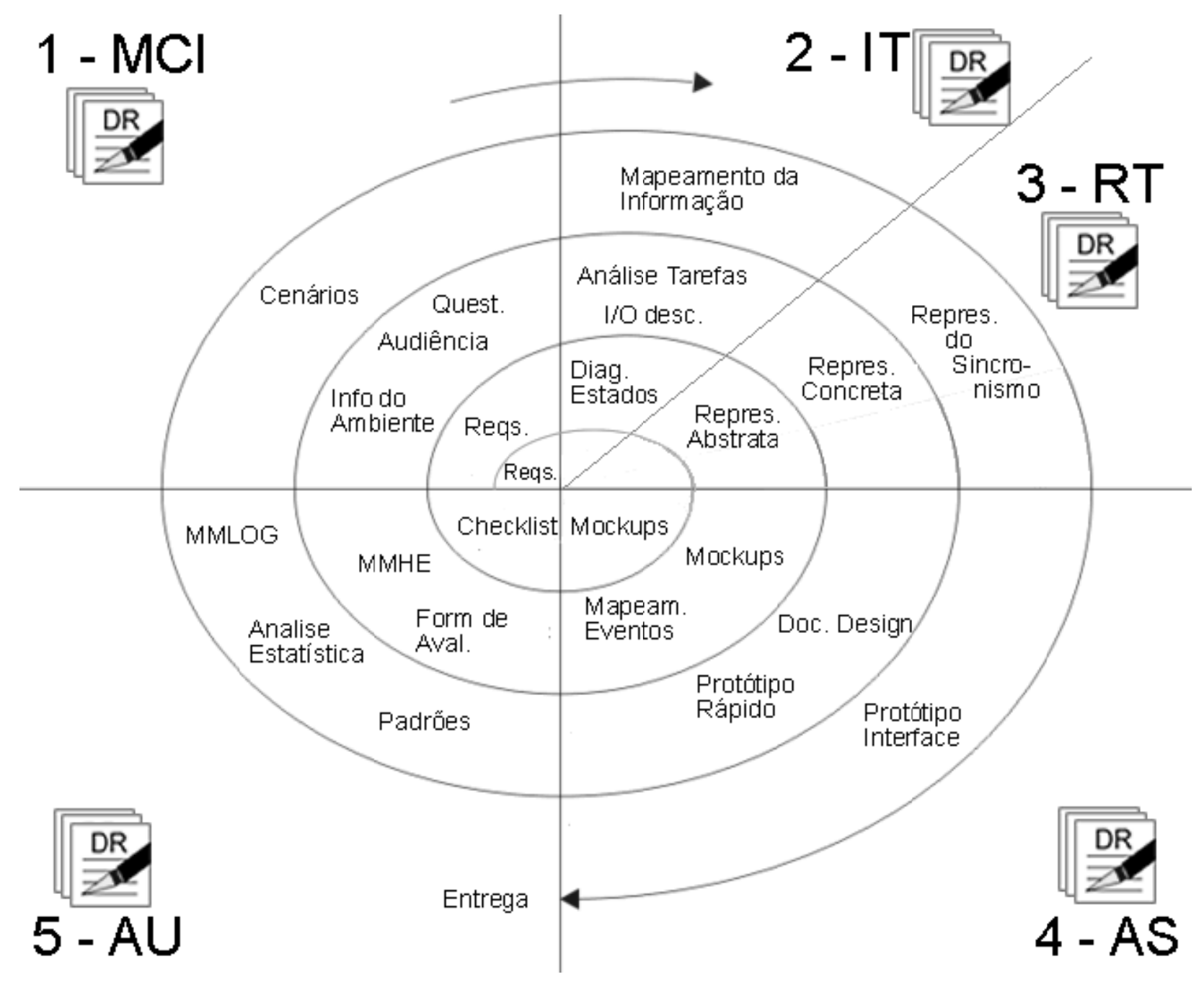

Figura 9 - As atividades da MMWA: 1-Modelo Comportamental Inicial (MCI); 2Identificação de Tarefas (IT); 3- Representação de Tarefas (RT); 4- Análise das Soluções (AS); 5-Avaliação de Usabilidade (AU).

O DR utilizado no contexto da MMWA, metodologicamente, visa reter o conhecimento e o raciocínio inerente ao processo de projeto. Nos estudos de caso realizados, o DR foi documentado como discussões entre os participantes envolvidos no projeto usando 
uma ferramenta de colaboração, um sistema de Wiki que foi configurado para gerar páginas com a estrutura necessária para o registro de DR. Essa particularidade permite a edição colaborativa de decisões de projeto e projeto participativo de forma coletiva, bem como controlar o histórico de edição, contar os acessos ao DR e facilitar o controle de versões.

Uma fase elementar no desenvolvimento de interfaces multimodais envolve a avaliação de protótipos fundamentando-se em estudos qualitativos e interações com usuários reais, descritos previamente nesta tese no Capítulo 2 e no Capítulo 3.

Uma das principais características da MMWA é o mecanismo de avaliação de usabilidade baseado na Web que foi projetado para permitir a obtenção de dados para a identificação, análise e correção de problemas, em estágios iniciais do projeto.

$\mathrm{O}$ benefício de se realizar estudos de usabilidade remotos usando a Web é que os usuários podem ser recrutados em qualquer lugar do mundo e podem interagir quando for mais conveniente, deixando-os mais à vontade para realizar as tarefas no local onde frequentemente realizam a interação, ou seja, sem a necessidade de expor o usuário a uma sala de monitoração que não é o seu ambiente corriqueiro de utilização de sistemas dessa natureza.

Um tópico adicional considerado pela MMWA, e que é muito abordado em artigos científicos na área em questão, é a fusão e a fissão das modalidades, que podem ser combinadas de quatro diferente maneiras, expressas pelas propriedades CARE (COUTAZ et $a l .$, 1995). Consequentemente essas propriedades são também usadas para estruturar e apoiar a atividade de avaliação de usabilidade.

Em resumo, os objetivos com a proposta da MMWA são:

- Permitir o projeto de interfaces multimodais Web fundamentando-se em teorias de comprovada eficiência, compilando os pontos positivos de cada técnica utilizada.

- Implementar as interfaces de forma rápida e considerar os conceitos relacionados a multimodalidade tais como gramáticas e prompts de voz, sincronização de interfaces, gerenciamento de eventos e tratamento de mensagens e erros.

- Testar e validar as interfaces projetadas e desenvolvidas em busca de padrões de interação e problemas de usabilidade. 
- Reusar o conhecimento capturado e armazenado previamente em projetos subsequentes utilizando DR

Nas seções seguintes serão descritas as cinco atividades da MMWA e as técnicas utilizadas em cada atividade.

\subsection{Modelo Comportamental Inicial (MCI)}

Rousseau et.al. (2005) recomendam que a primeira atividade a se fazer durante um projeto de uma nova interface é criar um corpo de dados consistindo de cenários e situações nas quais a interface será utilizada e também de informações sobre o ambiente em que a aplicação será executada.

Portanto, a primeira atividade da MMWA é o desenvolvimento de um modelo comportamental inicial, Figura 10, que consiste na definição de cenários, identificação de restrições, informações sobre o ambiente em que as tarefas multimodais serão executadas, tais como o público alvo e suas características e informações sobre experiência do usuário que devem ser consideradas no projeto e desenvolvimento das interfaces. Esses dados formam os elementos necessários para construir as partes essenciais do sistema. Tanto o projetista como os usuários devem estar envolvidos nesse trabalho inicial.

O objetivo é identificar a informação que será trocada entre o usuário e o sistema durante a execução da tarefa multimodal no artefato que será projetado (a interface). Para tanto, é necessário obter a informação do domínio para que se possa selecionar e projetar o mapeamento de tarefas apropriadas e a sua representação na forma de uma interface multimodal.

Toda a informação obtida com a execução dessa atividade é documentada como a especificação de requisitos da aplicação multimodal, que ajuda estabelecer as medidas de usabilidade que serão utilizadas nos testes para garantir que o software atenda a expectativa do cliente, bem como priorizar requisitos de acordo com um critério acordado com o cliente, incluir informações de contrato e aspectos legais, referências a padrões relevantes e documentos/requisitos internos do cliente. A atividade MCI é esquematizada na Figura 10. 


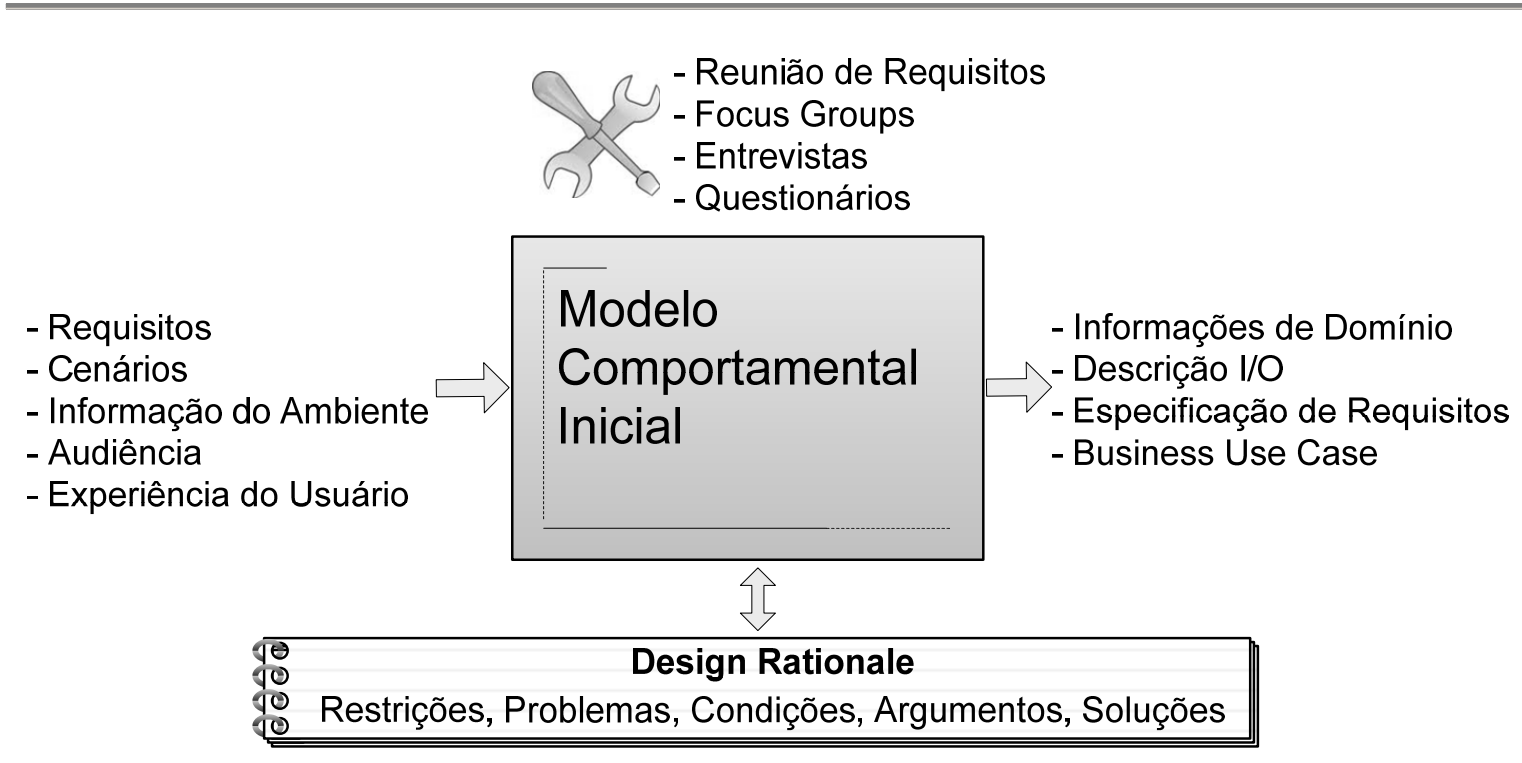

Figura 10 - MMWA: Modelo Comportamental Inicial

Toda a informação necessária para a especificação de requisitos na atividade de obtenção do modelo comportamental inicial da aplicação multimodal pode ser obtida com o uso das seguintes técnicas de acordo com as características do projeto:

- Em estudos de campo, utilizando Entrevistas e Questionários e Business Use Case.

- Com a participação direta de usuários em Focus Groups.

- Participação do cliente em Cenários de Uso e Reunião para coleta de Requisitos.

Entrevistas e Questionários, ou pesquisas, são um meio de descobrir como o software tende a ser utilizado por um conjunto específico de usuários. As respostas que os usuários fornecem devem ser relevantes para as questões que são importantes para a equipe de projeto. Pesquisas com usuários são tradicionalmente realizadas presencialmente, mas cada vez mais, a Internet é utilizada para esta finalidade. As pesquisas apenas são benéficas se geram respostas às perguntas da equipe de projeto. Pelo fato de ser possível fazer uma pesquisa com um grande número de usuários, perfis de uso podem ser obtidos se a metodologia correta for utilizada. Pesquisas são frequentemente analisadas estatisticamente, no entanto, dados qualitativos podem ser obtidos com esta técnica.

O Business Use Case ou Caso de Uso de Negócio é empregado para fornecer o contexto no qual o negócio da empresa opera. Ele representa os atores, como os clientes, as partes interessadas, as empresas, bem como as funções de negócio (casos de uso) e as relações entre eles. É usado como uma ferramenta essencial para identificar papéis e produtos 
da organização. O Business Use Case pode ser utilizado como uma alternativa ou como uma representação gráfica para a modelagem de cenários. No entanto a utilização da especificação de casos de uso UML (BOOCH; RUMBAUGH; JACOBSON, 2005) tem recebido algumas críticas. Paternò (1999) afirma que é difícil identificar casos de uso para sistemas complexos e definir o nível de granularidade adequado. Esse problema pode ser solucionado com a aplicação da análise de tarefas, como será apresentado na próxima seção, pois esta técnica permite que se obtenha uma visão ampla dos níveis abstrato e concreto das interfaces em um sistema complexo.

Focus Groups é uma técnica utilizada como pesquisa qualitativa, geralmente uma reunião informal de usuários para que suas opiniões sobre um determinado assunto sejam ouvidas por um moderador experiente, que é responsável por manter o foco do grupo sobre as questões de interesse para os resultados (KRUEGER; CASEY, 2000). O objetivo é obter as percepções do usuário sobre a usabilidade de uma interface antes que ela seja construída e não é uma técnica eficiente para avaliações de usabilidade (NIELSEN, 1997). Os resultados não geram informações quantitativas e não devem ser generalizados, mas podem ser utilizados como base para a geração de hipóteses para posterior avaliação e validação utilizando métodos qualitativos e quantitativos.

Cenários de Uso são histórias escritas sobre usuários e suas atividades no sistema e são utilizados para fornecer uma visão abstrata do sistema e ajudar na elucidação de requisitos (CARROL, 1999). É necessário definir um estado inicial, uma configuração e um ator para realizar as tarefas no cenário. O fluxo do cenário define o conjunto de tarefas que o usuário executa no sistema, bem como os eventos que acontecem durante a interação.

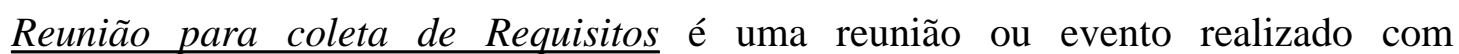
desenvolvedores, projetistas e clientes para identificar requisitos da aplicação que serão úteis na fase de desenvolvimento e testes. Esta técnica visa considerar a usabilidade em estágios iniciais do projeto, bem como, identificar os requisitos e quesitos de usabilidade que serão usados para avaliar as interfaces e como os requisitos eficácia, eficiência e satisfação serão medidos.

Além dessas técnicas, o modelo em camadas para obtenção de requisitos apresentado na Seção 2.4 deve ser utilizado para ajudar a compreender os diferentes conceitos durante a fase de análise de requisitos. 


\subsection{Identificação das Tarefas (IT)}

A fase de projeto tem início com a segunda atividade da MMWA, que consiste em identificar as tarefas que serão executadas pelos usuários na interface multimodal (Figura 11). Esse passo fornece uma visão geral de como a interação será executada sobre o ponto de vista do usuário final.

Uma tarefa na MMWA é composta por um nome, um tipo e uma representação. $O$ nome é definido nesta atividade e é composto por uma combinação de verbo e substantivo, por exemplo, SelecionarCartão. O verbo descreve o tipo de ação que será executada e o substantivo descreve o objeto alvo da ação. A representação final é obtida na próxima atividade e permite obter o Modelo de Tarefas.

O objetivo com a execução desta atividade é analisar aspectos importantes das tarefas como: objetivos, estados iniciais e finais, atividades e procedimentos envolvidos, identificar os problemas que podem ocorrer, identificar se existem restrições para a execução da tarefa no ambiente em que ela será executada, avaliar as informações obtidas na atividade anterior sobre o público alvo e sua experiência e planejar a entrada e saída multimodal.

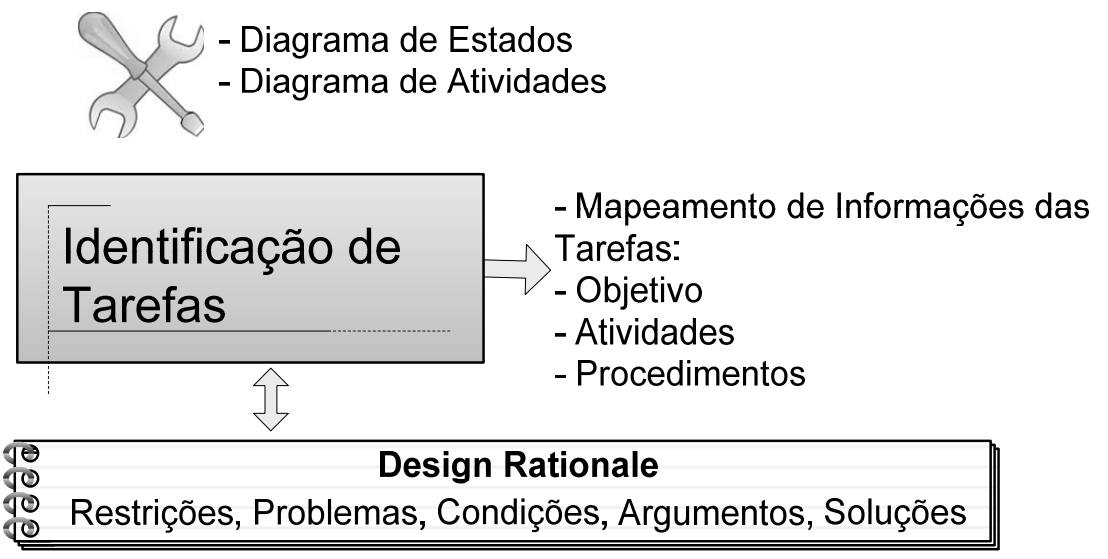

Figura 11 - MMWA: Identificação de Tarefas

Algumas técnicas auxiliam na identificação e na representação das tarefas, tais como o Diagrama de Estados e o Diagrama de Atividades da UML (BOOCH; RUMBAUGH; JACOBSON, 2005).

Na Figura 12 é ilustrado um diagrama de estados e transições para as tarefas que foram identificadas no segundo estudo de caso, que será apresentado no Capítulo 6, um sistema multimodal para encontrar a rota entre dois pontos de interesse em um mapa. Os estados representam as seguintes tarefas: T1:ChooseOrigin (escolher local de partida); T2: ChooseDestination (escolher local de chegada); T3: ConfirmPlaces (confirmar pontos de interesse), T4: HearStepCommands (apresentar o caminho entre os pontos escolhidos). As 
transições indicam os eventos que ocorrem para a ativação de um outro estado e o início de uma nova tarefa como apresentado no Quadro 3.

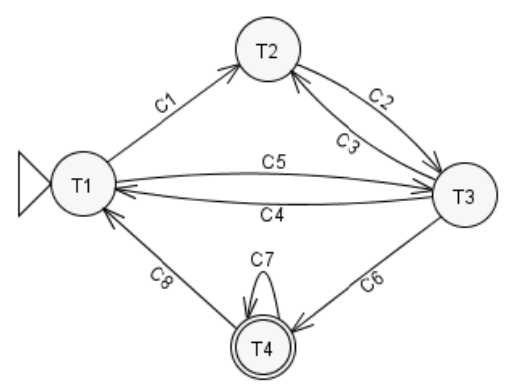

Figura 12 - Diagrama de transição de estados utilizado no estudo de caso 2

Nos estudos de caso realizados também foi utilizado o Diagrama de Atividades da UML, que é tipicamente usado para a modelagem de processos de negócio, para capturar a lógica de um caso de uso ou de um cenário, ou para modelar a lógica detalhada de uma regra de negócio. No exemplo da Figura 13, é apresentado o Diagrama de Atividades para a aplicação multimodal de rotas entre dois pontos de interesse em um mapa, desenvolvida no segundo estudo de caso.

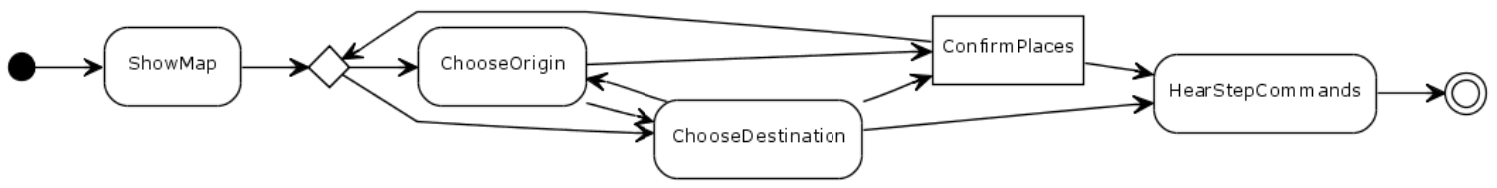

Figura 13 - Diagrama de atividades utilizado no estudo de caso 2

\subsection{Representação de Tarefas (RT)}

Na terceira atividade, que é representada na Figura 14, o projetista cria representações abstratas e concretas para as tarefas previamente identificadas. Representações abstratas são os tipos de tarefas. Na MMWA são possíveis os seguintes tipos: Seleção, Navegação (transições), Decisão, Agrupamento, Controle, Entrada e Saída.

Exemplos:

- Seleção de um tipo de carro em um sistema de locadora.

- Navegação (transição) entre a interface principal de um sistema e uma interface de pagamento de contas.

- Decisão baseada em uma lógica de negócio.

- Agrupamento de Seleções no caso de uma data: dia, mês e ano. 
- Controle da Navegação, por exemplo, submeter ou limpar os dados de um formulário, voltar para o menu principal, solicitar auxílio ou pedir para repetir uma informação.

- Entrada de dados, como um nome.

- Saída de dados, como ouvir os itens selecionados.

Técnicas como as descritas em (PATERNO, 1999) ou (STANCIULESCU et al., 2005), que realizam transformações nos níveis concretos e abstratos das interfaces até obter a interface multimodal final podem ser aplicadas para este propósito e também com o objetivo de transformar as interfaces para dispositivos diferentes dos convencionais.

Os elementos necessários para gerar e analisar qualquer tipo de entrada ou saída multimodal incluindo os seus prós e contras são documentados na forma de DR. Como resultado, uma lista de elementos de interface candidatos para cada modalidade ou combinação de modalidades é obtida. O objetivo é produzir uma série de discussões entre os projetistas com as soluções e argumentos, e comparar as vantagens e desvantagens do DR obtido.

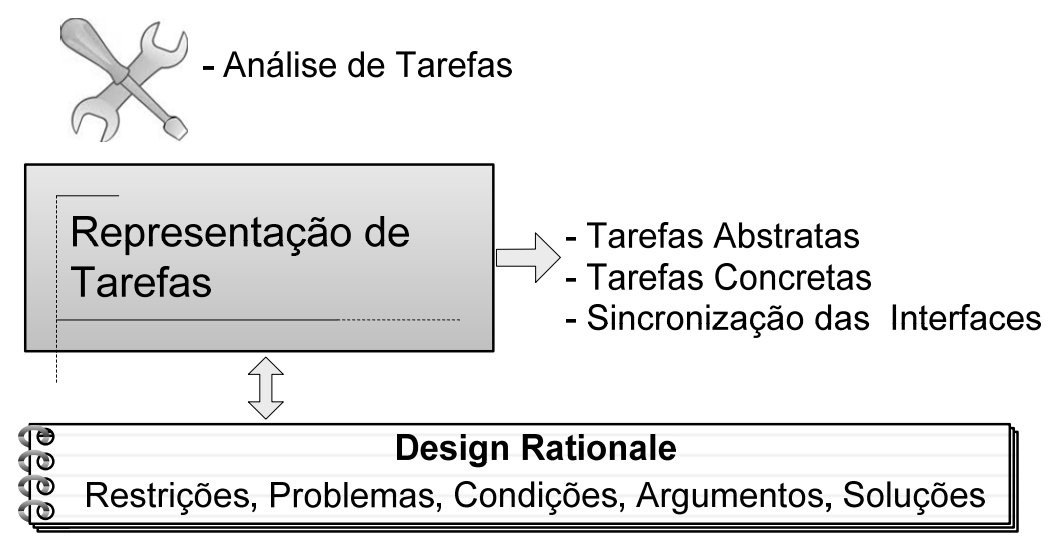

Figura 14 - MMWA: Representação de Tarefas

Após a identificação das representações abstratas das tarefas é possível definir a apresentação, ou seja, os elementos de interface gráfica (botões, menus, disposição dos elementos, etc) e de voz (prompts, gramáticas, comportamentos de erro, etc) e o comportamento, ou seja, os métodos e funções necessários para habilitar ou disparar as transições, bem como os eventos que serão ativados em cada elemento da interface.

Esse passo é chamado de representação concreta, pois depende da tecnologia disponível. Na MMWA, cada representação abstrata é composta por várias representações concretas, que podem ser implementadas na forma de padrões de projeto ou componentes 
como será apresentado mais adiante. Uma representação concreta pode agrupar várias tarefas abstratas, por exemplo, o projetista pode criar a tarefa "InformarData" do tipo "Seleção" e utilizar o padrão de projeto "Date Selection", que permite ao usuário informar a data com o dia, o mês e o ano utilizando uma ou mais modalidades, de uma única vez ou um item de cada vez.

O comportamento é especificado na forma de ações, que são responsáveis por sincronizar as tarefas e dar continuidade à interação. Uma ação é disparada por um evento em uma determinada tarefa e pode ser tratada dentro da mesma tarefa ou em uma outra tarefa.

É possível identificar opções nessa atividade. Uma opção é uma decisão feita pelo usuário que pode levar a diferentes caminhos, com diferentes ações, a partir de uma tarefa. Opções são geralmente utilizadas na especificação das gramáticas das interfaces de voz e na verificação do fluxo da aplicação, pois guardam dados sobre o fluxo da interação.

No Quadro 3 é possível visualizar parte de um documento de projeto de interfaces obtido com o uso da MMWA representando: as tarefas previamente identificadas (Figura 12 e Figura 13), os elementos de interface gráfica (GUI widgets) e os elementos da interface de voz (VUI), as ações e métodos que disparam eventos de renderização de mapas bem como eventos de sincronização de GUI e VUI.

Quadro 3 - Sincronização das interfaces de voz e gráfica do segundo estudo de caso

\begin{tabular}{|l|l|l|l|l|}
\hline Tarefas & \multicolumn{1}{|c|}{$\begin{array}{c}\text { GUI } \\
\text { Widget }\end{array}$} & \multicolumn{1}{|c|}{ VUI Widget } & \multicolumn{1}{|c|}{$\begin{array}{c}\text { Fventos } \\
\text { sinção de } \\
\text { sincroção }\end{array}$} \\
\hline T1 & place1Input & choose_place_1 & C1,C4,C5: Focus/ Recognition & setPlace1() \\
\hline T2 & place2Input & choose_place_2 & C2 and C3: Focus/ Recognition & setPlace2() \\
\hline T4 & $\begin{array}{l}\text { get_directio } \\
\text { ns }\end{array}$ & confirm_choices & C6: Blur / OnClick & confirmDirection() \\
& stepText & Step_commands & C7: Focus / OnClick & writeNextStep() \\
\cline { 4 - 5 } & & & & writeBackStep() \\
\hline
\end{tabular}

$\mathrm{Na}$ execução dos estudos de caso, observou-se a necessidade da criação de uma ferramenta para automatizar o processo de Análise de Tarefas pela equipe de projeto e desenvolvimento. Portanto, os requisitos para a criação de ferramentas de software baseadas em Análise de Tarefas descritos em (WELIE; VAN DER VEER; ELIËNS, 1999) foram considerados no desenvolvimento do ambiente de autoria que foi desenvolvido neste projeto e será apresentado no próximo capítulo, a saber: 
- A ferramenta deve ser projetada fundamentando-se em um framework conceitual. Todo o modelo de tarefa utilizado neste trabalho é obtido a partir das especificações abstratas e concretas das interfaces e utilizando-se os conceitos de ações e opções. Com essa utilização do modelo de tarefas a organização da informação fica mais completa e aspectos importantes que são inerentes a multimodalidade são incluídos tanto no projeto quanto na documentação e no DR para reutilização futura.

- Ofereça uma representação coerente e consistente. Existem diversas representações para realizar análise de tarefas, no entanto, a ferramenta que serve de framework para esta abordagem implementa um mecanismo simplificado. Toda a representação é realizada na forma de uma árvore de tarefas e links entre elas. A visualização pode ser vista diretamente no protótipo de interface.

- Permita que os projetistas interajam entre si para a criação da Análise de Tarefas. A abordagem prevê a colaboração por meio da utilização de sistemas Wiki que são responsáveis pela captura e o armazenamento de DR. Dessa forma é possível facilitar as discussões entre projetistas e utilizar o raciocínio de projetos anteriores aproveitando o conhecimento previamente gravado.

- Forneça suporte à documentação. A fase de projeto na MMWA é realizada de forma a promover a documentação de todas as atividades previstas.

- Permita controle de versões de projetos. A utilização de Wiki prevê o uso de controle de versões por natureza. As decisões que são tomadas e os comentários são gravados na forma de DR.

\subsection{Análise das Soluções (AS)}

A quarta atividade da MMWA, representada na Figura 15, consiste na Análise das Soluções obtidas nas atividades anteriores da abordagem. Os projetistas utilizam o DR previamente capturado, filtram as opções de interação e escolhem estratégias de diálogo e de prevenção de erros fundamentando-se na argumentação dos especialistas no domínio.

Esta atividade fornece as potenciais modalidades para serem usadas para completar uma tarefa, a sua representação concreta e o DR inerente. Ao final desta atividade são gerados um documento de projeto, contendo informações sobre requisitos, análise de tarefas, modelo do diálogo, fluxo da aplicação e o protocolo de testes de usabilidade, bem como um 
protótipo de interface para ser avaliada na próxima atividade de testes. Na MMWA também são consideradas as propriedades CARE apresentadas em (COUTAZ et al., 1995).

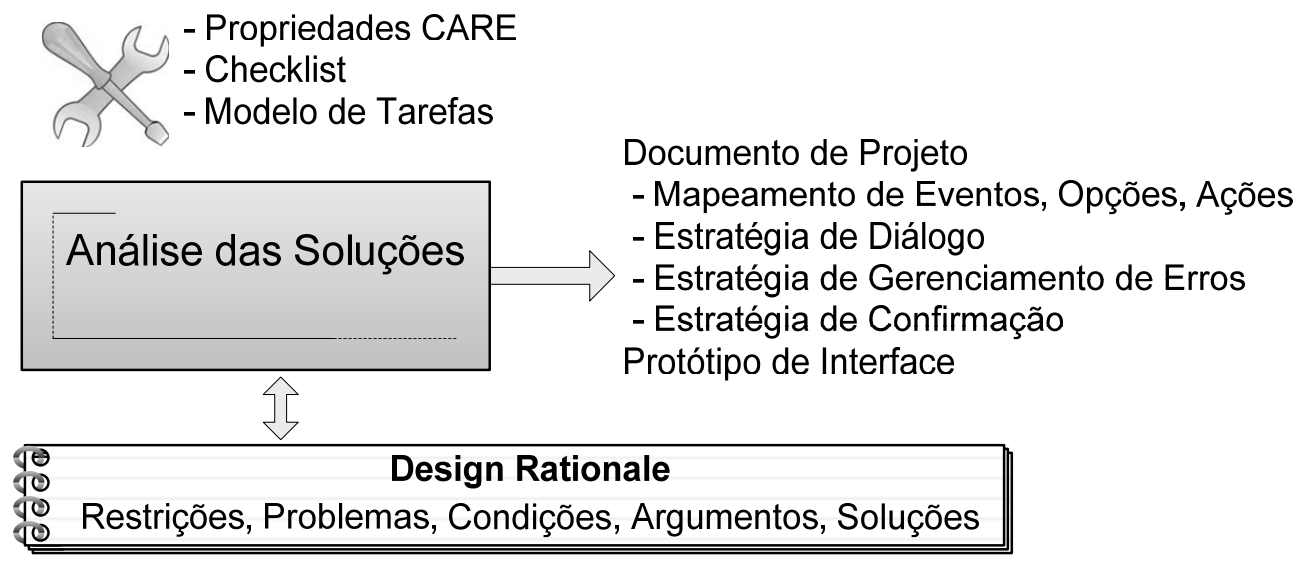

Figura 15 - MMWA: Análise de Soluções

Nesta tese de doutorado são consideradas duas modalidades de interação: interação gráfica com o uso de manipulação direta (mouse, teclado, dispositivos de toque), e interface de voz. Contudo, outras modalidades podem ser incluídas no futuro, pois o modelo de tarefas foi planejado para poder ser estendido com a inclusão de novas modalidades.

Para cada alternativa de projeto existe uma lista com os possíveis valores que os itens de interface podem assumir associando-se ao mesmo tempo a propriedade CARE correspondente.

Na Figura 16 é apresentado um trecho do documento de projeto gerado com o uso da MMWA. É possível verificar os diálogos (estados) que correspondem às tarefas T2:ChooseDestination (escolher local de chegada) e T3:ConfirmPlaces (confirmar pontos de interesse), bem como os elementos das interfaces de voz e das interfaces gráficas correspondentes, e os eventos associados com essas interfaces e as transições ou mensagens que conectam essas tarefas. Por exemplo, é possível verificar que um evento de foco (onFocus) é lançado no elemento da interface gráfica "place2Input", o tratador desse evento no formulário interface de voz "choose_place_2" é ativado para capturar a fala do usuário. Desse ponto, caso haja um evento de reconhecimento (OnRecognition) ou um evento de transferência de foco (OnBlur) o mapa será atualizado com o lugar de chegada que o usuário escolher. Quando a atualização do mapa for realizada (OnBlur), o estado T3, que representa uma tarefa de confirmação é ativado e o sistema apresenta a rota conectando os dois pontos selecionados pelo usuário (tarefas T1 e T2). 


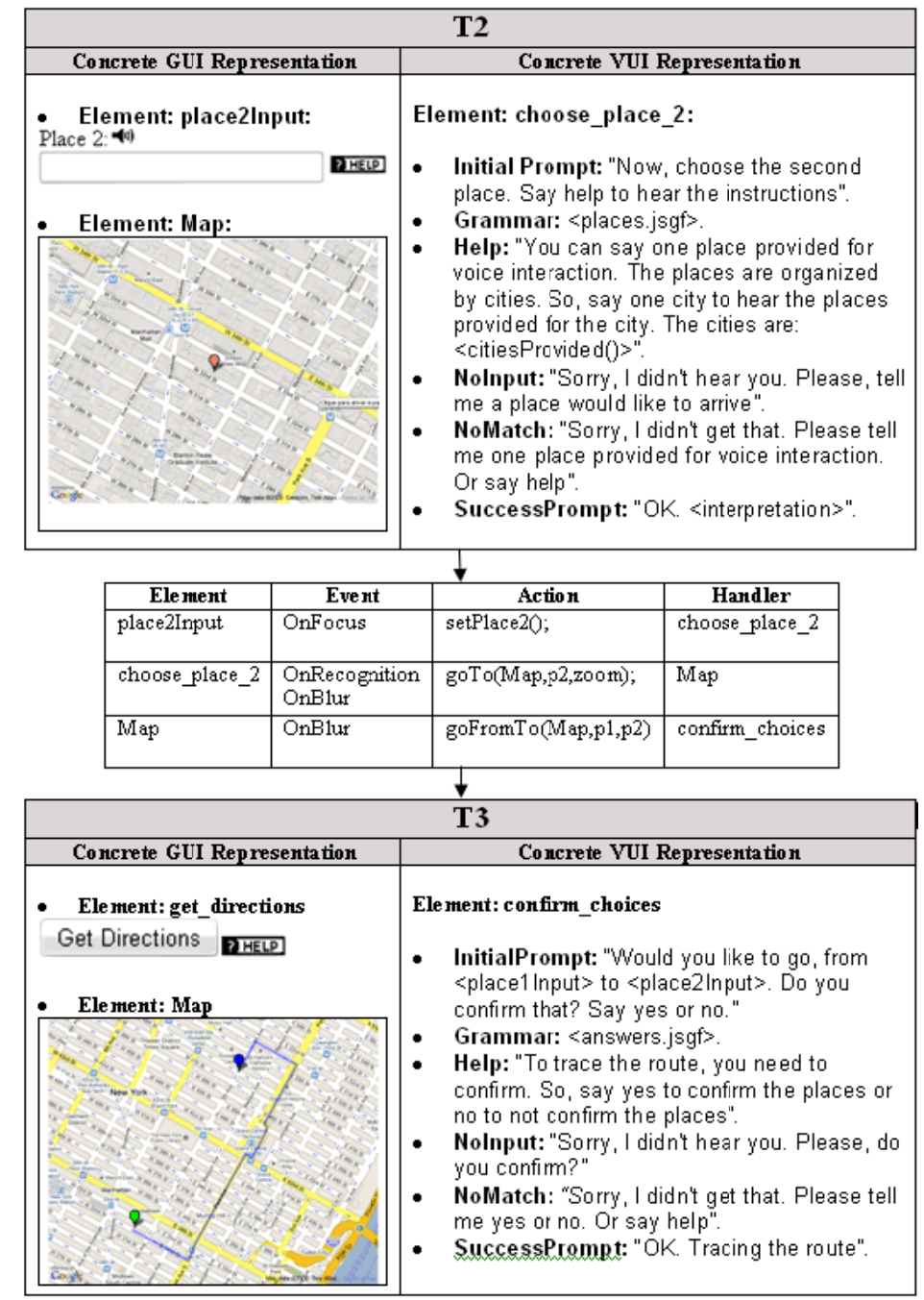

Figura 16 - Trecho do Documento de Projeto obtido com a MMWA

Outro trecho de um outro documento de projeto, apresentado no Quadro 4, mostra, para cada tarefa do segundo estudo de caso, as representações abstrata e concreta, as propriedades CARE e a estratégia de diálogo escolhida pelo projetista durante o uso da MMWA.

No Capítulo 5 serão elencados os elementos (widgets) implementados no modelo de tarefas e que podem ser utilizados na especificação das interfaces multimodais como representação concreta, bem como o exemplo de sua utilização em interfaces gráficas (GUI) e de voz (VUI) e as propriedades CARE que podem ser escolhidas na fase de projeto.

Conforme será apresentado nas seções seguintes, algumas estratégias como as de: diálogo, prevenção e correção de erros, confirmação e sincronização de interfaces, podem ser utilizadas durante o projeto de interfaces multimodais com o uso das modalidades gráfica e 
de voz com a finalidade de aumentar a usabilidade e consequentemente os níveis de satisfação dos usuários.

Quadro 4 - Trecho do documento de projeto do segundo estudo de caso

\begin{tabular}{|l|l|c|l|l|}
\hline \multicolumn{1}{|c|}{ Tarefa } & $\begin{array}{c}\text { Representação } \\
\text { Abstrata }\end{array}$ & $\begin{array}{c}\text { Propriedades } \\
\text { CARE }\end{array}$ & \multicolumn{1}{|c|}{ Estratégia de diálogo } & \multicolumn{1}{|c|}{$\begin{array}{c}\text { Representação } \\
\text { Concreta }\end{array}$} \\
\hline RealizarPagamento & Navegação & R,E & $\begin{array}{l}\text { interação iniciada pelo } \\
\text { usuário + preenchimento de } \\
\text { slot + confirmação tardia }\end{array}$ & Menu \\
\hline ReproduzirEscolha & Saída & A & Prompt de afirmação & Prompt de Saída \\
\hline SelecionarCartao & Agrupamento & - & Iniciativa mista & Formulário \\
\hline PerguntarTipo & Saída & R & $\begin{array}{l}\text { interação iniciada pelo } \\
\text { sistema Prompt Inicial + } \\
\text { Label }\end{array}$ \\
\hline EscolherCartao & Seleção & R;E & $\begin{array}{l}\text { preenchimento de slot + } \\
\text { Sincronização }\end{array}$ & $\begin{array}{l}\text { ComboBox + } \\
\text { Gramática }\end{array}$ \\
\hline ReproduzirEscolha & Saída & A & Prompt de afirmação & Prompt de Saída \\
\hline
\end{tabular}

\subsubsection{Sincronização entre modalidades diferentes}

A sincronização é um tópico específico das aplicações multimodais, pelo fato de que a aplicação multimodal apresenta a informação ao usuário em diversas modalidades, por exemplo, com o uso de interfaces gráfica e de voz. A interação por voz pode ser considerada como temporal, enquanto a interação visual gráfica pode ser considerada espacial. Quando combinadas em uma interface multimodal, as interfaces precisam estar sincronizadas para não comprometer a usabilidade do sistema.

No projeto da aplicação multimodal é necessário considerar que as transições do diálogo envolvem ambas as interfaces. Por exemplo, quando a interface de voz processar um diálogo na primeira página, a interface gráfica não deve ser levada à página seguinte a menos que a interface de voz estiver fazendo também uma transição a essa página. Se o usuário forçar a transição pela interface gráfica, a interface de voz deve se ajustar conformemente, parando o processo na primeira página e começando o processo para a página seguinte ou disparando uma mensagem de erro. A interface gráfica deve atualizar a página para mostrar também a resposta de voz.

Além de sincronizar as transições de diálogo as transições entre elementos também devem ser realizadas. Se o controle da voz se mover de um campo de texto para uma lista, o foco visual deve ser movido também do campo de texto para a lista. O contrário também precisa acontecer, quando o preenchimento é feito por voz, o foco muda para o campo visual correspondente. 


\subsubsection{Ativação de tarefas e estratégia de diálogo}

O diálogo, de acordo com Allen e seus colegas (ALLEN et al., 2001), enriquece a interação e permite que informações mais complexas do que uma mensagem falada sejam trocadas entre dois agentes. O objetivo de se utilizar interfaces de voz e sistemas com diálogo é aumentar o desempenho da interação humana utilizando a fala e seu aspecto mais importante é a criação de um contexto de diálogo, o qual permite ao sistema antecipar e prever as necessidades do usuário.

Em um diálogo entre dois agentes, o agente que conduz a conversa em um determinado momento é considerado como o detentor da iniciativa. Portanto, uma interação iniciada pelo sistema é aquela na qual o sistema controla o fluxo do diálogo com um usuário, por exemplo, oferecendo perguntas bem específicas ao usuário e esperando respostas específicas. Em contrapartida, os sistemas com interação iniciada pelo usuário são aqueles que permitem que o usuário detenha o controle da interação, permitindo maior flexibilidade no que o usuário pode dizer. Dependendo da fala do usuário, o sistema pode oferecer uma nova pergunta para retirar a ambigüidade da frase. Um diálogo com iniciativa mista é aquele no qual o usuário e o sistema se revezam no controle do fluxo do diálogo.

Existem quatro níveis de iniciativa mista (ALLEN; GUINN; HORVTZ, 1999). A forma mais simples de interação por iniciativa mista é a não solicitada, que permite a um agente fornecer a informação a qualquer momento. A iniciativa por subdiálogo permite que um agente detenha a iniciativa do diálogo durante a execução de um subdiálogo e, em seguida, retorne a iniciativa ao outro agente. A iniciativa por tarefa permite que o agente mantenha a iniciativa em uma tarefa e interaja com outro agente quando for necessário. E por último, no mais alto nível, os agentes podem negociar quem terá a iniciativa e continuar a interação.

Dependendo do projeto, uma abordagem mais rígida pode ser utilizada para a criação do diálogo por iniciativa mista, por exemplo, limitando as possibilidades do usuário influenciar no fluxo do diálogo. Em tais projetos, os usuários podem fornecer somente as informações solicitadas pelo sistema e podem executar controles básicos sobre o diálogo como: pedir ajuda, solicitar que o sistema repita a informação ou começar a interação novamente. Este tipo de diálogo é chamado de diálogo dirigido pelo sistema. Uma estratégia mais restrita ainda pode usar uma abordagem similar ao preenchimento de formulários das interfaces gráficas convencionais na qual o usuário pode somente fornecer as informações, que o sistema solicita em seus prompts, em frases curtas ou com apenas uma palavra. 


\subsubsection{Estratégias de gerenciamento do diálogo}

Uma questão crítica nos sistemas de voz é o gerenciamento do diálogo. Na visão de (MCTEAR, 2002), o gerenciador do diálogo desempenha o papel de mediador entre o usuário e um sistema de informação. Ele deve determinar se foi obtida informação suficiente do usuário para permitir a comunicação com a aplicação, executar as transações necessárias e retornar os resultados para o usuário.

Durante o processamento de linguagem natural, as palavras reconhecidas devem ser analisadas para determinar o que o usuário disse. A estratégia pode ser simples como comparação por palavras-chave ou o diálogo pode usar algoritmos sofisticados para entender a fala humana.

O gerenciador do diálogo geralmente usa algumas técnicas como análise da fala, contexto do discurso, modelos de estrutura de diálogo para interpretar falas não reconhecidas ou mal formadas (TRAUM et al., 1996). Em caso de falha, o sistema pode recorrer a recursos como soletrar palavras.

A estratégia de controle do diálogo varia conforme a complexidade do sistema. Isto envolve decidir o que o usuário pode ou não ter que dizer.

Geralmente, a estratégia seguida no gerenciamento do diálogo em um sistema de voz é a de preenchimento de espaços ou slots (SOUVIGNIER et al., 2000), na qual somente valores para slots previamente definidos são aceitos, enquanto que, em um diálogo com iniciativa mista o usuário pode fornecer quanta informação ele quiser, possivelmente com valores que não estão especificados nos prompts, para os slots. A tarefa do gerenciador do diálogo é preencher cada slot para cumprir o objetivo do diálogo com o usuário e manter o diálogo o mais breve possível. Para tanto é comum que o projetista de uma VUI solicite informações para preencher o slot com o máximo de "desambiguação", durante o processo de criação de uma VUI.

\subsubsection{Estratégia de prevenção e correção de erros}

Após a escolha da estratégia de diálogo, é necessário tratar da questão de como lidar com os elementos importantes desse diálogo, como a descoberta e recuperação de erros e os comandos universais (MCGLASHAN, 1999).

A recuperação de erros é necessária, pois nem a tecnologia nem os seres humanos são perfeitos. Todo reconhecedor de voz atribui um grau de confiança relacionado ao que foi dito pelo usuário e esse grau de confiança pode ser baixo, quando o reconhecedor ainda não estava pronto para aceitar a fala do usuário ou não ter ouvido o que ele disse, ou quando o 
usuário fala uma frase muito complexa que não permite gerar uma hipótese de reconhecimento.

Os usuários freqüentemente encurtam suas palavras, permanecem silenciosos, fornecem informação irrelevante, podem pressionar teclas impulsivamente quando o sistema está esperando uma entrada por voz e podem estar em diversos tipos de ambientes. Por isso, um projeto de aplicação de voz deve incluir mecanismos para tratar essas situações e permitir que o usuário possa fornecer a informação novamente ou obter ajuda até que consiga completar sua tarefa.

O projetista de interação multimodal deve considerar as duas mensagens mais comuns retornadas pelo reconhecedor que são rejeição ou nomatch, quando nenhuma hipótese é encontrada, e limite de tempo sem fala, quando nada é ouvido ou captado pelo reconhecedor.

Uma abordagem comum para retomar o diálogo depois da ocorrência de uma rejeição é a chamada progressive prompting, na qual o sistema fornece informações mais detalhadas e/ou exemplos do que o usuário pode dizer. Se mais erros forem ocorrendo, mais detalhes devem ser fornecidos (WEINSCHENK; BARKER, 2000).

Outra abordagem é o rapid reprompt, na qual o sistema ao invés de fornecer informação detalhada, reage ao erro com uma rápida fala, por exemplo, “o que você disse?", para indicar que ele não entendeu o que foi dito. Se outro erro ocorrer, o comportamento pode seguir a estratégia anterior fornecendo informações mais detalhadas do que pode ser dito (LAI et al., 2002).

A escolha da abordagem depende da tarefa. A desvantagem do progressive prompting é que o usuário pode ficar impaciente com mensagens de erros detalhadas e a desvantagem do rapid reprompt, é que os usuários que não estão seguros sobre o que dizer passam por um passo a mais para recuperar do erro.

O comportamento apresentado para o caso de rejeição também pode ser adotado para o caso do limite de tempo sem fala, mas deve ficar claro para o usuário que o sistema não conseguiu ouvi-lo, mesmo que o restante da mensagem for a mesma. Deve-se ficar atento para o uso de rapid reprompt, pois em muitos casos o usuário permanece em silêncio quando ele não está certo do que dizer, neste caso essa estratégia não é tão eficiente como para o caso de rejeição.

É importante salientar que esse tipo de abordagem é mais fácil de se implementar em uma interface gráfica convencional, pois a modalidade gráfica ou visual permite que o projetista possa fornecer informações mais detalhadas e ao mesmo tempo reagir ao erro de 
uma forma rápida destacando o local de sua ocorrência. Dessa forma, um usuário impaciente fica ciente do problema sem a necessidade de ler a mensagem detalhada. Esta questão tornase fundamental para o desenvolvimento deste projeto, pois será necessário pesquisar mecanismos para melhor apresentar esse tipo de informação de maneira multimodal ao usuário.

Na MMWA quando um erro do tipo nomatch ocorre e o projetista está utilizando multimodalidade, ou seja, interfaces de voz e gráfica na mesma tarefa, a estratégia escolhida para recuperação do erro é o sistema tocar um prompt definido pelo projetista, que pode conter exemplos de falas e ao mesmo tempo um destaque é dado na interface gráfica para permitir ao usuário trocar de modalidade de uma forma mais rápida e eficiente, pois o destaque alerta o usuário em qual parte da tela a informação deve ser fornecida. Este destaque pode ser implementado como um grifo, uma troca de cor de fundo ou até mesmo expandindo uma caixa de seleção para que o usuário veja as opções disponíveis.

\subsubsection{Estratégia de comandos Universais}

Um bom projeto também deve fornecer aos usuários comandos de controle da interação que ajudam na prevenção de erros e estão sempre disponíveis durante toda a aplicação em qualquer momento e em qualquer estado de diálogo, os chamados comandos universais. Os comandos universais são implementados em uma gramática paralela e oferece as opções de comandos que permitem possibilitar ao usuário pedir ajuda, solicitar que o sistema repita uma frase ou ainda começar de novo ou voltar uma tarefa (MCGLASHAN, 1999).

Em uma GUI, o usuário usa mecanismos convencionais que precisam estar presentes na interface, por exemplo, um ícone de interrogação com significado de obter ajuda. Já em uma VUI, o usuário solicita que o sistema repita uma informação. Em uma interação multimodal, o usuário solicita ajuda e sistema lê o prompt indicando o local que o usuário deve fornecer uma informação.

\subsubsection{Mecanismo de confirmação global/por tarefa}

Tanto os seres humanos como sistemas que tentam entender entrada natural cometem erros. No entanto, os seres humanos confirmam a entrada duvidosa. O diálogo fica prejudicando quando não existe um meio de reconhecer erros, pedir uma clarificação do que foi dito ou tirar a ambiguidade de uma entrada. 
Para assegurar que o diálogo tenha continuidade em uma tarefa, os projetistas devem decidir como realizar a confirmação, para quais modalidades, e em que momentos do diálogo.

$\mathrm{Na}$ estratégia de confirmação antecipada, a entrada do usuário é imediatamente transmitida a seu respectivo reconhecedor, uma hipótese de reconhecimento é retornada para a interface e a confirmação ou a retirada de ambiguidade é realizada. Em sistemas multimodais, as interpretações com maior probabilidades podem ser apresentadas ao usuário e este pode usar a modalidade mais conveniente para confirmar a sua entrada. O problema ocorre quando os usuários utilizam a multimodalidade de maneira complementar, ou seja, uma entrada é fornecida em duas ou mais etapas utilizando mais de uma modalidade. Neste caso a integração não é realizada, pois a confirmação ocorre à medida que as entradas vão sendo fornecidas ao sistema.

Uma solução para esse problema previamente apresentado é a utilização de confirmação tardia para garantir que as expectativas dos usuários sejam atingidas por meio da integração entre as modalidades. Nesse caso, o sistema espera a integração de todas as modalidades para verificar se a retirada de ambiguidade pode ser feita antes de realizar a confirmação com o usuário.

Suponha que o usuário está interagindo com o mapa do Brasil utilizando manipulação direta (interface gráfica). O usuário deseja selecionar o estado de Sergipe, mas no momento do toque ou clique o reconhecedor não entende se o usuário desejou selecionar Sergipe ou Alagoas, pois a área de toque disponível é muito pequena (os estados são bem pequenos e fazem fronteira). Caso não haja confirmação, há uma chance grande do sistema selecionar o estado incorreto. Caso haja confirmação antecipada o sistema pode não considerar uma entrada de fala que tiraria a ambiguidade da interação. Caso a estratégia utilizada seja a confirmação tardia e o usuário diga "Sergipe", o usuário não perceberá nenhum problema de interação.

\subsection{Avaliação de Usabilidade (AU)}

A quinta e última atividade que completa o ciclo da MMWA é a avaliação de usabilidade que é realizada com o uso do protótipo gerado a partir das atividades anteriores.

Para avaliar a usabilidade das interfaces multimodais é importante considerar como requisito primário suas especificidades tais como as modalidades disponíveis e a linguagem de interação escolhida pelo usuário. 
A literatura indica que as abordagens preferidas para a avaliação de usabilidade no contexto das interfaces multimodais são aquelas que utilizam simulações (LOPEZ-CEZAR et al., 2003) e testes com usuários reais executando tarefas pré-definidas no protótipo gerado (BERNHAUPT, 2008), pois assim é possível descobrir problemas de usabilidade bem como investigar os padrões de interação do usuário e obter informações importantes sobre experiência de uso. Da mesma forma, sabe-se que métodos empíricos e analíticos são complementares (DESURVIRE, 1994), portanto neste trabalho são considerados ambos com a finalidade de obter melhores resultados.

A atividade de avaliação de usabilidade é composta por um mecanismo de avaliação heurística (MMHE) e um mecanismo automático para a geração, coleta e análise de $\log s$ em Testes com Usuários remotos (MMLOG), descritos na sequência.

No final da quinta atividade, o protótipo é melhorado com as sugestões de correções de erros obtidas com as avaliações de usabilidade e o ciclo reinicia para que as novas características obtidas utilizando-se o DR gravado para cada iteração da MMWA sejam utilizadas. A atividade de AU é esquematizada na Figura 17 e os detalhes são apresentados nas seções 4.7.1 e 4.7.2.

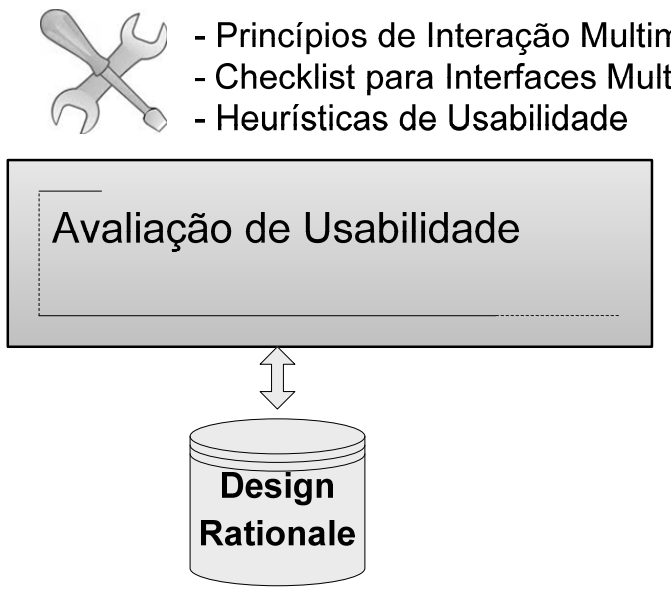

MMHE

- Formulário de Avaliação

- Diretivas para corrigir Problemas

MMLOG

- Captura de Logs

- Padrões de Interação

- Análise Estatística

- Testes Remotos

Figura 17 - MMWA: Avaliação de Usabilidade

\subsubsection{Mecanismo de avaliação heurística em interações multimodais Web (MMHE)}

Na abordagem MMWA foi definido um mecanismo para a realização de Avaliações Heurísticas, no qual utiliza-se o relacionamento de um conjunto de checklists obtidas a partir da proposta de 10 princípios de usabilidade para interfaces multimodais, relacionados com as 
10 heurísticas de Nielsen (1990) como uma forma de caracterizar e definir a presença de aspectos de usabilidade em um projeto de interação multimodal.

Os princípios, detalhados a seguir, devem ser utilizados como uma forma de facilitar a identificação de problemas de usabilidade na interação multimodal e também explicitar boas práticas em nível de projeto que sejam identificados por seus projetistas.

1. Sincronização. As múltiplas modalidades devem estar sincronizadas. A interação por voz pode ser considerada como temporal, enquanto a interação visual gráfica pode ser considerada espacial (JURAFSKY; MARTIN, 2000). Quando combinadas em uma interface multimodal, esses modos de interação precisam estar sincronizados para não comprometer a usabilidade do sistema.

2. Transição Perceptível. A transição entre diálogos em uma interação multimodal deve ser perceptível ao usuário, pois as suas habilidades e necessidades, bem como o contexto de uso podem ser modificado durante a interação.

3. Compartilhamento do Estado de interação. As múltiplas modalidades devem compartilhar o estado de interação para que durante a mudança de uma interface para outra ou se o usuário desejar trocar de modalidade em uma determinada seqüência do diálogo humano-computador, as várias mídias disponíveis sejam atualizadas.

4. Previsibilidade. As interfaces multimodais devem ser previsíveis, ou seja, a interface precisa possibilitar que o usuário saiba intuitivamente qual o melhor modo para se utilizar durante a execução de uma tarefa.

5. Adaptação. As interfaces multimodais devem se adaptar ao ambiente do usuário para assegurar que o melhor modo de se completar uma determinada tarefa em um determinado momento estará disponível ao usuário. A adaptatividade é também considerada como uma guideline. A adaptatividade dinâmica permite que a transição entre diálogos em uma interação seja perceptível ao usuário por meio de modalidades complementares.

6. Diversidade de usuários e dispositivos de interação. Durante a especificação de requisitos, o projeto da interação multimodal deve ser pensado para uma grande gama de usuários e contextos de uso. Além disso, o projetista deve considerar questões de privacidade e de segurança.

7. Projeto da entrada e saída multimodal. O projetista deve utilizar o recurso de múltiplas modalidades para maximizar as habilidades humanas cognitivas e 
físicas. Além disso, deve-se evitar a apresentação de informações desnecessárias nas diferentes modalidades, com o objetivo de maximizar as vantagens de cada modalidade para reduzir a carga de memória do usuário durante a execução de uma tarefa. É importante também integrar as modalidades de maneira compatível com as preferências do usuário, contexto e funcionalidades do sistema.

8. Consistência na interação. As Interfaces visuais e de voz devem compartilhar ao máximo as características comuns e devem se referenciar a uma tarefa com a mesma terminologia nas diferentes modalidades.

9. Retorno (feedback). Os usuários devem perceber que modalidades estão presentes em determinado momento da interação e devem perceber quais são os tipos de interação alternativas que estão presentes para executar uma tarefa.

10. Tratamento e prevenção de erros. Deve haver validações e elementos de interface que proporcionem clareza em sua utilização com feedback do resultado da interação seja por voz ou via mensagens gráficas.

Esses princípios, utilizados em conjunto com as heurísticas e as checklists, também podem ser usados para estruturar o processo de desenvolvimento como ferramenta de consulta associada ao design rationale coletado em projetos anteriores e protocolos de avaliação podem ser propostos observando-se a definição de cada princípio e os diferentes níveis de granularidade das checklists. Algumas formas de organização desses conceitos, que foram utilizadas nos estudos de caso podem ser encontradas no Apêndice B.

A primeira etapa do MMHE (MultiModal Heurist Evaluation Mechanism) consiste na preparação do formulário de avaliação. No início da utilização da MMWA, esse formulário era hospedado em uma Wiki para permitir a edição colaborativa e a captura e o armazenamento de DR, mas com a criação do ambiente de autoria que implementa a MMWA (o MMWA-ae), esse formulário passou a ser utilizado dentro da ferramenta conforme pode ser observado na Figura 18.

A elaboração deste formulário fundamenta-se nas dez heurísticas gerais de Nielsen (NIELSEN, 1993), considerando-se também um conjunto de Heurísticas para a Web (SHNEIDERMAN, 1998; NIELSEN; TAHIR, 2001; NIELSEN, 2006) como complemento, e no seu relacionamento com os princípios multimodais previamente definidos e com a sua associação com os itens disponíveis nas checklists para guiar os avaliadores na busca de problemas relacionados aos princípios definidos neste trabalho. 
O resultado é uma maneira mais organizada de descrever, documentar e abordar/resolver os problemas de usabilidade encontrados durante a Avaliação Heurística. Além disso, o relacionamento dessas teorias permitiu o desenvolvimento do mecanismo de sugestões de soluções utilizado na ferramenta de autoria que serve como framework para esta abordagem, pois é atribuído um conjunto de informações a um determinado problema de usabilidade e essas informações podem ser ranqueadas e usadas para a escolha automática de uma solução, baseada em um DR gravado anteriormente, como será apresentado mais adiante no Capítulo 7.

A versão final do formulário possui 6 campos, como pode ser observado na Figura 18: Tarefa, Heurística, Princípio, Checklist, Descrição Problema e Severidade; sendo que a severidade dos problemas pode ser definida através da seguinte escala: (0) caso não seja um problema de usabilidade; (1) caso o problema seja sem relevância: não precisa ser corrigido com urgência; (2) caso o problema de usabilidade tenha uma prioridade baixa de correção; (3) caso o problema de usabilidade tenha alta prioridade de solução e (4) caso a correção deva ser realizada antes do produto ser liberado.

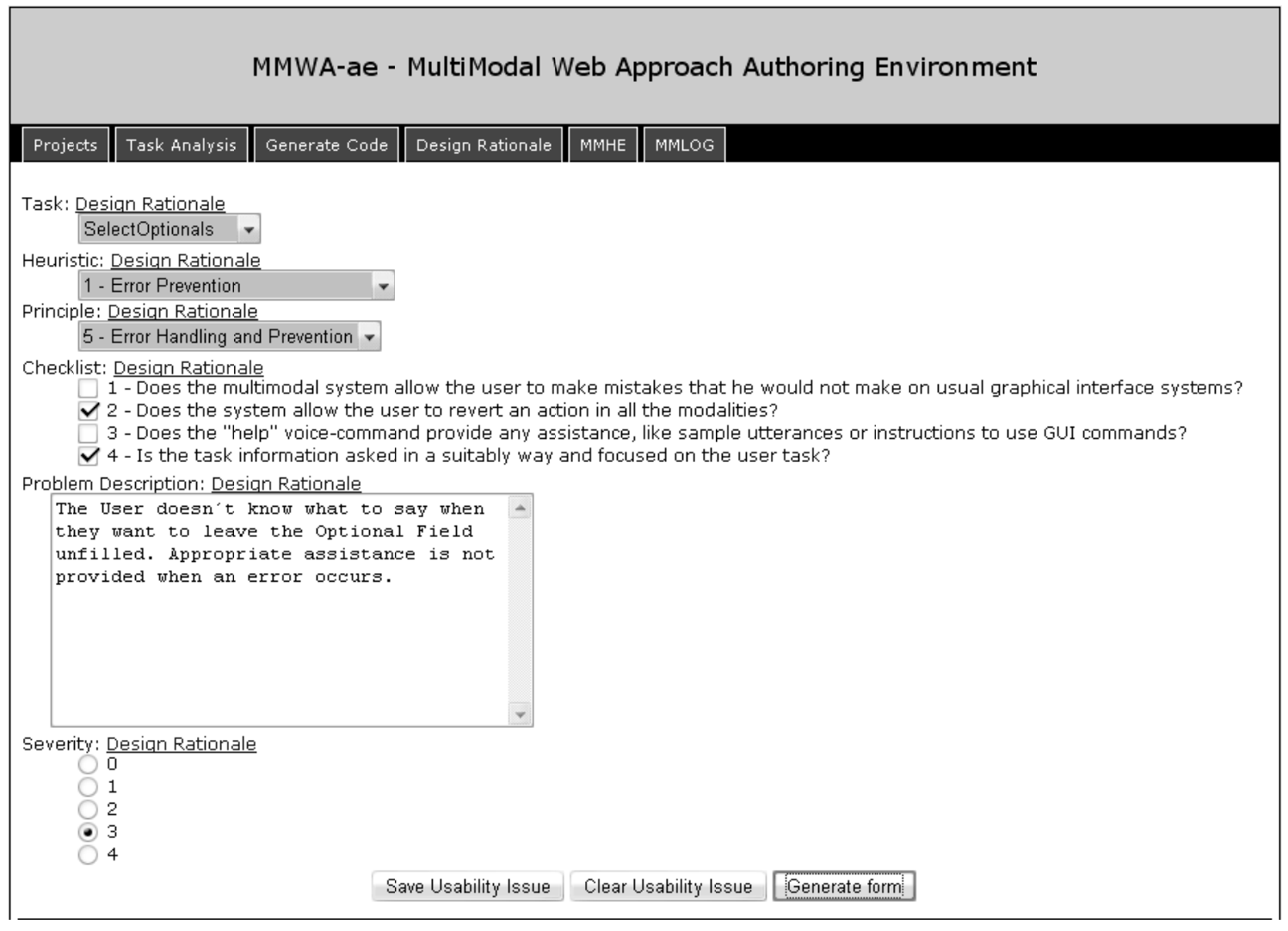

Figura 18 - MMHE: Formulário de avaliação heurística

O objetivo principal da preparação do formulário de avaliação é fornecer um guia aos testadores durante a captura e o armazenamento dos problemas encontrados e também 
permitir que as soluções para os problemas resolvidos sejam facilmente localizadas em um projeto subsequente, assim todo o DR obtido, inclusive em outras atividades da abordagem, pode ser encontrado e referenciado.

Na segunda etapa, o objetivo é aplicar o formulário para avaliar os protótipos a fim de verificar se os princípios multimodais estão presentes no projeto, relatando as falhas quanto ao cumprimento dos princípios de usabilidade e das heurísticas. Essa fase envolve um grupo de no mínimo quatro avaliadores, experientes em avaliação heurística, que examinam as interfaces de maneira impessoal, julgando se atendem aos princípios definidos. Os principais problemas encontrados e sua relação com as heurísticas por meio de checklists são gravados na forma de DR e discutidos posteriormente entre os avaliadores, gerando uma lista única com todo o raciocínio envolvido na identificação e correção dos problemas encontrados. Esse DR gravado pode também ser consultado pelos desenvolvedores em outras iterações da MMWA ou outros projetos aplicando a MMWA. No Quadro 5 pode ser observado um trecho do formulário de avaliação heurística que foi utilizado em um dos estudos de caso realizados no transcorrer deste trabalho.

Quadro 5 - Trecho do formulário de avaliação heurística

\begin{tabular}{|c|c|c|c|c|}
\hline Heurística & Checklist & Princípios & Problema & Severidade \\
\hline $\begin{array}{l}\text { Prevenção de } \\
\text { Erros }\end{array}$ & $\begin{array}{l}\text { O sistema multimodal } \\
\text { faz com que usuários } \\
\text { cometam erros que não } \\
\text { cometeriam r em } \\
\text { sistemas apenas com } \\
\text { interface visual? }\end{array}$ & $\begin{array}{l}\text { Tratamento e } \\
\text { prevenção de } \\
\text { erros }\end{array}$ & \multirow[t]{2}{*}{$\begin{array}{l}\text { O usuário não sabe o que dizer } \\
\text { quando ele quer deixar um } \\
\text { campo opcional não } \\
\text { preenchido. Não é fornecida } \\
\text { assistência apropriada quando } \\
\text { um erro ocorre. }\end{array}$} & \multirow[t]{2}{*}{4} \\
\hline $\begin{array}{l}\text { Flexibilidade e } \\
\text { Eficiência }\end{array}$ & $\begin{array}{l}\text { É possível ao usuário } \\
\text { selecionar se deseja ou } \\
\text { não que sejam lidas as } \\
\text { listas de opções da } \\
\text { caixa de seleção? }\end{array}$ & Previsibilidade & & \\
\hline $\begin{array}{l}\text { Reconhecimento } \\
\text { ao Invés de } \\
\text { Memorização. }\end{array}$ & $\begin{array}{l}\text { Existe algum modo } \\
\text { indisponível em um } \\
\text { determinado momento } \\
\text { da interação? }\end{array}$ & $\begin{array}{l}\text { Consistência na } \\
\text { Interação. }\end{array}$ & \multirow{2}{*}{$\begin{array}{l}\text { O usuário não sabe o conteúdo } \\
\text { interno de uma caixa de seleção } \\
\text { e não tem outra alternativa a } \\
\text { não ser utilizar a interface } \\
\text { gráfica, ou seja, o modo voz } \\
\text { está disponível, mas o usuário } \\
\text { não sabe o que pode dizer }\end{array}$} & \multirow[t]{2}{*}{4} \\
\hline $\begin{array}{ll}\text { Visibilidade } & \text { do } \\
\text { status } & \text { do } \\
\text { sistema. } & \end{array}$ & $\begin{array}{l}\text { As listas de opções das } \\
\text { caixas de seleção estão } \\
\text { claras para o usuário? }\end{array}$ & $\begin{array}{l}\text { Interfaces } \\
\text { Previsíveis. }\end{array}$ & & \\
\hline
\end{tabular}

\subsubsection{Mecanismo de geração e análise automática de log em interações multimodais Web (MMLOG)}

A proposta do MMLOG é permitir a realização de Testes com Usuários remotos, análise estatística das interações e reconhecimento de padrões de interação multimodal. Uma das vantagens desse mecanismo é que um grande grupo de usuários pode ser facilmente 
recrutado, pois os testes podem ser executados remotamente e no horário mais conveniente ao usuário.

O mecanismo de testes com usuários remotos requer alguns cuidados durante a execução do MMLOG, que serão abordados no Capítulo 5, como: a criação do protocolo de testes explicando a proposta da avaliação de usabilidade e a descrição das tarefas ou cenário de uso a serem executados, a criação de um questionário de satisfação de uso, a existência de um canal direto com os realizadores dos testes, entre outros.

Para que a avaliação da usabilidade nesse tipo de teste seja eficiente faz-se necessária a captura de todos os eventos que ocorrem durante a interação multimodal, bem como a modalidade escolhida pelo usuário, a fala do usuário e o tempo de interação com cada widget da interface, como ilustrado na Figura 19.

\begin{tabular}{|l|l|l|l|r|r|r|r|r|c|}
\hline \multicolumn{1}{|c|}{ Widget } & Modality & \multicolumn{1}{|c|}{ Utterance } & Interpretation & Confidence & Event & $\begin{array}{c}\text { Interaction } \\
\text { Time }\end{array}$ & $\begin{array}{c}\text { Prompt } \\
\text { Duration }\end{array}$ & $\begin{array}{c}\text { End } \\
\text { Pointing }\end{array}$ & $\begin{array}{c}\text { Selected } \\
\text { Value }\end{array}$ \\
\hline getData & voice & oh well... & Reject & 0.5 & NM & 5 & 3 & 1 & \\
\hline getData & voice & it is October 8th 2008 & $08,10,08$ & 0.75 & reco & 7.25 & 5.2 & 1 & 1 \\
\hline getCity & graphic & & & & & 3 & 2 & 1 Albany(N) \\
\hline getOpt & graphic & & & & & 3 & 3 & 1 & $\mathrm{CD}$ \\
\hline getOpt & voice & none & none & 0.95 & reco & 0.65 & 0 & 1 & \\
\hline
\end{tabular}
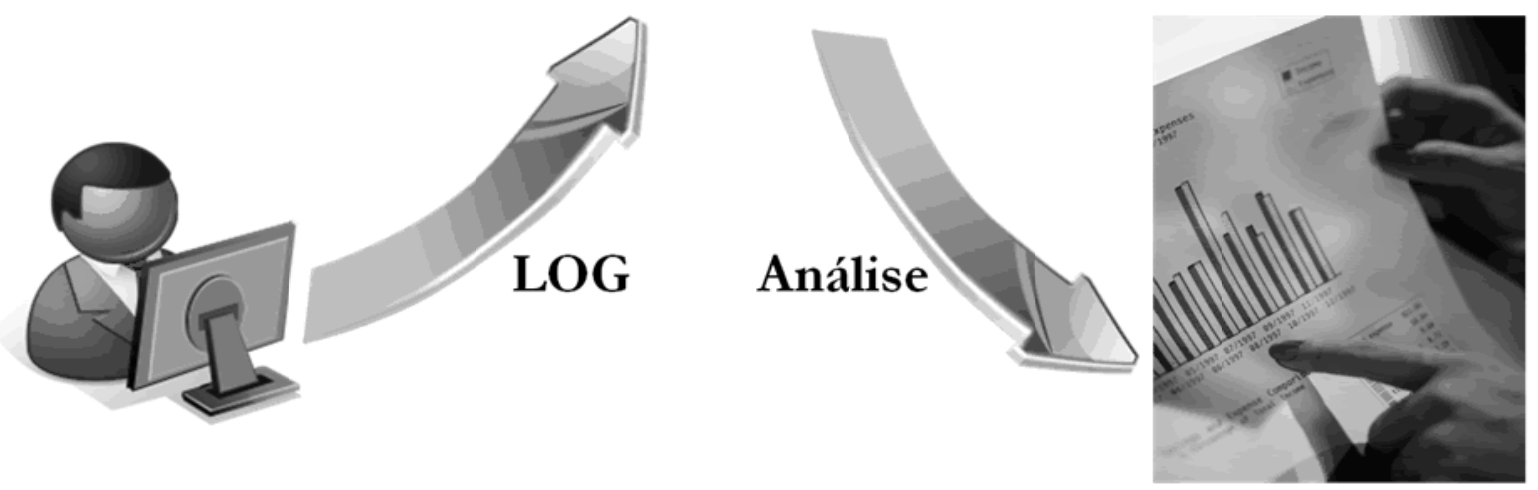

Figura 19 - Fluxo de interação do MMLOG

Os atributos de interação podem ser configuráveis para cada projeto, mas geralmente utilizam-se os seguintes atributos como padrão:

- SessionID: um identificador único da interação que serve para identificar um usuário interagindo com a aplicação multimodal.

- Modalidade: a modalidade escolhida pelo usuário para interagir com um elemento da interface;

- Interface: o nome da interface/widget em que a interação está acontecendo; 
- Tarefa: a tarefa que o usuário está executando;

- Valor: o valor de entrada fornecido pelo usuário;

- Interpretação: a interpretação do sistema para uma Entrada do usuário;

- Confiança: um valor probabilístico associado pelo reconhecedor de voz a uma entrada de voz do usuário;

- Tempo: o tempo gasto pelo usuário para interagir com a interface/widget;

O MMLOG foi desenvolvido para coletar $\log s$ em qualquer interface multimodal Web desenvolvida seguindo os padrões do W3C. O MMLOG é composto por 4 classes e 8 métodos, apresentados na sequência (Figura 20) que habilitam uma coleta estruturada de $\log s$, utilizados para gerar gráficos e tabelas permitindo a análise estatística das escolhas de interação por parte do projetista de interface além de viabilizar e facilitar a percepção e descoberta de padrões de interação (OVIATT; COULSTON; LUNSFORD, 2004) de grupos de usuários e até mesmo erros de projeto de interação multimodal e problemas de usabilidade.

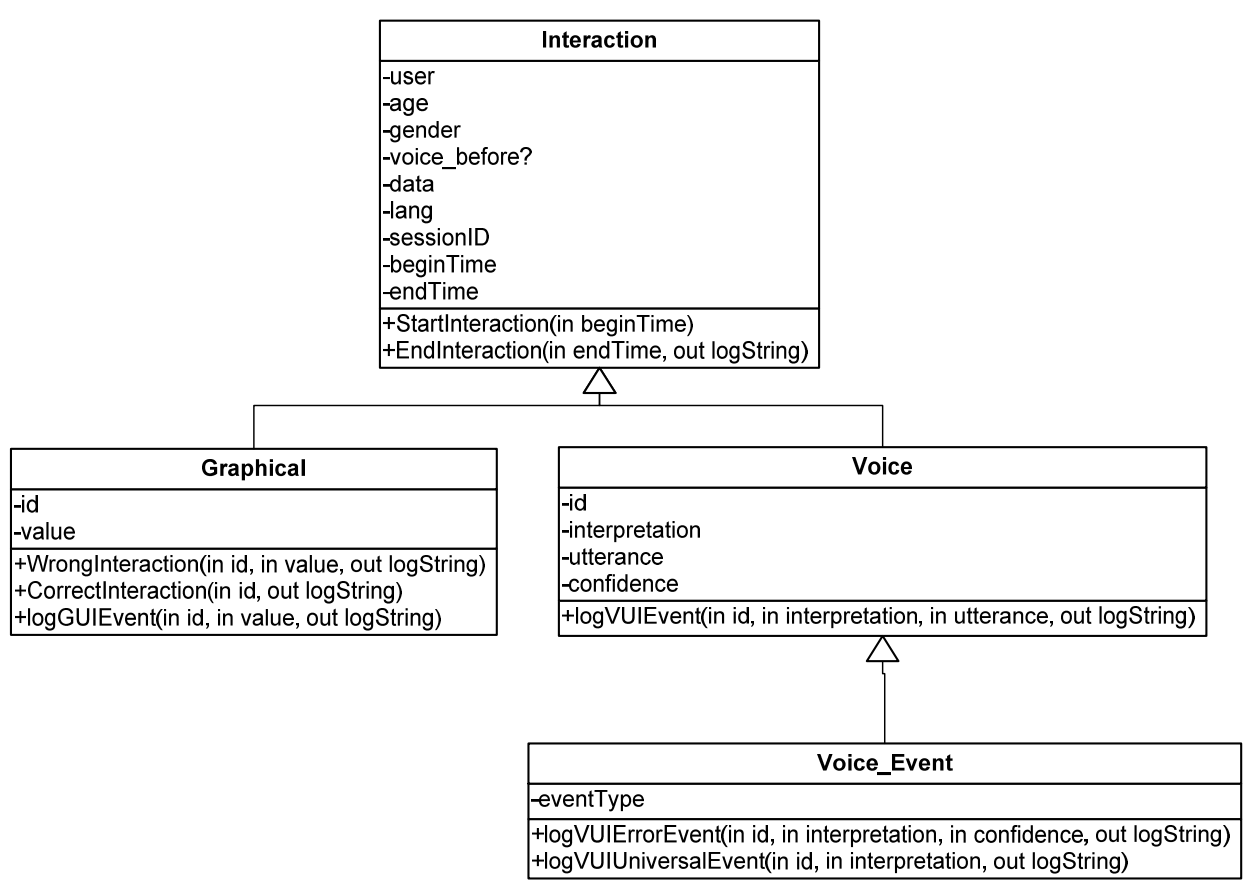

Figura 20 - MMLOG: Diagrama de Classe

O significado de cada classe e método está descrito a seguir: 
- Classe Interaction: contém os dados da interação de um usuário, como o nome, idade, sexo, idioma, data, hora, identificador único da sessão.

- Classe Graphical: contém informações sobre a interface gráfica como o identificador da widget e o valor utilizado pelo usuário para completar sua tarefa.

- Classe Voice: contém informações da interface de voz, como o identificador da tarefa, a interpretação obtida para uma fala, a representação em texto da fala do usuário e a confiança que o reconhecedor de voz atribui para uma entrada do usuário.

- Classe Voice_Event: contém informações sobre os tipos de eventos que podem ocorrer na interface de voz, como eventos de erro, confirmação e sincronização.

- Método StartInteraction: registra a hora que a interação começou.

- Método EndInteraction: registra a hora que a interação terminou.

- Método WrongInteraction: fundamentado no protocolo de testes de usabilidade é possível informar ao modelo de tarefas que o usuário completou uma determinada tarefa com dados errados.

- Método CorrectInteraction: fundamentado no protocolo de testes de usabilidade é possível informar ao modelo de tarefas que o usuário completou uma determinada tarefa com dados corretos.

- Método logGUIEvent: grava na base de $\log$, uma interação realizada pelo usuário com uma widget gráfica.

- Método logVUIEvent: grava na base de $\log$, uma interação realizada pelo usuário com uma widget de voz.

- Método logVUIErrorEvent: caso haja um erro na interface de voz, por exemplo de interpretação, é possível gravar no log informações sobre o que aconteceu na tarefa.

- Método logVUIUniversalEvent: eventos universais também podem ser gravados no $\log$. 
É importante salientar que novas classes e novos métodos podem ser incluídos no modelo, caso uma nova modalidade seja adicionada à MMWA, ou novos requisitos sejam identificados.

É possível realizar diversas buscas na base de dados do MMLOG para a geração de gráficos e tabelas, por exemplo, realizar uma análise de erros, por tarefa, para identificar possíveis problemas de usabilidade, como é apresentado na Figura 21, assim é possível verificar os tipos de erros que ocorreram e o número de usuários que cometeram esses erros.

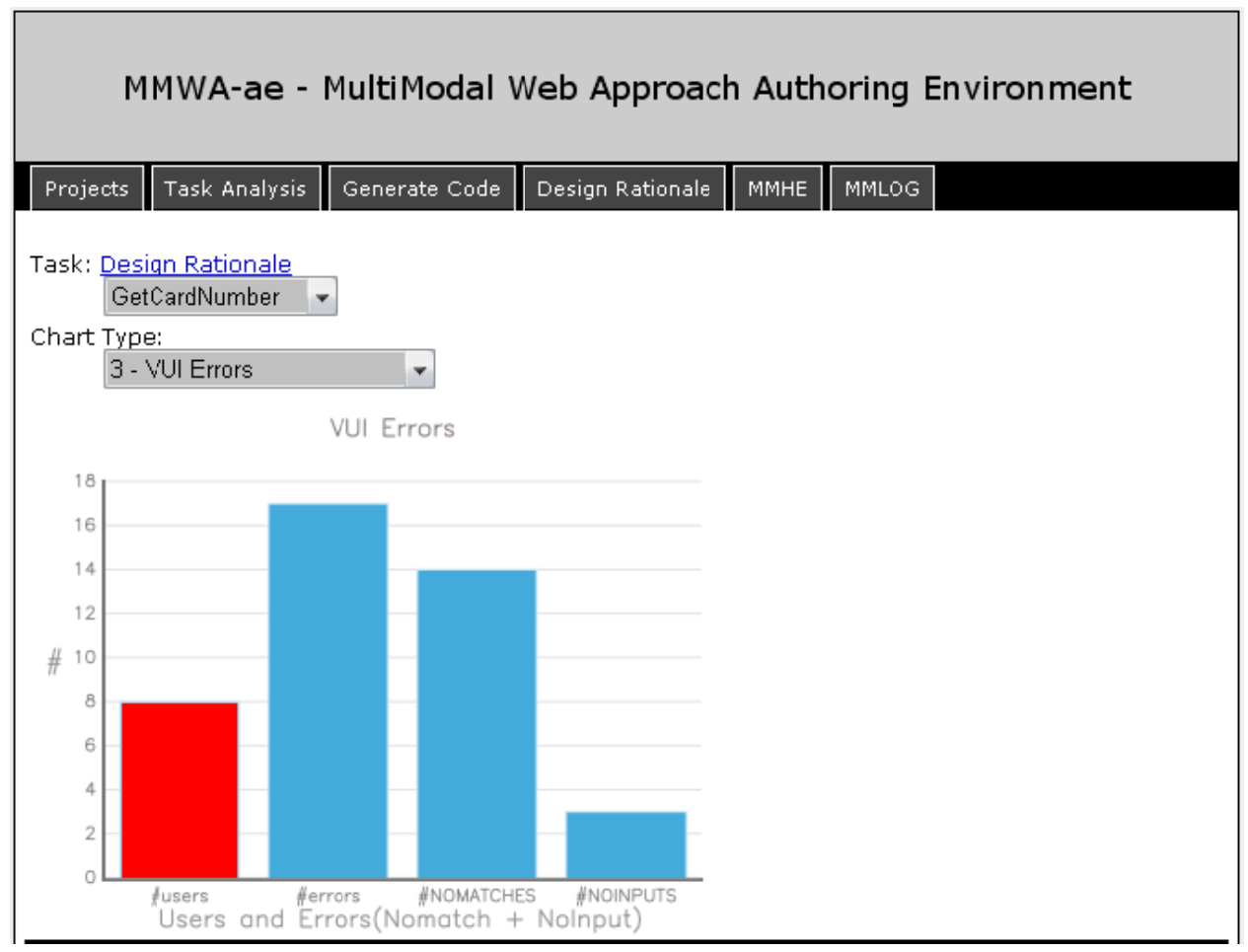

Figura 21 - MMLOG: gráfico que mostra o número e o tipo dos erros na interface de voz para uma tarefa específica

Também é possível comparar o uso das modalidades gráfico e voz, por tarefa, ou de forma global, como apresentado na Figura 22. Outros gráficos e tabelas podem ser gerados para analisar comportamentos do usuário ou do sistema, como:

- Comparar o tempo médio de interação para cada modalidade, dada uma mesma tarefa.

- Obter a taxa de recuperação de erros.

- Verificar o comportamento do usuário no momento que ocorre um erro.

- Obter o perfil dos usuários (sexo, idade, região, etc) que interagem de uma determinada maneira. 
- Gerar informações de fluxo percorrido pelo usuário para realizar uma determinada tarefa.

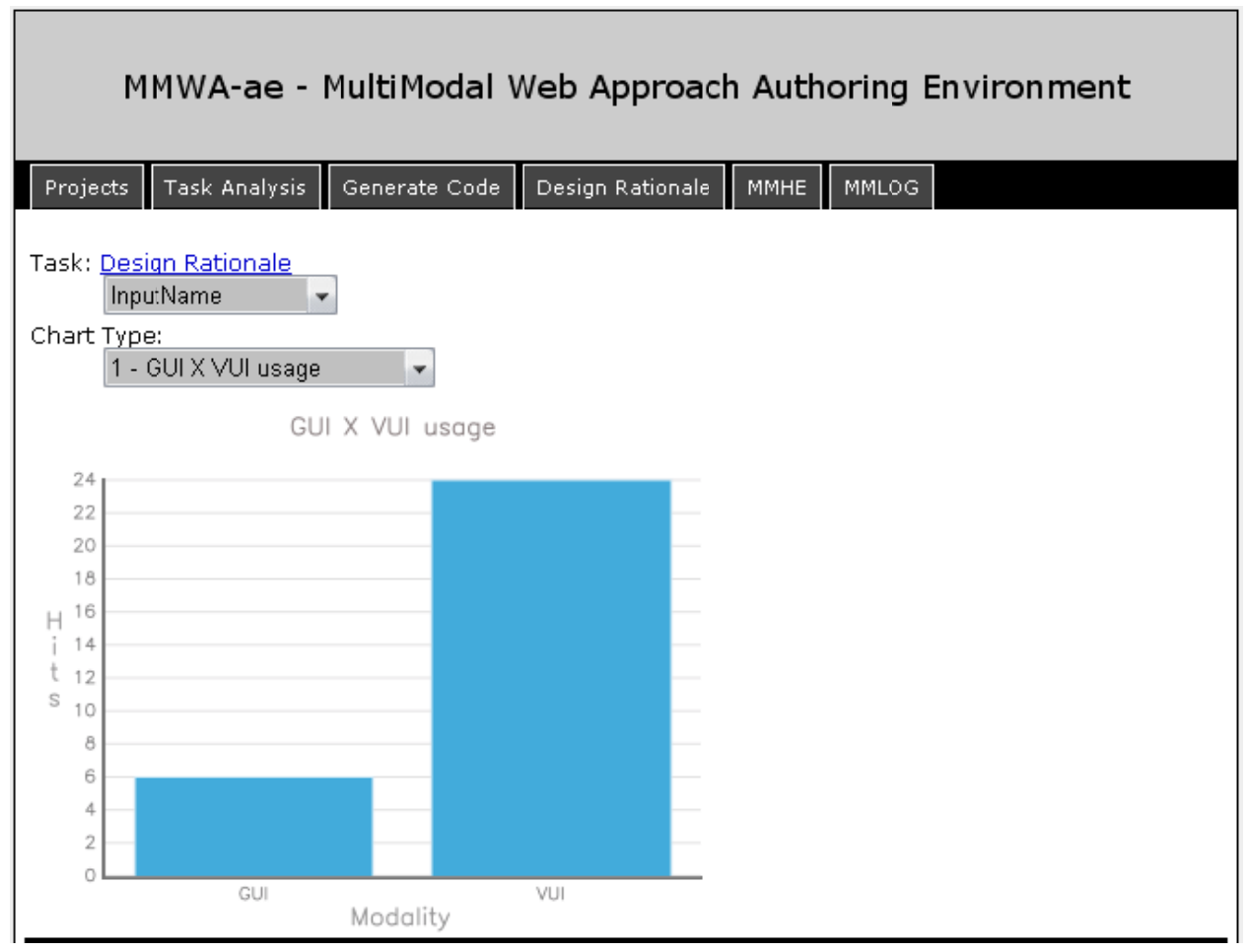

Figura 22 - MMLOG: gráfico que compara o uso de dois tipos de modalidade para uma tarefa

\subsection{A utilização de design rationale}

De acordo com Gruber e Russel (1991) e Moran e Carroll (MORAN; CARROLL, 1996), design rationale se refere ao raciocínio que justifica um projeto resultante e as descrições que justificam porque determinadas estruturas foram escolhidas sobre as demais alternativas. Jintae (1997) considera que o DR abrange não apenas as decisões de um projeto, mas também as justificativas, as alternativas e as argumentações que levaram à decisão. Essas informações adicionais valorizam a documentação do processo, colaboram para o aprendizado do projeto como um todo, aumentam a qualidade do produto e promove a reutilização.

Desde o surgimento dos primeiros estudos sobre DR, diversos benefícios foram apresentados em relação à adoção da abordagem na prática. De acordo com Burge e Brown (2000), DR é importante para auxiliar a execução das atividades de revisão, manutenção, documentação, avaliação e aprendizado de um projeto. Além disso, pode ser bastante útil para reuso de projetos passados, para coordenação de pessoas que fazem parte de um grupo de trabalho, para promoção de reflexões críticas durante o desenvolvimento de projetos, para 
manutenção de artefatos, para auxiliar o gerenciamento dos projetos e a colaboração entre os membros, melhorar a documentação e auxiliar na fase de engenharia de requisitos (DUTOIT et al., 2006).

De acordo com Dutoit et al. (2006), o DR pode ser utilizado principalmente com os seguintes propósitos:

- promover a colaboração entre membros de uma equipe;

- facilitar a manutenção e o reuso;

- melhorar a qualidade dos artefatos;

- transferir conhecimentos.

Durante o desenvolvimento de um projeto, as informações de DR são capturadas registrando-se o raciocínio, as decisões e as alternativas de projeto com o objetivo de construir uma estrutura formal e viabilizar a recuperação posterior das informações. $\mathrm{O}$ processo de captura de DR geralmente consiste em duas etapas: registro do conhecimento, que envolve a captura da maior quantidade de informação possível, e construção do conhecimento, que se refere a extração, organização e armazenamento do conhecimento (REGLI et al., 2000).

Para a representação de DR previamente capturado, é necessário que seja concebida uma estruturação das informações capturadas durante o desenvolvimento dos projetos, em geral, provenientes da discussão entre os membros da equipe. O DR pode ser observado sob diferentes perspectivas, denominadas: argumentação, comunicação e documentação, sendo que a forma de representação das informações varia de acordo com a perspectiva adotada pela equipe de trabalho.

O modelo Issue-Based Information System (IBIS) (KUNZ; RITTEL, 1970), utilizado neste trabalho, faz uso de três abstrações para representar o conhecimento, denominadas questão, posição e argumento. Tais abstrações são relacionadas entre si para representar a discussão dos desenvolvedores. Assim, as dúvidas que surgem durante o projeto são tratadas como questões, seguidas por uma ou mais posições que as respondem. Os argumentos podem suportar ou rejeitar as posições, como apresentado na Figura 23.

Os relacionamentos também são pré-determinados pelo modelo. Projetistas que trabalham sozinhos afirmam que a organização de idéias em termos de questão, posição e argumento ajuda a prestar mais atenção nas partes mais difíceis e críticas do problema, além 
de ajudar a perceber mais rapidamente as idéias que estejam incoerentes. Aqueles que trabalham em equipe consideram que a estrutura do modelo é muito útil e serve para mostrar opiniões dos participantes de forma clara (MONK et al., 1995).

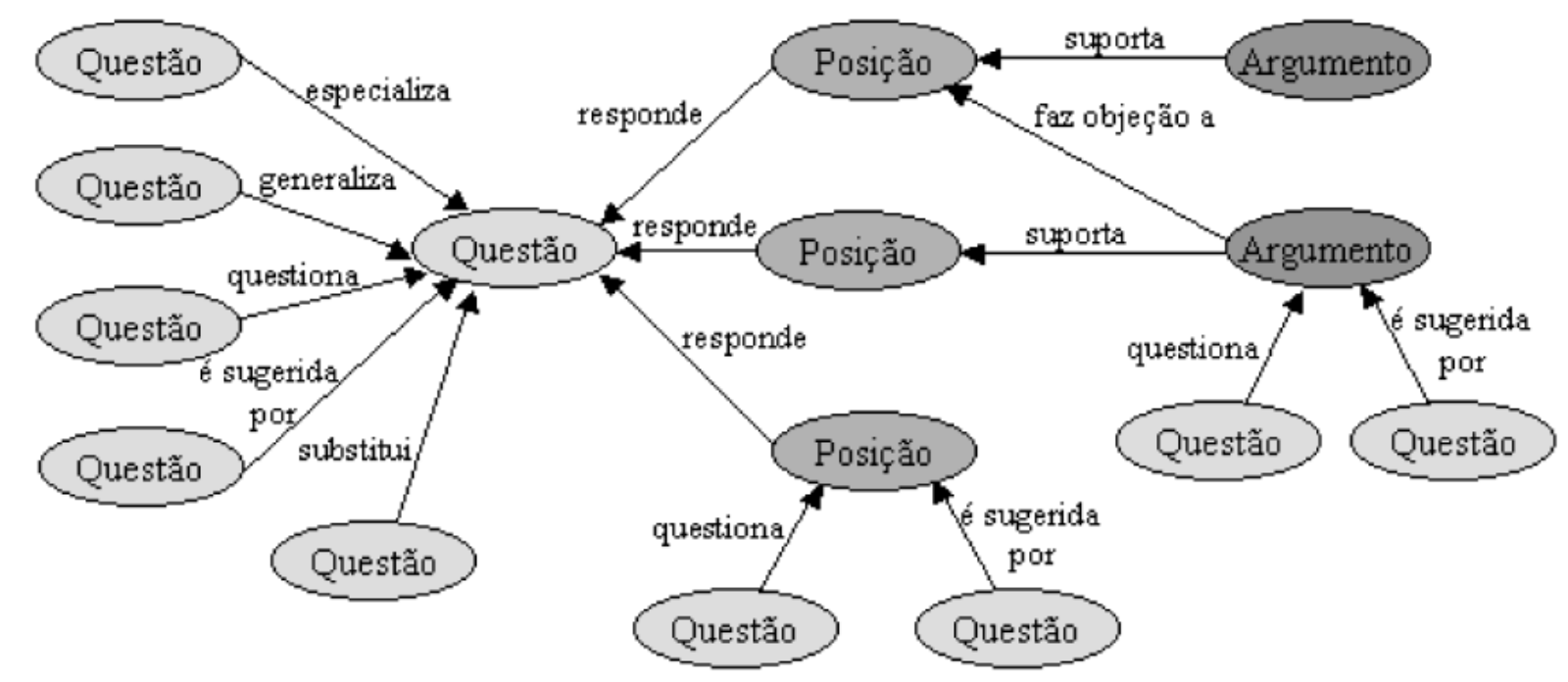

Figura 23 - Relacionamentos do Modelo IBIS adaptado de (KUNZ; RITTEL, 1970)

O modelo IBIS incentiva a discussão de idéias e, consequentemente, contribui para que as dúvidas dos desenvolvedores e dos usuários se tornem mais claras e sejam conhecidas. Outro fator importante é que o modelo IBIS suporta a comunicação entre engenheiros de requisitos ao possibilitar que questões e possíveis soluções sejam compartilhadas e debatidas. Um exemplo de DR coletado nos estudos de caso com a MMWA é apresentado no Quadro 6

A recuperação de DR é determinada, principalmente, pelo esquema de representação utilizado. Algumas situações (cenários) que motivam a recuperação de DR se referem a visualização de projetos similares e suas decisões associadas; a recuperação de critérios, regras e opções que ajudem a tomar decisões durante o projeto e a produção de documentos após o processo de projeto (REGLI et al., 2000).

Na MMWA o DR pode ser capturado em todas as atividades com a utilização de um sistema Wiki. Quando uma questão surge, o projetista insere o texto com a sua dúvida na Wiki e categoriza este texto como uma questão. À medida que posições e argumentos vão surgindo, estes vão sendo incluídos na Wiki e categorizados de acordo com o seu tipo. No final, uma solução é proposta e todo o raciocínio fica registrado e associado com o artefato em questão.

Nos estudos de caso iniciais com a MMWA identificou-se a necessidade da utilização de uma ferramenta para organizar tanto a coleta como a recuperação do DR. Na Figura 24 
pode-se observar que a aplicação da checklist permitia a coleta de DR, mas em um projeto futuro a recuperação desse DR poderia ser prejudicada, pois ele não estava estruturado.

Para solucionar este problema, o mecanismo de coleta, armazenamento e recuperação de DR foi incluído como parte do ambiente de autoria da MMWA que será apresentado no próximo capítulo. Nele, o projetista insere e categoriza o DR no momento do projeto de um artefato, visando facilitar a organização do conhecimento capturado e a sua futura recuperação.

Quadro 6 - Exemplo de utilização de DR em um estudo de caso com a MMWA Questão 1: De acordo com o modelo de tarefas, temos que apresentar as opções ao usuário para que ele selecione um item. Vamos usar interface gráfica ou de voz ou ambas?

Posição desenvolvedor1: vamos usar um menu de voz para a seleção das opções

Argumento desenvolvedor2 (contra): de acordo com os princípios para o desenvolvimento de interfaces, uma estrutura de $5+$ ou -2 itens de menu é recomendada para interfaces gráficas, e isso pode ocasionar em prompts demorados para interfaces de voz, diminuindo a velocidade da interação e prejudicando a organização na memória de curta duração do usuário.

Argumento desenvolvedor3 (contra): concordo com o desenvolvedor2, a interação por voz demanda menus reduzidos.

Posição desenvolvedor2: que tal usar as opções mais selecionadas no prompt e deixar todas as opções na interface gráfica?

Argumento desenvolvedor3 (a favor): concordo, mas não devemos usar muita hierarquia de menu.

Resposta à questão (Solução): em situações em que precisamos usar interações por voz e visual o usuário pode ser apresentado ao menu de maneira visual e fazer a seleção pela fala ou clique. A parte visual deve conter poucos itens 5+-2 e não possuir muita hierarquia. os itens devem ser divididos em grupos com nomes intuitivos e que sejam reconhecidos pela gramática para habilitar o seu uso por comando de voz. O feedback de voz pode informar em qual sub menu o usuário está. Os itens de menu podem ser falados, caso o usuário esteja usando a voz para interagir.

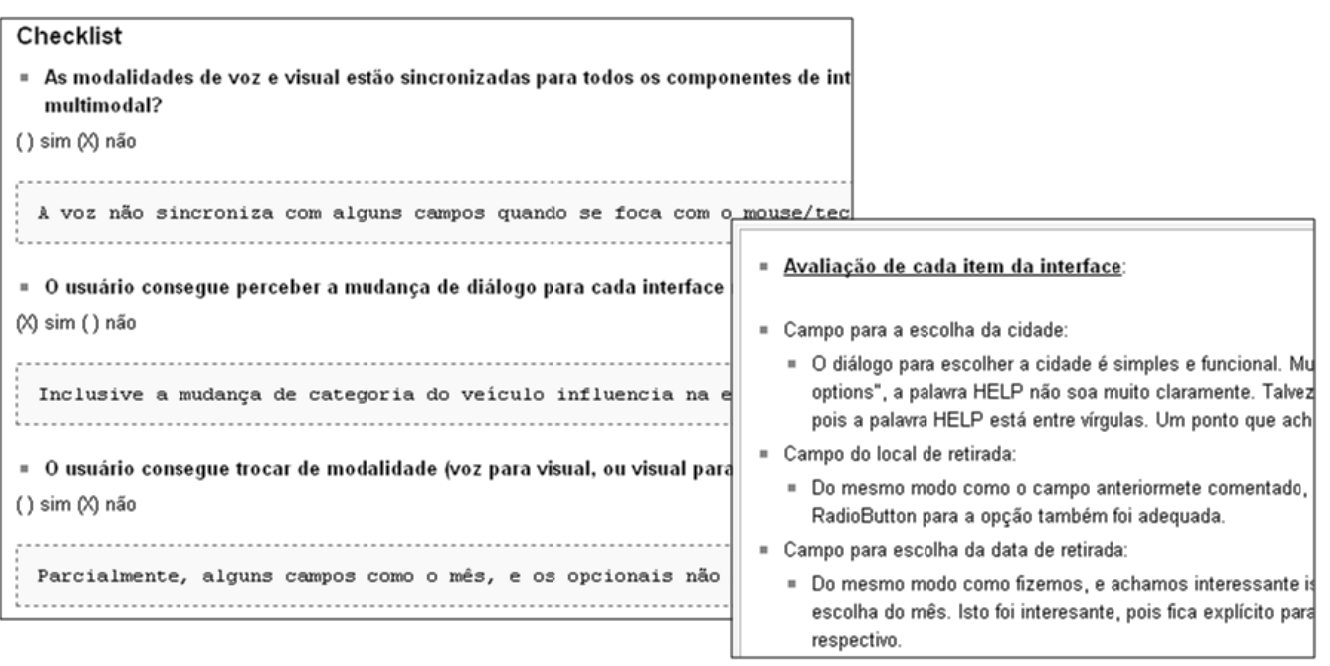

Figura 24 - Exemplo de DR capturado durante o preenchimento da checklist 


\subsection{Uma comparação com as abordagens pesquisadas}

As abordagens citadas na Seção 3.4.1 são utilizadas para resolver problemas pontuais no que se refere a transformações de interfaces multimodais para diferentes dispositivos, conceito este complementar ao trabalho apresentado nesta tese. No entanto, elas pouco consideram princípios, guidelines, DR ou padrões de projeto para melhorar a usabilidade e facilitar o trabalho da equipe de projeto de interfaces multimodais Web.

Já os frameworks citados na Seção 3.4.2 apóiam o desenvolvimento organizado de aplicações multimodais e abordam conceitos mais próximos dos problemas que o usuário enfrenta interagindo com tais aplicações, como as propriedades CARE utilizadas neste trabalho para a identificação de problemas de usabilidade e o Gerenciador da Interação, que apresenta ideias interessantes para a criação de estratégias de tratamento de erros e confirmação de entradas do usuário, amplamente utilizadas nesta pesquisa, como será apresentado mais adiante.

Além disso, as linguagens de marcação citadas na Seção 3.3, como o X+V, o SALT e o EMMA possibilitam o desenvolvimento de interfaces Web e aplicações multimodais de forma semelhante ao desenvolvimento Web tradicional, facilitando o trabalho dos desenvolvedores.

Esses dados pesquisados foram utilizados durante o desenvolvimento do projeto de doutorado, com o objetivo de servir como uma lista de requisitos que foi verificada em cada ciclo de atividades.

\subsection{Considerações finais}

Neste capítulo foram descritas as atividades que compõem a MMWA e as técnicas utilizadas nessas atividades, com alguns exemplos dos estudos de caso realizados neste trabalho e que serão detalhados no Capítulo 6.

Como resultados, que serão apresentados detalhadamente no Capítulo 7, a abordagem otimiza a metodologia de desenvolvimento de interfaces multimodais e habilita a identificação, a análise e a descoberta de soluções para problemas de usabilidade recorrentes nesse contexto de interação multimodal.

No próximo capítulo será apresentado o ambiente de autoria que implementa as atividades definidas na MMWA, visando ajudar os projetistas, desenvolvedores e testadores de interfaces multimodais em suas tarefas. 
Capítulo 4 - Abordagem para o Desenvolvimento de Interfaces Multimodais Web (MMWA) 


\section{Capítulo 5. Ambiente de autoria para o projeto de interfaces multimodais Web (MMWA-ae)}

\subsection{Considerações iniciais}

O desenvolvimento de interfaces multimodais é uma tarefa difícil para os projetistas e desenvolvedores e nesta pesquisa percebeu-se que ainda faltam ferramentas que auxiliem no projeto da interação e permitam avaliar a usabilidade das interfaces durante as fases iniciais do projeto, possibilitando que elas sejam modificadas à medida que os problemas de usabilidade são encontrados.

Esse contexto apresentou-se como uma excelente oportunidade para explorar ferramentas que permitem a captura e o armazenamento das experiências e do conhecimento investidos em projeto, de forma que as soluções propostas para resolver os problemas de projeto em um artefato possam ser reusadas no projeto de outros artefatos.

$\mathrm{O}$ ambiente de autoria para o projeto de interfaces multimodais Web, mais conhecido como MultiModal Web Approach Authoring Environment (MMWA-ae), foi desenvolvido para automatizar as atividades da MMWA e servir como um framework de projeto, desenvolvimento e testes de interfaces multimodais Web com o uso das modalidades gráfica e voz.

Este capítulo está organizado da seguinte maneira: na Seção 5.2 apresenta-se a arquitetura de implementação do ambiente de autoria. Na Seção 5.3 apresenta-se a arquitetura de integração das interfaces, módulos e base de dados da ferramenta desenvolvida. Na Seção 5.4 são discutidas as considerações sobre desenvolvimento baseado em modelos, usando o MMWA-ae. Na Seção 5.5 são apresentadas as vantagens da utilização do MMWA-ae em projetos multimodais Web. Na Seção 5.6 são descritas as limitações do MMWA-ae. Finalmente, na Seção 5.7, são apresentadas as considerações finais deste capítulo.

\subsection{Arquitetura de implementação do ambiente de autoria}

O MMWA-ae é um sistema Web projetado na arquitetura cliente-servidor utilizando o padrão de projeto Model-View-Controler (BUSCHMANN; HENNEY; SCHMIDT, 2007). 


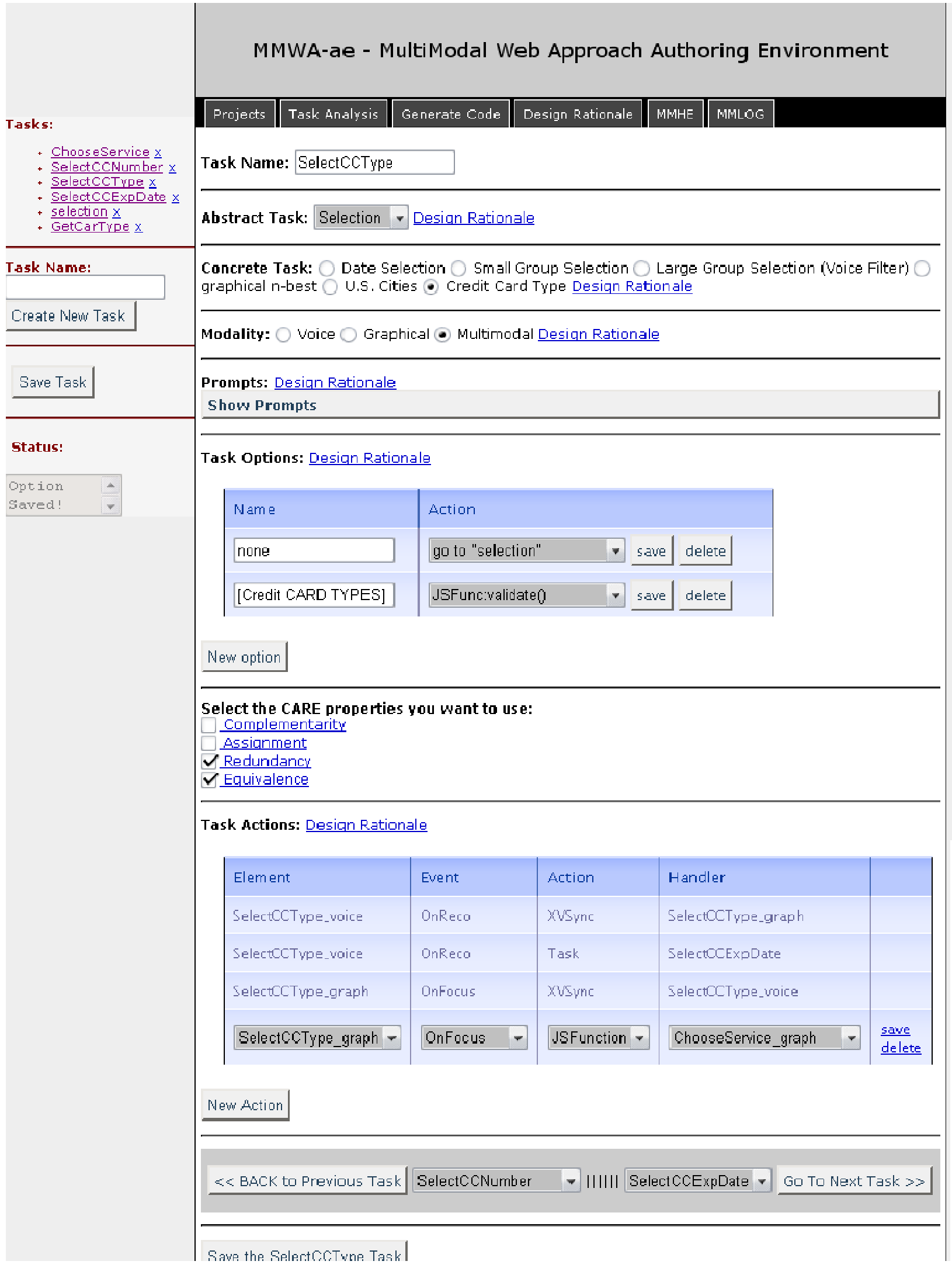

Figura 25 - MMWA-ae: Área de Projeto 
A arquitetura do MMWA-ae foi planejada com o objetivo de facilitar a separação entre os dois tipos de interfaces do usuário existentes nessa ferramenta (as interfaces de projeto e de testes de usabilidade) e a lógica da aplicação, bem como maximizar a manutenibilidade e a flexibilidade do código, permitindo que outros desenvolvedores possam estender suas funcionalidades e utilizar os módulos existentes em outros ambientes. $\mathrm{O}$ ambiente de autoria foi desenvolvido na linguagem Java $^{2}$ utilizando-se o ambiente de desenvolvimento Eclipse 3.4.23 . A interface principal da área de trabalho de projeto do MMWA-ae é apresentada na Figura 25.

$\mathrm{Na}$ implementação da camada Visão foram utilizadas as linguagens de programação JSP, ECMAScript ${ }^{4}$ e XHTML ${ }^{5}$, no caso da interface com o projetista. Para a implementação da interface para realização de testes com usuários foram utilizadas as linguagens de programação JSP, ECMAScript, JSGF ${ }^{6}$ e XHTML+Voice. No lado do servidor (Modelo e Controlador) foram utilizados a linguagem de programação Java e o sistema gerenciador de base de dados MySQL ${ }^{7}$.

A camada do Controlador, funcionando como um intermediário entre o Modelo e a Visão, consiste no código responsável por encaminhar cada solicitação ao módulo adequado do modelo para processamento. O resultado é encaminhado pelo Controlador ao componente da Visão.

A camada do Modelo possui os componentes responsáveis por processar as solicitações encaminhadas pelo Controlador no Módulo específico e fornecer acesso aos dados do Modelo de Domínio que estão armazenados nas bases de dados representadas na Figura 26.

Toda a apresentação interna do modelo de tarefas foi feita utilizando XML (Extensible Markup Language) (W3C, 1996) de forma a definir uma forma padronizada para a adição de marcações a documentos contendo informação estruturada e a API JDOM (JDOM, 2009) foi utilizada para transformação, criação, manipulação, e serialização de documentos XML de entrada que representa um esquema conceitual do modelo de tarefas do MMWA-ae.

\footnotetext{
${ }^{2}$ http://java.sun.com/

${ }^{3} \mathrm{http}: / /$ www.eclipse.org/

${ }^{4} \mathrm{http}: / / \mathrm{www}$.ecmascript.org/

${ }^{5}$ http://www.w3.org/TR/xhtml1/

${ }^{6} \mathrm{http}: / /$ java.sun.com/products/java-media/speech/forDevelopers/JSGF/

${ }^{7} \mathrm{http}: / /$ www.mysql.com/
} 
A utilização do JDOM permite simplificar a manipulação em Java de documentos $\mathrm{XML}$, de forma mais amigável e abrangente do que o $\mathrm{SAX}^{8}$, que não oferece uma forma padrão de escrever um documento XML, e do que o DOM, que pode manipular documentos XML, mas não permite sua análise gramatical.

Para a integração de design rationale com o sistema Wiki foi escolhida a DokuWiki ${ }^{9}$ pela sua simplicidade, facilidade de uso, estruturação de páginas hierárquicas (namespaces) e por implementar a interface Wiki RPC Interface (WIKIRPCINTERFACE, 2010) para a manipulação de funcionalidades da Wiki.

Para a implementação do código cliente para a comunicação com a DokuWiki foi utilizado o Apache XML-RPC ${ }^{10}$ que é uma implementação do XML-RPC em Java, para que seja usado XML sobre o HTTP para implementar as chamadas remotas RPC (Remote Procedure Call).

\subsection{Arquitetura de integração das interfaces, módulos e base de dados}

Uma visão geral da arquitetura do ambiente de autoria é apresentada na Figura 26.

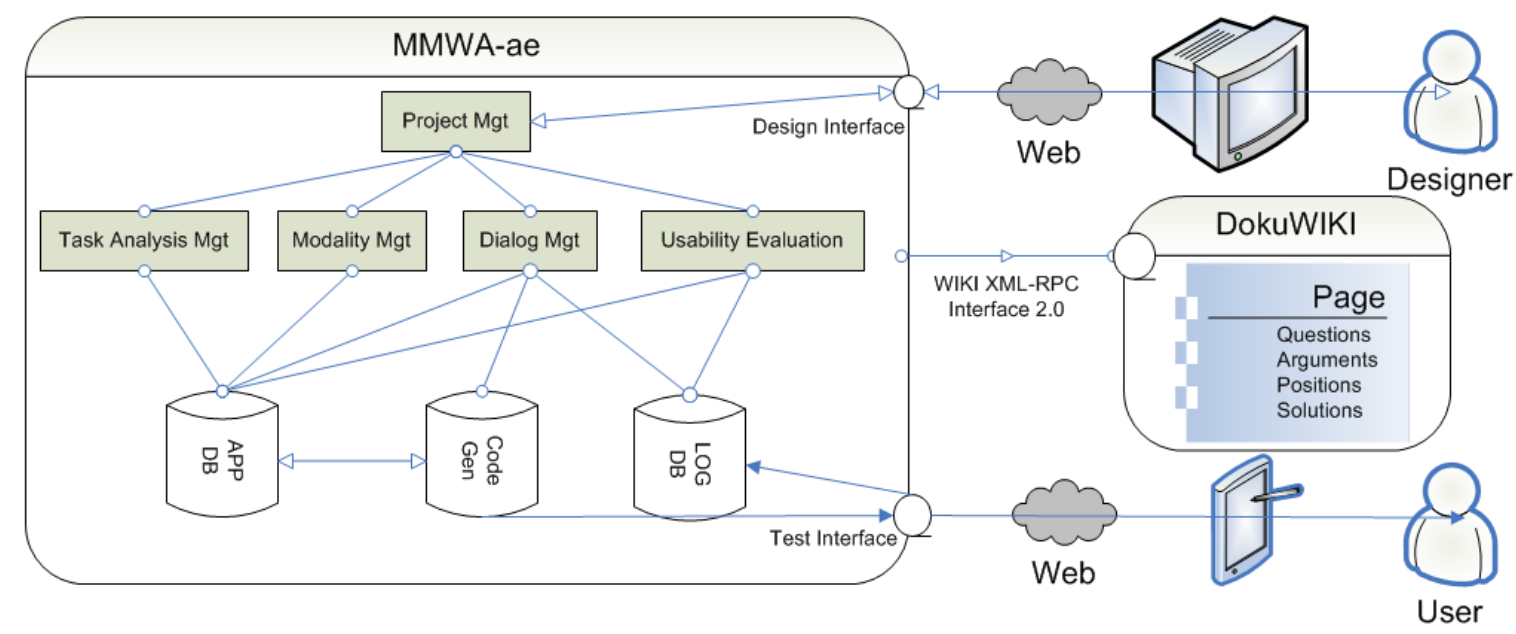

Figura 26 - MMWA-ae: Arquitetura

Como pode ser observado na Figura 26, a arquitetura do MMWA-ae foi projetada de forma a disponibilizar duas interfaces à equipe de projeto, descritas a seguir:

- A Interface de Projeto (Design Interface) pode ser acessada pelos projetistas utilizando qualquer navegador Web. O objetivo é propiciar a criação de um

\footnotetext{
${ }^{8}$ http://www.saxproject.org/

${ }^{9} \mathrm{http}: / /$ www.dokuwiki.org/dokuwiki

${ }^{10} \mathrm{http}: / /$ ws.apache.org/xmlrpc/
} 
projeto multimodal e trabalhar com as atividades da MMWA de uma forma controlada e assistida.

- A Interface de Testes (Test Interface) é disponibilizada aos projetistas para a execução de testes de usabilidade. O objetivo é facilitar a execução de testes com usuários remotos. O projetista disponibiliza o protótipo executável da interface multimodal e o usuário acessa esse protótipo via Web. Tanto o ambiente de autoria como o protótipo de interface multimodal gerado por ele podem ser executados em um mesmo servidor de aplicação.

A seguir serão apresentados os principais módulos que se comunicam com as duas interfaces disponibilizadas.

\subsubsection{Módulo de Gerenciamento de Projetos}

A atividade de projeto é gerenciada pelo Módulo de Gerenciamento de Projetos (Project Management Module) que é utilizado pelo projetista para criar, remover e alterar um projeto no ambiente de autoria. Portanto, esse módulo é o ponto de comunicação entre a Interface de Projeto e os outros módulos do MMWA-ae. Ele provê os mecanismos necessários para especificar e gerenciar o diálogo e para projetar interfaces usando o conhecimento armazenado na MMWA na forma de DR.

\subsubsection{Módulo Gerenciador de Análise de Tarefas}

Com o auxílio do Módulo Gerenciador de Análise de Tarefas (Task Analysis Management Module), o projetista cria a interação multimodal de acordo com o que especificam as atividades de Identificação (IT) e Representação de Tarefas (RT) da MMWA.

É possível criar, remover e alterar as tarefas, bem como organizá-las nos níveis abstrato e concreto, escolher uma ou várias modalidades e usar padrões de projeto, componentes e DR para resolver questões de projeto, além de obter o raciocínio para resolver problemas recorrentes com o auxílio das soluções usadas em projetos anteriores no mesmo contexto.

Como foi apresentado no capítulo anterior, as tarefas abstratas podem ser classificadas em: Seleção, Navegação, Decisão, Agrupamento, Controle, Entrada ou Saída. De acordo com a escolha do projetista, as tarefas concretas são dinamicamente disponibilizadas na interface do ambiente de autoria de forma que o projetista possa escolher a que melhor se aplica para seu projeto. 
No exemplo ilustrado na Figura 25, o projetista criou uma tarefa cujo nome é "SelectCCType" e escolheu o tipo "Selection" (Seleção) como sua representação abstrata. O MMWA-ae apresentou dinamicamente as possíveis tarefas concretas disponíveis e relacionadas com o tipo "Seleção" e o projetista escolheu "Credit Card Type" (Tipo de Cartão de Crédito), que implementa um componente com as funcionalidades de um diálogo multimodal (prompts, ações e opções) para obter o tipo de cartão de crédito. O projetista também poderia ter selecionado um padrão de projeto multimodal, por exemplo, "Small Group Selection" ou "Large Group Selection", mas neste caso ele precisaria especificar os itens da interface que não são criados automaticamente, como os prompts, as opções e as ações.

Alguns padrões de projeto, que são independentes da tarefa abstrata como o “Modality Synchronization" (Apêndice A), são implementados e aplicados instantaneamente, sem a interferência do projetista de forma que quando o usuário cria uma tarefa multimodal os elementos de sincronização e os eventos correspondentes são automaticamente apresentados na visão de Ações da área de trabalho (Task Actions) do MMWA-ae, conforme é ilustrado na Figura 25.

\subsubsection{Módulo Gerenciador de Modalidades}

O Módulo Gerenciador de Modalidades é responsável por selecionar e apresentar na interface do MMWA-ae as características inerentes a cada modalidade.

Por exemplo, quando o projetista seleciona que a interface deve permitir comandos de voz, o Módulo Gerenciador de Modalidades carrega as informações pertinentes a esse tipo de interface e disponibiliza a opção de criar prompts, bem como mecanismos automáticos que sincronizam as interfaces gráfica e de voz de acordo com o retorno das gramáticas e informações relacionadas com as propriedades CARE.

A seguir são elencados os elementos (widgets) implementados no modelo de tarefas e que podem ser utilizados na especificação das interfaces multimodais como representação concreta, bem como o exemplo de sua utilização em interfaces gráficas (GUI) e de voz (VUI) e as propriedades CARE que podem ser escolhidas na fase de projeto:

- Label: define um nome para um elemento de Entrada de informações.

○ GUI: sistema permite ao usuário clicar no label para selecionar uma opção.

- VUI: label é usado como componente da gramática da interface de voz e é lido no prompt inicial. 
o Multimodal: usuário diz o nome do label, sistema sincroniza com a interface gráfica e opção é selecionada.

- C: não ocorre

- A: (GUI) sistema só permite clicar no label, ou seja a interface de voz é desabilitada e o sistema não lê o nome da opção. (VUI) sistema só permite falar a opção desejada.

- R: Label é clicado em uma interface gráfica e falado em uma interface de voz.

- E: Ler a opção ou ouvi-la e selecionar a opção falando o seu nome ou selecionando o label com o mouse.

- Caixa de Texto: usada para obter informações de entrada de usuários, que variam em um amplo espectro. Exemplo informar um nome.

○ GUI: usuário escreve seu nome.

○ VUI: usuário fala seu nome.

○ Multimodal: usuário fala seu nome e escreve seu sobrenome.

- C: usuário fala o nome e escreve o sobrenome

- A: não permitir ao sistema ler o nome do usuário.

- R: nome é escrito e falado.

- E: falar ou digitar o nome.

- Combo Box: utilizado para representações abstratas do tipo seleção. Habilita a seleção de uma ou várias opções conhecidas de antemão pelo usuário.

- GUI: usuário usa mecanismos convencionais para selecionar a opção, por exemplo, clicando na caixa, expandindo a lista e utilizando a barra de rolagem.

○ VUI: sistema toca prompt inicial solicitando a entrada do usuário. Sistema lê as opções escondidas somente se o usuário tiver dificuldades de interagir (por exemplo, na ocorrência de um erro na interface de voz).

- Multimodal: usuário usa a barra de rolagem, sistema lê as opções, usuário fala a opção desejada, sistema seleciona a opção e pergunta se usuário deseja selecionar outra opção. 
- C: ocorre quando usuário deseja selecionar múltiplas opções. Usuário seleciona uma opção e sistema fornece a alternativa de selecionar outra opção. Usuário usa a interface gráfica para selecionar a segunda opção.

- A: não permitir ao usuário clicar ou falar.

- R: clicar na opção e falar ao mesmo tempo.

- E: clicar na opção ou falar a opção em tempos diferentes.

- List Box: permite ao usuário selecionar um ou mais itens de uma lista contida dentro de uma caixa de texto.

○ GUI: usuário usa mecanismos convencionais para selecionar a opção

○ VUI: sistema toca prompt inicial solicitando a entrada do usuário. Sistema lê as opções escondidas somente se o usuário tiver dificuldades de interagir (por exemplo, na ocorrência de um erro).

- Multimodal: usuário usa a barra de rolagem, sistema lê as opções, usuário fala a opção desejada, sistema seleciona a opção e pergunta se usuário deseja selecionar outra opção.

- C: ocorre quando usuário deseja selecionar múltiplas opções. Usuário seleciona uma opção e sistema fornece a alternativa de selecionar outra opção. Usuário usa a interface gráfica para selecionar a segunda opção.

- A: não permitir ao usuário clicar ou falar.

- R: clicar na opção e falar ao mesmo tempo.

- E: clicar na opção ou falar a opção em tempos diferentes.

- Radio Button: é um elemento de múltipla escolha (seleção), mas permite ao usuário escolher apenas uma opção.

○ GUI: usuário usa mecanismos convencionais para selecionar a opção

○ VUI: sistema toca prompt inicial solicitando a entrada do usuário. Usuário diz a opção desejada. 
- Multimodal: usuário diz a opção e sistema marca o item correspondente na interface gráfica.

- C: não ocorre.

- A: não permitir ao usuário clicar ou falar.

- R: clicar na opção e falar ao mesmo tempo.

- E: clicar na opção ou falar a opção em tempos diferentes.

- Check Box: é um elemento de múltipla escolha (seleção), mas permite ao usuário escolher várias opções.

○ GUI: usuário usa mecanismos convencionais para selecionar a opção

○ VUI: sistema toca prompt inicial solicitando a entrada do usuário. Usuário diz a(s) opção(ções) desejada(s).

o Multimodal: usuário diz a opção e sistema marca o item correspondente na interface gráfica.

- C: não ocorre.

- A: não permitir ao usuário clicar ou falar.

- R: clicar na opção e falar ao mesmo tempo.

- E: clicar na opção ou falar a opção em tempos diferentes.

- Button: é um elemento de controle que permite executar ações tais como limpar ou submeter dados de um formulário.

○ GUI: usuário usa mecanismos convencionais para pressionar o botão

- VUI: gramática de universais inclui a opção do botão que pode ser mencionada pelo usuário. Geralmente é utilizado um prompt de confirmação no final da interação para confirmar todos os dados antes de prosseguir para uma próxima página.

○ Multimodal: usuário ouve um prompt de confirmação e pressiona o botão confirmando suas entradas.

- C: usuário ouve um prompt de confirmação e pressiona o botão confirmando suas entradas. 
- A: não permitir ao usuário clicar no botão ou falar a ação correspondente.

- R: clicar na opção e falar ao mesmo tempo.

- E: clicar na opção ou falar a opção em tempos diferentes.

- Link: é um elemento de Navegação que permite dar continuidade no fluxo de um conjunto de tarefas.

○ GUI: usuário usa mecanismos convencionais para clicar no link.

- VUI: gramática global inclui as opções com todos os links de uma página que podem ser mencionados pelo usuário.

○ Multimodal: usuário diz o nome do link e sistema executa a ação correspondente.

- C: usuário visualiza o link e decide mudar de página ou executar outra tarefa e diz a opção desejada.

- A: não permitir ao usuário clicar no link ou falar o item correspondente.

- R: clicar no link e falar ao mesmo tempo.

- E: clicar no link ou falar a opção em tempos diferentes.

- Coordenada X,Y: é um elemento de Navegação, mais utilizado quando há a possibilidade de se usar dispositivos que permitem toque.

- Formulário: é um elemento de Agrupamento utilizado para armazenar dados de uma tarefa.

- Menu: é um elemento de Seleção com Navegação utilizado para resumir as funcionalidades de um site em um local conhecido pelo usuário.

- Gramática: uma gramática dirigida pode ser construída com base no nome e descrição de uma tarefa, bem como utilizando as opções e ações e dados obtidos na $1^{\mathrm{a}}$ atividade da abordagem. Gramáticas estatísticas podem ser desenvolvidas quando há a necessidade de projetar diálogos com pergunta aberta.

- Prompts: são mensagens de Saída apresentadas aos usuários em forma de arquivo de áudio ou texto sintetizado (Text To Speech - TTS), utilizadas em interfaces de 
voz. O TTS é mais simples de manter e modificar e pode ser utilizado durante o desenvolvimento do software e nos casos onde ainda não se sabe o que será dito de antemão. Já os áudios gravados são mais usados quando o software está sendo utilizado por usuários, pois são áudios com maior qualidade e apresentam pronúncia natural.

\subsubsection{Módulo Gerenciador de Diálogo}

O Módulo Gerenciador do Dialogo é responsável por armazenar informações relativas ao fluxo da aplicação e garantir que: todos estados são alcançados, não há estados órfãos e não há problemas de navegação.

Esse módulo também se comunica com a base de dados de log e extrai informações sobre interações do usuário com as interfaces projetadas. Dessa forma, é possível verificar se existem problemas de interação com um determinado componente da interface e sugerir alterações diretamente na área de trabalho do MMWA-ae.

De acordo com a especificação da MMWA, durante todo o processo de projeto deve ser possível coletar e armazenar DR, para que futuros projetos se beneficiem das decisões tomadas e do raciocínio correspondente às soluções implementadas. No entanto, a criação e a utilização de DR pode ser demorada, incômoda e gerar custos excessivos (DE LUCIA et al., 2009). Para resolver esta limitação o ambiente de autoria permite ao projetista extrair e capturar DR quando for necessário.

O MMWA-ae possui um mecanismo abstrato para capturar e armazenar DR permitindo que as organizações e os desenvolvedores utilizem as principais características de qualquer sistema Wiki para colaborar na especificação, execução de tarefas e durante as atividades de testes.

Isso é possível com a implementação da interface WIKI XML-RPC 2.0 (Figura 26) que é usada para conectar a área de trabalho do MMWA-ae com qualquer sistema Wiki que implemente essa interface, de forma que o DR pode ser armazenado e recuperado por meio da criação e gerenciamento de páginas Wiki estruturadas.

Na Figura 27 é demonstrada a interação entre o MMWA-ae e a DokuWiki. O projetista, neste exemplo, insere um argumento para uma posição que está relacionada a uma questão. Esta questão, por sua vez, está relacionada a uma tarefa concreta. Como pode-se observar, a página da DokuWiki é carregada dentro do MMWA-ae, mas esta página pode também ser acessada diretamente pela URL da Wiki. 
O título da página (p1_getcartype_concrete) contém o nome do projeto (p1) concatenado com o nome da tarefa (getcartype) concatenado com o tipo de artefato que está sendo alvo de discussão (concrete).

Essa particularidade facilita a busca por determinados tipos de DR. Acessando-se a aba "Design Rationale" do MMWA-ae existe a possibilidade de filtrar o DR por tipo. Isso facilita a busca por soluções relacionadas a um tipo de artefato, por exemplo, pode-se buscar por todos os DR relacionados com tarefas concretas. O DR completo registrado no exemplo desta tarefa pode ser lido no Apêndice C.

O ambiente de autoria MMWA-ae estabelece um canal de comunicação com a DokuWiki utilizando chamadas remotas (RPC), de forma a organizar todo o DR inerente ao projeto da interação multimodal com o auxílio de templates, ou seja, páginas predefinidas que são estruturadas e relacionadas.

Posteriormente, à medida que questões, respostas, argumentos e soluções são criados, a ferramenta organiza o conteúdo na Wiki e os exibe de maneira estruturada, permitindo que o projetista tenha acesso à informação específica à atividade que ele está projetando no momento em que a dúvida aparece, facilitando a busca por uma solução já utilizada previamente.

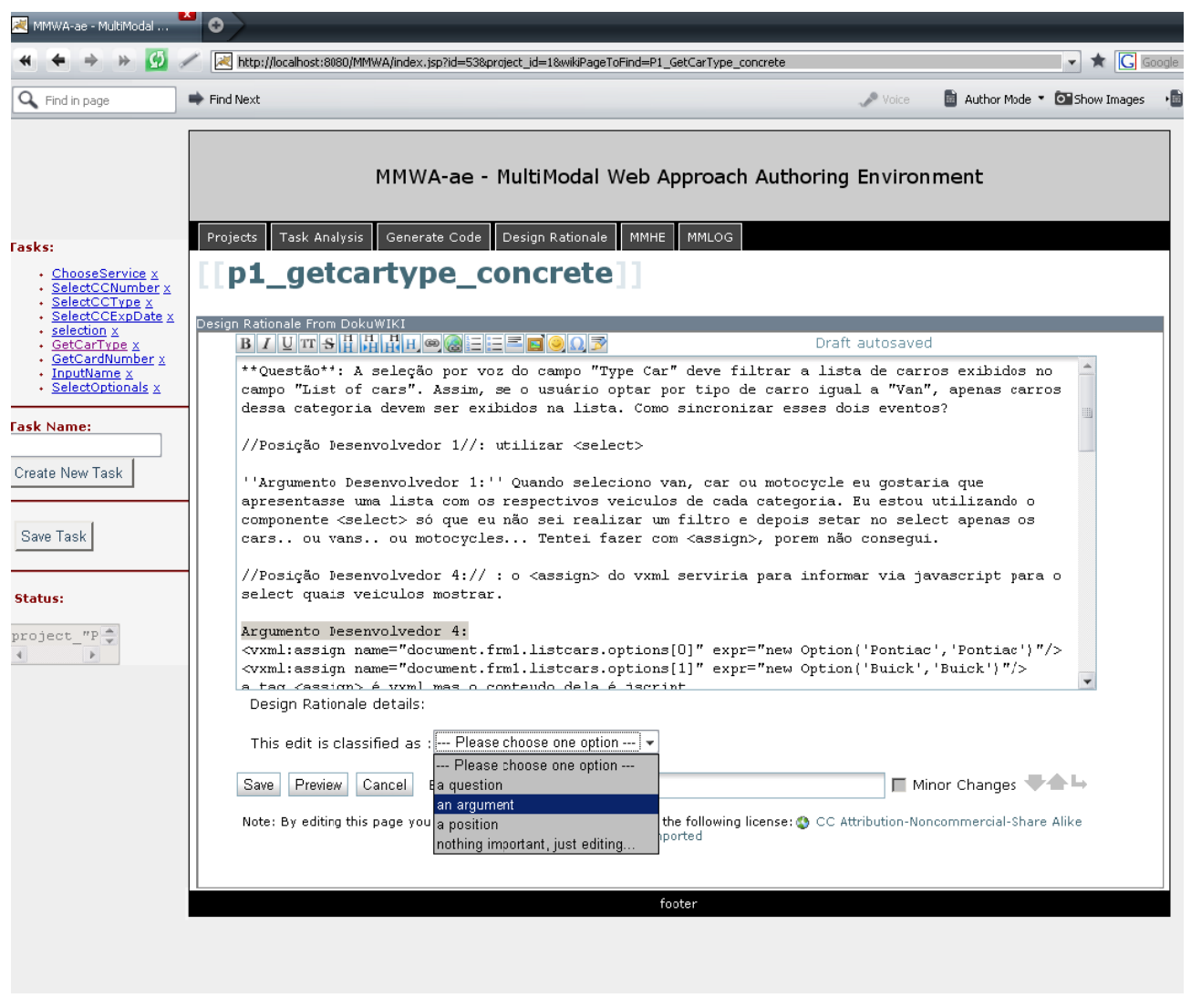

Figura 27 - Captura de DR usando o MMWA-ae e a DokuWiki 
Esse mecanismo também permite a organização da informação de forma que futuros projetos se beneficiem com buscas de DR eficientes assegurando que resultados precisos sejam obtidos. Essa organização de conhecimento/raciocínio visa facilitar a identificação de padrões de projeto, tendo em vista que a busca por conteúdos se relaciona a atividades específicas da MMWA em diferentes contextos de aplicação.

\subsubsection{Módulo de Gerenciamento de Avaliação de Usabilidade}

Outra característica importante do MMWA-ae é a possibilidade de gerar protótipos rápidos de interfaces multimodais para serem alvo de avaliações de usabilidade. Essa funcionalidade utiliza o Módulo de Gerenciamento de Avaliação de Usabilidade (Usability Evaluation Management Module) (Figura 26).

Este módulo é responsável por reunir toda a informação de diálogo do banco de dados da aplicação (Application Database), gerar o código do aplicativo usando o Gerador de Código (Code Generator Database) e incluir as funções para capturar os logs de interação na Base de Dados de log (LOG Database), além de permitir a criação do protocolo de testes de usabilidade.

Para cada tarefa especificada pelo projetista, a ferramenta cria um trecho de código que contém elementos de interface gráfica (Figura 29) e de voz (Figura 28), a sincronização entre elas (Figura 30) e inclui funções para capturar eventos de interação (Figura 31).

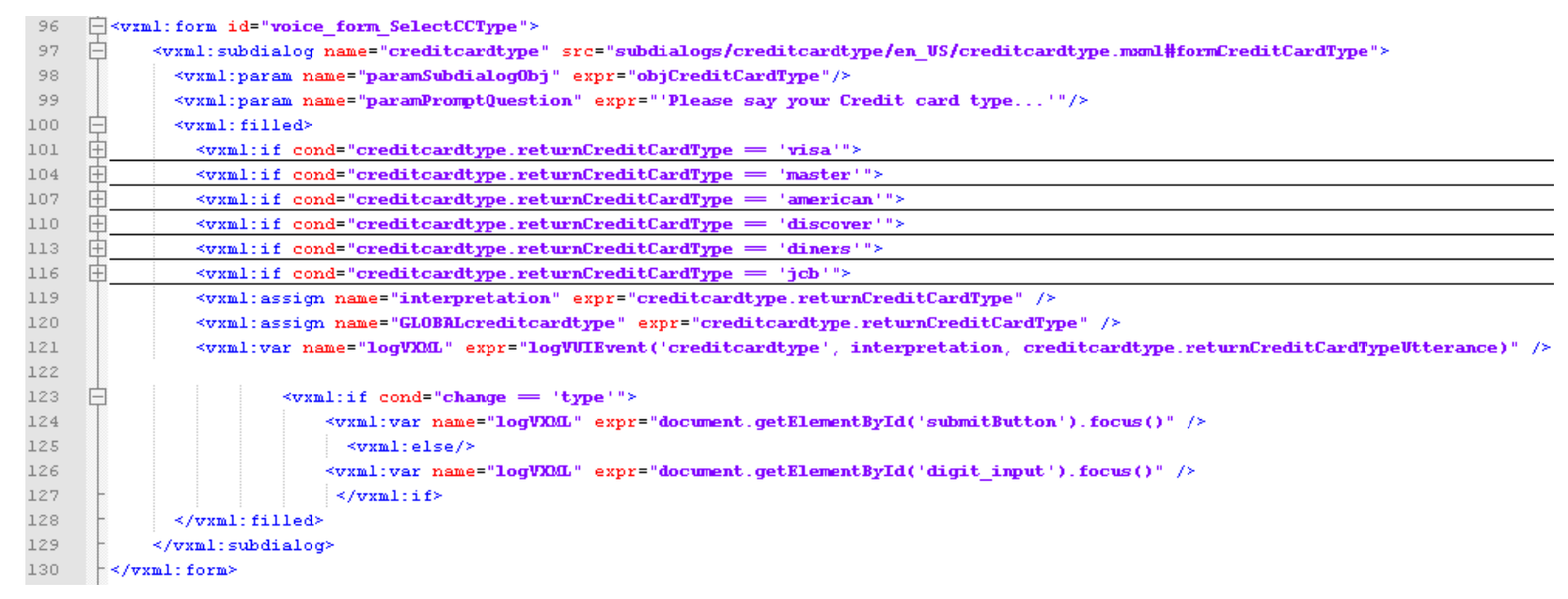

Figura 28 - Trecho de código de interface de voz gerado pelo MMWA-ae 


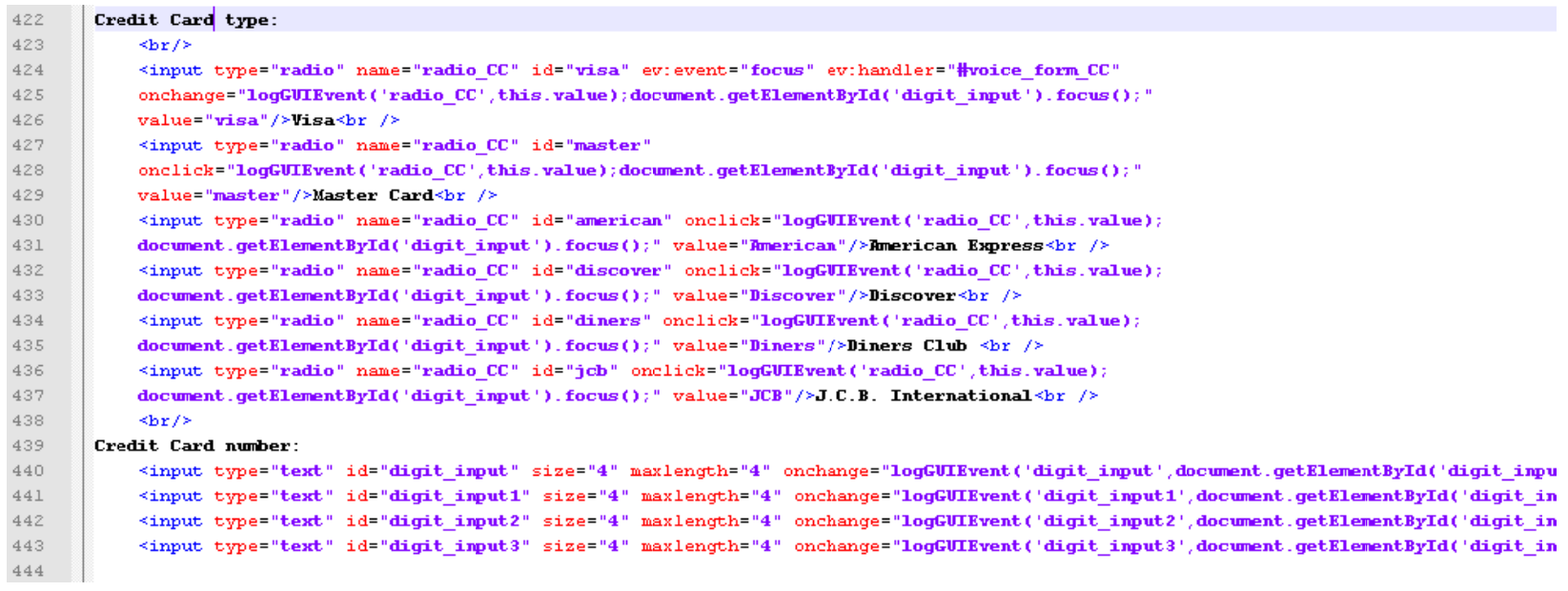

Figura 29 - Trecho de código de interface gráfica gerado pelo MMWA-ae

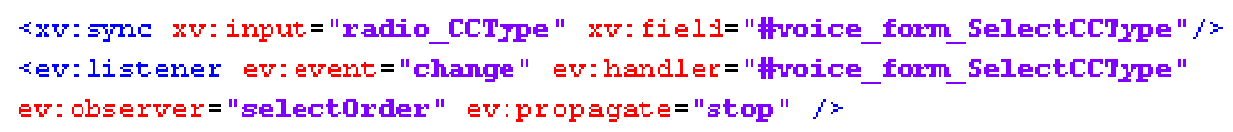

Figura 30 - Trecho de código de sincronização gerado pelo MMWA-ae

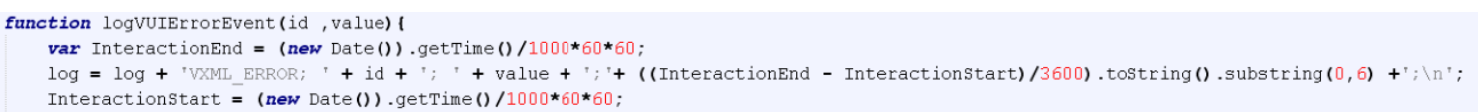

Figura 31 - Trecho da função que captura eventos de erro

Disponibilizando-se essa interface em um ambiente Web, que pode ser o mesmo que hospeda a MMWA-ae, é possível realizar testes remotos com usuários, avaliando-se assim a usabilidade da interface projetada na busca por problemas que possam ser corrigidos antes da entrega de uma versão final ao cliente.

Essa funcionalidade possibilita também a identificação de padrões de interação com determinado tipo de interface, por meio de análise de tabelas e gráficos gerados pelo MMWA-ae, bem como erros de projeto ou pontos de melhorias de usabilidade. Supre também as principais limitações dos testes com usuários que são a dificuldade de recrutamento de usuários, disponibilidade de tempo e recursos para realizar os testes, já que todo o processo é feito remotamente.

Na Figura 32, é apresentado o gráfico que mostra o tempo médio de interação na tarefa Choose Service (Escolher Serviço) nas interfaces gráfica (GUI) e de voz (VUI). É possível observar que a tarefa é completada mais rapidamente utilizando a interface de voz. 
Capítulo 5 - Ambiente de autoria para o projeto de interfaces multimodais Web (MMWA-ae)

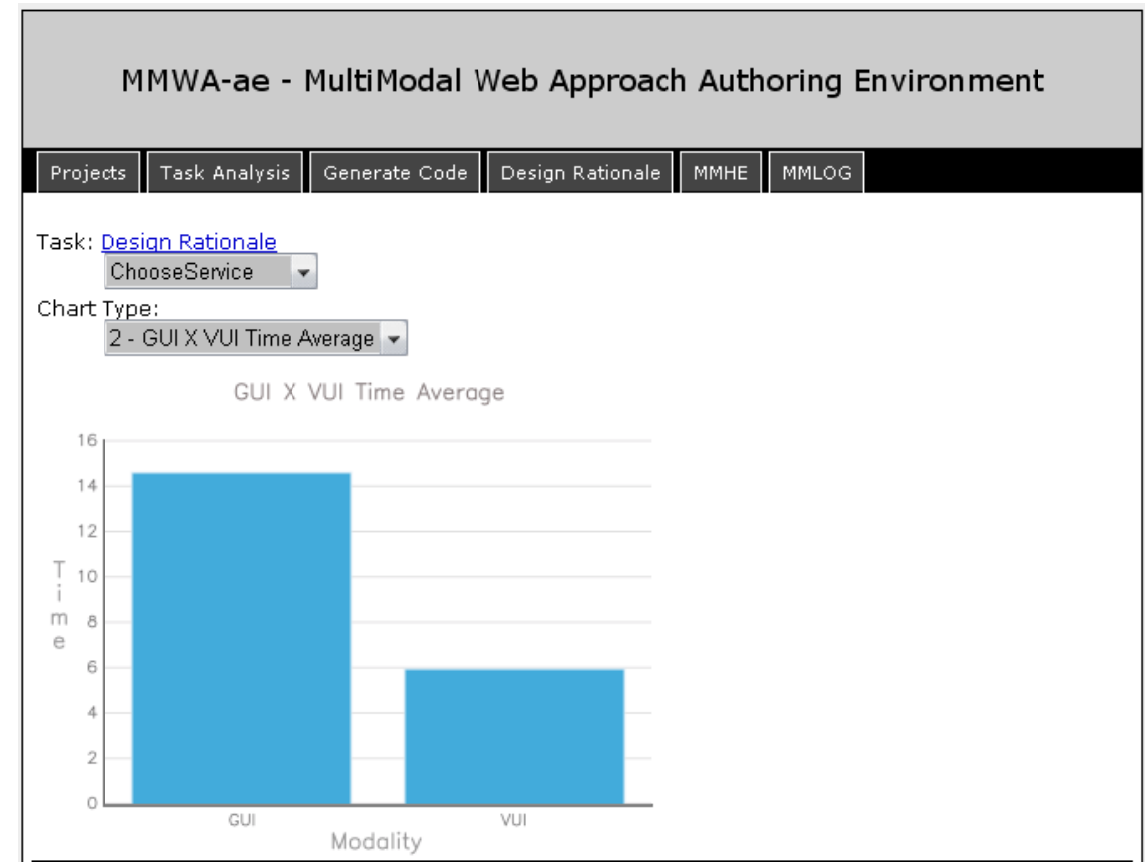

Figura 32 - Tempo médio de interação na tarefa ChooseService para GUI e VUI

Esse mecanismo de testes com usuários remotos requer alguns cuidados que são mencionados na MMWA, durante a execução do MMLOG, como: a criação do protocolo de testes explicando a proposta da avaliação de usabilidade (Figura 33 e Figura 34) e a descrição das tarefas ou cenário de uso a serem executados (Figura 35); a criação de um questionário de satisfação de uso; a existência de um canal direto com os realizadores dos testes, entre outros.

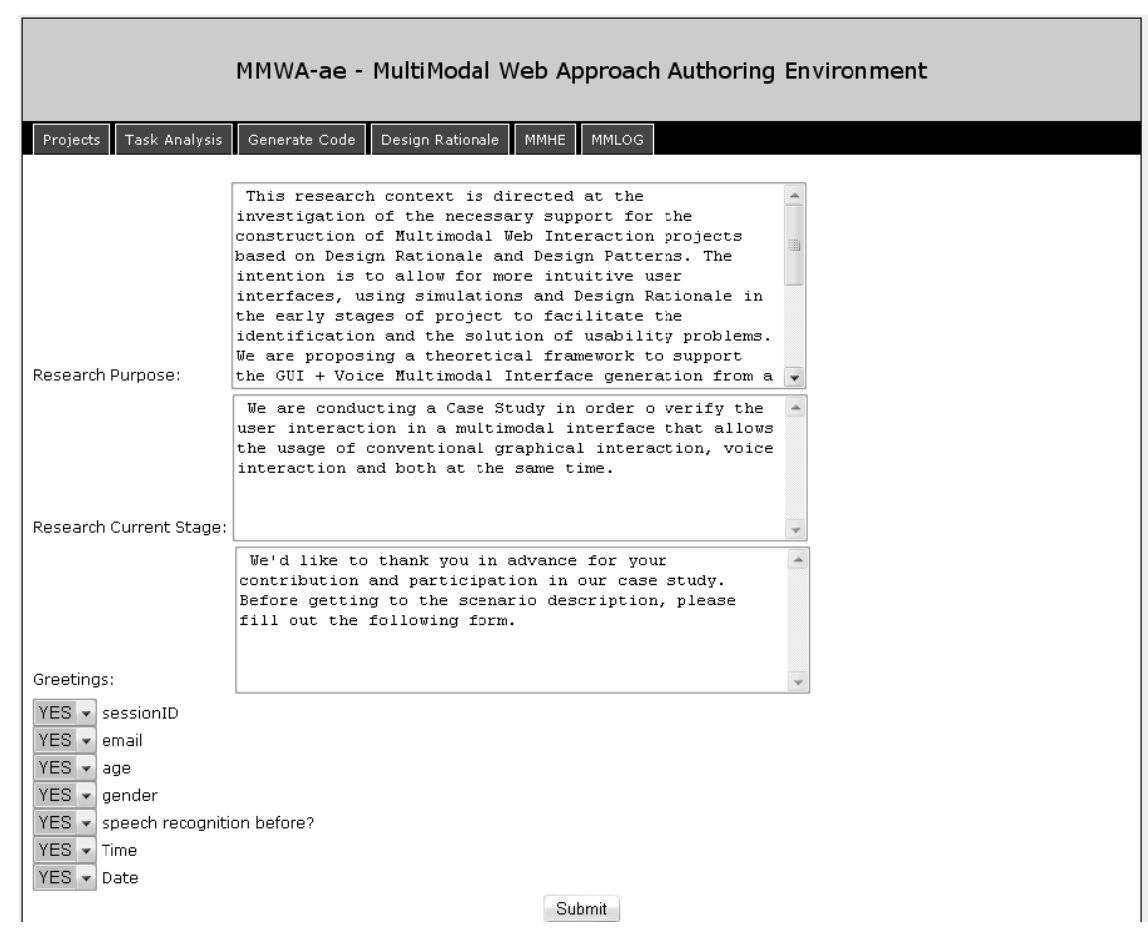

Figura 33 - MMLOG: Criação do protocolo de testes 


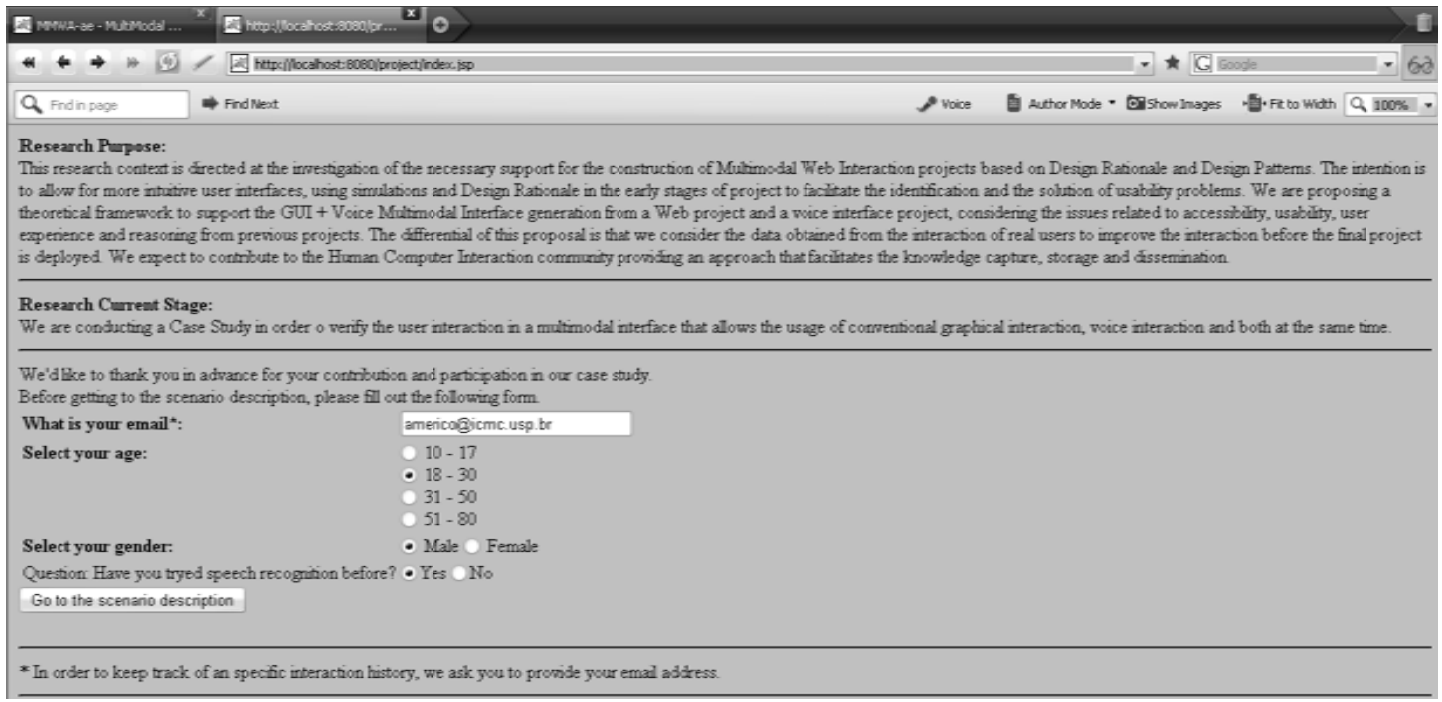

Figura 34 - Protocolo de testes em execução

Scenario Description:
Let's suppose that your name is John T Smith and you'd like to Make a Payment regarding your last phone bill.
For this purpose you will use the following fictitious Credit Card:
VISA
587430000722900
Tinu $06 / 12$
Name: John T Smith
Please take a note or print out the ficticious credit card. you'll be asked to provide this information in the following interface
Also, Make sure you have your sound card enabled and make sure gou have connected your mic and turned on the speakers
After that, please click on the following buttom, to start the multimodal interaction.
Go tothe scenario

Figura 35 - Cenário de uso criado pelo MMLOG

Por fim, a MMWA-ae também viabiliza a criação da documentação de projeto, pois durante a criação de cada uma das tarefas, o projetista é auxiliado por um wizard, cujas principais tarefas são: realizar a análise de soluções, obter os principais princípios de usabilidade para serem usados na geração do código, garantir que os itens que compõem a checklist disponível na MMWA sejam considerados na geração do protótipo.

\subsection{Desenvolvimento de interfaces multimodais orientado a modelos com o MMWA-ae}


Modelos são frequentemente usados no projeto e avaliação de sistemas interativos para ajudar na identificação e no entendimento de aspectos complexos do artefato que está sendo projetado (PATERNÒ, 2005). As abordagens baseadas em modelos fornecem uma descrição estruturada da informação disponível em aplicações multimodais de forma que ambientes inteligentes possam apresentar tal informação de acordo com o contexto de uso, podendo torná-las ubíquas e pervasivas.

A obtenção de informações sobre o uso das modalidades e a extração de recomendações para melhorar o projeto das interfaces multimodais geralmente é uma tarefa complexa, pois o número de modalidades utilizadas pode ser grande, as ferramentas e linguagens de programação existentes são complexas e não fornecem esse tipo de suporte. Nessa perspectiva, os métodos de modelagem têm sido utilizados para verificar a especificação dos sistemas, prever problemas de usabilidade, como os estados não alcançados, detectar conflitos de modalidades e sugerir eventos necessários para fusão e fissão de modalidades. Dessa forma, o projetista pode concentrar-se nos aspectos "semânticos" do projeto ao invés de preocupar-se com detalhes de implementação, plataforma, ferramentas, entre outros.

Paternò e Santos (2007) propuseram combinar a análise de tarefas realizada no Concurrent Task Trees Model com gravações em vídeo e a captura do movimento dos olhos (eye tracking) para melhor entender a interação.

Chang e Bourguet (2008) usam técnicas de especificação formal em combinação com os métodos tradicionais de avaliação de usabilidade para realizar uma verificação detalhada e a análise de usabilidade dos problemas relacionados aos eventos necessários para a fusão e fissão de modalidades.

O ambiente de autoria MMWA-ae tem como base um modelo cujo conceito central é a análise de tarefas. Para cada tarefa é possível armazenar informações sobre as escolhas do projetista com relação a: interfaces concretas e abstratas, modalidades, prompts, ações, opções, avaliação heurística e testes com usuários. A proposta da utilização do modelo de tarefas na fase de projeto é descrever as relações semânticas e temporais entre as tarefas identificadas.

Já na fase de testes, o mecanismo de avaliação de usabilidade definido na MMWA gera informações que são guardadas nesse modelo e em conjunto com o design rationale é uma fonte importante de sugestões para modificações das interfaces antes da finalização e entrega do produto final. 
Cada tarefa no modelo da MMWA é composta por oito elementos, mais precisamente:

1. Tarefa Abstrata (Abstract Task): representa a atividade de Identificação de Tarefas (IT) da MMWA;

2. Tarefa Concreta (Concrete Task): representa a atividade de Representação de Tarefas (RT) da MMWA;

3. Modalidade (Modality): representa a escolha de uma ou mais modalidades para serem usadas em uma tarefa, bem como as propriedades CARE correspondentes;

4. Prompts: representam as mensagens utilizadas para obter entrada do usuário em interfaces de voz, definidos na atividade de Análise de Soluções da MMWA;

5. Opções (Options): são utilizadas para definir a continuidade do diálogo fundamentado em decisões tomadas dentro de uma tarefa específica, definidos na atividade de Análise de Soluções da MMWA;

6. Ações (Actions): são definidas na atividade de Análise de Soluções da MMWA;

7. Dados obtidos com o mecanismo de avaliação heurística (MMHE): relativos à avaliação heurística, definidos na atividade de Avaliação de Usabilidade da MMWA;

8. Dados obtidos com o mecanismo de análise de logs (MMLOG): relativos aos $\log s$ que mostram a interação de usuários com as interfaces geradas, executando as tarefas definidas no protocolo dos Testes com Usuários, definidos na atividade de Avaliação de Usabilidade da MMWA.

Para ilustrar, os DR apresentados na Figura 36 estão relacionados com a mesma tarefa, "GetCarType", mas estão presentes em cinco elementos diferentes do modelo: Prompts, Actions, MMLOG, MMHE e Options. Pelo fato de que os problemas capturados neste exemplo são genéricos, um mesmo problema poderia ter sido extraído de uma outra aplicação no mesmo contexto, ou seja, de um projeto diferente com funcionalidades semelhantes.

Por esse motivo, foi desenvolvida uma funcionalidade que permite ao projetista agrupar todos os DR similares a um determinado componente do modelo de tarefas considerando todos os projetos existentes no banco de dados, tornando possível identificar 
padrões de projeto de uma maneira mais simplificada, como será explicado mais adiante no Capítulo 7 desta tese.

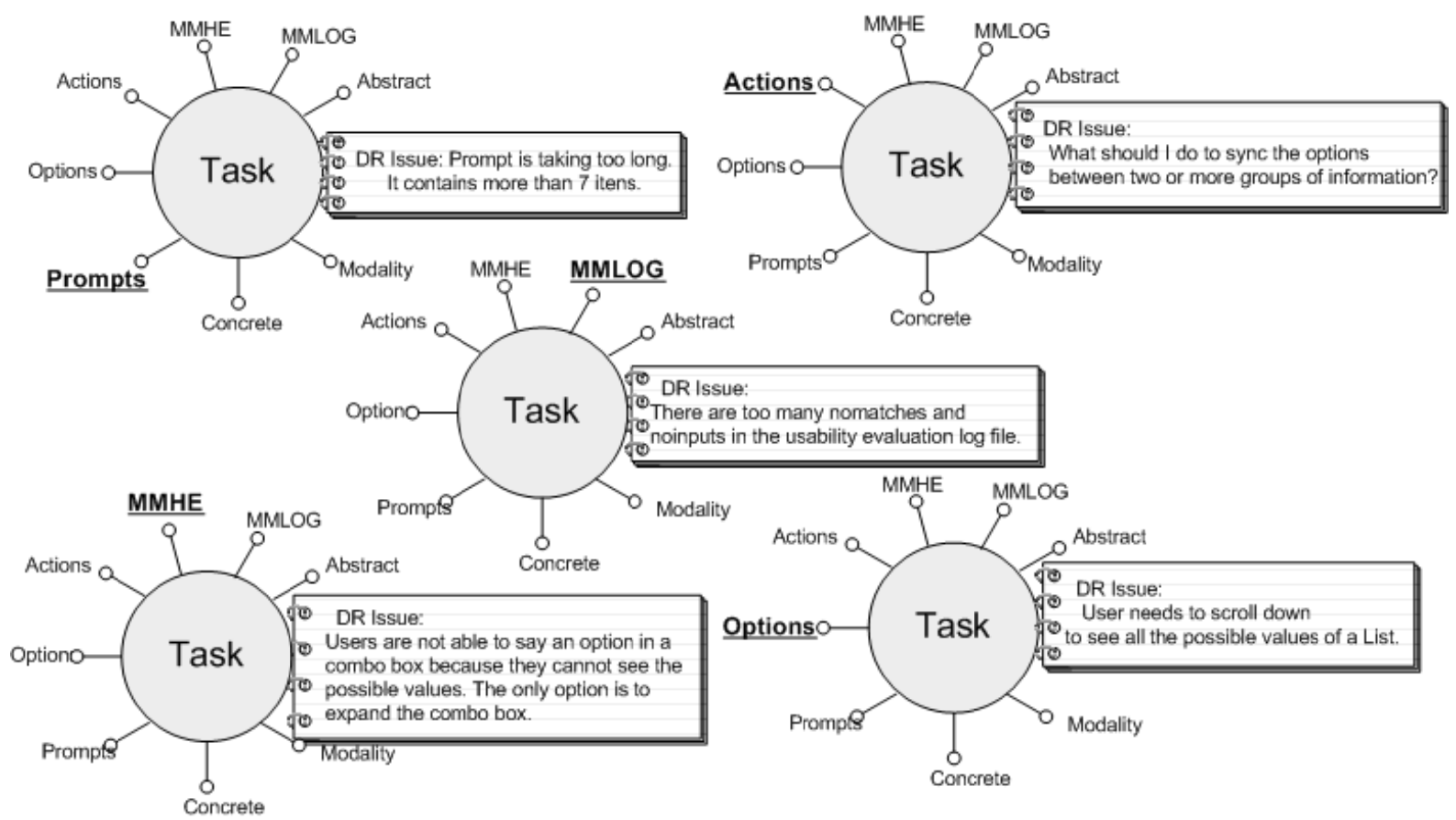

Figura 36 - Elementos do Modelo de Tarefas da MMWA e o DR recuperado

Como resultado, foi criado um mecanismo no MMWA-ae que permite ao projetista obter feedback de tratamento e correção de erros do modelo de tarefas diretamente na área de trabalho de projeto do ambiente de autoria, por meio dos dados obtidos com os logs gerados nos testes com usuários (MMLOG) e o DR coletado e armazenado durante todo o processo de projeto, desenvolvimento e testes.

Na Figura 37 pode-se observar que na tarefa "GetCarType" existe uma indicação sugerindo um padrão de projeto para corrigir um potencial problema de usabilidade.

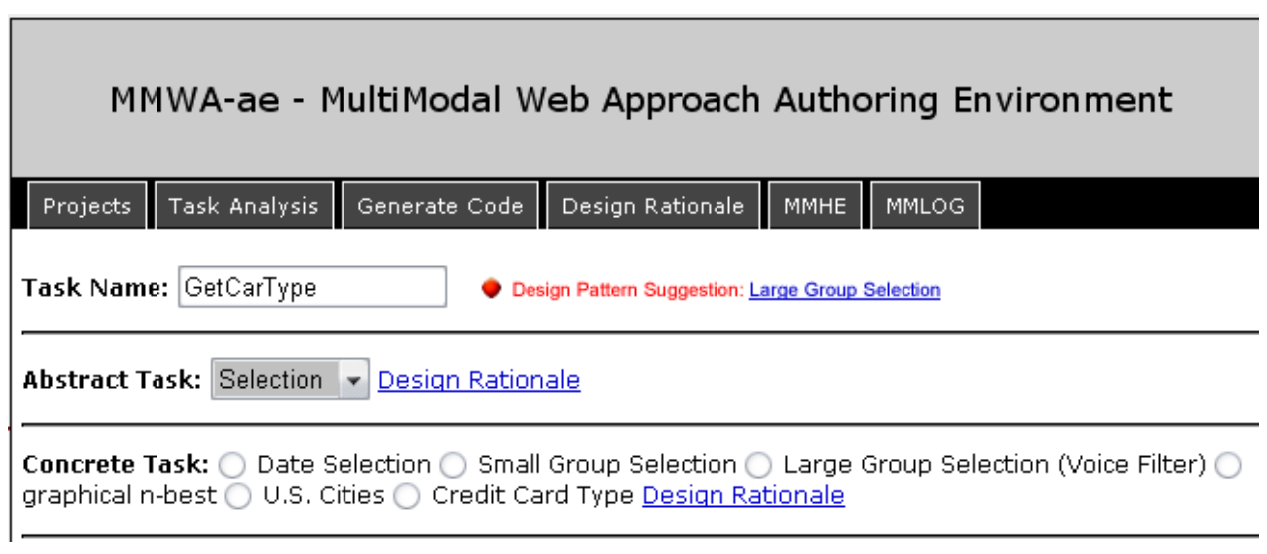

Figura 37 - Sugestão automática de padrão de projeto multimodal para corrigir um problema de usabilidade 
A identificação automática de um problema de usabilidade e o feedback fornecido pelo modelo de tarefas na área de trabalho onde a tarefa é projetada foi possível com o uso do MMLOG, nos testes com usuários remotos.

O MMLOG identificou erros do tipo nomatch na interface de voz, conforme pode ser observado na Figura 38 (linhas 71 e 77), e tentativas posteriores de interação com a interface gráfica correspondente (linha 80) para recuperar o erro ocorrido na interface de voz.

O MMWA-ae reconhece este potencial problema de usabilidade, salva a informação de sugestão no modelo de tarefas e então notifica o projetista que uma possível solução é utilizar o padrão de projeto multimodal Large Group Selection (Figura 37), para organizar o conjunto de possíveis escolhas/valores em uma ou mais tarefas, sincronizar essas tarefas e informar as possíveis opções do menu no prompt inicial, restringindo a fala do usuário.

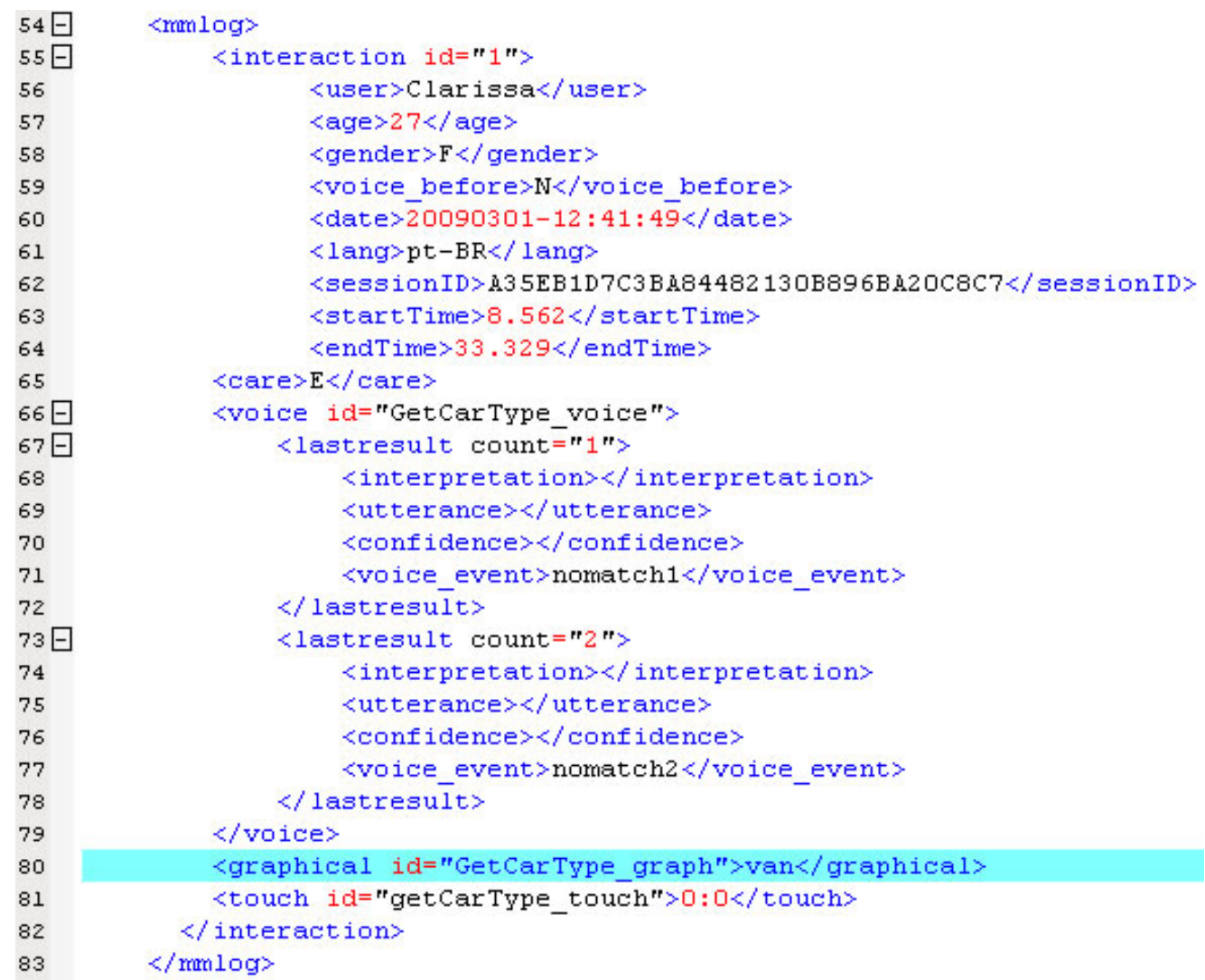

Figura 38 - Trecho do modelo que mostra dois erros na interface de voz e uma interação gráfica correta

O projetista pode também buscar por uma solução acessando o DR capturado em outros projetos na visão de Prompts do ambiente de autoria. Assim, caso o projetista opte por não utilizar o padrão de projeto sugerido, ele verifica que uma possível correção é informar no prompt inicial as possíveis opções do menu, limitando a fala do usuário. 
Com a implementação dessa sugestão os usuários experientes podem usar o mecanismo de barge-in das interfaces de voz (COHEN; GIANGOLA; BALOGH, 2004) para interromper a pergunta de saída do sistema, enquanto os novatos fornecem uma resposta mais restrita após ouvir toda a lista com as opções do menu.

Os outros problemas identificados nos componentes do modelo, que foram apresentados na Figura 36 também contribuíram para essa sugestão de padrão de projeto.

Outro exemplo de problema de usabilidade que é automaticamente identificado com o uso das informações presentes no modelo é o uso das propriedades CARE.

No projeto da interface para a criação de rotas entre dois pontos de interesses em um mapa, do terceiro estudo de caso, que será discutido no Capítulo 6, o projetista escolheu utilizar multimodalidade com as seguintes propriedades CARE: Redundância e Equivalência.

O gerador de código da MMWA-ae implementa a Redundância de tal forma que caso o usuário selecione e fale a mesma opção, a interface entenderá que são comandos redundantes, e não tentará sincronizar as modalidades duas vezes.

No caso da Equivalência, o software tomará a mesma decisão, relativa ao fluxo de informações, independente da modalidade escolhida pelo usuário para interagir com a interface.

No entanto, caso o usuário utilize um dispositivo que permita a interação por toque para apontar para o local e falar "Selecione esse", será necessário realizar uma fusão do significado "selecionar" com a coordenada correspondente ao toque realizado na tela do dispositivo.

Neste caso, a propriedade Complementaridade foi utilizada, mas como o projetista não previu o seu uso, a fusão não será realizada e poderá ocorrer uma confusão de interpretação caso o toque seja realizado antes do processamento da voz, pois não se saberá o que selecionar.

Comparando-se as informações das linhas 155 a 158 da Figura 39 com a linha 181 da Figura 40, ou seja, as propriedades selecionadas pelo projetista na MMWA com o resultado de uma interação de um usuário real é possível sugerir a inclusão da propriedade Complementaridade (C).

Neste exemplo, o erro foi identificado durante os testes com usuários e uma nova sugestão foi feita pelo modelo de tarefas, como pode ser observado no trecho de código grifado da Figura 39. A informação é então apresentada na área de trabalho do MMWA-ae, ajudando o projetista na realização de correções da interface multimodal. 


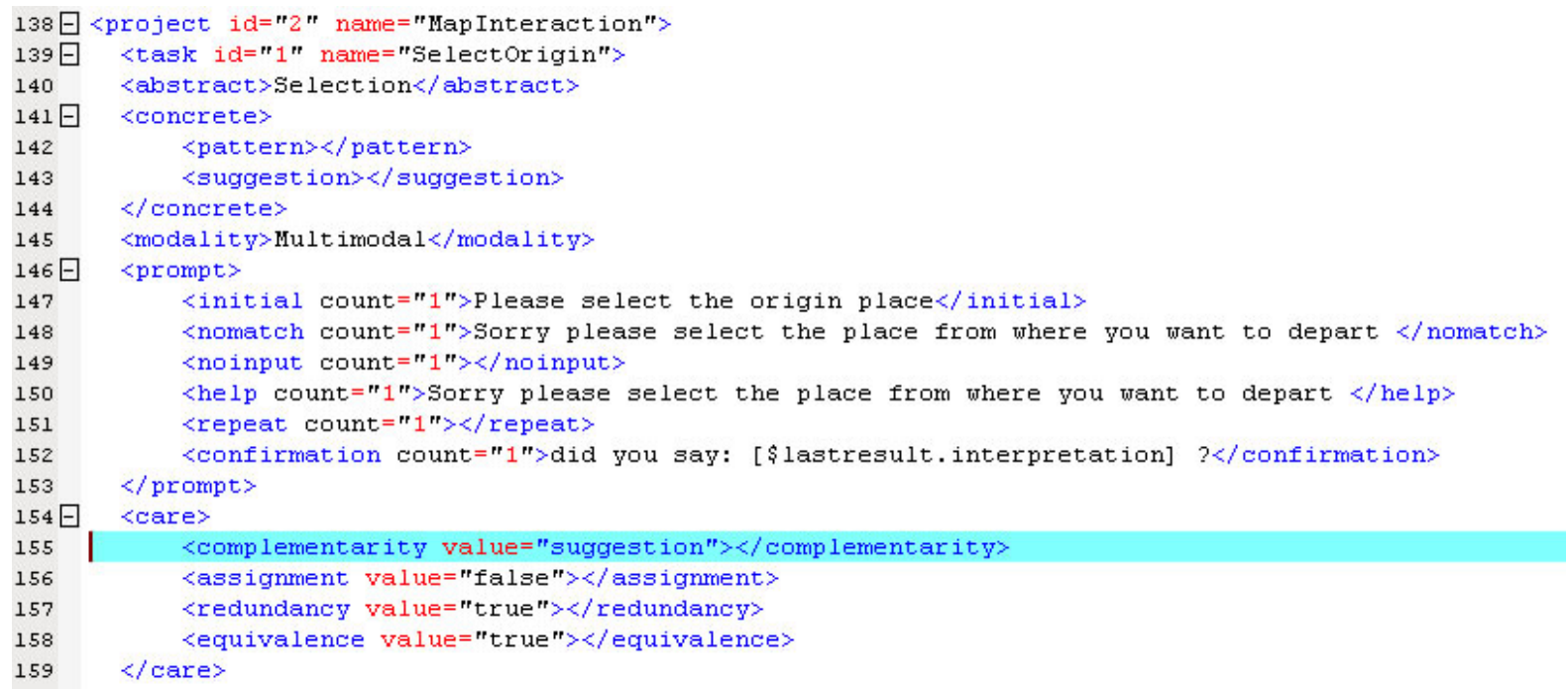

Figura 39 - Propriedades CARE escolhidas na fase de projeto

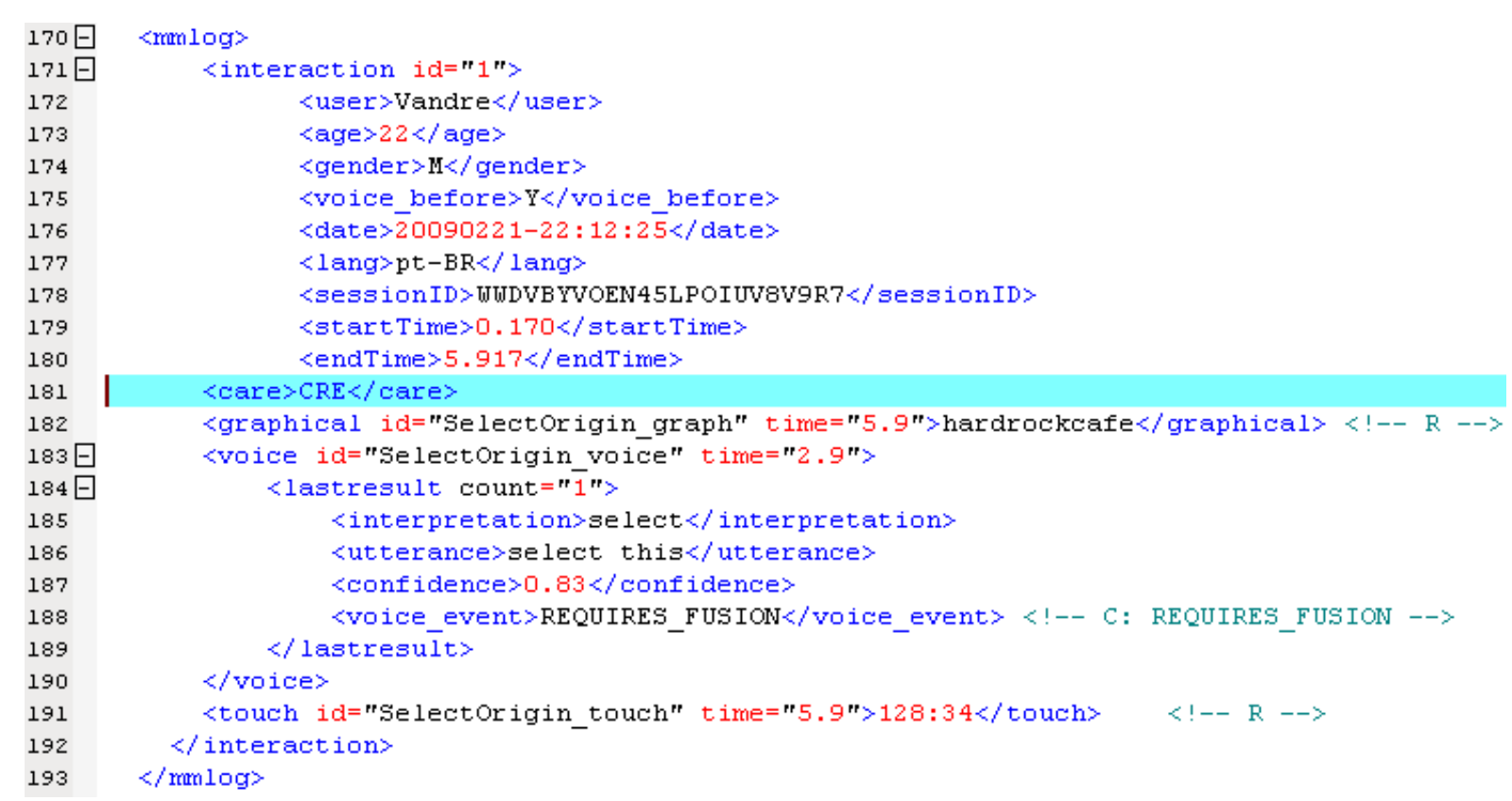

Figura 40 - Propriedades CARE utilizadas nos Testes com Usuários

Atualmente, os problemas e soluções encontrados no design rationale precisam ser manualmente incluídos no modelo. Como trabalho futuro pretende-se incluir um mecanismo automático para auxiliar na divulgação e na correção dos problemas encontrados no design rationale por meio da integração com o modelo de análise de tarefas da mesma forma que é feito para os testes com usuários. Essa tarefa é difícil, pois requer a interpretação do que foi concordado como solução entre os projetistas e a sua representação na linguagem do modelo, ou seja, em XML.

Outro ponto de destaque é o preenchimento do formulário do MMHE que também fornece informações importantes ao modelo de tarefas. 
Por exemplo, na Figura 41 é possível observar que por meio do relacionamento entre princípios, checklists, guidelines e heurísticas o avaliador identificou que existe um problema relacionado à caixa de seleção.

Em uma interface multimodal com reconhecimento de voz, o usuário não consegue visualizar todas as opções sem realizar uma interação de clique/toque na interface gráfica. Porém com a caixa de seleção aberta, o usuário pode compreender todas as expressões que ele pode dizer, a ordenação das opções também deve ser realizada.

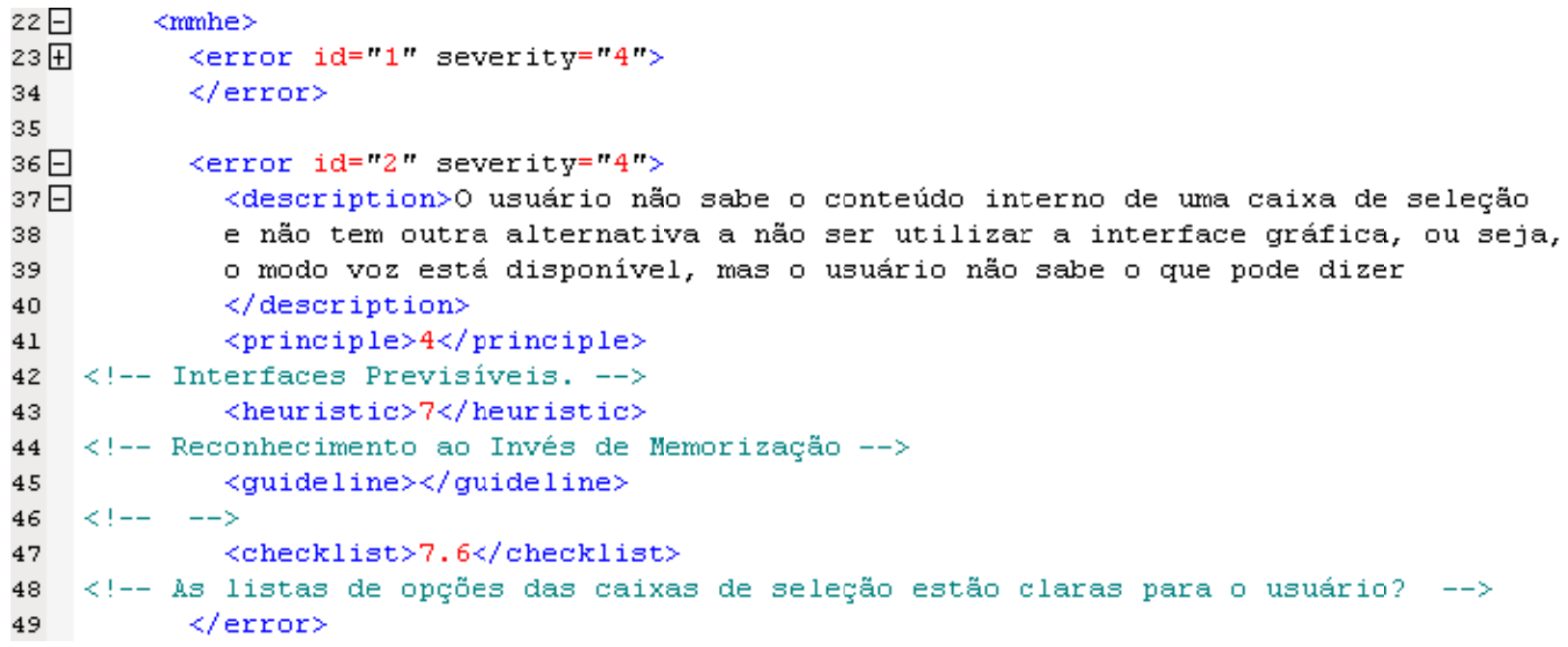

Figura 41 - Trecho do modelo que permite a identificação de um problema de usabilidade

Existe uma lógica no MMWA-ae que permite ao projetista visualizar que houve esse tipo de erro diretamente na visão de Ações (Task Actions) do ambiente de autoria e incluir uma chamada para uma função JavaScript que expande a caixa de seleção quando a tarefa é iniciada, conforme está destacado na Figura 42.

\section{Task Actions: Desian Rationale $\quad$ Checklist Suggestion: $\underline{\text { ComboBox Problem }}$}

\begin{tabular}{|c|c|c|c|c|}
\hline Element & Event & Action & Handler & \\
\hline SelectCCType_voice & OnReco & Xusync & SelectCCType_graph & \\
\hline SelectCCType_voice & OnReco & Task & SelectCCExpDate & \\
\hline SelectCCType_graph & OnFocus & XuSync & SelectCCType_voice & \\
\hline SelectCCType_graph $\boldsymbol{\nabla}$ & OnFocus $\quad$ - & JSFunction - & ExpandCombo(this) & $\begin{array}{l}\text { save } \\
\text { delete }\end{array}$ \\
\hline
\end{tabular}

Figura 42 - MMWA-ae sugerindo uma correção, fundamentado em um problema de usabilidade identificado pelo MMHE 


\subsection{Vantagens da ferramenta}

O gerador de código utilizado no MMWA-ae possui componentes de interface de multimodal que também permitem a criação de interfaces de voz convencionais. Os componentes disponíveis são: cartão de crédito, data, moeda, número de telefone, cidades/ estados americanos e código postal. A utilização de componentes é uma vantagem pois todo o raciocínio do projeto da interação envolvida no diálogo já está pronto, restando apenas configurar o componente para uma situação específica. O MMWA-ae também disponibiliza funções ECMAscript para verificação de dados de entrada, que estão embutidas nos componentes.

O sincronismo das interfaces é um problema recorrente nesta área de pesquisa e foi tratado nesta pesquisa com a proposta do padrão de projeto Modality Synchronization, apresentado no Apêndice A.

O MMWA-ae também pode ser estendido para utilizar novas modalidades, incluir novas linguagens de programação na base de geração de código, além de poder ser utilizado por outras ferramentas, pois são oferecidas interfaces de projeto, testes e organização de DR por meio da interface de comunicação com sistemas Wiki aos desenvolvedores de software.

Por último, o modelo proposto também é uma vantagem, pois além de promover a reutilização sistemática e gerenciável de conhecimento de projeto, considera informações úteis do mecanismo de avaliação de usabilidade, e fornece dicas de correção de problemas diretamente no ambiente de projeto, facilitando as tarefas da equipe de projeto.

\subsection{Limitações da ferramenta}

A personalização de layouts nas interfaces gráficas é uma limitação do MMWA-ae. O projetista precisa editar o código fonte caso queira incluir seus próprios estilos CSS. A inclusão de editores HTML pode melhorar a usabilidade da ferramenta, como foi sugerido nas entrevistas realizadas com os desenvolvedores.

A busca por DR pode ser melhorada com a criação de campos para permitir filtros com o objetivo de obter resultados mais expressivos e pontuais para o desenvolvedor.

Novas formas de gravação de DR podem ser incluídas, por exemplo, gravação de vídeo ou incluir uma funcionalidade que permita registrar e-mail ou mensagens instantâneas trocadas entre as equipes de projeto diretamente na Wiki (ETO; TAKABAYASHI; MASUI, 2005).

Como trabalho futuro pretende-se incluir no MMWA-ae um mecanismo que permita a fusão de interfaces gráficas previamente existentes com interfaces de voz. O projetista ficaria 
responsável por importar a interface gráfica no MMWA-ae e esta se encarregaria de obter as tarefas abstratas, selecionar possíveis representações concretas diferentes das existentes na interface atual, criar a interface de voz correspondente, sincronizar as interfaces e incluir o mecanismo de avaliação de usabilidade.

Dessa forma, o projetista despenderia menos esforço na verificação das checklists e da utilização das melhores práticas existentes e compiladas na forma de DR durante o processo de especificação e criação de interfaces multimodais Web.

\subsection{Considerações finais}

Neste capítulo foram discutidos os conceitos relacionados ao ambiente de autoria MMWA-ae, tais como a sua arquitetura, seus módulos e as tecnologias utilizadas, bem como as suas vantagens e limitações.

No capítulo seguinte serão apresentados os estudos de caso realizados com a abordagem e o ambiente de autoria propostos nesta tese. 



\section{Capítulo 6. Estudos de caso}

\subsection{Considerações iniciais}

Nos capítulos anteriores foram discutidos os conceitos e os trabalhos científicos que serviram como base para o desenvolvimento da abordagem e do ambiente de autoria propostos nesta tese.

Neste capítulo são apresentados os estudos de caso realizados para comprovar algumas hipóteses e testar as idéias propostas na prática.

Na Seção 6.2 apresenta-se a metodologia que foi utilizada para o desenvolvimento deste trabalho. Na Seção 6.3 é feita uma descrição rápida dos estudos de caso e nas Seções 6.4, 6.5 e 6.6 são discutidos os seus detalhes. Finalmente, na Seção 6.7, são apresentadas as considerações finais deste capítulo.

\subsection{Metodologia}

O desenvolvimento deste trabalho, visando alcançar os objetivos propostos, foi conduzido, principalmente, por meio de procedimentos de pesquisa bibliográfica e de estudos de caso.

A pesquisa bibliográfica foi realizada desde o início de 2007 e é uma atividade que foi mantida constante durante o desenvolvimento do doutorado. Conforme recomendado em (WAZLAWICK, 2009), inicialmente foram pesquisados surveys sobre o assunto com o objetivo de obter o estado da arte da área de pesquisa e sua evolução histórica. Na sequência, os trabalhos clássicos e livros foram pesquisados e posteriormente foram pesquisadas fontes mais recentes sobre o assunto da tese.

Os principais temas de pesquisa que contribuíram para este trabalho e foram alvo da pesquisa bibliográfica são: interação humano-computador, interação multimodal, interação por voz, interfaces adaptativas, geração automática de interfaces, integração entre projeto de interface Web e projeto de interface de voz, acessibilidade no projeto Web sendo alcançada com o auxílio do projeto da interface de voz, usabilidade e métodos para avaliação de usabilidade em sistemas multimodais, design rationale e padrões de projeto.

Foram analisados os trabalhos relacionados reportados em livros e nos principais periódicos e conferências especializados na área de interação multimodal disponíveis em bibliotecas digitais da ACM, IEEE, Springer, e outras fontes de artigos científicos da área. 
Após as etapas de estudos e pesquisa bibliográfica, foi iniciado o trabalho de estudos de caso.

O método de estudo de caso é um método específico de pesquisa de campo qualitativo. Estudos de campo são investigações de fenômenos à medida que ocorrem, sem qualquer interferência significativa do pesquisador. Seu objetivo é compreender o evento em estudo e ao mesmo tempo desenvolver teorias mais genéricas a respeito dos aspectos característicos do fenômeno observado (FIDEL, 1992).

Segundo (HARTLEY, 1994), o estudo de caso consiste em uma investigação detalhada de uma ou mais organizações, ou grupos dentro de uma organização, com vistas a prover uma análise do contexto e dos processos envolvidos no fenômeno em estudo. $\mathrm{O}$ fenômeno não está isolado de seu contexto (como nas pesquisas de laboratório), já que o interesse do pesquisador é justamente essa relação entre o fenômeno e seu contexto.

Para Trauth et al. (2000) uma das principais características do estudo de caso é que a pesquisa é dirigida aos estágios de exploração, classificação e desenvolvimento de hipóteses do processo de construção do conhecimento. Também relatam que, geralmente, uma ou mais entidades (pessoa, grupo, organização) são examinadas.

De acordo com Hamel et al. (1993) o estudo de caso emprega vários métodos como entrevistas, observação participante e estudos de campo. Bell (1989) concorda, mas ressalta que embora os métodos de coleta de dados mais comuns em um estudo de caso sejam a observação e as entrevistas, nenhum método pode ser descartado. Os métodos de coleta de informações são escolhidos de acordo com a tarefa a ser cumprida.

O trabalho de Hartley (1994) reforça a ligação entre os estudos de caso e métodos qualitativos: "Dentro da ampla estratégia de pesquisa do estudo de caso, pode-se empregar vários métodos - qualitativos, quantitativos ou ambos - embora a ênfase seja empregar métodos qualitativos, em função dos tipos de problemas que geralmente são associados e melhor compreendidos por meio de estudos de caso. Os métodos mais utilizados são: observação, observação participante e entrevistas (semi-estruturadas ou não estruturadas). Pode-se utilizar também questionários para complementar os dados obtidos a partir de observação e entrevistas".

Mais recentemente, Nielsen (2004) defendeu o uso de estudos qualitativos com a justificativa de que esses são menos frágeis e com menor possibilidade de falhar em pontos fracos da metodologia empregada. Segundo esse autor, mesmo que o estudo não seja perfeito, é possível obter bons resultados utilizando-se métodos qualitativos que se fundamentam em usuários e na observação de seus comportamentos. 
Assim, o método de pesquisa adotado neste trabalho foi o estudo de caso, utilizandose métodos qualitativos embasados em observação, entrevistas e questionários. Esses estudos foram realizados com a finalidade de observar o comportamento dos desenvolvedores de aplicações de diferentes domínios, com diferentes níveis de habilidade na utilização da abordagem proposta, possibilitando o refinamento da mesma e uma análise da contribuição da proposta no processo de projeto de interfaces multimodais.

\subsection{Visão geral dos estudos de caso}

Para realizar tanto a proposta como a avaliação da abordagem e do ambiente de autoria foram conduzidos três estudos de caso, nos quais foram desenvolvidos 5 projetos de aplicações multimodais, apresentados no Quadro 7.

Quadro 7 - Descrição geral dos estudos de caso

\begin{tabular}{|c|c|c|c|}
\hline & EC1 & EC2 & EC3 \\
\hline Hipóteses & $\begin{array}{ll}\text {-DR coletado ajuda na } & \text { na } \\
\text { solução de problemas de } \\
\text { outros grupos } \\
\text { desenvolvedores. } \\
\text { ·Wiki sistematiza } \\
\text { processo de captura e } \\
\text { utilização de DR. } \\
\text { Problemas de usabilidade } \\
\text { diminuem quando se usa } \\
\text { DR coletado previamente. }\end{array}$ & 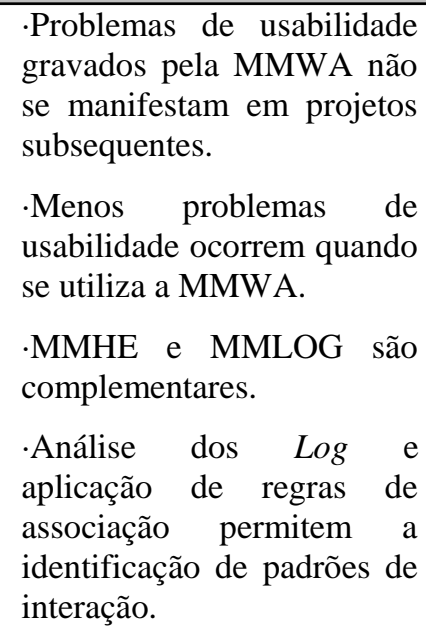 & $\begin{array}{l}\text { ·MMWA-ae aumenta a taxa de } \\
\text { reutilização de código. } \\
\text {-Geração de código e protótipo de } \\
\text { interface são mais rápidos com o } \\
\text { MMWA-ae. } \\
\text {-Menos problemas de usabilidade } \\
\text { ocorrem com o uso do MMWA- } \\
\text { ae. }\end{array}$ \\
\hline Foco & $\begin{array}{l}\text { Coleta, armazenamento } \mathrm{e} \\
\text { recuperação de DR. }\end{array}$ & MMWA & MMWA-ae \\
\hline Projetos & $\begin{array}{l}\text { Sistema de aluguel de } \\
\text { carros. }\end{array}$ & $\begin{array}{l}\text { Sistema de pagamentos de } \\
\text { conta de telefone, sistema de } \\
\text { navegação em mapas. }\end{array}$ & $\begin{array}{l}\text { Sistema de aluguel de carros, } \\
\text { sistema para apresentação de } \\
\text { palestras }\end{array}$ \\
\hline Equipe & 24 pessoas & 4 pessoas & 2 pessoas \\
\hline Tecnologia & $\begin{array}{l}\text { X+V, Java, JSP, Hibernate, } \\
\text { PostgreeSQL, JSGF }\end{array}$ & $\begin{array}{l}\text { X+V, JSP, ECMAScript, } \\
\text { JSGF, ActionScript, Adobe } \\
\text { Flex SDK, Google Maps } \\
\text { API }\end{array}$ & $\begin{array}{l}\text { X+V, Java, Hibernate, JSP, } \\
\text { PostgreeSQL, JSGF }\end{array}$ \\
\hline
\end{tabular}

Primeiramente, foi realizado um estudo de caso (EC1) para coletar DR utilizando a primeira versão da MMWA. Após a finalização deste estudo de caso, modificações foram feitas na MMWA e um novo estudo de caso (EC2) foi planejado e executado com o objetivo de continuar os testes com a MMWA especificamente na atividade de avaliação de 
usabilidade. Novas sugestões de melhorias foram adotadas, a ferramenta de autoria MMWAae foi desenvolvida e o último estudo de caso (EC3) foi executado. As sugestões do último estudo de caso foram incorporadas na MMWA-ae e apresentadas nesta tese no Capítulo 5.

$\mathrm{Na}$ linha do tempo apresentada na Figura 43 é possível verificar as atividades que foram desenvolvidas nesta pesquisa até a escrita desta tese. A figura está dividida em 3 grandes ciclos: pesquisa bibliográfica, abordagem e ferramenta. Cada ciclo é composto por atividades que representam um conjunto de resultados alcançados e marcam um período de tempo e em cada período de tempo foram publicados artigos que divulgam os resultados de cada atividade. Essas publicações são apresentadas no Capítulo 8.

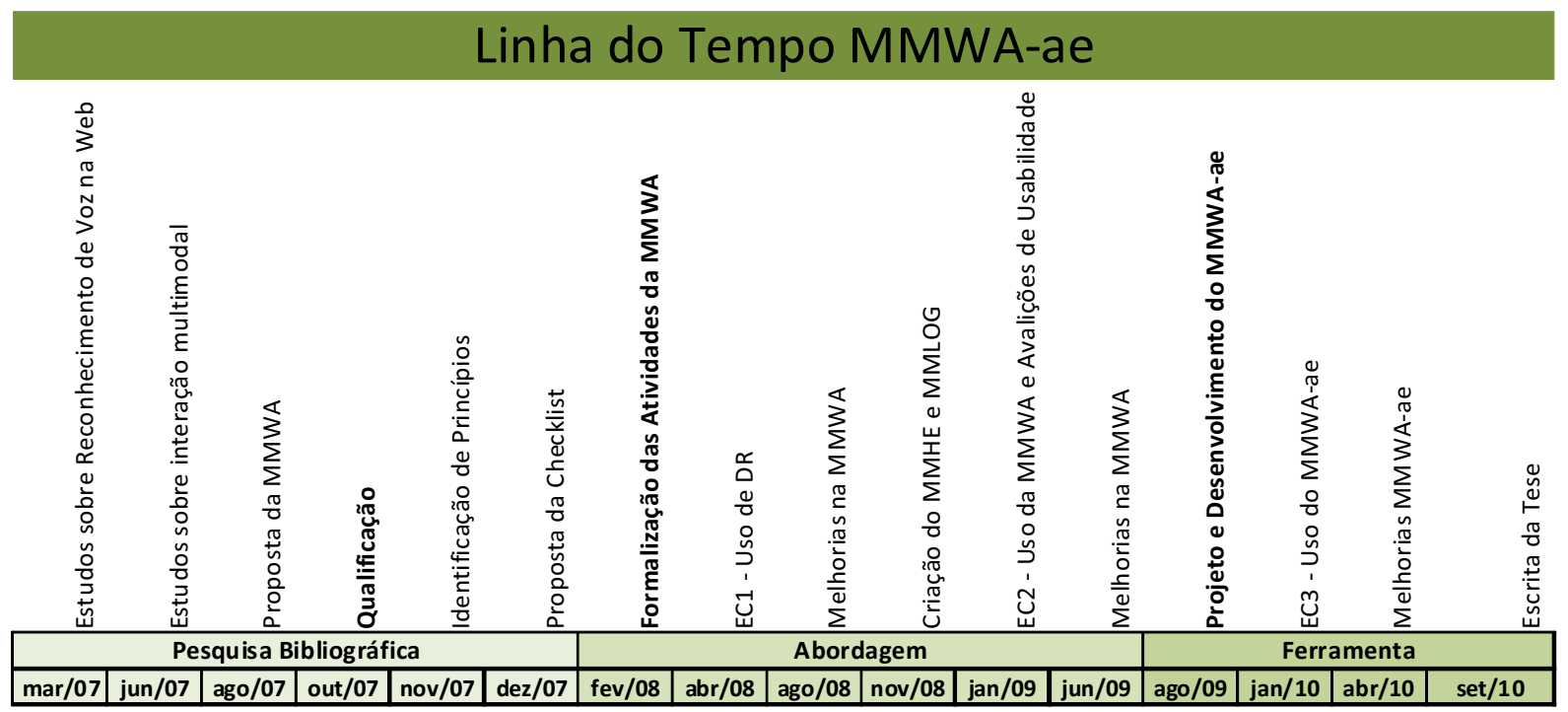

Figura 43 - Linha do tempo das atividades realizadas no doutorado

A seguir são detalhados os estudos de caso realizados.

\subsection{Estudo de caso 1}

O estudo de caso 1 (EC1) foi proposto com o objetivo de validar as atividades que compõem o ciclo da MMWA e, para cada atividade, testar as técnicas propostas e estabelecer um workflow para sua utilização em conjunto com a coleta, armazenamento e a recuperação de DR (um exemplo de DR pode ser encontrado no Quadro 6 no Capítulo 4).

O EC1 possibilitou o projeto de ferramentas para apoiar as atividades da MMWA, bem como a coleta, a organização, a estruturação, o armazenamento e a recuperação de DR, por meio da proposta de um mecanismo de utilização de DR com o uso de sistemas Wiki. Além disso, foi possível testar o uso dos princípios e guidelines e suas relações com as heurísticas em projetos reais, nas avaliações de usabilidade. Permitiu também que fosse 
identificada uma forma de se pensar na formalização de padrões de projeto de acordo com o DR armazenado.

\subsubsection{Definição do estudo de caso}

\section{Objeto de estudo:}

O objeto de estudo foi o monitoramento do projetista de interfaces multimodais Web utilizando a abordagem proposta para a coleta de requisitos, especificação de tarefas, criação de protótipos, identificando problemas recorrentes de projeto da interação multimodal, propondo e discutindo soluções e registrando todo o raciocínio envolvido na forma de DR.

\section{Motivações:}

- A tecnologia multimodal é emergente e só foram encontrados na literatura, métodos e técnicas que facilitam a geração de código com pouco ou nenhum apoio para testes de usabilidade e gravação de conhecimento de projeto para uso futuro.

- O DR pode ser entendido como uma organização do conhecimento fundamentado na experiência do projetista. Padrões de projeto são fundamentados em decisões de projeto bem estabelecidas. A falta de experiência no projeto de sistemas e interação multimodal e o fato de não haver corpo de DR suficiente de aplicações multimodais de sucesso de onde padrões pudessem ser identificados, justificam o propósito deste estudo de caso.

- Padrões de projeto já estão estabelecidos para o projeto de interfaces gráficas Web e acredita-se que a estrutura formal dos padrões fazem deles uma ferramenta importante para modelar novos tipos de interação, como a multimodal.

\subsubsection{Planejamento do estudo de caso}

\section{Proposta:}

Utilização da MMWA para o projeto de interfaces multimodais. Registro de DR de maneira semi automatizada utilizando templates e namespaces na DokuWiki. Monitorar os problemas sendo resolvidos por projetistas e desenvolvedores experientes em projeto Web, que receberam treinamento na tecnologia multimodal, e que atuam em um projeto colaborativo utilizando a MMWA. 


\section{Foco qualitativo:}

Eficácia na coleta, armazenamento e recuperação de DR e eficácia no uso da MMWA para o projeto de interfaces multimodais.

\section{Perspectiva:}

O estudo de caso foi realizado sob o ponto de vista de estudantes que possuem experiência no desenvolvimento de interfaces Web, no curso de pós-graduação na disciplina Hipermídia do ICMC-USP, durante o primeiro semestre de 2008.

\section{Hipóteses e Resultados Preliminares:}

A seguir serão apresentadas as principais hipóteses que guiaram a condução do EC1 e os resultados preliminares obtidos. Uma análise mais detalhada dos resultados será apresentada no Capítulo 7.

Hipótese 1: o DR serve como uma ferramenta de comunicação entre os projetistas.

Resultado: em alguns casos houve a verificação de que a solução adotada por um grupo está presente no projeto de um outro grupo e a verificação da comunicação de participantes de diferentes grupos em um mesmo DR. O DR pode ser usado como ferramenta para diversas finalidades como será apresentado na Seção 7.7.

Hipótese 2: a MMWA promove o uso de DR.

Resultado: as questões mais genéricas do DR gravado foram incluídas na checklist para que o projetista tenha uma ferramenta que auxilie na verificação de seu projeto. Quando o projetista não utiliza um DR já gravado para resolver um problema nas fases de projeto ou desenvolvimento, ele acaba sendo utilizado nas avaliações de usabilidade por meio do uso das checklists. Dessa forma, o problema é corrigido antes da entrega do produto para os testes com usuários. No Quadro 8 apresenta-se um resumo quantitativo sobre a utilização de DR no EC1. Pode-se observar o número de questões capturadas, bem como o número de argumentos e posições registradas e o número de consultas realizadas pelos projetistas.

Quadro 8 - Uso de design rationale no estudo de caso 1

\begin{tabular}{|l|c|}
\cline { 2 - 2 } \multicolumn{1}{c|}{} & EC1 \\
\hline Questões de DR capturadas & 36 \\
\hline Argumentos e Posições registradas & 472 \\
\hline Consultas ao DR registrado & 120 \\
\hline
\end{tabular}


Hipótese 3: o DR registrado permite a identificação de padrões de projeto.

Resultado: para a identificação de padrões de projeto é necessário que a mesma solução seja usada em diferentes projetos. Foi observado que questões similares com soluções iguais foram utilizadas entre os diferentes grupos (diferentes projetos em um mesmo contexto). Pretende-se observar se esse comportamento é mantido nos próximos estudos de caso e apresentar os resultados no Capítulo 7.

\subsubsection{Execução do estudo de caso}

O estudo de caso foi realizado, em ambiente acadêmico, por 24 projetistas e desenvolvedores divididos em 6 grupos, fora da sala de aula e sem supervisão, portanto, os desenvolvedores tiveram a liberdade de determinar seus próprios cronogramas para cumprir as atividades propostas. Um projeto multimodal envolvendo aluguel de carros utilizando interfaces de voz e gráfica foi desenvolvido por todos os grupos.

A especificação de requisitos foi fornecida aos participantes e foi solicitado que eles realizassem as atividades de desenvolvimento de software e documentação de DR, após um treinamento de aproximadamente 8 horas sobre desenvolvimento de interfaces multimodais Web utilizando $\mathrm{X}+\mathrm{V}$, design rationale e sobre os modelos e as ferramentas utilizadas.

Todos os grupos tinham acesso ao DR coletado por todos os projetistas e as discussões podiam ocorrer entre os grupos. Isso permitiu identificar que houve cooperação entre os projetistas de diferentes grupos e apesar do sistema ser o mesmo, diferentes problemas surgiam e à medida que os problemas eram corrigidos em um projeto, a solução era disponibilizada para os outros grupos. A realização de avaliações heurísticas no final do EC permitiu que a checklist desenvolvida e o DR coletado pelos grupos facilitassem a identificação de problemas de usabilidade nas interfaces projetadas. Dessa forma, se um grupo não tivesse consultado algum DR coletado por outro grupo, o erro poderia ser identificado na fase de avaliação de usabilidade e corrigido no próximo ciclo da abordagem.

Os artefatos gerados pelos grupos foram utilizados para estabelecer um conjunto de requisitos para o projeto da ferramenta de autoria, que seria criada mais adiante nesta pesquisa. Os artefatos gerados por um dos grupos de desenvolvimento pode ser encontrado no Apêndice E. 
A tarefa de desenvolvimento foi considerada cumprida quando os alunos demonstraram o software sendo executado em um ambiente Web e discutiram sobre o DR coletado e as avaliações de usabilidade realizadas.

\subsection{Estudo de Caso 2}

O segundo estudo de caso (EC2) foi realizado no ambiente acadêmico e teve como contribuição a publicação de uma monografia de conclusão de curso de graduação em Bacharelado em Ciência da Computação do ICMC-USP, e a orientação de um aluno de graduação voluntário.

O EC2 foi proposto com o objetivo de validar as atividades que compõem o ciclo da MMWA após as modificações decorrentes dos problemas encontrados no EC1, ou seja, fundamentado na experiência do estudo de caso anterior, a abordagem foi modificada para melhor atender aos requisitos dos projetistas e desenvolvedores de aplicações multimodais Web.

O EC2 também possibilitou a verificação dos mecanismos de avaliação de usabilidade propostos na quinta atividade da MMWA, bem como a especificação de componentes de software multimodal para reutilização de software. Componentes multimodais foram criados, por exemplo: diálogos, gramáticas, código para sincronismo e fusão de interfaces, entre outros.

Foi possível também testar o uso do DR coletado anteriormente além de permitir novas coletas para aumentar a base de dados de DR. No final do EC2 a ferramenta de autoria MMWA-ae foi desenvolvida para servir como um framework para as atividades da MMWA.

\subsubsection{Definição do estudo de caso}

\section{Objeto de estudo:}

O objeto de estudo é composto pelo conjunto de projetistas e testadores de interfaces multimodais Web utilizando a abordagem proposta para a coleta de requisitos, especificação de tarefas, criação de protótipos, utilização de DR armazenado, criação de novos DR e aplicação de mecanismos automáticos de avaliação de usabilidade em interfaces multimodais.

\section{Motivações:}

- Responder perguntas como: Qual comportamento dos usuários que navegam na Web com interfaces multimodais? Como eles interagem com as aplicações? Quais 
suas necessidades? Quais são suas dificuldades? Como elas identificam elementos funcionais de uma aplicação?

- Utilizar tecnologias para enriquecer a forma de interação para as diferentes necessidades e preferências em interfaces multimodais.

- Testar os dois mecanismos para avaliação de usabilidade propostos na MMWA, analisar os $\log s$ gerados automaticamente e identificar pontos falhos na interface que podem ser melhorados em ciclos de desenvolvimento subseqüentes.

\subsubsection{Planejamento do estudo de caso}

\section{Proposta:}

Duas aplicações Web foram desenvolvidas. A primeira, uma aplicação utilizando a API do Google Maps com o objetivo de utilizar tecnologias para enriquecer a forma de interação, define rotas entre dois locais especificados pelo usuário e possibilita seguir o passo a passo através de vias públicas para se chegar de um local ao outro. A segunda, uma aplicação para o pagamento de contas em uma empresa de telefonia fictícia. Criou-se também um mecanismo automático de avaliação de usabilidade como forma de identificar padrões de interação dos usuários.

\section{Foco qualitativo:}

Eficiência na reutilização de código fonte previamente criado e eficácia na avaliação de usabilidade com base no DR armazenado.

\section{Perspectiva:}

O estudo de caso foi realizado sob o ponto de vista de estudantes que possuem experiência no desenvolvimento de interfaces Web, em projetos de conclusão de curso de graduação do ICMC-USP, durante o primeiro semestre de 2009.

\section{Hipóteses e Resultados Preliminares:}

A seguir são apresentadas as principais hipóteses que guiaram a condução do EC2 e os resultados preliminares obtidos. Uma análise mais detalhada dos resultados será apresentada no Capítulo 7.

Hipótese 1: os problemas de usabilidade gravados no DR da MMWA não se repetem e o número de problemas de usabilidade encontrado é menor do que no EC anterior. 
Resultado: as estratégias de prevenção e correção de erros e de confirmação de entradas do usuário que apresentam características identificadas no DR foram utilizadas no estudo de caso. Foi possível identificar que os problemas presentes no EC1 não ocorreram no EC2 e no EC3.

Hipótese 2: métodos empíricos e analíticos de avaliação de usabilidade são complementares.

Resultado: apenas parte dos problemas que realmente ocorrem nos testes com usuários é identificado durante a avaliação heurística e os problemas repetidos decrescem à medida que os estudos de caso são realizados como pode ser observado no Quadro 9.

Quadro 9 - Dados gerais das avaliações de usabilidade nos Estudos de Caso executados com a MMWA

\begin{tabular}{|l|c|c|c|c|c|}
\cline { 3 - 6 } \multicolumn{1}{c|}{} & EC1 & \multicolumn{2}{c|}{ EC2 } & \multicolumn{2}{c|}{ EC3 } \\
\cline { 3 - 7 } \multicolumn{1}{c|}{} & Projeto1 & Projeto2 & Projeto3 & Projeto4 & Projeto5 \\
\hline $\begin{array}{l}\text { Problemas encontrados com o } \\
\text { MMHE }\end{array}$ & 12 & 8 & 7 & 3 & 0 \\
\hline $\begin{array}{l}\text { Problemas encontrados com o } \\
\text { MMLOG }\end{array}$ & 9 & 9 & 7 & 3 & 3 \\
\hline $\begin{array}{l}\text { Total de problemas (não } \\
\text { repetidos) }\end{array}$ & 17 & 14 & 13 & 6 & 3 \\
\hline
\end{tabular}

Hipótese 3: análise de log permite identificar padrões de interação.

Resultado: a análise de $\log s$ permite identificar as propriedades CARE utilizadas na interação em conjunto com o uso de regras de associação permite identificar comportamentos dos usuários.

\subsubsection{Execução do estudo de caso}

O estudo de caso foi realizado por quatro pessoas que desenvolveram duas aplicações multimodais: um sistema multimodal para pagamento de contas de telefone e um sistema de localização de rotas em um mapa.

A equipe de projeto foi responsável pela utilização da MMWA para todas as atividades de projeto, desde a especificação de requisitos até o desenvolvimento de software, documentação de DR e testes de usabilidade.

A equipe trabalhou em todas as atividades do ciclo da MMWA, desde a obtenção de requisitos, o estudo de tecnologias e o desenvolvimento de aplicações ricas para Web, a 
criação do protocolo de avaliação de usabilidade e a avaliação dos $\log s$ gerados nas interações remotas.

O sistema de localização de rotas em um mapa, desenvolvido nesse estudo de caso, é um exemplo interessante de aplicação da MMWA, pois mostra a aplicação da abordagem em um projeto com tecnologias diferentes das empregadas nos outros estudos de caso.

Para essa aplicação, algumas restrições, documentadas nas atividades de projeto da MMWA foram inicialmente identificadas e documentadas na forma de DR. Uma lista com o resumo do DR coletado foi construída para auxiliar na prevenção de erros e na modelagem da aplicação, identificar as limitações da aplicação e para realizar a avaliação de usabilidade. A seguir são apresentados os trechos de DR coletados no EC2 que foram organizados na forma de problemas e soluções para facilitar a formalização de padrões de projeto:

- Gramática usada no reconhecimento de voz:

- Problema: a entrada de voz é reconhecida através de uma gramática prédefinida que aceita ou não o comando de voz. Esse reconhecimento por meio de uma gramática impõe algumas restrições quanto à quantidade de palavras reconhecidas. Isso pode vir a ser um problema para aplicações que possuem um número grande de possíveis entradas, como é o caso dessa aplicação.

- Solução: a solução é especificar um domínio restrito de palavras para interação por voz fundamentado nos dados obtidos no Modelo Comportamental e no modelo de tarefas. Assim, haverá diminuição da quantidade de palavras aceitas pela gramática, mas será possível realizar os testes de usabilidade. Ainda é possível subdividir os tokens em grupos, seguindo alguma lógica e através desses grupos, aplicar filtros que especificam cada vez mais para um subconjunto menor de escolhas.

- Transições entre as tarefas:

- Problema: as transições por interações de voz podem ser controladas por meio de métodos de sincronização, mas as transições podem ser feitas utilizando o teclado ou mouse. Nada impede do usuário acessar tarefas finais sem ter passado por tarefas intermediárias.

- Solução: para esse problema, mensagens podem ser exibidas para alertar o usuário sobre a necessidade de realizar tarefas anteriores que não foram realizadas. 
- Escolha dos locais de partida e chegada:

- Problema: as escolhas dos locais de partida e chegada pode ser feita de duas formas: por opções pré-estabelecidas ou digitadas (livres). Na primeira tem-se um ambiente mais controlado, mas as opções para o usuário são limitadas. Na segunda tem-se maior liberdade de escolha, mas o geolocalizador do Google Maps ${ }^{11}$ pode não prever tal entrada.

- Solução: a solução é dar a liberdade de escolha para o usuário e caso o geolocalizador não preveja a entrada uma mensagem de alerta é emitida e um exemplo é fornecido, como estratégia de recuperação de erro.

- API JavaScript Google Maps:

- Problema: a API JavaScript Google Maps possui métodos que não são mais previstos no XHTML, como o document.write(). Isso impossibilita o desenvolvimento utilizando esta API.

- Solução: a implementação do mapa deverá ser feita utilizando a API ActionScript Google Maps.

- API ActionScript Google Maps:

o Problema: o mapa sendo desenvolvido em arquitetura Flex impossibilita a adição de um manipulador VXML no mapa. Ou seja, caso o usuário desvie o foco para o mapa nenhuma interface de voz estará disponível.

○ Solução: este problema é resolvido capturando o evento de foco dentro da aplicação Flex e retornando o foco para algum elemento XHTML que tenha um manipulador da interface de voz.

As tarefas identificadas na segunda atividade da MMWA (IT) foram fundamentadas a partir dos cenários criados da primeira atividade (MCI). Para representar as tarefas e as possíveis transições entre elas foi utilizado o Diagrama de Transição de Estados, que indica a tarefa inicial, tarefas intermediárias e a tarefa final e os eventos que ocorrem entre essas tarefas.

Os elementos gráficos que representam as tarefas (RT) foram dispostos em uma seqüência lógica, seguindo as transições previstas. A Figura 44 ilustra o posicionamento adotado.

${ }^{11}$ http://maps.google.com.br/ 


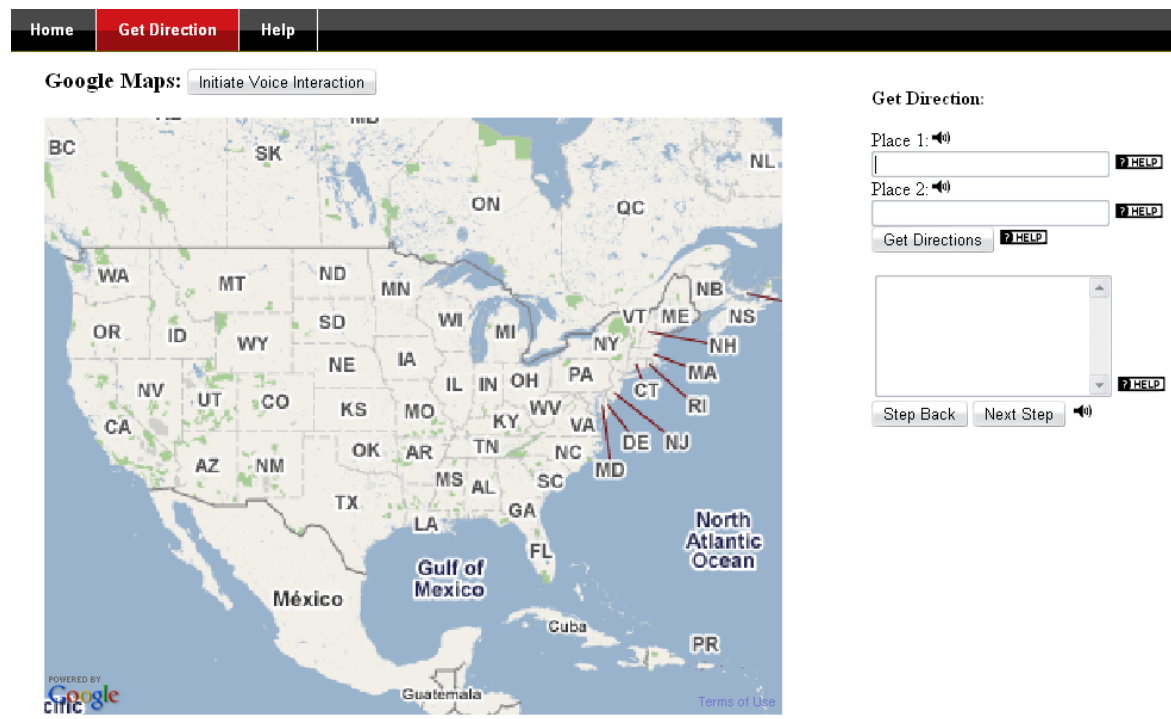

Figura 44 - Disposição dos elementos gráficos no sistema de localização de rotas.

Em uma aplicação multimodal é importante que as interfaces estejam sincronizadas. A modelagem da comunicação e o sincronismo das interfaces constituem a quarta atividade (AS) na qual também se desenvolve o protótipo. O diagrama da Figura 45 representa a comunicação entre as camadas da aplicação para realização do sincronismo entre as modalidades.

$\mathrm{O}$ sincronismo em aplicações $\mathrm{X}+\mathrm{V}$ pode ser feito de duas formas. Umas delas é a utilização do elemento <sync> que a própria linguagem oferece. Esta forma é mais simples e organizada de se implementar o sincronismo. Outra forma é a utilização de métodos JavaScript que podem ser chamados por elementos $\mathrm{X}+\mathrm{V}$. Essa opção apresenta um grau de liberdade maior, permitindo que qualquer elemento XHTML seja modificado através do DOM, além da possibilidade de se chamar outros métodos no sincronismo. Nesta aplicação utilizou-se esta última opção pelo fato do mapa ter que ser sincronizado de acordo com a tarefa.

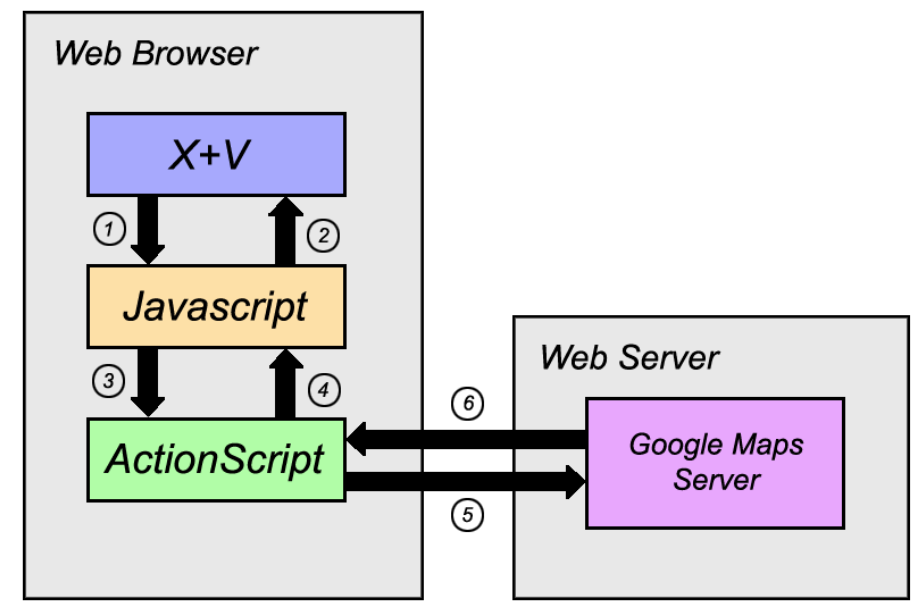

Figura 45 - Diagrama das camadas da aplicação de localização de rotas do EC2. 
A sincronização ocorre da seguinte forma: quando uma interação por voz é efetuada, chama-se um método JavaScript (1) que sincroniza a entrada de voz com o elemento gráfico XHTML (2) associado ao formulário de voz. Ou seja, a interpretação do comando de voz aceita pela gramática do formulário VoiceXML é passada para o elemento gráfico que representa a tarefa. O método JavaScript responsável por sincronizar as interfaces de uma tarefa também sincroniza o mapa chamando um método ActionScript (3). Este por sua vez, se comunica com o servidor Google Maps (5), através dos métodos fornecidos na API ActionScript do Google Maps e recebe as informações necessárias (6) para renderizar o mapa de acordo com a tarefa que está sendo realizada. Essas informações recebidas (6) podem ser repassadas, (4) e (2), para que a informação seja sincronizada com as interfaces de voz e gráfica. Por exemplo, na realização da tarefa de obter os passos necessários para se chegar do local de partida até o de chegada, a informação do passo é retornada pelo servidor Google Maps (6), essa informação é repassada para as interfaces $\mathrm{X}+\mathrm{V}$ (4 e 2), para que a informação seja ouvida e observada graficamente. Assim, quando o usuário interage com a aplicação na realização de uma tarefa, tanto as interfaces criadas na linguagem $\mathrm{X}+\mathrm{V}$ quanto o mapa, acessado pela interface da API ActionScript do Google Maps, são sincronizados.

Na Figura 46 estão os elementos existentes nas interfaces multimodais para cada uma das tarefas da aplicação e a associação de cada elemento visual XHTML com o respectivo formulário de voz VXML que se mantem sincronizado. A ativação do formulário de voz está associada ao foco do elemento XHTML que representa a tarefa. Por exemplo, quando o elemento place1Input é focado, o formulário VoiceXML que representa a tarefa (choose_place_1) é ativado. O mesmo ocorre para place2Input com choose_place_2, confirmButton com confirm_chooses e stepText com step_commands. Os elementos backStepButton e nextStepButton não possuem formulários de VoiceXML associados a eles diretamente mas estão indiretamente sincronizados com step_commands através de stepText.

A descrição dos elementos XHTML mencionados anteriormente é apresentada a seguir:

- place1Input: representa a interface gráfica da tarefa (T1) de escolher o local de partida;

- place2Input: representa a interface gráfica da tarefa (T2) de escolher o local de chegada; 
- confirmButton: representa a interface gráfica da tarefa (T3) de confirmar os locais escolhidos;

- stepText: representa a interface gráfica (T4) onde a informação do passo será descrito;

- backStepButton: representa a interface gráfica (T4) onde o usuário optará por voltar para o passo anterior;

- nextStepButton: representa a interface gráfica (T4) onde o usuário optará por seguir para o próximo passo.

A descrição dos elementos VoiceXML mencionados anteriormente é apresentada a seguir:

- choose_place_1: representa o formulário de voz para a tarefa (T1) de escolher o local de partida;

- choose_place_2: representa o formulário de voz para a tarefa (T2) de escolher o local de chegada;

- confirm_chooses: representa o formulário de voz para a tarefa (T3) de confirmar os locais de partida e chegada;

- step_commands: representa o formulário de voz para as tarefas (T4) de seguir para o próximo passo ou voltar para o passo anterior;

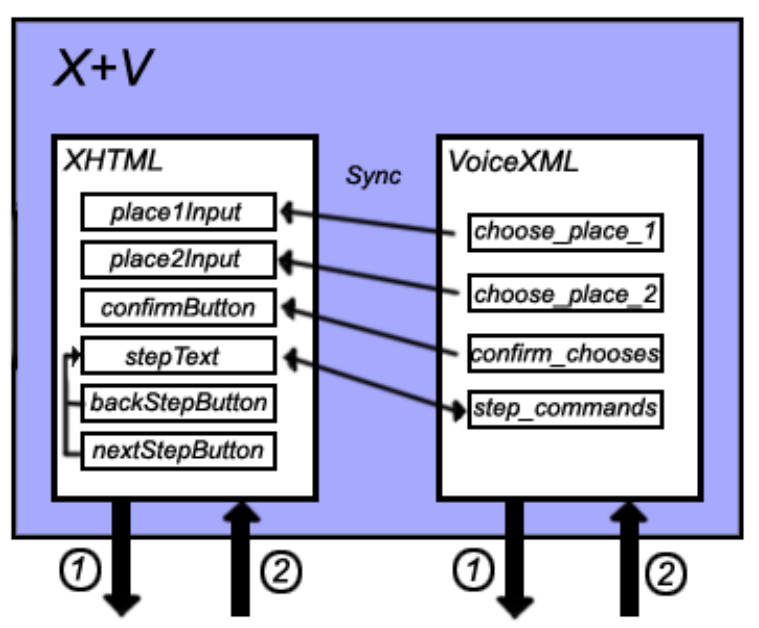

Figura 46 - Elementos X+V da aplicação de localização de rotas do EC2.

Na Figura 47 são apresentados os métodos usados para sincronizar os elementos das interfaces da Figura 46 e o mapa. O mapa é sincronizado por meio de métodos JavaScript, apresentados na sequência, que chamam métodos ActionScript da aplicação Flex responsável por renderizar o mapa. 
- setPlace1(): sincroniza place1Input, choose_place_1 e o mapa através do método goTo(str,zoom);

- setPlace2(): sincroniza place2Input, choose_place_2 e o mapa através do método goTo(str,zoom);

- confirmDirection(): sincroniza confirmButton, confirm_chooses e o mapa através do método goFromTo(from,to);

- writeNextStep(): sincroniza stepText, nextStepButton, step_commands e o mapa através do método nextStep();

- writeBackStep(): sincroniza stepText, nextStepButton, step_commands.e o mapa através do método backStep();

- goTo(str,zoom): chama o método da aplicação Flex que renderiza o mapa exibindo o local e o zoom especificado;

- goFromTo(from,to): chama o método da aplicação Flex que renderiza o mapa exibindo a rota do local de partida para o local de chegada;

- nextStep(): chama o método da aplicação Flex que obtém o próximo passo;

- backStep(): chama o método da aplicação Flex que obtém o passo anterior.

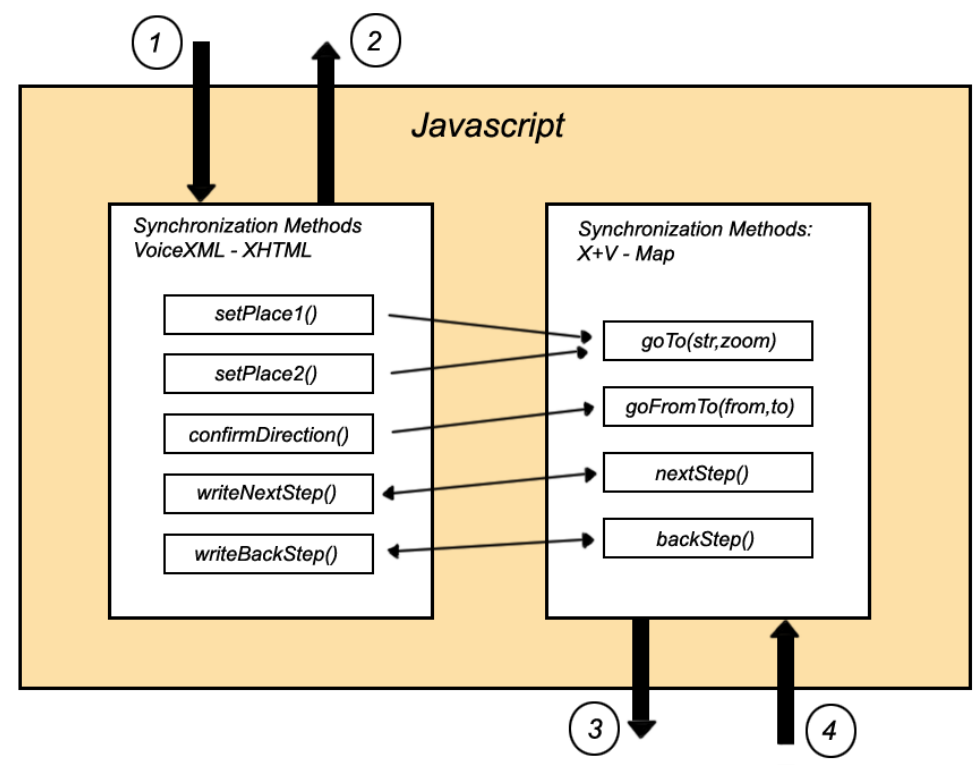

Figura 47 - Métodos JavaScript da aplicação de localização de rotas do EC2.

Na Figura 48 estão representados os métodos ActionScript da aplicação Flex utilizados para renderização do mapa. Esses métodos, descritos a seguir, são retirados da aplicação $\mathrm{X}+\mathrm{V}$ de forma que possam ser chamados com código JavaScript.

- goTo(p1,zoom): renderiza o mapa exibindo o local e o zoom especificado; 
- goFromTo(from,to): renderiza o mapa exibindo a rota do local de partida para o local de chegada;

- nextStep(): obtém o próximo passo;

- backStep(): obtém o passo anterior.

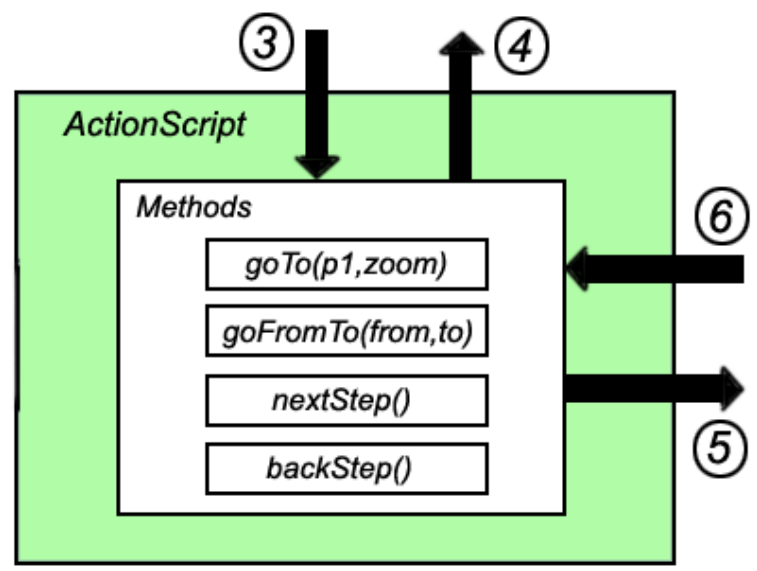

Figura 48 - Métodos ActionScript da aplicação de localização de rotas do EC2.

No Quadro 10 é apresentada, para cada tarefa, a associação das interfaces gráfica e de voz com os respectivos métodos sincronizadores.

Quadro 10 - Sincronização das interfaces do sistema de localização de rotas do EC2.

\begin{tabular}{|l|l|l|l|l|l|l|}
\hline Tarefa & $\begin{array}{l}\text { Elemento } \\
\text { Gráfico }\end{array}$ & $\begin{array}{l}\text { Formulár } \\
\text { io de Voz }\end{array}$ & Ativação & $\begin{array}{l}\text { Método } \\
\text { ActionScript } \\
\text { Renderizador } \\
\text { do Mapa }\end{array}$ & $\begin{array}{l}\text { Metodos } \\
\text { JavaScript de } \\
\text { Interface com } \\
\text { a Aplicação } \\
\text { Flex }\end{array}$ & $\begin{array}{l}\text { Método } \\
\text { JavaScript } \\
\text { Sincronizador }\end{array}$ \\
\hline $\begin{array}{l}\text { Selecionar } \\
\text { lugar de } \\
\text { partida }\end{array}$ & place1Input & $\begin{array}{l}\text { choose_pl } \\
\text { ace_1 }\end{array}$ & $\begin{array}{l}\text { Foco no } \\
\text { elemento } \\
\text { gráfico }\end{array}$ & goTo(p1,zoom) & goTo(p1,zoom) & setPlace1() \\
\hline $\begin{array}{l}\text { Selecionar } \\
\text { lugarde } \\
\text { chegada }\end{array}$ & place2Input & $\begin{array}{l}\text { chosse_pla } \\
\text { ce_2 }\end{array}$ & $\begin{array}{l}\text { Foco no } \\
\text { elemento } \\
\text { gráfico }\end{array}$ & goTo(p2,zoom) & goTo(p2,zoom) & setPlace2() \\
\hline $\begin{array}{l}\text { Confirmar } \\
\text { lugar de } \\
\text { partida e } \\
\text { chagada }\end{array}$ & $\begin{array}{l}\text { confirmBut } \\
\text { ton }\end{array}$ & $\begin{array}{l}\text { confirm_c } \\
\text { hooses }\end{array}$ & $\begin{array}{l}\text { Foco no } \\
\text { elemento } \\
\text { gráfico }\end{array}$ & $\begin{array}{l}\text { goFromTo(p1,p } \\
\text { 2) }\end{array}$ & $\begin{array}{l}\text { goFromTo(p1,p } \\
2)\end{array}$ & $\begin{array}{l}\text { confirmDirectio } \\
\text { n() }\end{array}$ \\
\hline $\begin{array}{l}\text { Obter } \\
\text { Passos }\end{array}$ & stepText & $\begin{array}{l}\text { step_com } \\
\text { mands }\end{array}$ & $\begin{array}{l}\text { Foco no } \\
\text { elemento } \\
\text { gráfico }\end{array}$ & nextStep() & nextStep() & writeNextStep() \\
\cline { 4 - 7 } & & backStep() & backStep() & writeBackStep() \\
\hline
\end{tabular}

Cabe ressaltar que os artefatos gerados pelos desenvolvedores foram utilizados para estabelecer um conjunto de requisitos para o projeto do mecanismo de avaliação de usabilidade utilizado na ferramenta de autoria MMWA-ae.

A tarefa foi considerada cumprida quando foram apresentados os resultados obtidos em uma monografia de conclusão de curso de graduação (MURAKAMI, 2009). 


\subsection{Estudo de Caso 3}

O Estudo de Caso 3 foi proposto com o objetivo de validar o uso da ferramenta de autoria desenvolvida para facilitar a utilização da MMWA em projetos de interfaces multimodais Web, por meio da criação de protótipos rápidos e avaliações de usabilidade remotas.

\subsubsection{Definição do estudo de caso}

\section{Objeto de estudo:}

Projetistas, desenvolvedores e testadores de interfaces multimodais Web utilizando o ambiente de autoria desenvolvido para suas atividades no projeto de interfaces multimodais Web.

\section{Motivações:}

- Necessidade de um ambiente de autoria para apoiar a utilização da MMWA de forma automatizada e simplificada.

- Necessidade de uma ferramenta para realizar a coleta, o armazenamento e a recuperação de DR de forma não intrusiva e semi automatizada.

\subsubsection{Planejamento do estudo de caso}

\section{Proposta:}

Avaliar o uso da ferramenta de autoria para verificar se ela implementa as atividades da MMWA e se ela auxilia a equipe de projeto em suas atividades de projeto, desenvolvimento e testes de interfaces multimodais Web.

\section{Foco qualitativo:}

Criação rápida de protótipo de interface multimodal com usabilidade, reutilização de interfaces multimodais e fácil utilização do DR.

\section{Perspectiva:}

O estudo de caso foi realizado sob o ponto de vista de profissionais que possuem experiência no desenvolvimento de interfaces Web e de voz, em um projeto acadêmico no ICMC-USP, durante o primeiro semestre de 2010.

\section{Hipóteses e Resultados Preliminares:}


A seguir serão apresentadas algumas hipóteses que guiaram a condução do EC3 e os resultados preliminares obtidos. Uma análise mais detalhada dos Resultados será apresentada no Capítulo 7.

Hipótese 1: geração rápida de código fonte

Resultados: comparando-se o tempo para obtenção do código fonte que serviu para a execução de testes com usuários, o MMWA-ae gerou o protótipo aproximadamente 8 vezes mais rápido do que na aplicação de referência. Isto ocorre pois além dos componentes multimodais disponíveis existem padrões de projeto implementados e que facilitam a geração do código.

Hipótese 2: projetista comete menos erros de usabilidade

Resultados: quando os componentes de software, os padrões de projeto e também o DR são utilizados pelo projetista/desenvolvedor, menos erros de usabilidade são cometidos, pois os artefatos desenvolvidos trazem o raciocínio que já foi implementado e testado em outro projeto.

Hipótese 3: MMWA-ae promove a reutilização de código fonte

Resultados: foi conseguido um bom percentual de reutilização nas aplicações desenvolvidas com o MMWA-ae. Para o sistema multimodal para aluguel de carros, obtevese $83 \%$ de reutilização com apenas $3.2 \%$ de métodos não desejados.

\subsubsection{Execução do estudo de caso}

O estudo de caso foi realizado com 2 projetistas especialistas em interfaces multimodais que receberam treinamento sobre a MMWA e o ambiente de autoria e desenvolveram duas aplicações envolvendo interfaces multimodais: um sistema multimodal para aluguel de carros e um sistema de apresentações de palestras.

O sistema multimodal para aluguel de carros foi escolhido por ter sido o mesmo projeto desenvolvido no primeiro estudo de caso. A interface do projeto selecionado do EC1 está representada na Figura 49.

A escolha de uma aplicação de referência possibilitou obter medidas de comparação entre as aplicações geradas com e sem o MMWA-ae, como, o tempo de desenvolvimento das interfaces, o número de linhas de código geradas pelo MMWA-ae, o número de problemas de usabilidade, além de informações sobre o uso de DR em aplicações do mesmo tipo. 
Na Figura 50 é possível observar a interface desenvolvida no EC3 com o auxílio do MMWA-ae sendo executada em um simulador de dispositivos móveis.

Na Figura 51 pode-se observar a interface multimodal do sistema de apresentações de palestras desenvolvida no EC3 que foi utilizada para apresentação de um artigo resultante desta tese no "28th ACM International Conference on Design of Communication" (NETO; FORTES, 2010).

A equipe de projeto utilizou a MMWA-ae no EC3 para todas as atividades de projeto, desde a especificação de requisitos até o desenvolvimento de software, documentação de DR e testes de usabilidade.

A tarefa foi considerada cumprida quando as interfaces foram disponibilizadas para os testes remotos.

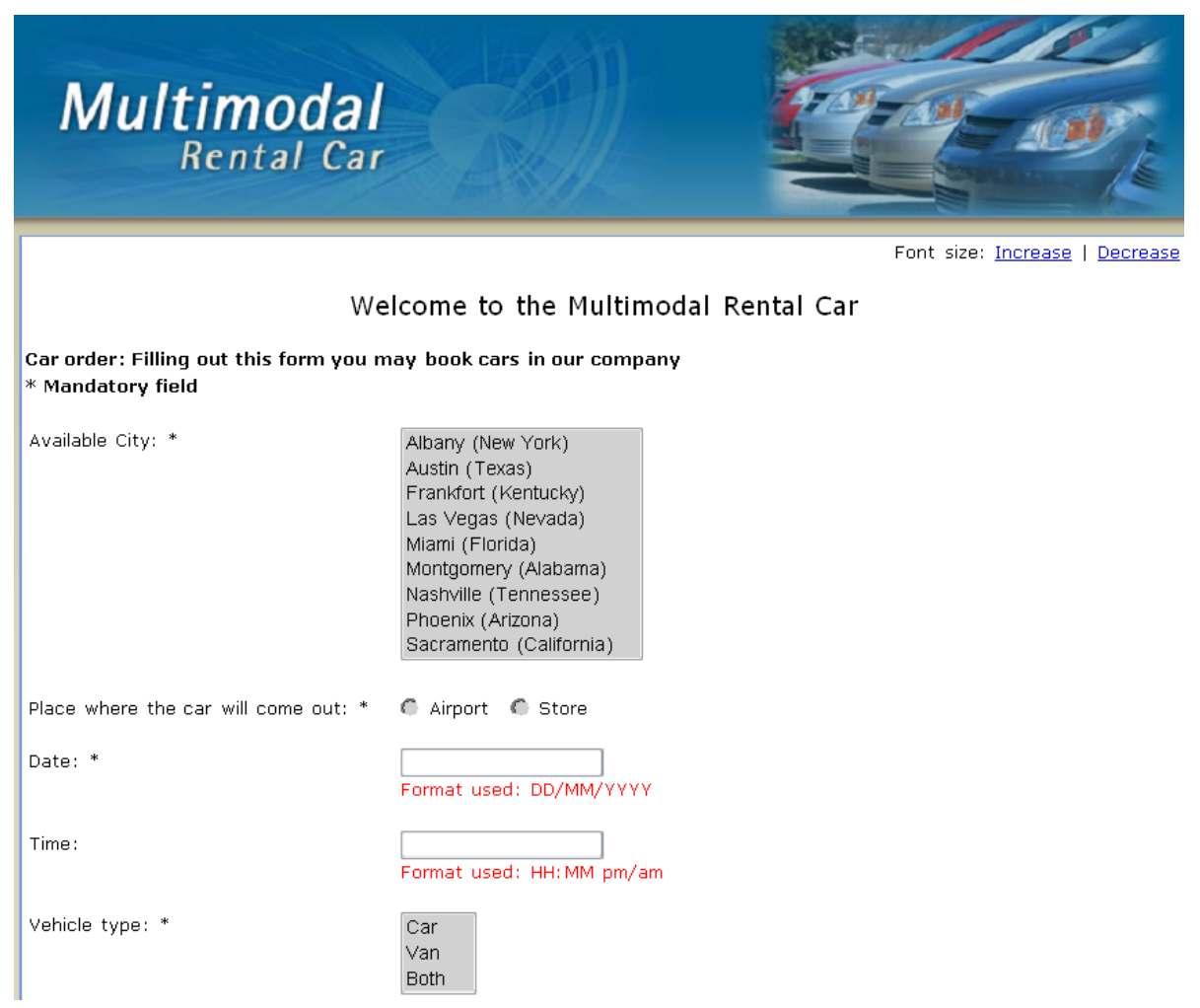

Figura 49 - Interface desenvolvida no EC1, sem o auxílio do MMWA-ae 


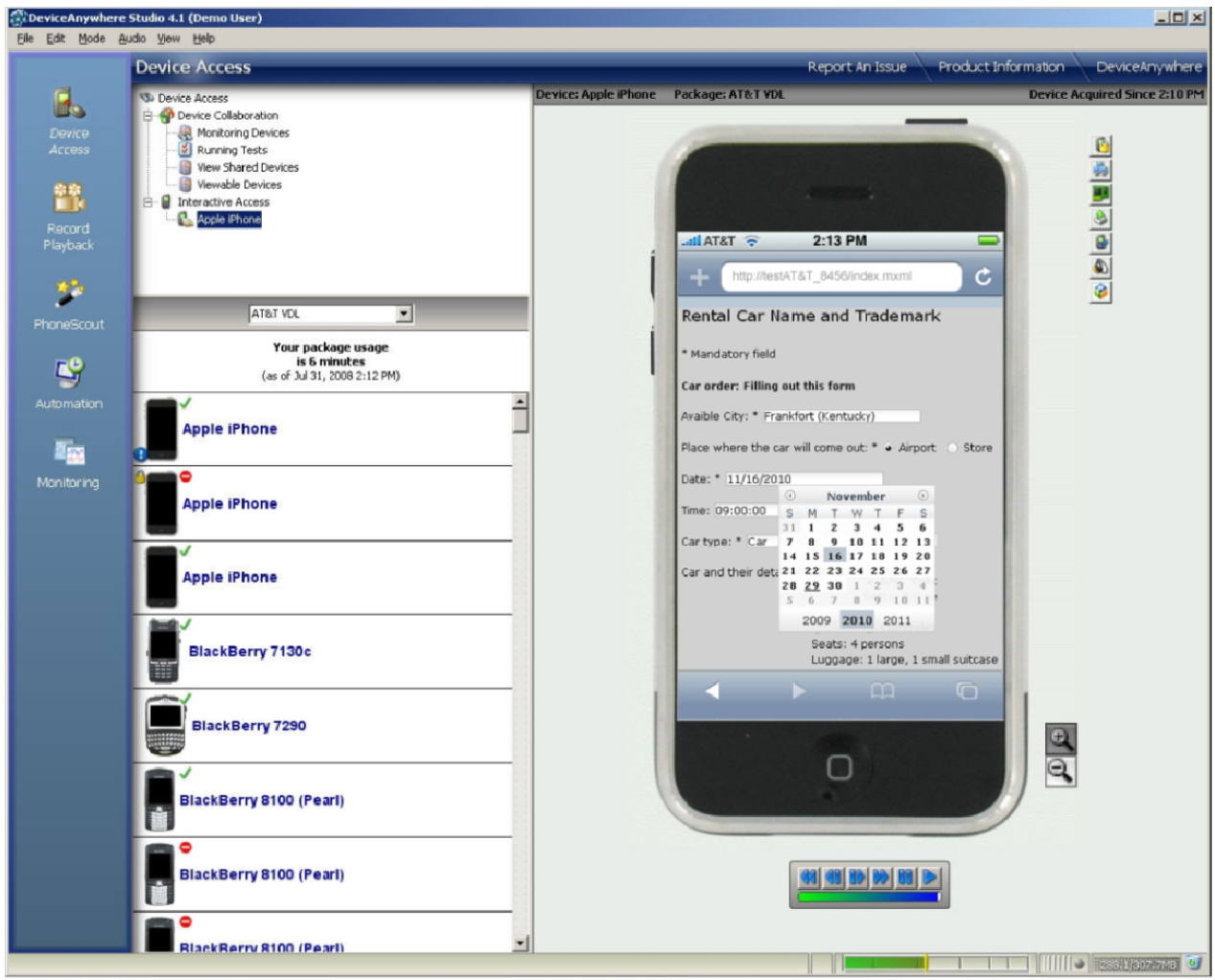

Figura 50 - Interface do EC3, projetada com o MMWA-ae, sendo executada em uma plataforma de testes de aplicações móveis.

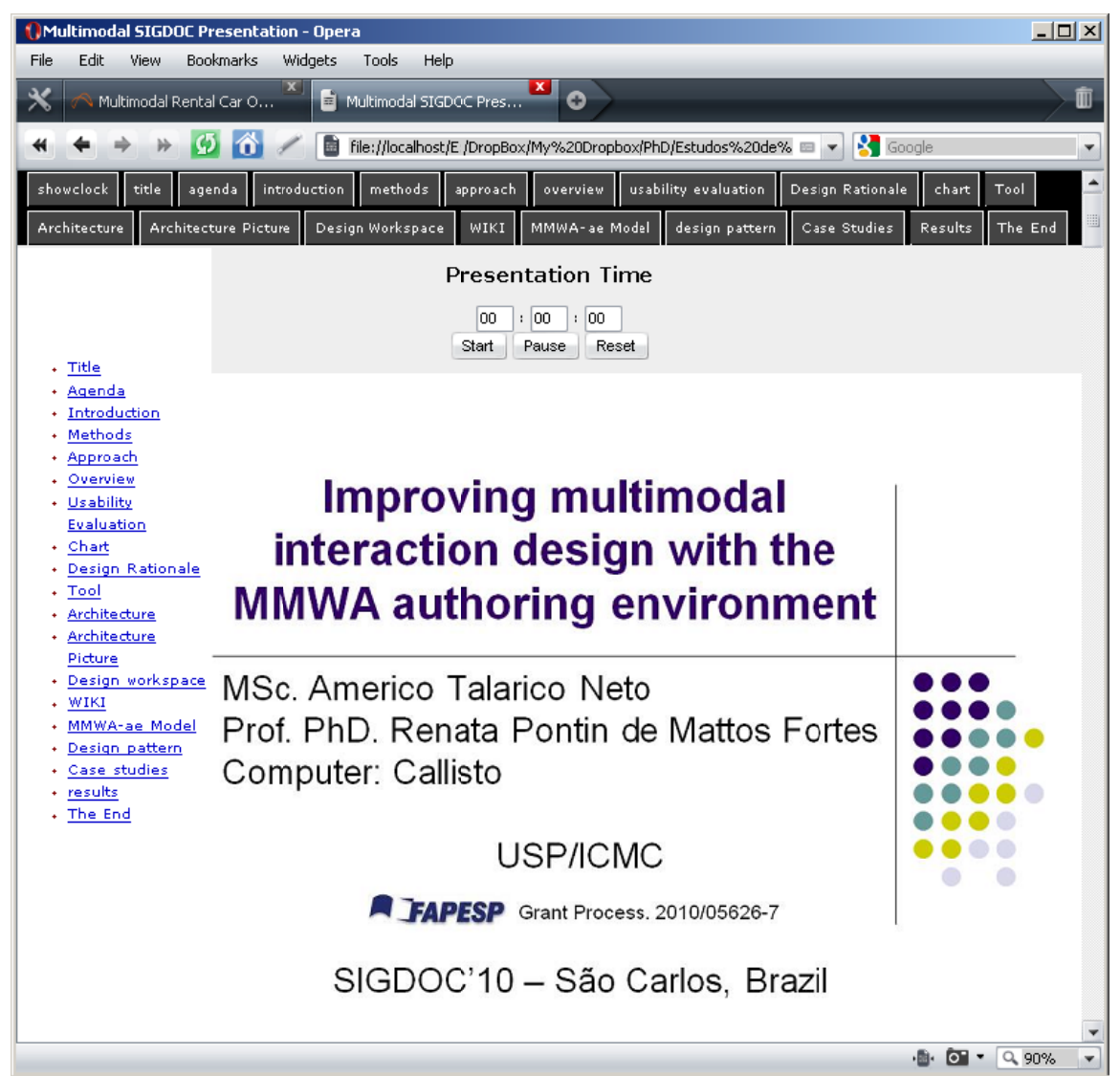

Figura 51 - Sistema de apresentações de palestras desenvolvido no EC3 


\subsection{Considerações finais sobre os estudos de caso}

Neste capítulo apresentaram-se os três estudos de caso realizados nesta tese.

As medidas qualitativas utilizadas para avaliar o desempenho da abordagem e do ambiente de autoria foram:

1) A verificação que os problemas de usabilidade não se repetem em estudos de caso subsequentes.

2) O feedback obtido com questionários aplicados aos desenvolvedores (exemplo de questionário no Apêndice D).

3) O feedback obtido com os questionários aplicados nos testes com usuários.

4) A verificação da utilização do DR nos estudos de caso com as características do DR presentes nas interfaces desenvolvidas.

5) A possibilidade da escrita de padrões de projeto com base no DR coletado nos estudos de caso.

6) A facilidade para a criação de componentes de software fundamentados nas informações presentes no DR coletado.

7) A identificação de padrões de interação utilizando o MMLOG em conjunto com as propriedades CARE e regras de associação.

As medidas quantitativas utilizadas para avaliar o desempenho da abordagem e do ambiente de autoria foram:

8) A verificação que os problemas e as severidades diminuíram de um estudo de caso para outro nas avaliações de usabilidade com as interfaces projetadas.

9) A verificação dos dados presentes nos gráficos e tabelas gerados com o MMLOG.

10) O tempo de desenvolvimento de interfaces,

11) A taxa de reutilização de código.

Instrumentação: o material fornecido aos participantes para a execução dos estudos de caso está publicado na forma de relatório técnico, referenciado na Seção 8.4 , e é composto por material didático sobre $\mathrm{X}+\mathrm{V}$, princípios, guidelines e checklists para o desenvolvimento de interfaces multimodais Web, diretivas para executar o estudo de caso, requisitos do sistema e treinamento sobre DR.

Ameaças à validade: é importante observar que os estudantes receberam notas de avaliação nas disciplinas por suas participações nos estudos. Há o risco de que o incentivo influencie os resultados. Além disso, os estudos de caso foram realizados com alunos de graduação e pós-graduação. Considera-se aceitável a realização dos estudos com alunos sobre 
um tópico de estudo nas disciplinas de graduação e pós-graduação em Hipermídia, pois sabese que em geral os alunos participam de equipes que desenvolvem os projetos de tal natureza (projetos de interfaces Web) seja no ambiente acadêmico ou no ambiente profissional.

No próximo capítulo são analisados os resultados obtidos com a realização dos estudos de caso. 



\section{Capítulo 7. Análise dos Resultados dos Estudos de Caso}

\subsection{Considerações iniciais}

Como foi exposto no capítulo anterior, três estudos de caso foram realizados utilizando a MMWA e permitiram apresentar resultados sobre a abordagem e seu ambiente de autoria.

Neste capítulo são discutidos os principais resultados que evidenciam as hipóteses definidas nos estudos de casos, visando proporcionar uma análise mais detalhada das questões envolvidas.

Na Seção 7.2 são discutidos os tópicos que mostram a diminuição dos problemas de usabilidades à medida que os estudos de caso foram sendo executados. Nas Seções 7.3, $7.4 \mathrm{e}$ 7.5 são discutidos os resultados obtidos com as principais estratégias de diálogo utilizadas no projeto das interfaces multimodais. Nas Seções 7.6 e 7.7 são apresentados como Regras de Associação e propriedades CARE podem ser utilizadas para identificar padrões e problemas de interação em testes com usuários.

Nas Seções 7.8 e 7.9 são discutidos os aspectos relacionados ao DR, como a documentação de software e a técnica usada para identificar padrões de projeto.

Nas duas últimas Seções, 7.10 e 7.11 são feitas considerações sobre reutilização de código e tempo gasto para obtenção de protótipos de interfaces multimodais.

\subsection{Usabilidade das interfaces geradas pelo MMWA-ae}

Com a utilização do MMHE e do MMLOG para a realização de avaliações de usabilidade foi possível identificar que os problemas de usabilidade encontrados no primeiro estudo de caso não estavam presentes nas interfaces criadas nos outros dois estudos de casos, principalmente no terceiro estudo de caso, que foi o mesmo projeto de locadora de carros desenvolvido no primeiro estudo de caso, mas executado por uma equipe diferente e usando o MMWA-ae.

Argumenta-se que isso foi possível devido ao conhecimento de DR disponível no MMWA-ae e ao mecanismo de sugestão de soluções para problemas de usabilidade fundamentado em DR, checklists, princípios e padrões de projeto, que permite ao projetista 
escolher uma solução para implementar suas idéias, resolver problemas e entender o raciocínio utilizado na solução.

Além disso, os princípios e as checklists de usabilidade para interfaces multimodais são automaticamente implementados no código fonte gerado e também contribuíram para o aumento da usabilidade geral.

Comparando-se os dados dos três estudos de caso, percebeu-se que os problemas de usabilidade encontrados diminuíram de um estudo de caso para outro, como mostrado no Quadro 11. Acredita-se que isso aconteceu devido à utilização de DR em projetos subsequentes e, devido à utilização da avaliação heurística e dos testes com usuários, validando as suposições feitas em (DESURVIRE, 1994) a respeito da natureza complementar dos métodos de avaliação de usabilidade empíricos e analíticos. Em outras palavras, apenas parte dos problemas que realmente ocorrem nos testes com usuários é identificado durante a avaliação heurística e os problemas encontrados em um método analítico de avaliação de usabilidade são complementares aos problemas encontrados nos métodos empíricos.

Quadro 11 - Dados gerais dos Estudos de Caso executados com a MMWA

\begin{tabular}{|l|c|c|c|c|c|}
\cline { 2 - 6 } \multicolumn{1}{c|}{} & EC1 & \multicolumn{2}{c|}{ EC2 } & \multicolumn{2}{c|}{ EC3 } \\
\cline { 2 - 6 } \multicolumn{1}{c|}{} & Projeto1 & Projeto2 & Projeto3 & Projeto4 & Projeto5 \\
\hline Questões de DR & 36 & 11 & 10 & 3 & 0 \\
\hline Discussões de DR & 472 & 97 & 75 & 20 & 0 \\
\hline Consultas ao DR & 120 & 13 & 18 & 45 & 11 \\
\hline $\begin{array}{l}\text { Problemas encontrados } \\
\text { com o MMHE encontrados }\end{array}$ & 12 & 8 & 7 & 3 & 0 \\
\hline $\begin{array}{l}\text { Problemas } \\
\text { com o MMLOG }\end{array}$ & 9 & 9 & 7 & 3 & 1 \\
\hline $\begin{array}{l}\text { Total de problemas (Não } \\
\text { repetidos) }\end{array}$ & 17 & 14 & 13 & 6 & 1 \\
\hline
\end{tabular}

Além disso, a utilização do mecanismo de avaliação heurística da MMWA (o MMHE) permitiu a obtenção de vários resultados relacionados com a identificação e solução de problemas com base nas teorias pesquisadas neste trabalho: DR, princípios de usabilidade multimodal, listas de verificação (checklists), padrões de projeto e as heurísticas de usabilidade de Nielsen (1990). Essa atividade foi importante para que fossem obtidos os relacionamentos entre os princípios, as checklists e as heurísticas, pois o MMWA-ae utiliza esses relacionamentos em seu modelo de tarefas para sugerir soluções apropriadas para resolver problemas de usabilidade. Exemplos de dados obtidos com o MMHE que permitem visualizar os relacionamentos mencionados anteriormente são apresentados a seguir (uma descrição mais detalhada pode ser encontrada no Apêndice B): 
Problema 1: o usuário não sabe o conteúdo interno de uma caixa de seleção e não tem alternativa a não ser utilizar a interface de forma gráfica, ou seja, o modo voz está disponível, mas o usuário não sabe o que pode dizer. Além disso, mostrar a caixa de seleção aberta pode ocupar muito espaço na interface gráfica.

Solução: Utilizar filtros gráficos e de voz para permitir que a interface multimodal apresente o menor número de opções de acordo com o filtro selecionado.

\section{Heurísticas:}

- Visibilidade do estado sistema: O sistema deve sempre manter os usuários informados sobre o que está acontecendo, através de feedback apropriado dentro de prazo razoável;

- Reconhecimento ao invés de memorização: Tornar objetos, ações e opções visíveis. O usuário não deve ter que lembrar informações de uma parte do diálogo para outra. Instruções para a utilização do sistema devem ser visíveis ou facilmente recuperáveis sempre que apropriado.

Princípios: Transição Perceptível; Previsibilidade.

\section{Checklists com problemas:}

- O usuário consegue perceber qual modalidade ele deve utilizar para cada componente de interface e para cada interface?

- Existe alguma representação visual para auxiliar o usuário na identificação do tipo de interface disponível?

- As listas de opções das caixas de seleção estão claras para o usuário?

Exemplo: Encontrar um ponto de referência em um mapa, filtrando-se por cidade.

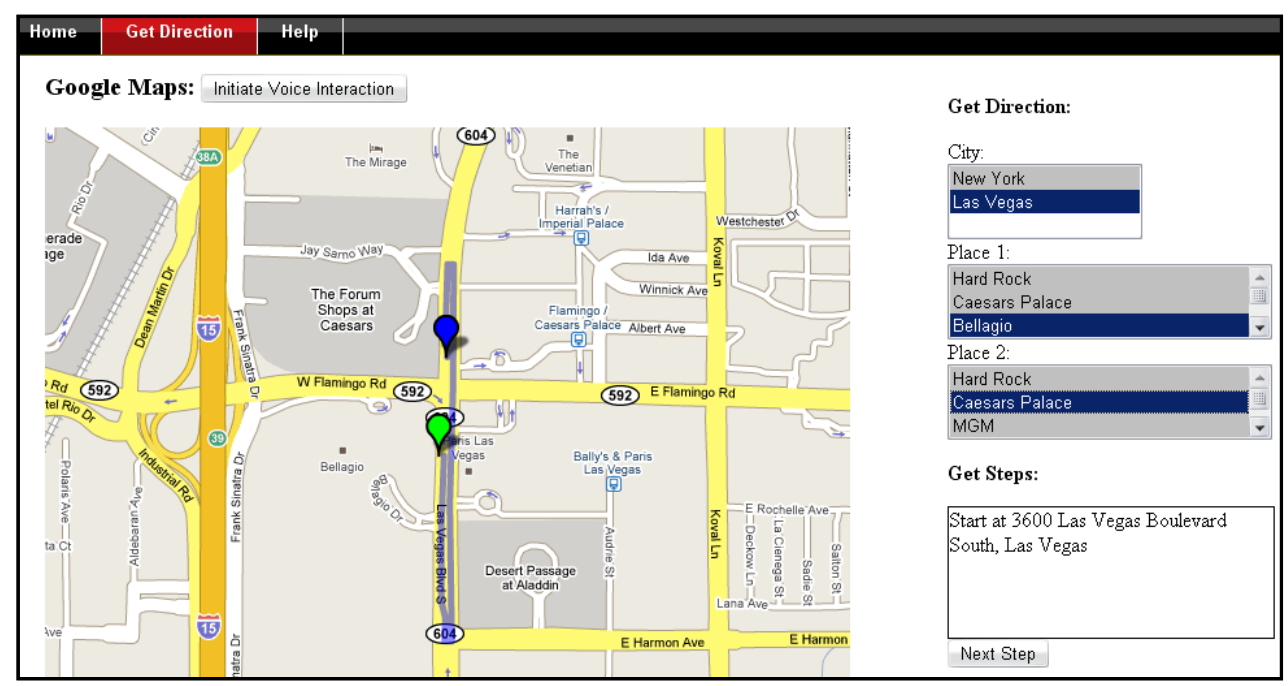

Figura 52 - Filtro de voz utilizado na interface gráfica 
Problema 2: para campos que são opcionais, o usuário não sabe o que dizer caso ele queira deixar o campo em branco. Ajuda apropriada não é fornecida quando o erro ocorre.

Solução: Instruir o usuário para que ele possa executar a próxima tarefa deixando o campo em branco. É possível usar os contadores de erro e o mecanismo para distinguir tipos de erro da tecnologia de voz para fornecer a mensagem de erro adequada ao usuário e facilitar a recuperação de um erro ou o entendimento da tarefa.

\section{Heurísticas:}

- Prevenção de erro: um projeto cuidadoso que previne a ocorrência de um problema em primeiro lugar é melhor do que boas mensagens de erro;

- Flexibilidade e eficiência de uso: permitir aos usuários personalizar ações freqüentes.

Princípios: Adaptação; Diversidade de usuários e dispositivos de interação; Tratamento e prevenção de erros.

\section{Checklist com problemas:}

- O sistema multimodal faz com que usuários cometam erros que não cometeriam em sistemas apenas com interface gráfica?

- Em virtude de mudança ou correção de sua solicitação, o usuário pode alterar suas entradas usando qualquer modalidade?

Problema 3: as mensagens de ajuda da interface de voz não apresentam termos que são reconhecidos pela gramática.

Solução: Fornecer assistência focando na tarefa do usuário (por exemplo, uma janela de ajuda que abre em um elemento <div> quando um evento mouseover acontece ou quando o usuário solicita ajuda pela interface de voz).

\section{Heurísticas:}

- Ajuda aos usuários para reconhecer, diagnosticar e se recuperar de erros: mensagens de erro devem ser expressas em linguagem simples (sem códigos), indicar com precisão o problema e sugerir uma solução construtiva.

- Ajuda e documentação: mesmo que o sistema possa ser usado sem documentação é necessário fornecer ajuda e documentação, tais informações devem ser fáceis de pesquisar e centradas na tarefa do usuário. Devem conter uma lista de medidas concretas a serem realizadas e que não seja demasiadamente grande.

Princípios: Consistência na interação; Previsibilidade.

Checklist com problemas: 
- Uma ajuda apropriada é fornecida quando ocorre um erro? As mensagens de erro são expressas em linguagem "plena” (sem códigos)? Elas sugerem uma solução?

- Uma ajuda apropriada é fornecida pelo comando "help"? Essa informação é fácil de ser solicitada e focada na tarefa do usuário?

Problema 4: Usuários com dificuldades em selecionar hora/data.

Solução: Mostrar claramente que a interface permite entrada multimodal e que os campos estão bem determinados, mostrando uma data padrão, por exemplo. O mecanismo de ajuda pode mostrar que o sistema aceita entradas de voz como "hoje" e "amanhã". Um algoritmo deve ser utilizado para calcular datas relativas nesse caso.

Heurísticas: Correspondência entre o sistema e o mundo real; Flexibilidade e eficiência de uso; Ajuda e documentação.

Princípios: Sincronização, Previsibilidade, Diversidade de usuários e dispositivos de interação.

Exemplo: Entrada de datas e hora da Figura 53.

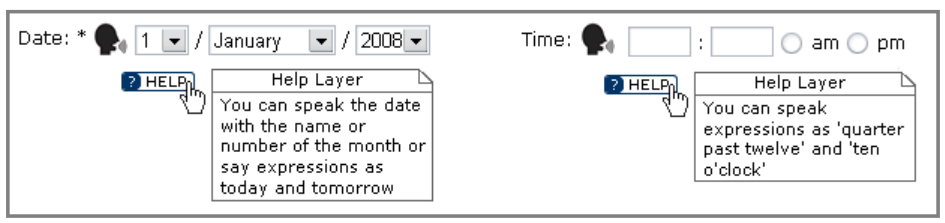

Figura 53 - Entrada de datas e hora

Finalmente, a aplicação do MMLOG nos estudos de caso com a MMWA ajudou na identificação de problemas de interação e de soluções que não poderiam ser obtidas ou propostas realizando apenas a avaliação heurística (MMHE), como será apresentado nos tópicos a seguir. Além disso, ajudou na identificação de sugestões de melhorias do projeto da interação na fusão das interfaces gráficas com as interfaces de voz permitindo a análise do padrão de comportamento dos usuários em suas interações, além da verificação das estratégias de prevenção/recuperação de erros utilizadas neste trabalho, como será mostrado adiante neste capítulo.

\subsection{Estratégia de recuperação de erros}

Basicamente existem dois tipos de erros nas tecnologias de reconhecimento: erro de não entendimento e erro de interpretação (BOHUS; RUDNICKY, 2008) (OVIATT; VANGENT, 1996). 
O erro de não entendimento ocorre quando o sistema falha para obter uma interpretação da entrada fornecida pelo usuário, por exemplo, quando este diz algo que não está previsto em uma gramática de reconhecimento de voz. Neste caso, o sistema precisa obter novamente uma entrada do usuário com o objetivo de tentar obter um dado para completar a tarefa.

Já o erro de interpretação ocorre quando o sistema obtém uma interpretação incorreta da entrada do usuário, por exemplo, quando este diz "seis" e o sistema interpreta como "três", devido à similaridade na pronúncia das palavras. Neste caso, o sistema completa a tarefa com um dado incorreto que pode ou não ser percebido pelo usuário.

A estratégia de prevenção e correção de erros está diretamente relacionada ao projeto da interface, ou seja, o projetista deve escolher a melhor forma para obter a entrada do usuário, por exemplo, definindo prompts que sejam consistentes com o que é apresentado na interface gráfica ou criando mecanismos de confirmação das entradas fundamentando-se em níveis de confiança de reconhecimento. Apesar disso, algumas estratégias para identificação, confirmação, correção e recuperação de erros foram utilizadas neste trabalho de acordo com uma situação específica (SUHM, 1997; BOHUS; RUDNICKY, 2008) (SUHM, 1997).

- DetailedReprompt: O sistema repete o prompt, incluindo mais detalhes e a opção de se utilizar outra modalidade.

- MoveOn: O sistema avança para a próxima tarefa, completando com um valor padrão quando possível.

- YouCanSay: O sistema oferece ao usuário exemplo de falas que ele pode dizer para completar uma tarefa.

- FullHelp: o sistema fornece uma longa mensagem de ajuda explicando o contexto da tarefa, as falas que o usuário pode dizer e a opção de se utilizar outra modalidade.

Essas estratégias foram criadas a partir da identificação de erros nos $\log s$ analisados nos ECs e também a partir da coleta de DR. Uma inspeção minuciosa nos logs, tabelas e gráficos gerados pelo MMLOG possibilitou a verificação de que tanto a estratégia utilizada para a correção de erros de reconhecimento identificada na avaliação heurística como a do projeto das gramáticas tendo como base o modelo do domínio e o projeto das tarefas foi eficiente durante os testes com usuários.

Essa análise foi possível com a realização de um processo de transcrição manual, ou seja, ouvindo-se os áudios gravados e comparando-se com o texto gravado nos logs, o qual 
representa o que foi entendido pelo sistema e como essa entrada foi interpretada pelo reconhecedor.

Nessa análise foram transcritas 957 falas e foi possível identificar que o reconhecedor de voz cumpriu com sua tarefa de reconhecer a entrada fornecida pelo usuário em $86 \%$ das vezes, como pode ser visto na Figura 54.

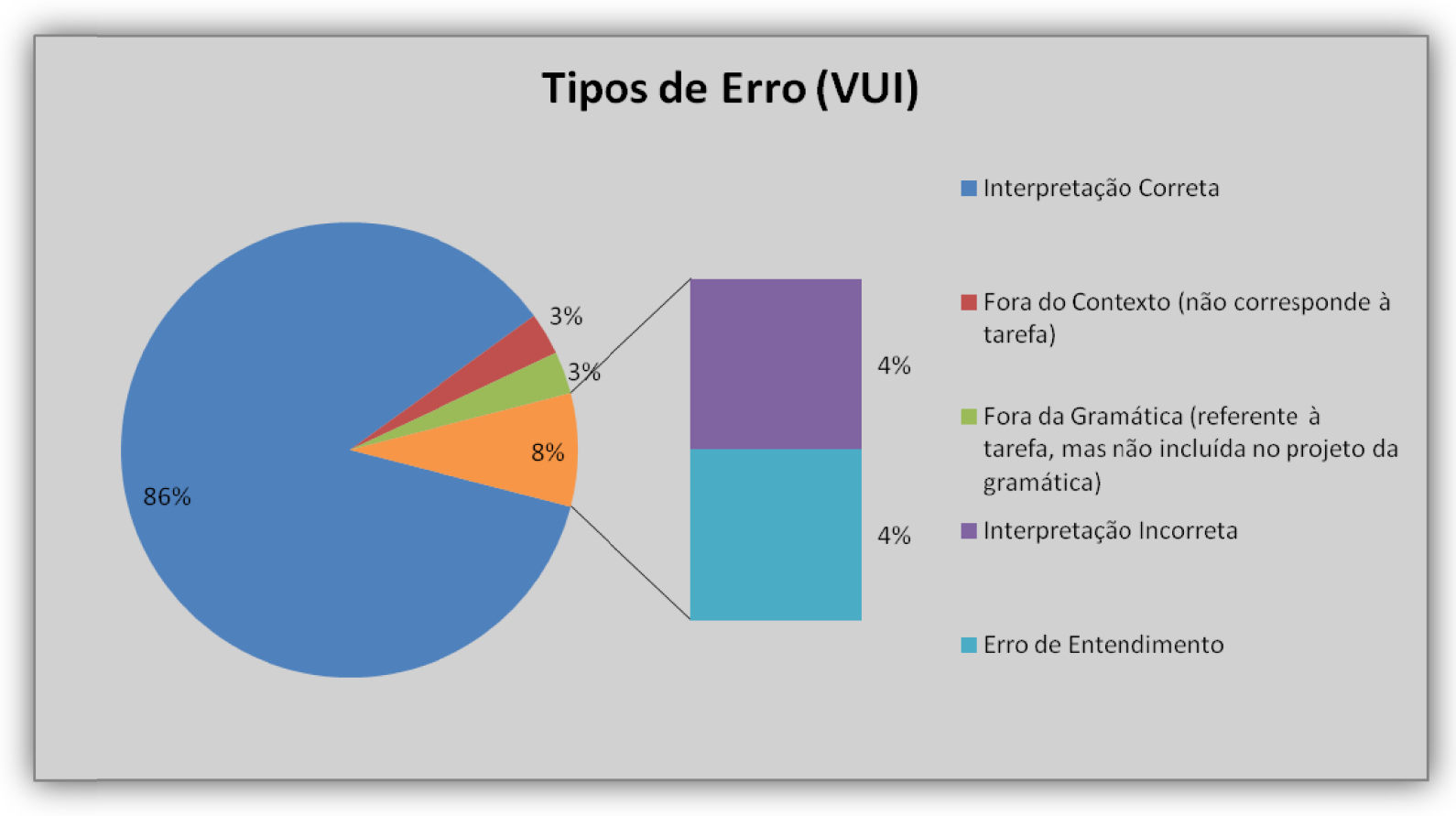

Figura 54 - Tipos de erro identificados na interface de voz

Vale lembrar que o objetivo nos ECs não foi o de avaliar e melhorar o software de reconhecimento de voz, mas sim projetar interfaces que possibilitassem a recuperação em casos de erro e a prevenção destes erros.

Em 14\% das interações ocorreram erros de reconhecimento de voz, dos quais 3\% foram falas fora do contexto, ou seja, falas que não estavam relacionadas com a tarefa proposta. Outros $3 \%$ foram falas fora da gramática, ou seja, falas dentro do contexto da tarefa, mas fora do alcance da gramática projetada.

Sobre os erros do reconhecedor de voz, $4 \%$ foram de interpretação errônea de uma frase, e $4 \%$ erros de entendimento. Destes $8 \%$ de erros do reconhecedor de voz, apresentados na Figura 54, a maioria, ou seja, 73\% ocorreram devido a problemas com o mecanismo de end-pointer, que estabelece o início e o fim de uma fala, $18 \%$ de falas muito longas dos usuários e 9\% de ruídos no ambiente em que ocorreu a interação, como pode ser visto no gráfico da Figura 55. 


\section{Interpretação Incorreta e Erro de Entendimento}

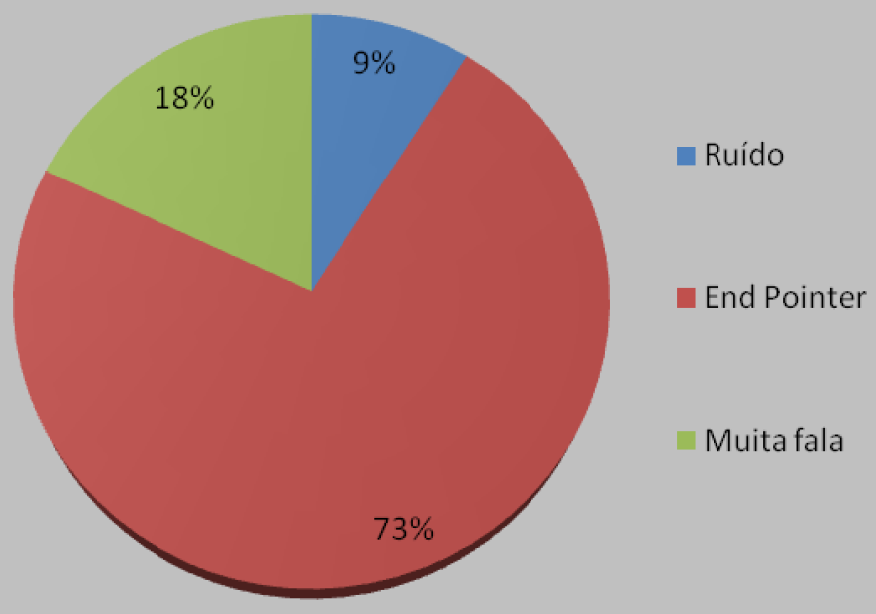

Figura 55 - Subdivisão dos tipos de erros

A pouca taxa de erros na gramática da interface de voz sugere que o uso da abordagem proposta nesta tese durante as fases do projeto foi eficiente e a maioria dos problemas foram corrigidos nas outras atividades do ciclo até o momento dos Testes com Usuários. Além disso, a taxa de recuperação de erros também mostra que as técnicas usadas neste trabalho para prevenção e recuperação de erros foram eficientes, pois em $74 \%$ dos casos de erro, ou seja 134 casos ou $14 \%$ do total de interações, os usuários conseguiram se recuperar de um erro de reconhecimento e completar a tarefa em até 3 tentativas, como é apresentado no gráfico da Figura 56. 


\section{Taxa de Recuperação de Erro}

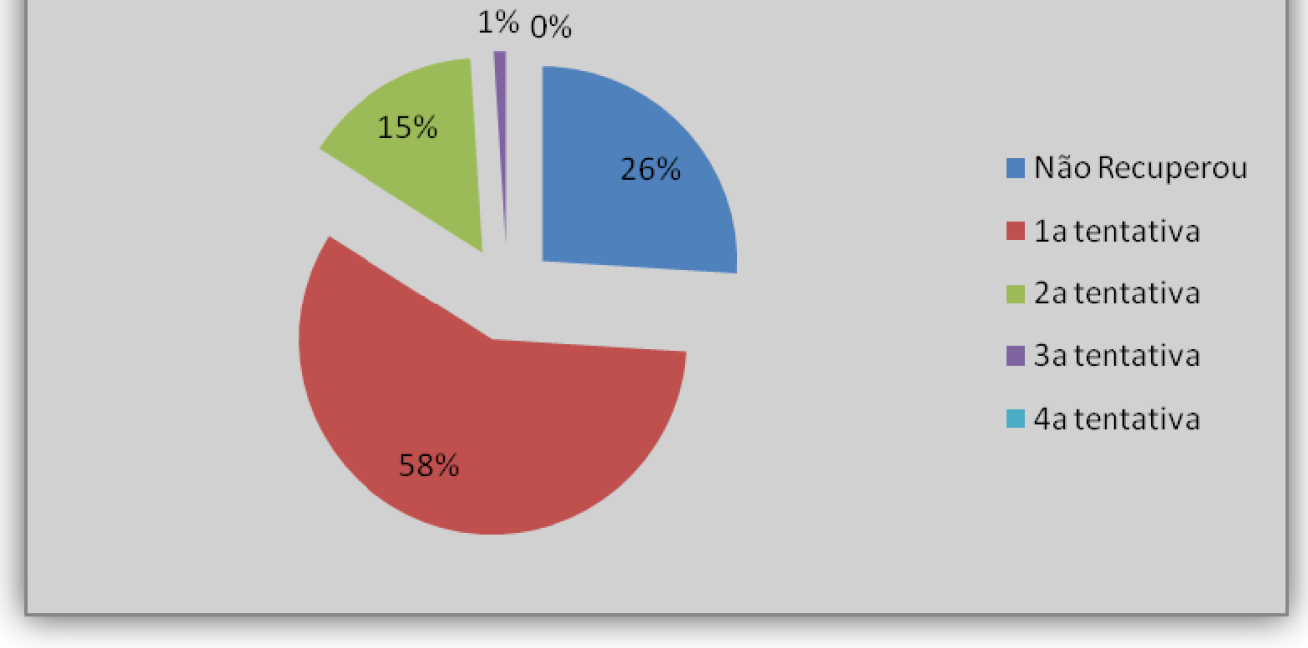

Figura 56 - Taxa de Recuperação de Erro

Pode-se ainda inferir pelas Figura 56 e Figura 57 que apenas uma taxa de 3,65\% do total de interações analisadas das tarefas foram completadas com dados errados, ou seja fora do contexto do protocolo de Testes com Usuários, pois $26 \%$ dos casos de erro, ou seja 35 interações de 957 no total, foram completadas com dados incorretos. Percebe-se que após a aplicação da estratégia de recuperação de erros, a taxa de sucesso aumentou de $86 \%$ para $96 \%$.

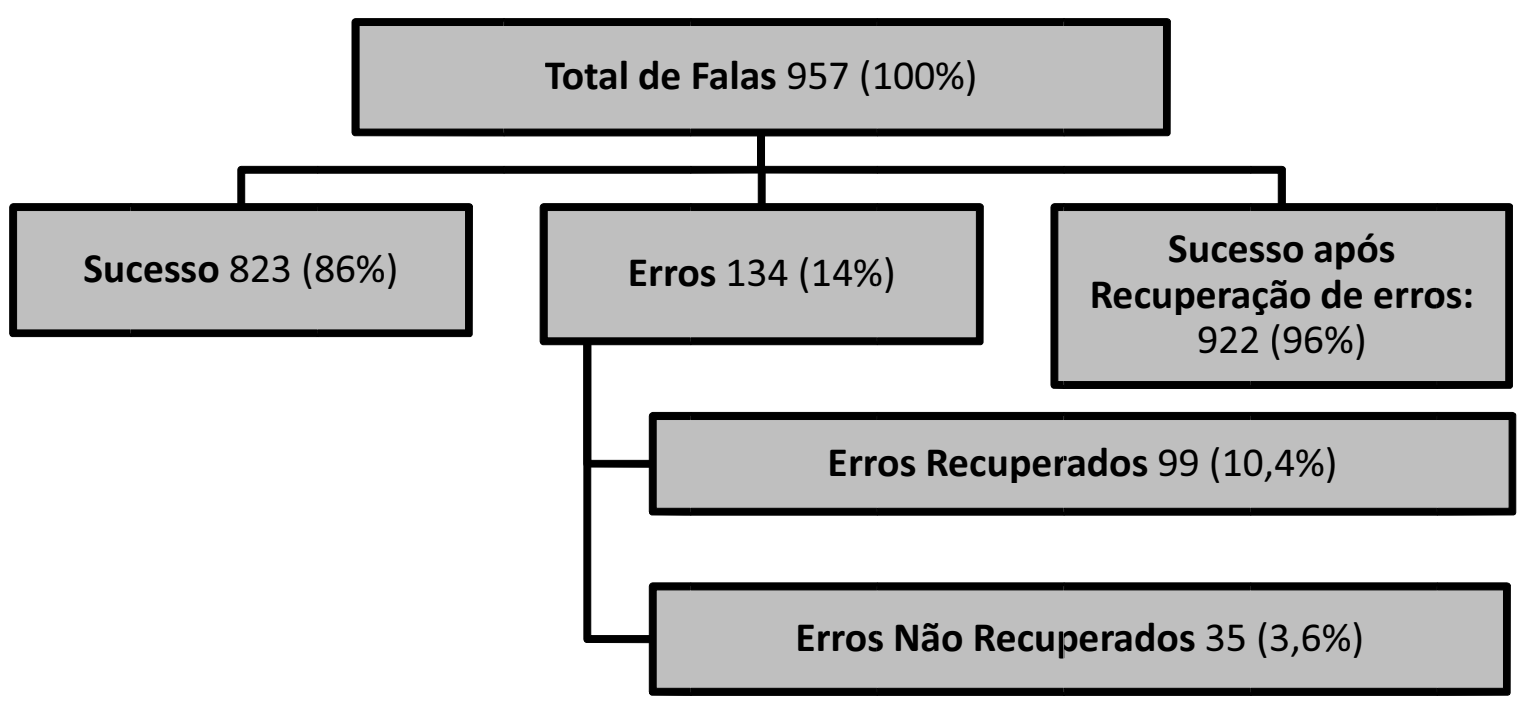

Figura 57 - Taxa de Recuperação de Erros em relação ao total de interações analisadas

Verificou-se também que quando o usuário interage com a interface gráfica em sincronismo com a interface de voz, ele geralmente usa os termos que estão escritos na 
interface gráfica para elaborar a sua fala. Esse é um dos princípios definidos no DR capturado e armazenado pela abordagem proposta de acordo com a teoria da lingüística (ALMOR, 1999) que afirma que é mais fácil se referir a uma entidade quando ela está inserida no diálogo pois o usuário evita o esforço de rearticular uma frase para se referir à entidade e é mais fácil usar um substantivo que está visualmente acessível do que criar uma sentença para se referir à entidade.

Esse tipo de análise não seria possível utilizando-se somente a avaliação heurística e seria realizada com uma amostra pequena de usuários caso os Testes com Usuários fossem realizados sem o auxílio do MMLOG.

Outro ponto interessante identificado nos ECs foi a recuperação de erros de reconhecimento de voz por meio do uso da interface gráfica tanto para usuários não nativos em inglês como para ambientes com ruído ou problemas no software de reconhecimento de voz quando este falha na tarefa de obter uma interpretação no que foi falado (erros ou abrangência limitada das gramáticas projetadas para a interface - falas fora da gramática ou fora do domínio da tarefa) ou quando este interpreta de forma errônea a fala do usuário, por exemplo, durante o reconhecimento de uma cadeia de dígitos, a troca de "five" por "nine" devido à semelhança na fonética das duas palavras, ou até mesmo por erros no mecanismo de end-pointer que é responsável por segmentar o sinal de entrada de áudio, truncando a fala do usuário e impossibilitando o seu reconhecimento.

Outro fato que pôde ser percebido analisando-se os gráficos gerados pelo MMLOG é que a precisão do reconhecedor de voz está diretamente associada com ruído no ambiente, velocidade da fala, frustração do usuário não nativo e uso de frases muito grandes. No caso da frustração, que é subjetivo, verificou-se que quando o usuário tem sua fala rejeitada na sua primeira tarefa as falas posteriores incluem interjeições que demonstram frustração e descontentamento com o uso da voz e ele tende a usar os comandos gráficos para realizar tarefas mais difíceis como falar uma cadeia de dígitos ou falar uma data (para o caso dos não nativos).

\subsection{Estratégia de comandos universais}

Correlacionando os resultados obtidos neste trabalho com os dados de projetos de interfaces de voz (COHEN; GIANGOLA; BALOGH, 2004), percebeu-se que houve pouco uso do mecanismo de comandos universais (comandos globais que permitem: obter ajuda, repetir algo que não foi entendido pelo usuário, desfazer uma ação ou tarefa, entre outros). 
Isso se deveu ao fato de que, durante a atividade de análise de tarefas, as interfaces de voz foram projetadas com informações complementares à interface gráfica, que apresenta a informação de maneira resumida. Dessa forma, o usuário utilizou poucas vezes o mecanismo de ajuda na interface gráfica diminuindo assim a carga necessária no seu sistema cognitivo para compreender e utilizar a interface.

Os comandos "repetir" e "desfazer" também foram usados com pouca frequência nas interfaces multimodais avaliadas, pelo fato de que a interface gráfica funciona como um mecanismo de resumo do que foi utilizado como prompt de voz para uma determinada tarefa e pelo fato de que o usuário consegue visualizar as tarefas anteriores, não sendo necessário pedir para voltar ou repetir.

No Quadro 12 são apresentados os comandos que estavam disponíveis aos usuários nos estudos de caso e o número de vezes que eles foram utilizados. O total de falas coletadas foi de 26010 e o número de interações foi de 1530. Verifica-se que a taxa de utilização desses comandos é inferior a $1 \%$ nas interfaces multimodais estudadas, enquanto que nas interfaces de voz essa taxa está próxima dos $7 \%$.

Quadro 12 - Utilização de comandos universais nos estudos de caso

\begin{tabular}{|c|c|c|c|}
\cline { 2 - 4 } \multicolumn{1}{c|}{} & EC1 & EC2 & EC3 \\
\hline Comandos & Total de falas = 4571 & Total de falas = 19855 & Total de falas 1584 \\
\hline Ajuda & $\mathbf{5}$ & $\mathbf{1 9}$ & $\mathbf{2}$ \\
\hline Repetir & $\mathbf{6}$ & $\mathbf{3}$ & $\mathbf{0}$ \\
\hline Menu Principal & $\mathbf{6}$ & $\mathbf{2 3}$ & $\mathbf{1}$ \\
\hline Desfazer & $\mathbf{1}$ & $\mathbf{0 , 2 5 \%}$ & $\mathbf{0 , 1 9 \%}$ \\
\hline Total & $\mathbf{0 , 2 8 \%}$ & & \\
\hline
\end{tabular}

\subsection{Estratégia de confirmação de entradas incertas}

As interfaces multimodais são probabilísticas e as entradas do usuário têm que ser interpretadas por reconhecedores, como na tecnologia de reconhecimento de voz, na qual as dificuldades de reconhecimento são intensificadas pelas condições sob as quais o sistema opera (BOURGUET, 2008).

A estratégia de confirmação é utilizada para garantir que as entradas incertas das interfaces probabilísticas possam ser simplificadas nas interfaces multimodais, atrasando a confirmação para depois que as entradas de voz ou gestos forem combinadas em um comando completo multimodal (MCGEE; COHEN; OVIATT, 1998).

O mecanismo de confirmação, muito usado nas interfaces de voz, também pode ser simplificado nas interfaces multimodais pelo fato de que o sincronismo das interfaces de voz 
e gráfica funciona como um mecanismo de confirmação automática, já que o usuário consegue ver em tempo real o que ele acabou de fornecer como entrada de voz, e assim utilizar o modo gráfico para apontar um erro. A correção pode ser feita com o uso de ambas as modalidades.

Nos estudos de caso percebeu-se que os usuários tentam corrigir usando a mesma modalidade em que houve o erro, e caso o erro ainda persista, ele troca de modalidade já no segundo erro, como pode ser observado no Quadro 13. Pode-se observar que o usuário "daniel" ao interagir com a tarefa de informar o número do cartão de crédito (CCNum), utilizou a interface de voz nas duas primeiras interações, nas quais ocorreram erros de NoMatch, ou seja, a fala do usuário não confere com os dados presentes na gramática. Na terceira tentativa o usuário trocou de modalidade, informando o número do cartão pela interface gráfica, completando sua tarefa com sucesso.

Quadro 13 - Trecho do MMLOG que apresenta mudança de modalidade após um erro

\begin{tabular}{|c|c|c|c|c|c|c|c|}
\hline SsID & $\begin{array}{c}\text { Modalida } \\
\text { de }\end{array}$ & Usuário & Tarefa & Interpretação & $\begin{array}{c}\text { Confianç } \\
\mathbf{a}\end{array}$ & Evento & Tempo \\
\hline 96bef... & Voz & daniel & CCNum & $\begin{array}{c}5874.3500 .4175 .29 \\
00\end{array}$ & 0.3 & NoMatch1 & 5.6089 \\
\hline 96bef... & Voz & daniel & CCNum & $\begin{array}{c}9874.3500 .0079 .25 \\
00\end{array}$ & 0.2 & NoMatch2 & 6.8900 \\
\hline 96bef... & Gráfica & daniel & CCNum & $\begin{array}{c}5874.3500 .0072 .29 \\
00\end{array}$ & 1.0 & TaksCompleted & 13.518 \\
\hline
\end{tabular}

Nas pesquisas de interfaces de voz recomenda-se o uso de três tentativas seguidas de duas confirmações para obter um dado do usuário. Caso não haja sucesso no $3^{\circ}$ prompt, ele deve ser ajudado de outra maneira ou ser transferido para um atendente humano no caso de sistemas de call center. Essa é uma grande vantagem das interfaces multimodais, pois o usuário consegue ter a possibilidade de usar uma outra modalidade para fornecer a entrada que é esperada em uma tarefa. Esse comportamento foi verificado aplicando-se regras de associação (AGRAWAL; IMIELINSKI; SWAMI, 1993), como é apresentado na sequência.

\subsection{Regras de associação para a identificação de padrões de interação}

Uma regra de associação é uma regra da forma $\mathrm{A} \rightarrow \mathrm{B}$ na qual $\mathrm{A}$ e $\mathrm{B}$ são conjuntos de itens da base de dados, e de tal forma que $\mathrm{A} \cap \mathrm{B}=\varnothing$. As duas medidas clássicas para a geração de regras de associação são suporte e confiança.

$\mathrm{O}$ valor do suporte mede a probabilidade conjunta de ocorrência de um conjunto de itens em uma base de dados, ou seja, $\sup (\mathrm{A} \rightarrow \mathrm{B})=\mathrm{n}(\mathrm{A}$ U B $) / \mathrm{N}$, na qual n(A U B) é o número de transações nas quais os itens em $\mathrm{A}$ e em $\mathrm{B}$ ocorrem juntos, e $\mathrm{N}$ é o número total de 
transações. Já a confiança indica a probabilidade de ocorrência de A e B dado que A ocorreu, ou seja, $\operatorname{conf}(\mathrm{A} \rightarrow \mathrm{B})=\mathrm{n}(\mathrm{A} \mathrm{U} \mathrm{B}) / \mathrm{N}(\mathrm{A})$.

Como foi exemplificado anteriormente, durante as iterações do usuário com o sistema, foram criados $\log s$ das ações dos usuários e das respostas do sistema aplicando-se a técnica MMLOG. Foram criados dois tipos de arquivos de logs: um mantendo todas as iterações de cada usuário e respostas do sistema em uma única tupla da base de dados, que será tratado como BASE-1, e outro arquivo contendo cada ação do usuário e a respectiva resposta do sistema um uma única tupla da base de dados, que será nomeado BASE-2.

A BASE-1 contém 1.530 transações, ou seja, houve 1.530 registros de interação com um protótipo gerado pelo MMWA-ae salvos na base de dados. Cada interação neste caso representa um conjunto de tarefas que foi realizado por um usuário, seguindo o protocolo de testes proposto pelo projetista.

A BASE-2 contém 26.010 transações, ou seja, houve 26.010 interações com elementos específicos de interface do protótipo gerado pelo MMWA-ae. Cada interação neste caso representa uma tarefa específica que foi realizada por um usuário seguindo o protocolo de testes proposto pelo projetista. Ou seja, ambas as bases são iguais, mas a BASE-2 permite uma análise mais detalhada da interação com uma tarefa específica.

Como o número de transações na BASE-2 é consideravelmente maior e o número de itens nas transações é consideravelmente menor, há a necessidade do suporte ser menor. Por exemplo, em uma base com 10 transações, com suporte de 50\%, os itens poderiam coocorrer em 5 transações, o que não seria muito difícil de acontecer. Já em uma base com 1.000 transações, os itens teriam que coocorrer em 500 transações, o que já seria mais improvável apesar de mantida a proporção de 50\%. Além disso, quanto mais itens existirem em uma mesma transação, maior é a chance de um item coocorrer com outro item. Quando há transações com menos itens, a chance de coocorrência é menor, portanto o suporte mínimo deve diminuir também.

Com o uso de associações, foi possível extrair relações do tipo qual a coocorrência e com que confiança o usuário utiliza as modalidades gráfica e de voz ou ambas em conjunto em uma mesma interação, ou ainda, quando o usuário utiliza a interface de voz, qual o tipo de erro mais frequente, em que parte da interface o erro ocorre e como é feita a recuperação do erro.

Para a obtenção das regras de associação da base de $\log s$ foi utilizada a implementação de Christian Borgelt (2004) para encontrar regras de associação utilizando o algoritmo APRIORI (AGRAWAL; SRIKANT, 1994). Como suporte mínimo e confiança 
mínima foram utilizados os valores $50 \%$ e $70 \%$ respectivamente, ou seja, só serão obtidas regras cujos itemsets coocorram no mínimo em $70 \%$ das transações e que a ocorrência de um determinado itemset implica a ocorrência de um itemset em pelo menos em $50 \%$ das vezes. Algumas das regras obtidas utilizando a BASE-1 estão ilustradas no Quadro 14.

Quadro 14 - Exemplos de Regras da BASE-1

\begin{tabular}{|l|c|c|}
\hline \multicolumn{1}{|c|}{ Regras } & Suporte & Confiança \\
\hline$\varnothing \rightarrow$ VOICE & 85.9 & 85.9 \\
\hline$\varnothing \rightarrow$ GRAPHICAL & 87.3 & 87.3 \\
\hline VOICE $\rightarrow$ GRAPHICAL & 74.6 & 86.9 \\
\hline GRAPHICAL $\rightarrow$ VOICE & 74.6 & 85.5 \\
\hline VXML ERROR $\rightarrow$ GRAPHICAL & 50.7 & 92.3 \\
\hline VOICE $\rightarrow$ name GRAPHICAL & 71.8 & 98.1 \\
\hline
\end{tabular}

Pode-se notar que na grande maioria das iterações o usuário opta por usar as modalidade voz e gráfica em conjunto, ou seja, em $74.6 \%$ das interações, utilizou-se da multimodalidade, sendo que a ocorrência do uso de voz implica a ocorrência do uso da interface gráfica com $86.9 \%$ de confiança, e o uso da modalidade gráfica implica o uso de voz com $85.5 \%$ de confiança (Apesar de em $87.3 \%$ das vezes o usuário utilizar a modalidade gráfica, em 74,6\% houve a coocorrência em a modalidade gráfica e a de voz).

Também foram obtidas regras utilizando a BASE-2, ilustradas no Quadro 15. O intuito de utilizar esta base é identificar os erros mais comuns com o uso da modalidade voz. Para este tipo de arquivo foi utilizado um suporte mínimo de $2 \%$ e uma confiança mínima de $10 \%$. O erro mais comum identificado com os limiares de suporte e confiança utilizados foi a identificação do nome quando se utiliza a interface de voz.

Quadro 15 - Regras da BASE-2

\begin{tabular}{|c|c|c|}
\hline \multicolumn{1}{|c|}{ Regras } & Suporte & Confiança \\
\hline VXML ERROR $\rightarrow$ name & 3.3 & 33.6 \\
\hline name $\rightarrow$ VXML ERROR & 3.3 & 32.8 \\
\hline
\end{tabular}

Esse tipo de erro ocorre devido a grande diversidade de nomes e à complexidade da gramática de voz. Nesse caso, a recuperação de erro mais comum é realizada trocando-se para a modalidade gráfica após uma segunda tentativa por voz. Em $71.8 \%$ das interações gráficas com a interface de captura de nomes houve uma interação por voz anterior com $98.1 \%$ de confiança como pode ser verificado na última linha do Quadro 14. 


\subsection{Identificação das propriedades CARE nos logs gerados pela técnica MMLOG.}

Como foi apresentado na Seção 4.7.2, o mecanismo de geração e análise automática de $\log$ em Interações Multimodais Web (MMLOG) é uma técnica utilizada para realizar testes com usuários na atividade de avaliação de usabilidade da MMWA.

Como resultado da execução do MMLOG um arquivo de $\log$ é gerado, contendo informações de interações com cada um dos elementos de interface (widgets).

Pelo fato de que as propriedades CARE podem ser descritas usando uma notação matemática, é possível consultar o MMLOG procurando por uma propriedade específica, ou por erros relacionados a uma propriedade que não tenha sido considerada, mas que é utilizada pelos usuários, gerando um problema de interação.

As fórmulas em notação matemática adaptadas de (COUTAZ et al., 1995; KAMEL; AIT AMEUR, 2007) são apresentadas a seguir:

(1) $C\left(t, M, t^{\prime}\right) \leftrightarrow \operatorname{Card}(M)>1 \wedge \operatorname{Dur}(\Delta t \neq \infty) \wedge\left(m^{\prime} \neq m\right) \wedge\left(\operatorname{Reach}\left(t, m^{\prime}, t^{\prime}\right) \wedge\right.$

$$
\left.\operatorname{Reach}\left(t, m, t^{\prime}\right)\right) m, m^{\prime} \in M
$$

(2) $A\left(t, m, t^{\prime}\right) \leftrightarrow \operatorname{Reach}\left(t, m, t^{\prime}\right) \wedge\left(\forall m^{\prime} \in M \operatorname{Reach}\left(t, m^{\prime}, t^{\prime}\right)\right) \Rightarrow m^{\prime}=m$

(3) $R\left(t, M, t^{\prime}, t w\right) \Leftrightarrow E\left(t, M, t^{\prime}\right) \Rightarrow t w=0$

(4) $E\left(t, M, t^{\prime}\right) \leftrightarrow(\operatorname{Card}(M)>1) \wedge\left(\forall m \in M \operatorname{Reach}\left(t, m, t^{\prime}\right)\right)$

Onde:

- $\mathrm{t}=$ tarefa atual.

- $\mathrm{t}^{\prime}=$ próxima tarefa.

- $\mathrm{tw}=($ tempo final - tempo inicial $)$.

- $\mathrm{M}=$ conjunto de modalidades $\left(m, m^{\prime} \in M\right)$.

- $\quad$ Card = cardinalidade de $\mathrm{M}$.

- $\quad$ Reach = função que descreve o fluxo entre as tarefas $t$ e $t$ '.

$\mathrm{Na}$ Seção 5.4, foi apresentado um exemplo de propriedade CARE que gerou um problema de usabilidade, e como as informações contidas no modelo e atualizadas com a aplicação do MMLOG contribuíram para a solução deste problema, pois o usuário utilizou complementaridade, em sua interação, e o sistema somente entendia redundância e equivalência. 
Essa identificação de problema é possível, analisando-se o log gerado. No exemplo do Quadro 16 percebe-se que houve um evento de nomatch na interface de voz seguido de uma interação com a interface gráfica que completou a tarefa. Nesse caso o usuário ouviu um prompt de erro que poderia ser evitado.

Após a transcrição da fala que gerou o evento de erro, é possível aplicar a fórmula (1) e identificar que se a propriedade complementaridade fosse utilizada, a tarefa teria sido completada com sucesso, pois a utilização de duas modalidades para a mesma tarefa resultou na finalização bem sucedida de uma tarefa.

Essa informação fica disponível no modelo de tarefas e o projetista pode aceitar a sugestão diretamente na interface do MMWA-ae.

Quadro 16 - Exemplo de erro que pode ser corrigido com o uso das propriedades CARE

\begin{tabular}{|c|c|c|c|c|c|c|c|c|}
\hline SsID & Modalidade & Usuário & Tarefa & Interface & Interpretação & Confiança & Evento & Tempo \\
\hline 44 xqs... & Voz & vandre & ChoosePlace1 & choose_place_2 & - & - & NoMatch1 & 23.40 \\
\hline $44 x q s . .$. & Gráfica & vandre & ChoosePlace1 & place2Input & CentralPark & - & TaksCompleted & 24.00 \\
\hline \multicolumn{7}{|c|}{ Mesma interação, após inclusão da propriedade Complementaridade: } \\
\hline 03qwe... & Voz & vandre & ChoosePlace1 & choose_place_2 & Select this & 1.0 & Recognition & 21.20 \\
\hline 03qwe... & Gráfica & vandre & ChoosePlace1 & place2Input & CentralPark & - & TaksCompleted & 22.44 \\
\hline
\end{tabular}

\subsection{Documentação e processo de captura, armazenamento e recuperação de DR}

O intuito de capturar DR nos estudos de caso foi criar uma base de informações contendo o raciocínio das decisões de projetos obtidas durante o projeto de artefatos. $\mathrm{O}$ entendimento da justificativa das decisões de projeto feitas ao longo do processo de criação das interfaces é necessário para compreender, recriar, reutilizar ou modificar o projeto.

O formato de representação de DR é importante para certificar que o raciocínio capturado será utilizado eficientemente em outros projetos. A abordagem que foi utilizada para representar o DR foi a representação em páginas Wiki de forma que o DR pudesse ser capturado e armazenado usando os métodos e mídias tradicionalmente aceitos para a representação do conhecimento de maneira colaborativa.

As páginas da Wiki são criadas automaticamente pelo MMWA-ae e organizadas de acordo com o projeto que está sendo desenvolvido, e de acordo com a atividade da abordagem que está sendo utilizada no momento. A ferramenta também oferece suporte para 
que o DR seja coletado em um formato pré definido de modo que possa ser interpretado e entendido por ferramentas computacionais e um suporte à recuperação da informação possa ser fornecido.

A vantagem dessa abordagem é que o método utilizado para capturar e recuperar informações de DR é semiautomatizado. A informação também pode ser acessada pela página principal da Wiki, em uma maneira convencional, ao invés de usar a ferramenta de autoria, de acordo com um modelo de página predefinido (namespace). Isso é possível, pois o MMWA-ae cria automaticamente uma página com links para os DR, organizados por projeto e atividade da MMWA.

Como resultado, o MMWA-ae facilita e promove a recuperação de DR para verificar se as decisões de projeto e o produto refletem o que foi definido na atividade de especificação do MCI. Da mesma forma, o DR foi utilizado nos ECs para avaliar as várias alternativas de projeto discutidas no processo de projeto na atividade de Análise das Soluções da MMWA.

Foi verificado que o design rationale é também importante para ajudar a determinar as mudanças que são necessárias para alterar o projeto nas fases de manutenção e também para determinar como um determinado artefato pode ser reutilizado em um novo projeto com a MMWA.

Além disso, o DR foi utilizado como um recurso para ensinar novos membros da equipe de projeto que não eram familiares com o projeto ou com a tecnologia e as linguagens de programação multimodais a aprender sobre as melhores práticas neste contexto. Da mesma forma, promoveu a comunicação entre a equipe de projeto facilitando a troca de informações entre as pessoas que estavam envolvidas no processo, ajudando-os a obter um projeto mais organizado de maneira mais rápida e a verificar as decisões tomadas no processo de projeto.

Em complemento, favoreceu e facilitou a criação da documentação do produto, que envolvia reuniões de projeto, discussões de alternativas de projeto, raciocínio das soluções, melhor entendimento do fluxo de atividades e tarefas, entre outros, devido às características do design rationale para documentar as atividades de projeto como um todo.

\subsection{Identificação de padrões de projeto a partir de DR}

Outro resultado significativo obtido foi uma técnica para identificação de padrões de projeto a partir do DR capturado nos estudos de caso. Com base no DR coletado em vários projetos, foi criada uma técnica que ajuda na identificação de um padrão de projeto, também 
conhecido como uma fonte de soluções comprovadas para um problema recorrente em um contexto conhecido (NETO et al., 2006).

Na Figura 58 é ilustrado como um padrão de projeto pode ser identificado com base em características do DR como questões, posições e argumentos e algumas atividades agregadoras (atividades guarda-chuva) que são aplicadas em todo o processo da MMWA para a identificação do raciocínio, como as propriedades CARE, padrões de interação e preferências do usuário, bem como as heurísticas, princípios e checklists que ajudam na formalização dos padrões de projeto.

Essa técnica fundamenta-se em questões sobre problemas repetidos que são encontrados no DR, os quais são resumidos como o problema, posições recorrentes apoiadas por argumentos bem formulados, o que leva às forças e todo o raciocínio capturado, que pode ser derivado em uma solução.

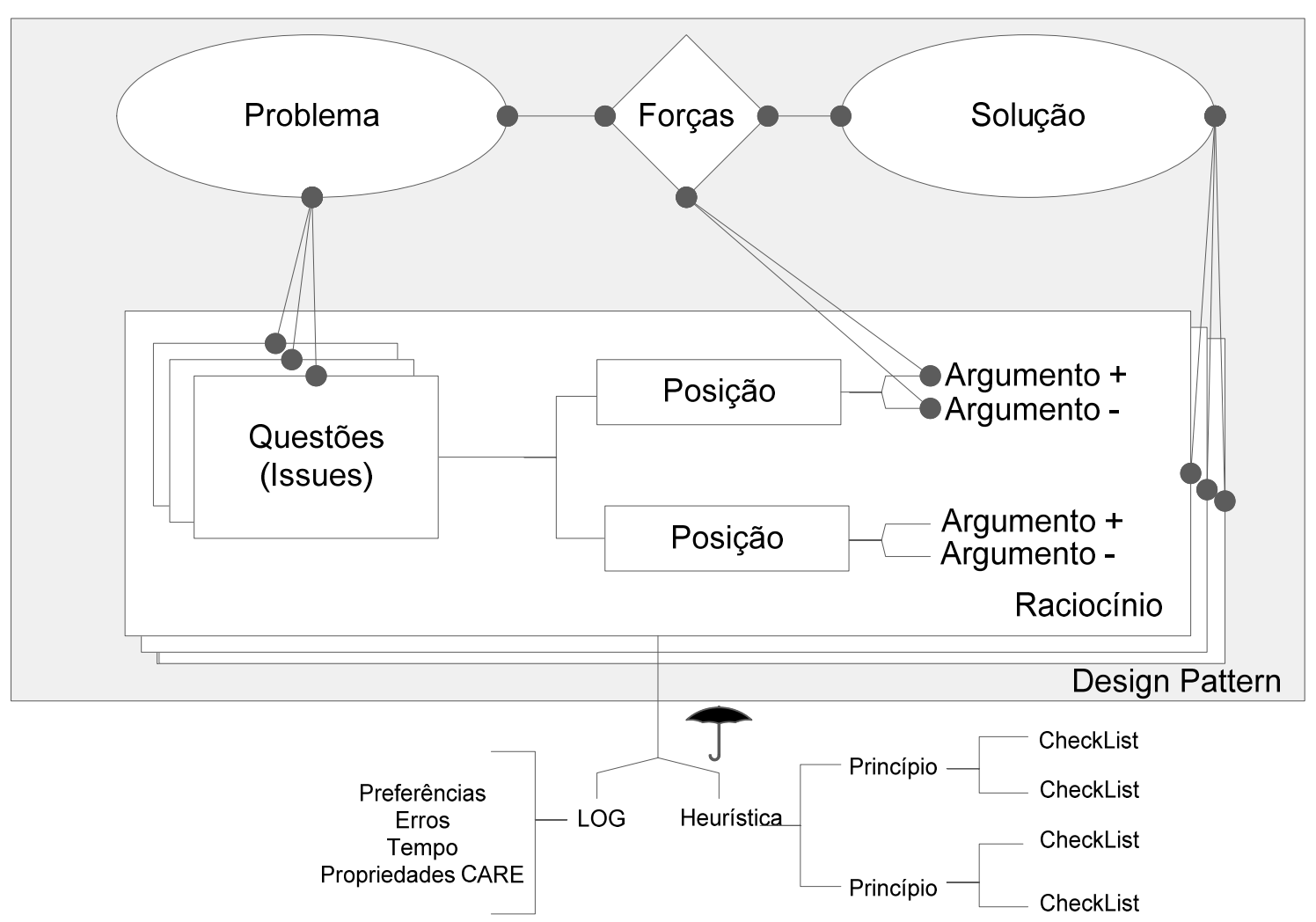

Figura 58 - Estrutura para identificação de padrões de projeto

O padrão Large Group Selection, Apêndice A, foi identificado utilizando como base o DR dos ECs armazenado na DokuWiki.

O Problema, "Como apresentar um grande grupo de informações de entrada para o usuário na interface multimodal?", foi identificado a partir de diferentes Questões em diversos artefatos do Modelo de Tarefas, como foi apresentado na Figura 36 da seção 5.4. As Forças ou motivações são um resumo dos Argumentos utilizados pelos projetistas para se 
chegar a uma conclusão. A Solução e os Exemplos são obtidos das Posições dos projetistas que levaram às Soluções finais dos DR e o Contexto Resultante foi obtido de Questões que foram geradas a partir da questão principal.

\subsection{Considerações quanto à reutilização de código}

A reutilização de código pode ocorrer de diversas maneiras, por exemplo, por meio de geração de código fonte ou por herança, sendo assim difícil determinar qual oferece maior vantagem. Existem diferentes métricas para reutilização, como as estruturais, econômicas e de repositório (LUCREDIO et al., 2008), mas neste trabalho serão considerados os aspectos estruturais, com as métricas de taxa de reutilização desejada e não desejada.

Para obter a taxa de reutilização e verificar que o reuso foi promovido pela MMWAae, a seguinte fórmula foi definida e utilizada:

(1) ReutilizationRate $=($ LOCreused + LOCWhiteBox - LOC of non-desired methods $) /$ LOC total

Onde:

- LOCreused: LOC gerado pelo MMWA-ae. Inclui a implementação de gramáticas, código CSS, interface $\mathrm{X}+\mathrm{V}$, sugestões obtidas dos DRs e dos padrões de projeto identificados neste trabalho.

- LOCWhiteBox: LOC gerado pelo MMWA-ae, tais como, a definição de métodos e templates que devem ser completados pelo desenvolvedor. Isso requer que o desenvolvedor entenda o que deve ser feito para usá-lo de maneira eficiente. Por essa razão o uso do DR é importante para explicar o "como" e o "porquê". Exemplo: o MMWA-ae gera a definição de funções ECMAscript para permitir validação, verificação, etc. Os métodos utilizado nas classes de avaliação de usabilidade também podem ser estendidos.

- LOC of non-desired methods: LOC que deve ser removido do produto final, por não ter serventia.

- LOC total: o número total de linhas de código gerado pela MMWA-ae.

É importante mencionar que o mecanismo de geração de código do MMWA-ae segue as referências de implementação dos DR e padrões de projeto, evitando assim a geração intensa de código, geralmente produzida por geradores de código convencionais. O 
"LOCWhiteBox" foi considerado porque acredita-se que essa é a contribuição mais valiosa do gerador de código, uma vez que fornece aos desenvolvedores uma boa percepção sobre a forma de complementar os métodos para obter um código de boa qualidade e, assim, aumentar a usabilidade da interface como um todo.

No MMWA-ae foram incluídos até o momento da escrita da tese os DRs relacionados com usabilidade/acessibilidade, padrões de projeto, prompts de voz, gramáticas de voz, código fonte $\mathrm{X}+\mathrm{V}$, sincronização e documentação.

Esses DR foram embutidos no código gerado, ou seja, o projetista seleciona uma opção no MMWA-ae e o código é gerado automaticamente.

Apenas os DR relacionados com a arquitetura de projeto e a plataforma em que o reconhecedor de voz funciona não foram considerados no código do MMWA-ae.

Aplicando-se a fórmula de reutilização para o código gerado no último estudo de caso com o MMWA-ae foi obtida uma taxa de reutilização de $83 \%$ e $3,2 \%$ de reutilização não desejada.

Taxa de Reutilização para o EC3 = 0,83 = 83\%:

- LOCreused: 534

- LOCWhiteBox: 13

- LOC of non-desired methods: 20

- LOC total: 636

Porcentagem de métodos não desejados $=20 / 636=3.2 \%$

Em um outro exemplo, retirado do terceiro estudo de caso, pode-se citar o fato que o MMWA-ae foi utilizado para gerar a interface de apresentações para eventos, ou seja, uma interface multimodal Web foi criada. Três arquivos foram automaticamente criados. Pode-se aplicar a fórmula para o cálculo da taxa de reutilização para cada artefato gerado:

Uma gramática de voz, cuja taxa de reutilização foi igual a 100\%:

○ LOCreused: 59

○ LOCWhiteBox: 0

○ LOC of non-desired methods: 0

○ LOC total: 59 
○ Non-desired methods percentage $=0 \%$

Um arquivo $\mathrm{X}+\mathrm{V}$, cuja taxa de reutilização foi igual a $84 \%$ :

○ LOC reused: 416

○ LOC criado pelo desenvolvedor: 42

○ LOCWhiteBox: 23

- LOC of non-desired methods: 13

○ LOC total: 494

$\circ$ Non-desired methods percentage $=2.6 \%$

Um arquivo CSS, cuja taxa de reutilização foi igual a 100\%:

○ LOC reused: 96

○ LOC criado pelo desenvolvedor: 0

○ LOCWhiteBox: 0

○ LOC of non-desired methods: 0

○ LOC total: 96

$\circ \quad$ Non-desired methods percentage $=0 \%$

É interessante notar que no exemplo anterior a taxa de reutilização é maior do que no primeiro exemplo e o LOC é menor, ou seja, para projetos pequenos e para a geração de protótipos rápidos para testes de usabilidade, o MMWA-ae é eficiente, principalmente se for considerado o tempo gasto para a obtenção das interfaces, conforme será apresentado na próxima seção.

\subsection{Tempo gasto para projetar a interface e para obter o protótipo de interface para testes com usuários.}

O tempo gasto para projetar a interface é uma das principais vantagens da utilização do MMWA-ae, uma vez que o protótipo pode ser obtido logo após a conclusão da fase de projeto. 
Em contraste, quando o MMWA-ae não é utilizado várias tarefas devem ser realizadas antes da geração do protótipo, como: consultas de DR na base de dados, discussões em equipe para validar a implementação, rodadas de análise de erros para corrigir problemas de usabilidade das interfaces, criação e testes de gramáticas de interfaces de voz, etc.

Outra área de interesse é o tempo utilizado para criar interfaces de voz (VUI), que foi reduzido. O MMWA-ae oferece ao projetista um assistente para gerar todos os importantes prompts para serem utilizados em cada interface, por exemplo, prompts iniciais, de erro, confirmação, etc. Além disso, escolhendo um dos padrões de projeto ou um componente, por exemplo, o componente "Calendário", a ferramenta cria automaticamente a GUI, a VUI, a gramática e os mecanismos para sincronizá-las, economizando tempo de desenvolvimento. Isso também contribui para o aumento de usabilidade das interfaces, uma vez que o MMWAae implementa a estratégia de recuperação de erros e os comandos de voz universais (BOHUS; RUDNICKY, 2008), criando uma interface multimodal mais robusta.

Para a criação do sistema de aluguel de carros do EC3, foi considerada uma implementação de referência, ou seja, um dos sistemas desenvolvidos no EC1, sem o uso da MMWA-ae.

O resultado relativo ao número de horas e linhas de código criadas pode ser observado no Quadro 17. Pode-se observar que o número de horas gastas para o desenvolvimento das interfaces do EC3 foi aproximadamente oito vezes menor do que para o EC1, o que reforça a afirmação de que o tempo gasto para a obtenção de protótipos com o uso do MMWA-ae é uma vantagem.

Quadro 17 - Tempo de desenvolvimento das interfaces geradas no EC1 e EC3

\begin{tabular}{|c|c|c|}
\cline { 2 - 3 } \multicolumn{1}{c|}{} & Implementação Referência EC1 & Implementação MMWA-ae EC3 \\
\hline $\begin{array}{l}\text { Tempo de desenvolvimento } \\
\text { (não inclui projeto e testes) }\end{array}$ & $\sim 24 \mathrm{hs}$ & $\sim 3 \mathrm{hs}$ \\
\hline LOC & 575 & $\mathbf{6 3 6}$ \\
\hline
\end{tabular}

\subsection{Considerações finais}

Neste capítulo foram apresentados os principais resultados obtidos com a avaliação e interpretação dos dados dos estudos de caso, visando caracterizar os efeitos da aplicação da abordagem e do ambiente de autoria propostos no projeto de interfaces multimodais Web.

Esses resultados também permitiram determinar as principais contribuições e as principais limitações deste trabalho, conforme será discutido no próximo capítulo. 


\section{Capítulo 8. Conclusões}

\subsection{Considerações iniciais}

O principal objetivo do desenvolvimento de aplicações multimodais é possibilitar uma maneira mais natural dos seres humanos se comunicarem com as máquinas, por meio de interfaces mais eficientes, intuitivas, fáceis de usar e, de certa forma, mais inteligentes.

No entanto, a literatura da área mostra que a usabilidade é um objetivo constante procurado por pesquisadores e profissionais envolvidos com desenvolvimento de software, mas até então pouco considerada nas ferramentas de autoria de interfaces multimodais existentes atualmente.

A percepção é que a usabilidade é um conceito simples de se colocar em prática e não requer tanto esforço nas fases de projeto e desenvolvimento, mas a sua aplicação na prática é complexa principalmente no que tange à reutilização sistemática e gerenciável de conhecimento de projeto.

A reutilização, tanto de conhecimento como de código fonte, ainda apresenta problemas, dados a complexidade do código em sistemas multimodais, a falta de mecanismos eficientes de testes de usabilidade e a dificuldade em se gerenciar a captura, o armazenamento e a recuperação de conhecimento de projeto, tópicos que foram abordados no texto desta tese de doutorado.

As soluções, para problemas específicos, que são encontradas na literatura são difíceis de reutilizar em projetos diferentes dos propostos pelos autores. É também difícil entender as razões para se especificar uma determinada interface, pois nenhuma ferramenta apresenta mecanismos para recuperar e facilitar o entendimento do raciocínio a ser utilizado na criação de uma determinada interface. As soluções apresentadas em artigos científicos provêm soluções circunstanciais empregadas em um tipo de interação particular.

As ferramentas e a tecnologia utilizadas para a criação aplicações multimodais são complexas e consomem muito recurso de máquina, tornando difícil a instalação e a utilização em projetos Web pequenos ou diferentes da proposta de uso, modalidades e dispositivos de interação planejados pelos autores.

Além disso, as ferramentas encontradas na pesquisa bibliográfica apresentam problemas de extensibilidade e, as que são baseadas em modelos, dificilmente incluem informações de usabilidade das interfaces em seus modelos. 
Neste capítulo são resumidas as contribuições apresentadas nesta tese de doutorado para o projeto, desenvolvimento e avaliação de interfaces multimodais Web, no que tange:

- Contribuições teóricas e conceituais, uso e validação dos conceitos que circundam o problema atacado;

- Contribuições metodológicas aos projetistas com a finalidade de prover auxílio na manipulação dos conceitos introduzidos neste trabalho;

- Suporte ferramental expressando como as contribuições metodológicas podem ser apoiadas por um software.

\subsection{Contribuições}

Nesta tese foram discutidas propostas e idéias para resolver parte dos problemas abordados anteriormente sobre o projeto e desenvolvimento de interfaces multimodais Web.

Estudos e pesquisas nas principais fontes de artigos científicos da área foram realizados para a definição de uma abordagem centrada no usuário e um ambiente de autoria composto por um modelo de tarefas visando também guiar o projetista e o desenvolvedor deste tipo de interface desde as atividades iniciais de levantamento de requisitos até a fase de avaliação de usabilidade.

Assim, pode-se identificar as seguintes contribuições, resultados deste trabalho:

- Uma abordagem centrada no usuário, sistemática, contendo atividades, entradas e saídas que descrevem as tarefas necessárias para a obtenção de uma interface multimodal com usabilidade.

- Definição de um mecanismo de avaliação de usabilidade automática contendo métodos analíticos e empíricos, que se conectam a um modelo de análise de tarefas, por meio do relacionamento de lista de verificação (checklists), princípios e heurísticas e com o auxílio de dados obtidos com a análise de interações com usuários reais.

- Desenvolvimento e utilização de uma técnica para a utilização de sistemas Wiki para a coleta, armazenamento e recuperação de DR, para que o conhecimento de projeto seja armazenado estruturadamente de uma maneira não intrusiva, de forma que futuros projetos possam se beneficiar, diminuindo o tempo necessário para a criação de interfaces multimodais Web.

- Ambiente de autoria e modelo de tarefas que permitem a geração de protótipos de interfaces. 
- Diretrizes para promover a reutilização de código e DR e a criação de um mecanismo automático de sugestões de correção de problemas de usabilidade, fundamentado no modelo de tarefas proposto nesta tese.

- Identificação e formalização de padrões de projeto específicos para interfaces multimodais Web.

- Elaboração de um material de treinamento, um relatório técnico e de um curso sobre Interfaces Multimodais Dinâmicas, que podem vir a ser reaproveitados em cursos de extensão, mini cursos, workshops e tutoriais relacionados aos principais temas da tese.

- Publicação de artigos científicos e apresentações em conferências importantes para a área de pesquisa.

- Orientação de dois alunos de graduação que utilizaram esta pesquisa em suas monografias de projeto final na disciplina de Projeto/Estágio (SCC298/299) do ICMC/USP.

\subsection{Lições aprendidas}

Em 2006, no início desta pesquisa, era difícil encontrar ferramentas para o projeto de interfaces multimodais Web disponíveis para acesso e avaliação. Todo o conhecimento era divulgado em artigos científicos, e até mesmo os dispositivos para acessar essa tecnologia não eram facilmente encontrados.

Hoje em dia, com a disseminação de dispositivos como o celular IPhone e o tablet IPad da Apple Inc, o videogame Wii da Nintendo ${ }^{\circledR}$ e o console Kinect para Xbox da Microsoft ${ }^{\circledR}$, e com a criação de mecanismos para acesso e simulação de testes em dispositivos remotos para desenvolvedores, como o Device Anywhere ${ }^{12}$, novas aplicações multimodais surgem a cada dia e novas pesquisas na área, incluindo novas ferramentas e abordagens, vão sendo divulgadas no ambiente acadêmico e comercial.

Além disso, as empresas começaram a fornecer aos desenvolvedores, os kits de desenvolvimento de software (SDK), com o objetivo de permitir que qualquer pessoa em qualquer lugar possa criar um software para ser executado em um determinado dispositivo utilizando a sua tecnologia. Isso dá às empresas um grande diferencial competitivo, uma vez que mais produtos são lançados com a sua tecnologia ou mais dispositivos da empresa são vendidos por causa das funcionalidades que eles oferecem.

${ }^{12} \mathrm{http} / \mathrm{www}$. deviceanywhere.com/ 
Outra característica importante do mercado atualmente é o conceito de software como serviço, do inglês Software As A Service (SAAS), que é um instrumento mercadológico para fornecer um software, em forma de um serviço ou prestação de serviços. O software é executado em um servidor, não sendo necessário instalar o sistema no computador do cliente, bastando acessá-lo pela Internet. Como exemplo, o Google-Docs ${ }^{13}$ oferece um pacote de programas similares ao pacote MS Office da Microsoft.

A experiência adquirida no ambiente industrial pelo doutorando também é um ponto interessante para ser analisado, pois muitas das ideias aplicadas no trabalho de doutorado surgiram de necessidades reais de clientes e até mesmo a escolha das tecnologias e das atividades usadas neste trabalho são utilizadas em projetos reais.

De igual importância, pode-se citar as atividades acadêmicas, como orientação de alunos de graduação e seminários apresentados sobre o tema da tese que contribuíram muito para o crescimento intelectual e profissional do doutorando.

Dessa forma, pode-se dizer que essas características aqui mencionadas, bem como as particularidades da tecnologia do contexto mercadológico em que o trabalho está inserido contribuíram para a criação da MMWA e da MMWA-ae.

A validação do trabalho foi alcançada aplicando-se o método estudo de caso, cujo objetivo principal foi mostrar a viabilidade da abordagem proposta e as vantagens do ambiente de autoria desenvolvido e do uso de DR no processo como um todo. No Capítulo 6 apresentaram-se o planejamento, a definição e a execução dos estudos de caso e foram identificadas as principais hipóteses que foram exploradas em detalhes no Capítulo 7.

Cabe ressaltar que a diversidade de interfaces multimodais desenvolvidas e o fato do MMWA-ae ter sido projetado para ser reutilizável, extensível, adaptável e modular são resultados importantes obtidos para que ele possa ser continuamente evoluído e possa ser utilizado em projetos no ambiente industrial.

\subsection{Publicações resultantes do trabalho realizado nesta tese}

Conforme foi citado na Seção 8.2, foram publicados trabalhos relacionados ao tema desta tese. As publicações estão relacionadas com a linha do tempo apresentada na Seção 6.3 e que está complementada a seguir, na Figura 59.

\footnotetext{
${ }^{13}$ http://docs.google.com
} 
Como pode-se observar, para cada ciclo definido (Pesquisa Bibliográfica, Abordagem e Ferramenta) foram publicados artigos que divulgam os resultados de cada atividade e período de tempo.

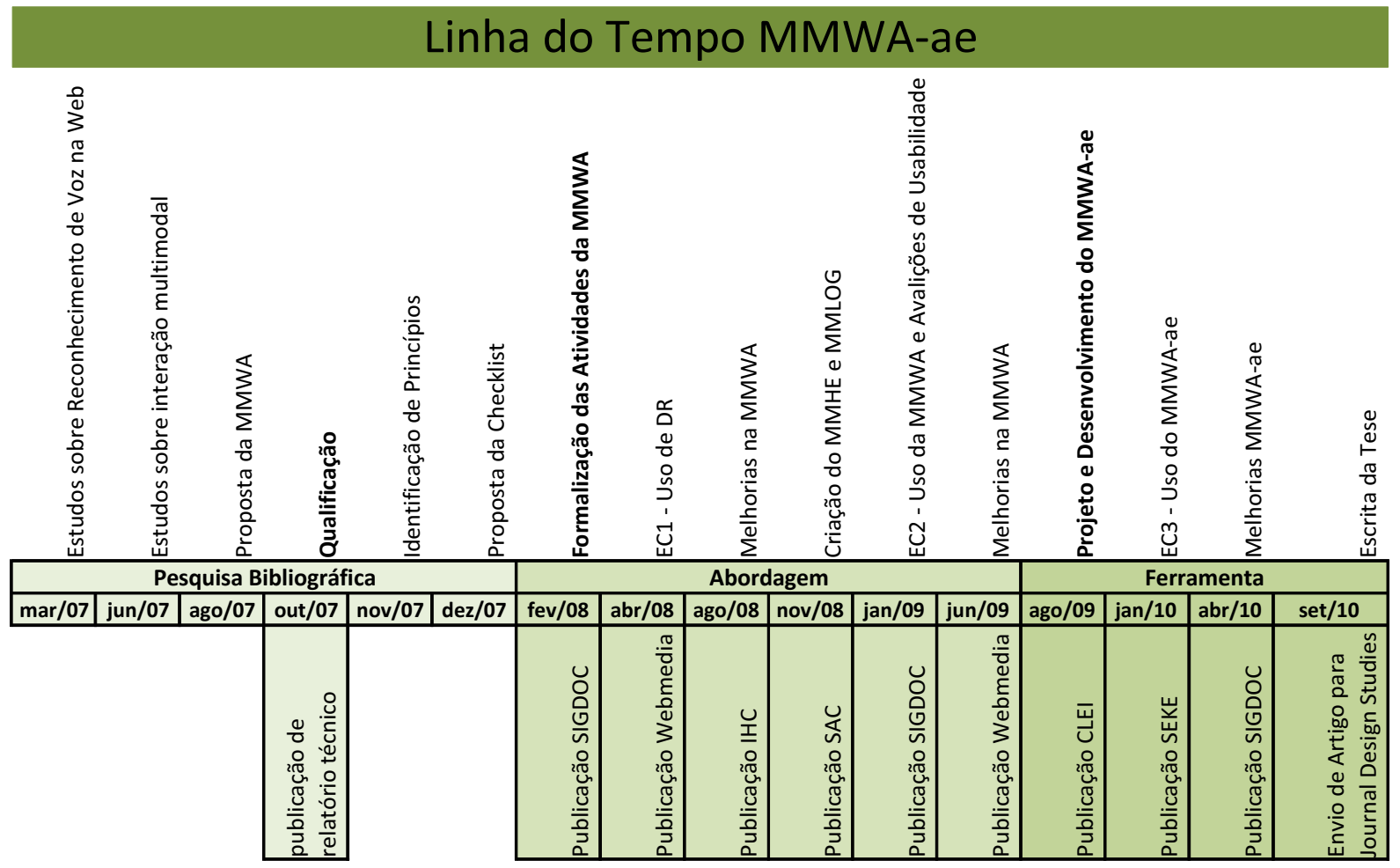

Figura 59 - Linha do tempo das atividades realizadas no doutorado e publicações

A seguir, estão listadas as publicações realizadas no período do doutorado:

\section{Capítulo de livro publicado:}

- TALARICO NETO, A. ; Fortes, R.P.M . Interfaces Multimodais Dinâmicas Utilizando J2EE. In: Marcos Roberto da Silva Borges e José Gonçalves Pereira Filho. (Org.). XIV SIMPÓSIO BRASILEIRO DE SISTEMAS MULTIMÍDIA E WEB: WEBMEDIA 2008: MINICURSOS. 14 ed. VILA VELHA: Sociedade Brasileira de Computação, 2008, v. 1, p. 1-48.

Trabalhos completos publicados em anais de congressos:

- TALARICO NETO, A., Fortes, R.P.M. Improving multimodal interaction design with the MMWA authoring environment In: SIGDOC 2010, 2010, São Carlos. ACM International Conference on Design of Communications. New York: The Association for Computer Machinery, 2010. v.1. p.151 - 158

- TALARICO NETO, A. ; Fortes, R.P.M ; RESENDE, S. ; ROSSI, R. . MMWA-ae: boosting knowledge from Multmodal Interface Design, Reuse and Usability Evaluation. In: The 22nd International Conference on Software Engineering \& Knoledge Engineering., 2010, San Francisco. SEKE 2010 - The 22nd International 
Conference on Software Engineering \& Knoledge Engineering. Skokie : Knowledge Systems Intitute Graduate School, 2010. v. 1. p. 355-360.

- $\quad$ TALARICO NETO, A. ; Fortes, R.P.M ; Bittar, T.J. ; Felizardo K.R . Developing and evaluating Web multimodal interfaces - a case study with usability Princípios. In: ACM symposium on Applied Computing, 2009, Honolulu, Hawaii. Proceedings of the 2009 ACM symposium on Applied Computing. New York, NY, USA : ACM, 2009. p. 116-120.

- TAlARICO NETO, A. ; Fortes, R.P.M ; Assis, Alessandro . Avaliação de Usabilidade em Interfaces Multimodais Web: Estudos de caso com a Abordagem MMWA. In: XXXV CLEI - Latin American Informatics Conference, 2009, Pelotas RS. Anais do CLEI 2009., 2009. v. 1. p. 1-10.

- $\quad$ TALARICO NETO, A. ; Fortes, R.P.M ; Assis, Alessandro ; Watanabe, W.M . O uso de técnicas automáticas para Avaliação de Usabilidade no projeto de Interfaces Multimodais Web. In: XV Webmedia - Simpósio Brasileiro de Sistemas Multimídia e Web, 2009, Fortaleza. Anais do Webmedia 2009. Porto Alegre : SBC, 2009. v. 1. p. $1-8$.

- $\quad$ TAlARICO NETO, A. ; Fortes, R.P.M ; Assis, Alessandro ; ANACLETO, J. C. . Design of Communication in Multimodal Web Interfaces. In: ACM International Conference on Design of Communication, 2009, Bloomington. 27th ACM International Conference on Design of Communication.. New York : ACM Digital Library, 2009. v. 1. p. 81-88.

- TAlARICO NETO, A. ; Bittar, T.J. ; Fortes, R.P.M ; Felizardo K.R . Abordagem para o desenvolvimento e avaliação de interfaces multimodais Web pautada em princípios de usabilidade. In: VIII Simpósio sobre Fatores Humanos em Sistemas Computacionais IHC 2008, 2008, Porto Alegre. VIII Simpósio Sobre Fatores Humanos em Sistemas. Porto Alegre: Sociedade Brasileira de Computação SBC, 2008. v. 1. p. 21-30.

\section{Resumos publicados em anais de congressos:}

- WATANABE, W.M ; TALARICO NETO, A. ; Silva Filho, A.G ; Fortes, R.P.M . Desenvolvimento de componentes de interfaces multimodais ricas para a Web utilizando X+V e Dojo Widgets. In: XIV Simpósio Brasileiro de Sistemas Multimídia e Web, 2008, Vila Velha. XIV Simpósio Brasileiro de Sistemas Multimídia e Web. Porto Alegre: SBC, 2008. v. 1. p. 97-100.

- TAlARICO NETO, A. ; Fortes, R.P.M ; Silva Filho, A.G . Multimodal interfaces design issues: the fusion of well-designed voice and graphical user interfaces. In: 26th ACM International Conference on Design of Communication, 2008, Lisbon. 26th ACM International Conference on Design of Communication, 2008. v. 1. p. 277-278.

\section{Relatório técnico:}


- TALARICO NETO, A. ; Fortes, R.P.M . Introdução a XHTML+Voice: Adicionando voz às aplicações Web. 2008.

\subsection{Limitações e oportunidades para trabalhos futuros}

Durante o desenvolvimento desta tese foram identificadas algumas limitações e oportunidades para o desenvolvimento de trabalhos futuros que não foram investigados neste trabalho:

- Estudos empíricos: os dados obtidos com os estudos de caso e que expressam resultados relacionados com problemas de usabilidade identificados pelo MMHE possuem deficiências como a falta de rigor estatístico. Nos estudos de caso, procurou-se seguir as orientações encontradas em (NIELSEN, 2004) e avaliar questões qualitativas embasadas em observação, entrevistas e questionários com a finalidade de observar o comportamento dos desenvolvedores e usuários. Assim, pode-se obter mais resultados com a realização de novos experimentos quantitativos com equipes maiores ou em estudos fora do ambiente acadêmico. Por outro lado, os dados relativos à coleta de $\log s$ de interação realizadas pelo MMLOG foram analisados empiricamente, conforme explicado na Seção 7.6.

- Fusão de interfaces existentes: apesar do MMWA-ae permitir o uso de código fonte existente no desenvolvimento de novas interfaces, é interessante criar um mecanismo que importe esse código, analise a sua estrutura e sugira a correção de possíveis problemas de usabilidade que possam surgir por causa da fusão das modalidades.

- Coleta de DR e identificação de padrões de projeto: nos estudos de caso realizados, foram obtidos os seguintes números em relação ao DR: 60 questões foram criadas, 664 discussões foram obtidas para as questões e 207 consultas foram feitas em busca de soluções. Essa base de dados pode ser aumentada e mais resultados podem ser obtidos principalmente no tocante à identificação de padrões de projeto.

- Inclusão de outras modalidades e outros ambientes, diferentes da Web, podem ser realizados para validar a extensibilidade dos módulos projetados para o MMWA-ae. 
- Adaptação de interfaces, para diferentes tipos de dispositivos, pode ser testada modificando-se apenas o gerador de código do MMWA-ae, pois a MMWA foi criada com esse objetivo, tendo em vista que a especificação das tarefas e o seu modelo não mudam e somente o código que representa as interfaces concretas deve ser modificado. 


\section{Referências Bibliográficas}

[ABRAMS, M.; et al., 1999] ABRAMS, M.; PHANOURIOU, C.; BATONGBACAL, A. L.; WILLIAMS, S. M.; SHUSTER, J. E. UIML: an appliance-independent XML user interface language. Comput. Netw., v. 31, n. 11-16, p. 1695-1708, 1999. ISSN 1389-1286.

[AGRAWAL, R.; IMIELINSKI, T.; SWAMI, A., 1993] AGRAWAL, R.; IMIELINSKI, T.; SWAMI, A. Mining Association Rules between Sets of Items in Large Databases. In: PETER BUNEMAN e SUSHIL JAJODIA, Proceedings of the 1993 ACM SIGMOD International Conference on Management of Data, 1993. p.207-216.

[AGRAWAL, R.; SRIKANT, R., 1994] AGRAWAL, R.; SRIKANT, R. Fast algorithms for mining association rules. p. 487-499, 1994. Disponível em: < http://citeseerx.ist.psu.edu/viewdoc/summary?doi=10.1.1.40.7506 >.

[ALEXANDER, C.; ISHIKAWA, S.; SILVERSTEIN, M., 1977] ALEXANDER, C.; ISHIKAWA, S.; SILVERSTEIN, M. A Pattern Language. New York: Oxford University Press, 1977.

[ALLEN, J.; et al., 2001] ALLEN, J.; BYRON, D.; DZIKOVSKA, M.; FERGUSON, G.; GALESCU, L. Toward conversational human-computer interaction. AI Mag., v. 22, n. 4, p. 27-37, 2001. ISSN 0738-4602.

[ALLEN, J. E.; GUINN, C. I.; HORVTZ, E., 1999] ALLEN, J. E.; GUINN, C. I.; HORVTZ, E. Mixed-Initiative Interaction. IEEE Intelligent Systems, v. 14, n. 5, p. 14-23, 1999. ISSN 1541-1672.

[ALMOR, A., 1999] ALMOR, A. Noun-Phrase Anaphora and Focus: The Informational Load Hypothesis. 1999.

[ANEGG, H.; et al., 2004] ANEGG, H.; NIKLFELD, G.; SCHATZ, R.; SIMON, R.; WEGSCHEIDER, F. Multimodal interfaces in mobile devices - the mona project MobEA II - Emerging Applications for Wireless and Mobile Access Workshop at the 13th International World Wide Web Conference 2004.

[BAGGIA, P. L.; et al., 2007] BAGGIA, P. L.; CARTER, J.; DAHL, D. A.; MCCOBB, G. EMMA: Extensible MultiModal Annotation markup language. W3C Working Draft: W3C 2007.

[BARFIELD, L.; et al., 1994] BARFIELD, L.; BURGSTEDEN, W. V.; LANFERMEIJER, R.; MULDER, B.; JURRI; OSSEWOLD, N.; RIJKEN, D.; WEGNER, P. Interaction design at the Utrecht School of the Arts. SIGCHI Bull., v. 26, n. 3, p. 49-86, 1994. ISSN 07366906. 
[BELL, J., 1989] BELL, J., Ed. Doing your research project: a guide for the first-time researchers in education and social science. London, England: Open University Press, p.195ed. 1989.

[BERNHAUPT, R., 2008] BERNHAUPT, R. Methods for Usability Evaluation of Multimodal Interfaces. . In: (Ed.). Tailoring Usability into Agile Software Development Projects IGI Globa, v.1, 2008. p.96-119.

[BERNHAUPT, R.; et al., 2008] BERNHAUPT, R.; NAVARRE, D.; PALANQUE, P.; WINCKLER, M. Tailoring Usability into Agile Software Development Projects. In: EFFIE LAI-CHONG LAW;EBBA THORA HVANNBERG, e col (Ed.). Maturing Usability: Springer London, 2008. p.96-119. (Human-Computer Interaction Series). ISBN 978-184628-941-5.

[BERTI, S.; PATERNO, F., 2005] BERTI, S.; PATERNO, F. Migratory MultiModal interfaces in MultiDevice environments. Proceedings of the 7 th international conference on Multimodal interfaces. Torento, Italy: ACM: 92-99 p. 2005.

[BHATTI, S., 2005] BHATTI, S. Why quality?: ISO 9126 software quality metrics (Functionality) support by UML suite. SIGSOFT Softw. Eng. Notes, v. 30, n. 2, p. 1-5, 2005. ISSN 0163-5948. Disponível em: < http://dx.doi.org/10.1145/1050849.1050860 >.

[BOHUS, D.; RUDNICKY, A. I., 2008] BOHUS, D.; RUDNICKY, A. I. Sorry, I Didn't Catch That! In: LAILA DYBKJÆR e WOLFGANG MINKER (Ed.). Recent Trends in Discourse and Dialogue: Springer Netherlands, v.39, 2008. p.123-154. (Text, Speech and Language Technology). ISBN 978-1-4020-6821-8.

[BOLT, R. A., 1980] BOLT, R. A. Put-that-there: Voice and gesture at the graphics interface. Proceedings of the 7th annual conference on Computer graphics and interactive techniques. Seattle, Washington, United States: ACM: 262-270 p. 1980.

[BOOCH, G.; RUMBAUGH, J.; JACOBSON, I., 2005] BOOCH, G.; RUMBAUGH, J.; JACOBSON, I. Unified Modeling Language User Guide, The (2nd Edition) (AddisonWesley Object Technology Series). Addison-Wesley Professional, 2005. ISBN 0321267974.

[BORCHERS, J., 2001] BORCHERS, J. A Pattern Approach to Interaction Design. John Wiley \& Sons, Inc., 2001. 268 ISBN 0471498289.

[BORGELT, C., 2004] BORGELT, C. Implementação do algoritmo Apriori (Versão 4.27) 2004.

[BOUCHET, J.; NIGAY, L.; GANILLE, T., 2004] BOUCHET, J.; NIGAY, L.; GANILLE, T. ICARE software components for rapidly developing multimodal interfaces. Proceedings of the 6th international conference on Multimodal interfaces. State College, PA, USA: ACM: 251-258 p. 2004.

[BOUILLON, L.; VANDERDONCKT, J.; CHOW, K. C., 2004] BOUILLON, L.; VANDERDONCKT, J.; CHOW, K. C. Flexible re-engineering of web sites. Proceedings of 
the 9th international conference on Intelligent user interfaces. Funchal, Madeira, Portugal: ACM: 132-139 p. 2004.

[BOURGUET, M.-L., 2008] BOURGUET, M.-L. SOFTWARE DESIGN AND DEVELOPMENT OF MUTIMODAL INTERACTION 2008.

[BURGE, J.; BROWN, D. C., 2000] BURGE, J.; BROWN, D. C. Reasoning With Design Rationale. Artificial Intelligence in Design, 2000. p.611-629.

[BUSCHMANN, F.; HENNEY, K.; SCHMIDT, D., 2007] BUSCHMANN, F.; HENNEY, K.; SCHMIDT, D. Pattern-Oriented Software Architecture: A Pattern Language for Distributed Computing (Wiley Software Patterns Series). John Wiley II\& Sons, 2007. ISBN 0470059028.

[CARD, S. K.; NEWELL, A.; MORAN, T. P., 1983] CARD, S. K.; NEWELL, A.; MORAN, T. P. The Psychology of Human-Computer Interaction. L. Erlbaum Associates Inc., 1983. 469 ISBN 0898592437.

[CARROL, J., M, 1999] CARROL, J., M. Five Reasons for Scenario-Based Design. 1999. p.3051-3051.

[CHANG, J.; BOURGUET, M.-L., 2008] CHANG, J.; BOURGUET, M.-L. Usability framework for the design and evaluation of multimodal interaction. Proceedings of the 22nd British HCI Group Annual Conference on People and Computers: Culture, Creativity, Interaction - Volume 2. Liverpool, United Kingdom: British Computer Society: 123-126 p. 2008.

[COHEN, M.; GIANGOLA, J.; BALOGH, J., 2004] COHEN, M.; GIANGOLA, J.; BALOGH, J. Voice User Interface Design. Addison Wesley Longman Publishing Co., Inc., 2004. ISBN 0321185765.

[COHEN, P.; MCGEE, D.; CLOW, J., 2000] COHEN, P.; MCGEE, D.; CLOW, J. The efficiency of multimodal interaction for a map-based task. Proceedings of the sixth conference on Applied natural language processing. Seattle, Washington: Association for Computational Linguistics: 331-338 p. 2000.

[COHEN, P. R.; et al., 1997] COHEN, P. R.; JOHNSTON, M.; MCGEE, D.; OVIATT, S.; PITTMAN, J.; SMITH, I.; CHEN, L.; CLOW, J. QuickSet: multimodal interaction for distributed applications. Proceedings of the fifth ACM international conference on Multimedia. Seattle, Washington, United States: ACM: 31-40 p. 1997.

[COUTAZ, J.; et al., 1995] COUTAZ, J.; NIGAY, L.; SALBER, D.; BLANDFORD, A.; MAY, J.; YOUNG, R. M. Four easy pieces for assessing the usability of multimodal interaction: the CARE properties. Interact: ACM Press: 115-120 p. 1995.

[CROSS, C.; et al., 2003] CROSS, C.; AXELSSON, J.; MCCOBB , G.; RAMAN, T. V.; WILSON, L. XHTML+Voice Profile 1.1. W3C Note 2003. 
[DE LUCIA, A.; et al., 2009] DE LUCIA, A.; FASANO, F.; GRIECO, C.; TORTORA, G. Recovering design rationale from email repositories. Software Maintenance, 2009. ICSM 2009. IEEE International Conference on, 2009. p.543-546.

DECRETO No 6.523, DE 31 DE JULHO DE 2008., 2008], 2008. Disponível em: < http://www.planalto.gov.br/ccivil_03/_ato2007-2010/2008/Decreto/D6523.htm >. Acesso em: November.

[DESURVIRE, H. W., 1994] DESURVIRE, H. W. Faster, cheaper!! Are usability inspection methods as effective as empirical testing? In: (Ed.). Usability inspection methods: John Wiley \& Sons, Inc., 1994. p.173-202. ISBN 0-471-01877-5.

[DILLON, A., 2000] DILLON, A., Ed. Group dynamics meet cognition: Combining sociotechnical concepts and usability engineering in the design of information systems. The new SocioTech: Graffiti on the long wall. London: Springer-Verlag, v.1, p.354, The new SocioTech: Graffiti on the long walled. 2000.

[DIX, A.; et al., 1998] DIX, A.; ABOWD, G.; BEALE, R.; FINLAY, J. Human-Computer Interaction. Prentice Hall Europe., 1998.

[DUMAS, B.; INGOLD, R.; LALANNE, D., 2009] DUMAS, B.; INGOLD, R.; LALANNE, D. Benchmarking fusion engines of multimodal interactive systems. Proceedings of the 2009 international conference on Multimodal interfaces. Cambridge, Massachusetts, USA: ACM: 169-176 p. 2009.

[DUMAS, B.; LALANNE, D.; OVIATT, S., 2009] DUMAS, B.; LALANNE, D.; OVIATT, S. Multimodal Interfaces: A Survey of Principles, Models and Frameworks. In: (Ed.). Human Machine Interaction: Research Results of the MMI Program: Springer-Verlag, 2009. p.3-26. ISBN 978-3-642-00436-0.

[DUTOIT, A. H.; et al., 2006] DUTOIT, A. H.; MCCALL, R.; MISTRIK, I.; PAECH, B. Rationale Management in Software Engineering: Concepts and Techniques. . Springer, 2006.

[ETO, K.; TAKABAYASHI, S.; MASUI, T., 2005] ETO, K.; TAKABAYASHI, S.; MASUI, T. qwikWeb: integrating mailing list and WikiWikiWeb for group communication. Proceedings of the 2005 international symposium on Wikis. San Diego, California: ACM: $17-23$ p. 2005.

[FIDEL, R., 1992] FIDEL, R. The case study method: a case study. . In: JACK D. \& POWELL IN: GLAZIER, RONALD R. (Ed.). Qualitative research in information management. . Englewood, CO: Libraries Unlimited, v.1, 1992. p.238.

[FLIPPO, F.; KREBS, A.; MARSIC, I., 2003] FLIPPO, F.; KREBS, A.; MARSIC, I. A framework for rapid development of multimodal interfaces. Proceedings of the 5th international conference on Multimodal interfaces. Vancouver, British Columbia, Canada: ACM: 109-116 p. 2003.

[FREIRE, A. P.; RUSSO, C. M.; FORTES, R. P. M., 2008] FREIRE, A. P.; RUSSO, C. M.; FORTES, R. P. M. A survey on the accessibility awareness of people involved in web 
development projects in Brazil. Proceedings of the 2008 international cross-disciplinary conference on Web accessibility (W4A). Beijing, China: ACM: 87-96 p. 2008.

[GAMMA, E.; et al., 1995] GAMMA, E.; HELM, R.; JOHNSON, R.; VLISSIDES, J. Design patterns: elements of reusable object-oriented software. Addison-Wesley Longman Publishing Co., Inc., 1995. 395 ISBN 0-201-63361-2.

[GRUBER, T. R.; RUSSEL, D. M., 1991] GRUBER, T. R.; RUSSEL, D. M. Design Knowledge and Design Rationale: A Framework for Representation, Capture, and Use. . Knowledge Systems Laboratory. Standford, California, p.9-45. 1991

[GRUENSTEIN, A.; MCGRAW, I.; BADR, I., 2008] GRUENSTEIN, A.; MCGRAW, I.; BADR, I. The WAMI toolkit for developing, deploying, and evaluating web-accessible multimodal interfaces. Proceedings of the 10th international conference on Multimodal interfaces. Chania, Crete, Greece: ACM: 141-148 p. 2008.

[HAMEL, J.; DUFOUR, S.; FORTIN, D., 1993] HAMEL, J.; DUFOUR, S.; FORTIN, D. Case Study Methods. Sage Publications, Inc, 1993. ISBN 0803954166. Disponível em: < http://www.amazon.ca/exec/obidos/redirect?tag=citeulike09-

20\&amp;path=ASIN/0803954166 > .

[HARTLEY, J., 1994] HARTLEY, J. Case Studies in Organizational Research. In: CATHERINE CASSELL e GILLIAN SYMON (Ed.). Qualitative Methods in Organizational Research: A Practical Guide: Sage Publications Ltd, 1994. p.208-229.

[HOLZINGER, A., 2005] HOLZINGER, A. Usability engineering methods for software developers. Commun. ACM, v. 48, n. 1, p. 71-74, 2005. ISSN 0001-0782.

[HONKALA, M.; POHJA, M., 2006] HONKALA, M.; POHJA, M. Multimodal interaction with xforms. Proceedings of the 6th international conference on Web engineering. Palo Alto, California, USA: ACM: 201-208 p. 2006.

[HUBERT, R., 2006] HUBERT, R. Accessibility and usability guidelines for mobile devices in home health monitoring. SIGACCESS Access. Comput., n. 84, p. 26-29, 2006. ISSN $1558-2337$.

[JDOM, 2009] JDOM. JDOM 1.0. 2009. Disponível em: < http://www.jdom.org/ >. Acesso em: November.

[JINTAE, L., 1997] JINTAE, L. Design Rationale Systems: Understanding the Issues. 12: 78-85 p. 1997.

[JOHN W. STAMEY, J.; HONEYCUTT, T. L., 2004] JOHN W. STAMEY, J.; HONEYCUTT, T. L. Christopher Alexander's fifteen properties applied to the design of communication. Proceedings of the 22nd annual international conference on Design of communication: The engineering of quality documentation. Memphis, Tennessee, USA: ACM: 64-71 p. 2004. 
[JOHNSTON, M., 2009] JOHNSTON, M. Building multimodal applications with EMMA. Proceedings of the 2009 international conference on Multimodal interfaces. Cambridge, Massachusetts, USA: ACM: 47-54 p. 2009.

[JURAFSKY, D.; MARTIN, J. H., 2000] JURAFSKY, D.; MARTIN, J. H. Speech and Language Processing: An Introduction to Natural Language Processing, Computational Linguistics, and Speech Recognition. Prentice Hall PTR, 2000. 934 ISBN 0130950696.

[KAMEL, N.; AIT AMEUR, Y., 2007] KAMEL, N.; AIT AMEUR, Y. A Formal Model for CARE Usability Properties Verification in Multimodal HCI. Pervasive Services, IEEE International Conference on, 2007. p.341-348.

[KJELDSKOV, J.; GRAHAM, C., 2003] KJELDSKOV, J.; GRAHAM, C. A Review of Mobile HCI Research Methods. 5th International Symposium on Mobile Human-Computer Interaction Udine, Italy 1: 75-84 p. 2003.

[KLEMMER, S. R.; et al., 2000] KLEMMER, S. R.; SINHA, A. K.; CHEN, J.; LANDAY, J. A.; ABOOBAKER, N.; WANG, A. Suede: a Wizard of Oz prototyping tool for speech user interfaces. Proceedings of the 13th annual ACM symposium on User interface software and technology. San Diego, California, United States: ACM: 1-10 p. 2000.

[KRUEGER, R.; CASEY, M., 2000] KRUEGER, R.; CASEY, M. Focus Groups: A Practical Guide for Applied Research. Sage Publications, Inc, 2000. ISBN 0761920714. Disponível em: < http://www.amazon.ca/exec/obidos/redirect?tag=citeulike0920\&amp;path=ASIN/0761920714 >.

[KUNZ, W.; RITTEL, H. W. J., 1970] KUNZ, W.; RITTEL, H. W. J. Issues as Elements of Information Systems. Working Paper No. 131, Berkeley, 1970.

[LAI, J.; et al., 2002] LAI, J.; DAHLB, N.;CK; J, A. Robustness in speech based interfaces: sharing the tricks of the trade. $\underline{\mathrm{CHI}}$ '02 extended abstracts on Human factors in computing systems. Minneapolis, Minnesota, USA: ACM: 915-915 p. 2002.

[LARA, S. M. A. D.; et al., 2010] LARA, S. M. A. D.; WATANABE, W. M.; SANTOS, E. P. B. D.; FORTES, R. P. M. Improving WCAG for elderly web accessibility. Proceedings of the 28th ACM International Conference on Design of Communication. São Carlos, São Paulo, Brazil: ACM: 175-182 p. 2010.

[LARSON, J. A., 2003] LARSON, J. A. W3C Multimodal Interaction Framework. W3C Note 2003.

[LEWIS, C.; et al., 1990] LEWIS, C.; POLSON, P. G.; WHARTON, C.; RIEMAN, J. Testing a walkthrough methodology for theory-based design of walk-up-and-use interfaces. Proceedings of the SIGCHI conference on Human factors in computing systems: Empowering people. Seattle, Washington, United States: ACM: 235-242 p. 1990.

[LIMBOURG, Q.; et al., 2005] LIMBOURG, Q.; VANDERDONCKT, J.; MICHOTTE, B.; BOUILLON, L.; LÓPEZ-JAQUERO, V. USIXML: A Language Supporting Multi-path Development of User Interfaces. In: RÉMI BASTIDE;PHILIPPE PALANQUE, e col (Ed.). 
Engineering Human Computer Interaction and Interactive Systems: Springer Berlin / Heidelberg, v.3425, 2005. p.200-220. (Lecture Notes in Computer Science).

[LOPEZ-CEZAR, R.; et al., 2003] LOPEZ-CEZAR, R.; TORRE, A. D. L.; SEGURA, J. C.; RUBIO, A. J. Assessment of dialogue systems by means of a new simulation technique. Speech Commun., v. 40, n. 3, p. 387-407, 2003. ISSN 0167-6393.

[LUCREDIO, D.; et al., 2008] LUCREDIO, D.; BRITO, K. D. S.; ALVARO, A.; GARCIA, V. C.; ALMEIDA, E. S. D.; FORTES, R. P. D. M.; MEIRA, S. L. Software reuse: The Brazilian industry scenario. J. Syst. Softw., v. 81, n. 6, p. 996-1013, 2008. ISSN 0164-1212.

[MAES, S. H.; SARASWAT, V., 2003] MAES, S. H.; SARASWAT, V. Multimodal Interaction Requirements 2003.

[MARCUS, A., 2002] MARCUS, A. Dare we define user-interface design? interactions, v. 9, n. 5, p. 19-24, 2002. ISSN 1072-5520.

[MCGEE, D. R.; COHEN, P. R.; OVIATT, S., 1998] MCGEE, D. R.; COHEN, P. R.; OVIATT, S. Confirmation in multimodal systems. Proceedings of the 36th Annual Meeting of the Association for Computational Linguistics and 17th International Conference on Computational Linguistics - Volume 2. Montreal, Quebec, Canada: Association for Computational Linguistics: 823-829 p. 1998.

[MCGLASHAN, S., 1999] MCGLASHAN, S. Dialog Requirements for Voice Markup Languages. W3C Working Draft 1999.

[MCTEAR, M. F., 2002] MCTEAR, M. F. Spoken dialogue technology: enabling the conversational user interface. ACM Comput. Surv., v. 34, n. 1, p. 90-169, 2002. ISSN 0360-0300.

[MELO, A. M.; et al., 2006] MELO, A. M.; CECILIA, M. BARANAUSKAS, L. C. Design para a inclusão: desafios e proposta. Proceedings of VII Brazilian symposium on Human factors in computing systems. Natal, RN, Brazil: ACM: 11-20 p. 2006.

[MOLLER, S.; et al., 2009] MOLLER, S.; ENGELBRECHT, K. P.; KUHNEL, C.; WECHSUNG, I.; WEISS, B. A taxonomy of quality of service and Quality of Experience of multimodal human-machine interaction. Quality of Multimedia Experience, 2009. QoMEx 2009. International Workshop on, 2009. p.7-12.

[MONK, S.; et al., 1995] MONK, S.; SOMMERVILLE, I.; PENDARIES, J.; DURIN, B. Supporting design rationale for system evolution. In: WILHELM SCHÄFER e PERE BOTELLA (Ed.). Software Engineering - ESEC '95: Springer Berlin / Heidelberg, v.989, 1995. p.307-323. (Lecture Notes in Computer Science).

[MORAN, T. P.; CARROLL, J. M., 1996] MORAN, T. P.; CARROLL, J. M. Design Rationale: Concepts, Techniques, and Use New Jersey: Lawrence Erlbaum Associates, , 1996. 
[MORI, G.; PATERNO, F.; SANTORO, C., 2004] MORI, G.; PATERNO, F.; SANTORO, C. Design and Development of Multidevice User Interfaces through Multiple Logical Descriptions. IEEE Trans. Softw. Eng., v. 30, n. 8, p. 507-520, 2004. ISSN 0098-5589.

[MURAKAMI, V. T., 2009] MURAKAMI, V. T. Princípios de usabilidade na Web com interações multimodais. Trabalho de Conclusão de Curso. Sao Carlos: Maio de 2009, p.1121. 2009

[NARAYAN, M.; et al., 2004] NARAYAN, M.; WILLIAMS, C.; PERUGINI, S.; RAMAKRISHNAN, N. Staging transformations for multimodal web interaction management. Proceedings of the 13th international conference on World Wide Web. New York, NY, USA: ACM: 212-223 p. 2004.

[NETO, A. T.; et al., 2006] NETO, A. T.; ANACLETO, J. C.; VANIA; NERIS, N. A.; GODOI, M. D. S.; CARVALHO, A. F. P. A framework to support the design of learning objects based on the Cog-Learn Pattern Language. Proceedings of the 12th Brazilian Symposium on Multimedia and the web. Natal, Rio Grande do Norte, Brazil: ACM: 128-137 p. 2006.

[NETO, A. T.; FORTES, R. P. D. M., 2010] NETO, A. T.; FORTES, R. P. D. M. Improving multimodal interaction design with the MMWA authoring environment. Proceedings of the 28th ACM International Conference on Design of Communication. São Carlos, São Paulo, Brazil: ACM: 151-158 p. 2010.

[NETO, A. T.; et al., 2009] NETO, A. T.; FORTES, R. P. D. M.; ASSIS, A. R.; ANACLETO, J. C. Design of communication in multimodal web interfaces. Proceedings of the 27th ACM international conference on Design of communication. Bloomington, Indiana, USA: ACM: 81-88 p. 2009.

[NETO, A. T.; FORTES, R. P. M., 2009] NETO, A. T.; FORTES, R. P. M. Developing and evaluating web multimodal interfaces - a case study with usability principles. Proceedings of the 2009 ACM symposium on Applied Computing. Honolulu, Hawaii: ACM: $116-120$ p. 2009.

[NICHOLS, J.; et al., 2002] NICHOLS, J.; MYERS, B.; HARRIS, T. K.; ROSENFELD, R.; SHRIVER, S.; HIGGINS, M.; HUGHES, J. Requirements for Automatically Generating Multi-Modal Interfaces for Complex Appliances. Proceedings of the 4th IEEE International Conference on Multimodal Interfaces: IEEE Computer Society: 377 p. 2002.

[NIELSEN, J., 1993] NIELSEN, J. Usability Engineering. Morgan Kaufmann Publishers Inc., 1993. 358 ISBN 0125184050.

[NIELSEN, J., 1995] NIELSEN, J. Usability inspection methods. Conference companion on Human factors in computing systems. Denver, Colorado, United States: ACM: 377-378 p. 1995.

[NIELSEN, J., 1997] NIELSEN, J. The Use and Misuse of Focus Groups. IEEE Softw., v. 14, n. 1, p. 94-95, 1997. ISSN 0740-7459. 
[NIELSEN, J., 2004] NIELSEN, J. Risks of Quantitative Studies. Alertbox publicado em Useit.com. http://www.useit.com/alertbox/20040301.html, 2004.

[NIELSEN, J., 2006] NIELSEN, J. Ensuring Web Usability: Understanding What Users Want. New Riders Publishing, 2006. ISBN 0321286707.

[NIELSEN, J.; MOLICH, R., 1990] NIELSEN, J.; MOLICH, R. Heuristic evaluation of user interfaces. Proceedings of the SIGCHI conference on Human factors in computing systems: Empowering people. Seattle, Washington, United States: ACM: 249-256 p. 1990.

[NIELSEN, J.; TAHIR, M., 2001] NIELSEN, J.; TAHIR, M. Homepage Usability: 50 Websites Deconstructed. New Riders Publishing, 2001. 336 ISBN 073571102X.

[NORMAN, D. A., 1995] NORMAN, D. A. The psychopathology of everyday things. In: (Ed.). Human-computer interaction: toward the year 2000: Morgan Kaufmann Publishers Inc., 1995. p.5-21. ISBN 1-55860-246-1.

[OVIATT, S., 1997] OVIATT, S. Multimodal interactive maps: designing for human performance. Hum.-Comput. Interact., v. 12, n. 1, p. 93-129, 1997. ISSN 0737-0024.

[OVIATT, S., 1999a] OVIATT, S. Mutual disambiguation of recognition errors in a multimodel architecture. Proceedings of the SIGCHI conference on Human factors in computing systems: the $\mathrm{CHI}$ is the limit. Pittsburgh, Pennsylvania, United States: ACM: 576583 p. 1999a.

[OVIATT, S., 1999b] OVIATT, S. Ten myths of multimodal interaction. Commun. ACM, v. 42, n. 11, p. 74-81, 1999b. ISSN 0001-0782.

[OVIATT, S., 2003] OVIATT, S. Multimodal interfaces. In: (Ed.). The human-computer interaction handbook: fundamentals, evolving technologies and emerging applications: L. Erlbaum Associates Inc., 2003. p.286-304. ISBN 0-8058-3838-4.

[OVIATT, S., 2003] OVIATT, S. User-centered modeling and evaluation of multimodal interfaces. Proceedings of the IEEE, v. 91, n. 9, p. 1457-1468, 2003. ISSN 0018-9219.

[OVIATT, S.; et al., 2000] OVIATT, S.; COHEN, P.; WU, L.; VERGO, J.; DUNCAN, L.; SUHM, B.; BERS, J.; HOLZMAN, T.; WINOGRAD, T.; LANDAY, J.; LARSON, J.; FERRO, D. Designing the user interface for multimodal speech and pen-based gesture applications: state-of-the-art systems and future research directions. Hum.-Comput. Interact., v. 15, n. 4, p. 263-322, 2000. ISSN 0737-0024.

[OVIATT, S.; COULSTON, R.; LUNSFORD, R., 2004] OVIATT, S.; COULSTON, R.; LUNSFORD, R. When do we interact multimodally?: cognitive load and multimodal communication patterns. Proceedings of the 6th international conference on Multimodal interfaces. State College, PA, USA: ACM: 129-136 p. 2004.

[OVIATT, S.; DEANGELI, A.; KUHN, K., 1997] OVIATT, S.; DEANGELI, A.; KUHN, K. Integration and synchronization of input modes during multimodal human-computer interaction. Proceedings of the SIGCHI conference on Human factors in computing systems. Atlanta, Georgia, United States: ACM: 415-422 p. 1997. 
[OVIATT, S.; LUNSFORD, R.; COULSTON, R., 2005] OVIATT, S.; LUNSFORD, R.; COULSTON, R. Individual differences in multimodal integration patterns: what are they and why do they exist? Proceedings of the SIGCHI conference on Human factors in computing systems. Portland, Oregon, USA: ACM: 241-249 p. 2005.

[OVIATT, S.; VANGENT, R., 1996] OVIATT, S.; VANGENT, R. Error resolution during multimodal human-computer interaction. Spoken Language, 1996. ICSLP 96. Proceedings., Fourth International Conference on, 1996. p.204-207 vol.1.

[PATERNO, F., 1999] PATERNO, F. Model-Based Design and Evaluation of Interactive Applications. Springer-Verlag, 1999. 192 ISBN 1852331550.

[PATERNÒ, F., 2005] PATERNÒ, F. Model-based tools for pervasive usability. Interacting with Computers, v. 17, n. 3, p. 291-315, 2005. ISSN 0953-5438. Disponível em: < http://www.sciencedirect.com/science/article/B6V0D-4DB5FGK-

2/2/e0faa90a4e6b3b2be9f81b2c9bfd2014 >.

[PATERNO, F.; GIAMMARINO, F., 2006] PATERNO, F.; GIAMMARINO, F. Authoring interfaces with combined use of graphics and voice for both stationary and mobile devices. Proceedings of the working conference on Advanced visual interfaces. Venezia, Italy: ACM: 329-335 p. 2006.

[PATERNÒ, F.; SANTOS, I., 2007] PATERNÒ, F.; SANTOS, I. Designing and Developing Multi-User, Multi-Device Web Interfaces. In: GAËLLE CALVARY;COSTIN PRIBEANU, $e$ col (Ed.). Computer-Aided Design of User Interfaces V: Springer Netherlands, 2007. p.111-122. ISBN 978-1-4020-5820-2.

[PREECE, J., 1993] PREECE, J., Ed. A Guide to Usability: Human Factors in Computing. : Addison Wesley;, p.144 ed. 1993.

[PUERTA, A.; EISENSTEIN, J., 2002] PUERTA, A.; EISENSTEIN, J. XIML: a common representation for interaction data. Proceedings of the 7th international conference on Intelligent user interfaces. San Francisco, California, USA: ACM: 214-215 p. 2002.

[RAJANEN, M.; IIVARI, N., 2007] RAJANEN, M.; IIVARI, N. Usability cost-benefit analysis: how usability became a curse word? Proceedings of the 11th IFIP TC 13 international conference on Human-computer interaction - Volume Part II. Rio de Janeiro, Brazil: Springer-Verlag: 511-524 p. 2007.

[RAMAN, T. V., 2003] RAMAN, T. V. Design principles for multimodal interaction. Computer Human Interfaces. Fort Lauderdale, USA.: 5-10 p. 2003.

[RATZKA, A., 2008] RATZKA, A. Explorative studies on multimodal interaction in a PDA- and desktop-based scenario. Proceedings of the 10th international conference on Multimodal interfaces. Chania, Crete, Greece: ACM: 121-128 p. 2008.

[RATZKA, A.; WOLFF, C., 2006] RATZKA, A.; WOLFF, C. A Pattern-Based Methodology for Multimodal Interaction Design. In: PETR SOJKA;IVAN KOPECEK, e col (Ed.). Text, 
Speech and Dialogue: Springer Berlin / Heidelberg, v.4188, 2006. p.677-686. (Lecture Notes in Computer Science).

[REEVES, L. M.; et al., 2004] REEVES, L. M.; LAI, J.; LARSON, J. A.; OVIATT, S.; BALAJI, T. S.; ST; BUISINE, P.; COLLINGS, P.; COHEN, P.; KRAAL, B.; MARTIN, J.C.; MCTEAR, M.; RAMAN, T.; STANNEY, K. M.; SU, H.; WANG, Q. Y. Guidelines for multimodal user interface design. Commun. ACM, v. 47, n. 1, p. 57-59, 2004. ISSN 00010782 .

[REGLI, W. C.; et al., 2000] REGLI, W. C.; HU, X.; ATWOOD, M.; SUN, W. A Survey of Design Rationale Systems: Approaches, Representation, Capture and Retrieval. Engineering with Computers, v. 16, n. 3, p. 209-235, 2000. ISSN 0177-0667. Disponível em: < http://dx.doi.org/10.1007/PL00013715 >.

[ROMBACH, D., 2000] ROMBACH, D. Fraunhofer: the German model for applied research and technology transfer. Software Engineering, 2000. Proceedings of the 2000 International Conference on, 2000. 2000. p.531-537.

[ROUSSEAU, C.; BELLIK, Y.; VERNIER, F., 2005] ROUSSEAU, C.; BELLIK, Y.; VERNIER, F. Multimodal output specification / simulation platform. Proceedings of the 7th international conference on Multimodal interfaces. Torento, Italy: ACM: 84-91 p. 2005.

[SCHAPIRA, E.; SHARMA, R., 2001] SCHAPIRA, E.; SHARMA, R. Experimental Evaluation of Vision and Speech based Multimodal Interfaces. Proc. Workshop on Perceptive User Interfaces. Orlando, FL: ACM Digital Library p. 2001.

[SEFFAH, A.; et al., 2006] SEFFAH, A.; DONYAEE, M.; KLINE, R. B.; PADDA, H. K. Usability measurement and metrics: A consolidated model. Software Quality Control, v. 14, n. 2, p. 159-178, 2006. ISSN 0963-9314.

[SERRANO, M.; et al., 2008] SERRANO, M.; NIGAY, L.; LAWSON, J.-Y. L.; RAMSAY, A.; MURRAY-SMITH, R.; DENEF, S. The openinterface framework: a tool for multimodal interaction. $\mathrm{CHI}$ '08 extended abstracts on Human factors in computing systems. Florence, Italy: ACM: 3501-3506 p. 2008.

[SHNEIDERMAN, B., 1998] SHNEIDERMAN, B. Designing the user interface: strategies for effective human-computer interaction. Addison-Wesley Longman Publishing Co., Inc., 1998. 448 ISBN 0-201-16505-8.

[SOUVIGNIER, B.; et al., 2000] SOUVIGNIER, B.; KELLNER, A.; RUEBER, B.; SCHRAMM, H.; SEIDE, F. The thoughtful elephant: strategies for spoken dialog systems. Speech and Audio Processing, IEEE Transactions on, v. 8, n. 1, p. 51-62, 2000. ISSN 1063-6676.

[STANCIULESCU, A.; et al., 2005] STANCIULESCU, A.; LIMBOURG, Q.; VANDERDONCKT, J.; MICHOTTE, B.; MONTERO, F. A transformational approach for multimodal web user interfaces based on UsiXML. Proceedings of the 7th international conference on Multimodal interfaces. Torento, Italy: ACM: 259-266 p. 2005. 
[SUHM, B., 1997] SUHM, B. Empirical evaluation of interactive multimodal error correction. Automatic Speech Recognition and Understanding, 1997. Proceedings., 1997 IEEE Workshop on, 1997. p.583-590.

[SWADE, J.; REUSCH, P. J. A., 2007] SWADE, J.; REUSCH, P. J. A. XHTML+Voice vs. SALT: Two Standards for Multimodal Websites. Intelligent Data Acquisition and Advanced Computing Systems: Technology and Applications, 2007. IDAACS 2007. 4th IEEE Workshop on, 2007. 6-8 Sept. 2007. p.555-558.

[TAIB, R.; RUIZ, N., 2007] TAIB, R.; RUIZ, N. Wizard of oz for multimodal interfaces design: deployment considerations. Proceedings of the 12th international conference on Human-computer interaction: interaction design and usability. Beijing, China: SpringerVerlag: 232-241 p. 2007.

[TIDWELL, J., 2005] TIDWELL, J. Designing Interfaces

Patterns for Effective Interaction Design. new york: O'Reilly Media 2005. 352 ISBN 9780-596-00803-1

[TRAUM, D. R.; et al., 1996] TRAUM, D. R.; SCHUBERT, L. K.; POESIO, M.; MARTIN, N. G.; LIGHT, M. N.; HWANG, C. H.; HEEMAN, P. A.; FERGUSON, G. M.; ALLEN, J. F. Knowledge Representation in the TRAINS-93 Conversation System. University of Rochester. 1996

[TRAUTH, E. M.; O'CONNOR, B., 2000] TRAUTH, E. M.; O'CONNOR, B. A study of the interaction between information technology and society: an illustration of combined qualitative research methods. 2000.

[VEER, G. V. D.; WELIE, M. V., 2000] VEER, G. V. D.; WELIE, M. V. Task based groupware design: putting theory into practice. Proceedings of the 3rd conference on Designing interactive systems: processes, practices, methods, and techniques. New York City, New York, United States: ACM: 326-337 p. 2000.

[W3C, 1996] W3C. XML - Extensible Markup Language 1996.

[W3C, 2007] W3C. Voice Extensible Markup Language (VoiceXML) 2.1. W3C Recommendation 2007.

[WAZLAWICK, R., 2009] WAZLAWICK, R. Metodologia de Pesquisa para Ciência da Computação. Elsevier, 2009. 184 ISBN 8535235221.

[WEINSCHENK, S.; BARKER, D. T., 2000] WEINSCHENK, S.; BARKER, D. T. Designing effective speech interfaces. John Wiley \& Sons, Inc., 2000. 405 ISBN 0-47137545-4.

[WELIE, M., TRÆTTEBERG, H., 2000] WELIE, M., TRÆTTEBERG, H. Interaction Patterns in User Interfaces. Pattern Languages of Programs (PLoP 2000). Monticello, Illinois, USA 2000.

[WELIE, M. V., 2010] WELIE, M. V. Patterns in Interaction Design. 2010. Disponível em: < http://www.welie.com/ > . Acesso em: Novembro de 2010. 
[WELIE, M. V.; VAN DER VEER, G. C.; ELIËNS, A., 1999] WELIE, M. V.; VAN DER VEER, G. C.; ELIËNS, A. Breaking down Usability. Interact 99. Edinburgh, Scotland. 1: 613-620 p. 1999.

[WIKIRPCINTERFACE, 2010] WIKIRPCINTERFACE. Wiki RPC Interface 2.8.4 2010. Disponível em: < http://www.jspwiki.org/wiki/WikiRPCInterface >. Acesso em: Novembro de 2010. 



\title{
Apêndice A. Padrões de projeto multimodal referenciados nesta Tese
}

\begin{abstract}
Design Pattern: Modality synchronization
Context: The voice interaction can be regarded as temporal, as the graphical interaction can be considered spacial. When combined in a multimodal interface, these interaction modalities need to be synchronized to avoid compromising the system usability.
\end{abstract}

Problem (based on DR issues): Interfaces that are not syncronized can make the user confused and decrease the overall usability.

DR Issue (From MMWA Task Model: Prompt ): how to stop TTS when the user select an option?

DR Issue (From MMWA Task Model: Actions): I want to play the next task prompt when the user press Tab to move to the next task or when the user set the focus in the next task. How?

DR Issue (From MMWA Task Model: Actions): How to update the graphical interface when the user say an option?

DR Issue (From MMWA Task Model: Actions): Once an option is selected I wanna go to the next task.

Forces (based on DR Arguments):

Event-level synchronization: Inputs in one modality are captured at the level the individual DOM events and immediately reflected in the other modality; when it makes sense

Field-level synchronization: Inputs in one modality are reflected in the other after the user changes focus (e.g. moves from input field to input field) or completes the interaction with a field (e.g. completes a select in a menu)

Form-level synchronization: Inputs in one modality are reflected in the other only after a particular point in the presentation is reached (e.g. after a certain number of fields have been completed in the form).

Session-level synchronization: Inputs in one modality are reflected in the other only after a switch from one modality to another.

Solution (based on DR Positions): an input in one modality is reflected in the output in another modality/device as well as way that it may be combined across modalities.

Design the consistency of focus between the various modalities. The visual browser verbal browsers should present the same information at the same time.

In a multifield form, the focus field of the visual browser should correspond to the field prompt currently presented by the verbal browser.

Example(based on DR Positions): 
The MMWA-ae Actions functionality automatically syncronizes the modalities and tasks according to events that might occur during the interaction in the following way: MULTIMODAL INTERACTION: task_graph -> onFocus -> xv:sync -> task_voice (sync graphic and voice elements of the same task when a 'focus' event occurs)

MULTIMODAL INTERACTION: task_graph -> onChange -> stopTTS -> task_voice (sync graphic and voice elements of the same task when a 'change' event occurs)

GRAPH/MULTIMODAL INTERACTION: task_graph -> onChange -> gotoTask-> next task (when using graphical interface, go to the next task once the user completed the task filling the appropriate graphic field) MULTIMODAL INTERACTION: task_voice -> onRECOGNITION -> xv:sync -> task_graph (sync graphic and voice elements of the same task when a 'recognition' event occurs) VOICE/MULTIMODAL INTERACTION: task_voice -> onRECOGNITION-> gotoTask-> next task (when using VUI, go to the next task once the recognition event occurs)

Task 1 GUI

Task 1 VUI

TASK N

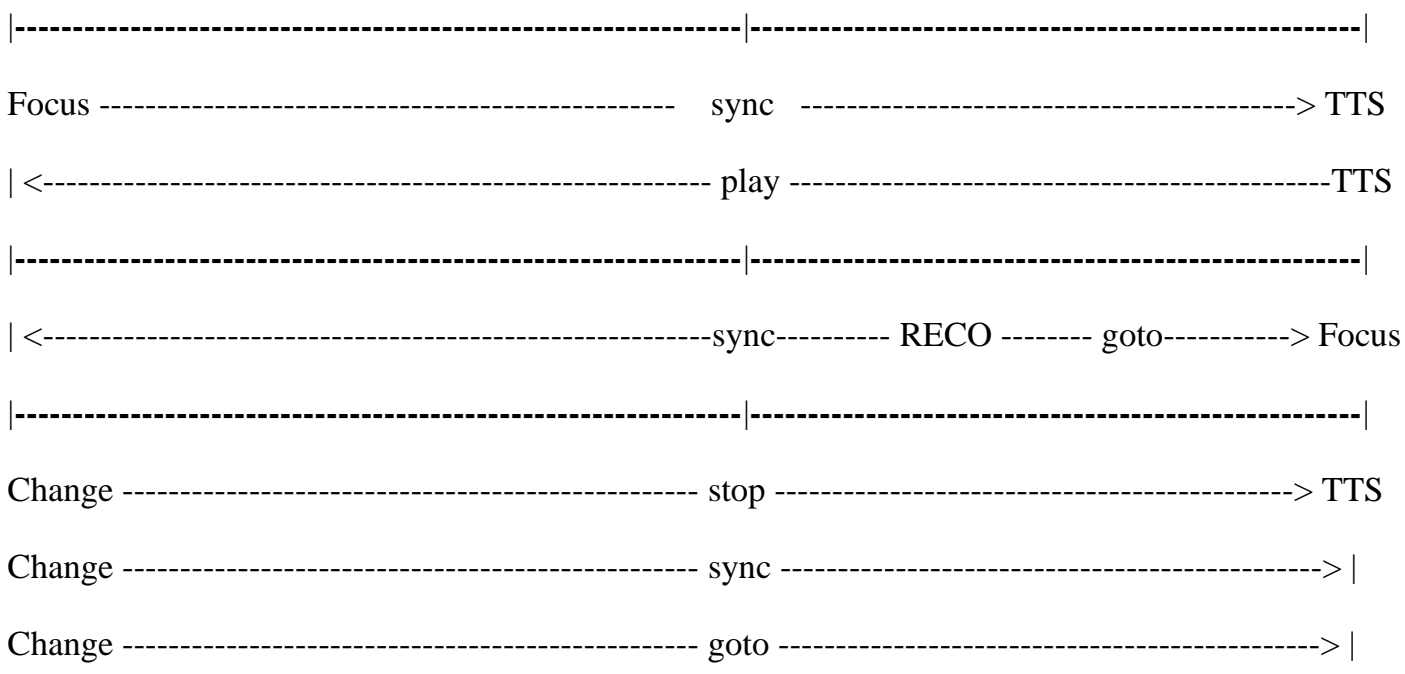

Resulting Context: Fusion and Fission 


\section{Design Pattern: Large Group Selection}

Context: The interface shows, utters and allows the user to select a value which is part of a large set of possible values.

Problem (based on DR issues): How should the interface show a large group of multimodal input information to the user?

DR Issue (From MMHE (Heuristic Evaluation)): Users are not able to say an option in a combo box because they cannot see the possible values. The only option is to expand the combo box.

DR Issue (From MMWA Task Model: Options): User needs to scroll down to see all the possible values of a List.

DR Issue (From MMWA Task Model: Prompt): Prompt is taking too long. It contains more than 7 itens.

DR Issue (From MMLOG (User Testing), updated in the task model): : There are too many nomatches and noinputs in the usabilityevaluation $\log$ file.

DR Issue (MMWA Task Model: Actions):: What should I do to sync the options between two or more groups of information?

Forces (based on DR Arguments):

- The user should know what choices are available.

- The user should be able to find the value they want quickly.

- Small chunks of information make the choice easier and faster.

- Large numbers of things take a long time to read/hear, take up lots of space and are complicate to remember.

- Experienced users like to respond without listening to the enumerated options, while novice users will listen to the enumerated options before selecting an option.

\section{Solution (based on DR Positions):}

Organize the set of possible values in two or more tasks and sync these tasks. Clearly show the selected value up front and provide a default value (most used). Speak the options values in a Consistent command format. Organize the dialog in the way most appropriate to how the user will be searching. Allow experienced users to directly selecting the choice.

Consistent command format: Keyword recognition is much faster and accurate. Many tasks lend themselves to keyword commands better than natural language sentences.

Example(based on DR Positions): 
Selecting a car from a list of Car types using HTML select, $\mathrm{X}+\mathrm{V}$ Assign and DOM Events:

Given a blank select element:

<select size="2" name="Select_Model">

<option value $=" 0 "></$ option $>$

<option value="1"></option>

$</$ select $>$

The VXML assign element is used to inform via JavaScript which vehicles to show, based on a previous car type choice.

$<$ if cond="carType $==$ 'Van"'/>

<vxml:assign name="document.frm1.listcars.options[0]" expr="new Option('Pontiac Vibe','Pontiac Vibe')"/>

<vxml:assign name="document.frm1.listcars.options[1]" expr="new Option('Blazer','Blazer')"/>

The JavaScript "new Option('Pontiac','Pontiac')" will create the first option. One can use this code to build dynamic lists. This way one can break the large list into to tasks: SelectCarType and then SelectRentCar.

Scrolled combo boxes are really only necessary if the dropdown list is going to run off the edge of the screen -- it's easy to miss the choices beyond the visible area. It takes the bad features of scrolled lists and makes them worse, first by making you show the list and then by shrinking the scrollbar.

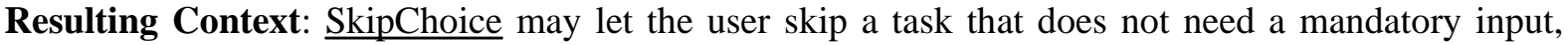
without even bothering to set the value. If the choices are tricky, or are cryptic in some other way, ShortDescription may be needed to describe the choices further. 


\section{Apêndice B. Relacionamentos entre heurísticas, checklists, guidelines e princípios}

A seguir é apresentado um trecho do formulário de avaliação heurística, utilizado no estudi de caso 1, que relaciona heurísticas e checklists.

\begin{tabular}{|c|c|}
\hline Heurística & Checklist \\
\hline \multirow[t]{9}{*}{$\begin{array}{l}\text { 1) Visibilidade do } \\
\text { estado sistema. }\end{array}$} & $\begin{array}{l}\text { 1.1 As modalidades de voz e visual estão sincronizadas para todos os componentes de interface e } \\
\text { para todas as possíveis entradas da(s) gramática(s) na interface multimodal? }\end{array}$ \\
\hline & $1.2 \mathrm{O}$ usuário consegue perceber a mudança de diálogo para cada interface multimodal? \\
\hline & $1.3 \mathrm{O}$ usuário consegue perceber a mudança de diálogo entre todos os componentes de interface? \\
\hline & $\begin{array}{l}\text { 1.4 É possível identificar transição entre os campos por uso de animação, som ou até mesmo } \\
\text { pausa? }\end{array}$ \\
\hline & 1.5 A mudança de diálogo entre os componentes de interface é realizada em um tempo aceitável? \\
\hline & $\begin{array}{l}\text { 1.6 O tempo de espera para que o "help" seja lido par ao usuário está dentro de um tempo } \\
\text { aceitável? }\end{array}$ \\
\hline & 1.7 A confiabilidade de resposta do usuário é reconhecida dentro de um tempo aceitável? \\
\hline & $\begin{array}{l}1.8 \text { Os componentes de interface, as gramáticas e JavaScripts são atualizados durante a transição } \\
\text { de um diálogo para outro ou durante a transição de interfaces? }\end{array}$ \\
\hline & 1.9 O usuário percebe o estado atual de uma tarefa e sabe quando a terminou? \\
\hline \multirow{3}{*}{$\begin{array}{l}\text { 2) Correspondência } \\
\text { entre o sistema e o } \\
\text { mundo real }\end{array}$} & 2.1 As listas de opções são lidas numa ordem lógica? \\
\hline & $\begin{array}{l}2.2 \mathrm{O} \text { "help" do sistema faz uso de conceitos e linguagem familiares aos usuários ao invés de } \\
\text { termos técnicos? }\end{array}$ \\
\hline & $\begin{array}{l}\text { 2.3 Campos de senha ou de entrada de dados particulares permitem entrada por teclado ao invés } \\
\text { de voz? O resultado da entrada na interface no caso de senhas é mascarado? }\end{array}$ \\
\hline \multirow[t]{2}{*}{$\begin{array}{l}\text { 3) Controle e } \\
\text { liberdade do usuário }\end{array}$} & $\begin{array}{l}\text { 3.1 É possível ao usuário selecionar se deseja ou não que sejam lidas as listas de opções da caixa } \\
\text { de seleção? }\end{array}$ \\
\hline & $\begin{array}{l}3.2 \text { O usuário pode fazer o que quer quando deseja? Ou seja, é possível cancelar a execução do } \\
\text { sistema em qualquer momento ou solicitar por "help"? }\end{array}$ \\
\hline
\end{tabular}


4) Consistência e padronização
4.1 Existem informações duplicadas (texto e voz individualmente e separadamente) sendo apresentadas ao usuário?

4.2 A terminologia e os comandos são consistentes entre as interfaces, componentes e modalidades? Ou seja, os elementos visuais e de voz tem o mesmo significado?

5) Prevenção de erros 5.1 O sistema multimodal faz com que usuários cometam erros que não cometeriam em sistemas apenas com interface visual?

5.2 O sistema de "Tratamento de Erros" é adaptado ao número de ocorrências?

5.3 Existem informações duplicadas (texto e voz individualmente e separadamente) sendo apresentadas ao usuário?

5.4 O sistema consegue tratar erros de reconhecimento, estouro de tempo sem fala, ajudar o usuário, repetir a última fala, voltar para um local seguro e conhecido pelo usuário?

5.5 Em virtude de mudança ou correção de sua solicitação, o usuário pode alterar suas marcações?

6) Ajuda aos usuários .1 As mensagens de "help" são expressas em linguagem "plena" (sem códigos)? Elas sugerem para reconhecer, diagnosticar e se uma solução?

recuperar de erros

7) Reconhecimento ao invés de memorização

.1 O sistema garante que a troca entre interfaces mantém os componentes atualizados sem que o usuário precise memorizá-los?

7.2 O usuário consegue perceber qual modalidade ele deve utilizar para cada componente de interface e para cada interface?

7.3 Existe alguma representação visual para auxiliar o usuário na identificação do tipo de nterface disponível?

7.4 O usuário percebe facilmente o mecanismo de "help"?

7.5 O usuário percebe facilmente o mecanismo de acionamento de "links"?

7.6 As listas de opções das caixas de seleção estão claras para o usuário?

\begin{tabular}{|l|l}
\hline \hline $\begin{array}{l}\text { 8) Flexibilidade e } \\
\text { eficiência de uso }\end{array}$ & 8.1 O usuário consegue trocar de modalidade (voz para visual, ou visual para voz) durante a \\
interação? A interface e/ou seus componentes são atualizados?
\end{tabular}

eficiência de uso

.2 Existe algum modo indisponível em um determinado momento da interação?

.3 Existe alguma lógica na aplicação multimodal que permita a adaptação da interface?

8.4 O usuário pode habilitar/desabilitar modalidades? Ou seja, escolher se deseja interagir de forma gráfica, por voz, ou utilizando ambas?

9) Design estético e minimalista

9.1 Os diálogos contidos no "help" contém informações irrelevantes ou raramente utilizadas?

10) Ajuda e

10.1 Uma ajuda apropriada é fornecida pelo "help"? Essa informação é fácil de ser solicitada e 
|documentação $\quad$ focada na tarefa do usuário?

A seguir apresenta-se um trecho do formulário utilizado no estudo de caso 1 para verificar a consistência das interfaces multimodais projetadas com os Princípios, guidelines e checklists identificados nesta pesquisa para o desenvolvimento de interfaces multimodais Web.

1) As múltiplas modalidades precisam estar sincronizadas. A interação por voz pode ser considerada como temporal, enquanto a interação visual gráfica pode ser considerada espacial. Quando combinadas em uma interface multimodal, esses modos de interação precisam estar sincronizados para não comprometer a usabilidade do sistema.

CheckList - As modalidades de voz e visual estão sincronizadas para todos os componentes de interface e para todas as possíveis entradas da(s) gramática(s) na interface multimodal?

Guideline: Projete a consistência no foco entre as diversas modalidades.

Aplicação: sim, foi feita a sincronia dos componentes de interface e para todas as possíveis entradas das gramáticas na interface multimodal.

*componentes de interface - tradução de widget. São as partes que formam a interface Web como: campos de texto, listas, itens de seleção, botões, links, etc; e no caso das interfaces de voz: prompts, entradas e saídas de gramáticas, formulários, menus, etc.

2) A transição entre diálogos em uma interação multimodal deve ser perceptível ao usuário, pois as suas habilidades e necessidades, bem como o contexto de uso pode ser modificado durante a interação.

CheckList - O usuário consegue perceber a mudança de diálogo para cada interface multimodal?

Aplicação: sim, isso é feito com a verificação da mudança de foco, seja pelo reconhecimento de alguma frase, seja pela interação coma interface gráfica.

3) As múltiplas modalidades devem compartilhar o estado de interação para que durante a mudança de uma interface para outra ou se o usuário desejar trocar de modalidade em uma determinada sequiência do diálogo humano-computador, as várias mídias disponíveis sejam atualizadas.

CheckList - Os componentes de interface, as gramáticas e JavaScripts são atualizados durante a transição de um diálogo para outro ou durante a transição de interfaces?

CheckList - O usuário consegue trocar de modalidade (voz para visual, ou visual para voz) durante a interação? A interface e/ou seus componentes são atualizados?

Aplicação: sim, quando há uma transição entre modalidades as variáveis que contemplam o reconhecimento do valor de atribuição dos campos são tratadas novamente para compartilhar o estado de interação. Inclusive, caso o usuário confirme via voz o submit do formulário o botão é pressionado via voz ou pode fazê-lo via teclado. 
4) As interfaces multimodais devem ser previsíveis, ou seja, a interface precisa possibilitar que o usuário saiba intuitivamente qual o melhor modo para se utilizar durante a execução de uma tarefa. A interface deve permitir que o usuário perceba se em um dado momento algum modo estiver indisponível.

CheckList - O usuário consegue perceber qual modalidade ele deve utilizar para cada componente de interface e para cada interface?

CheckList - Existe algum modo indisponível em um determinado momento da interação? Descreva o DR para cada caso separadamente e diga como o usuário é alertado ou percebe essa situação.

Aplicação: sim, os DRs para tanto estão separados na Wiki pelas discussões. As interfaces estão bem previsíveis com a gramática de modo flexível com muitas expressões opcionais para que o match ocorra de forma mais segura. Sobre a questão intuitiva foram usados componentes gráficos para reforçar a corretude da interação como mostrar uma foto do carro e cidade desejada no momento da escolha.

5)As interfaces multimodais devem se adaptar ao ambiente do usuário para assegurar que o melhor modo de se completar uma determinada tarefa em um determinado momento estará disponível ao usuário. A adaptatividade é também considerada como uma guideline. As interfaces multimodais devem se adaptar às necessidades e habilidades de diferentes usuários e a diferentes contextos de uso. A adaptatividade dinâmica permite que a transição entre diálogos em uma interação seja perceptível ao usuário por meio de modalidades complementares.

CheckList - Existe alguma lógica na aplicação multimodal que permita a adaptação da interface? Em que caso isto poderia se utilizado?

Aplicação: sim, um componente para isso é a possibilidade de aumento e diminuição do tamanho da fonte utilizada. Caso fosse usada uma linguagem dinâmica acreditamos que essa adaptabilidade seja bem maior, mas fica como um próximo estudo de melhoria de nosso trabalho.

6) Durante a Especificação de Requisitos, o projeto da interação multimodal deve ser pensado para uma grande gama de usuários e contextos de uso. Além disso, o projetista deve considerar questões de privacidade e de segurança.

CheckList - Que tipo de usuário consegue utilizar a interface (ou o componente) que está sendo desenvolvida?

CheckList - (Privacidade) campos de senha ou de entrada de dados particulares devem permitir entrada por teclado ao invés de voz e mascarar o resultado da entrada na interface no caso de senhas.

Aplicação: no caso da aplicação desenvolvida os usuários devem dominar a língua inglesa para a boa interação, principalmente na questão de voz. Sobre Privacidade não existe o campo de senha ou outro que exija uma maior preocupação nesse sentido.

7) Projeto da entrada e saída multimodal. O projetista deve utilizar o recurso de múltiplas modalidades para maximizar as habilidades humanas cognitivas e físicas. Além disso, deve evitar a 
apresentação de informações desnecessárias nas diferentes modalidades, com o objetivo de maximizar as vantagens de cada modalidade para reduzir a carga de memória do usuário durante a execução de uma tarefa. É importante também integrar as modalidades de maneira compatível com as preferências do usuário, contexto e funcionalidades do sistema.

CheckList - Existem informações duplicadas (texto e voz individualmente e separadamente) sendo apresentadas ao usuário?

CheckList - Quais funcionalidades do sistema são melhor utilizadas usando-se interfaces ou componentes de voz? e gráfico? e ambos simultaneamente? Explique suas decisões?

Guideline: Para cada tarefa, use o modo de interação mais simples disponível no dispositivo.

Guideline: Se a mão ou a visão do usuário está ocupada, use interface de voz.

Guideline: se o usuário está em um ambiente ruidoso, use o toque ou interface gráfica.

Guideline: Use áudio para indicar que a informação fornecida deve ser verbal.

Guideline: Use pausas para dividir a informação em "grupos" naturais.

Guideline: Use animação e som para indicar transições.

Guideline: Use navegação por voz para reduzir o numero de telas

Guideline: Use interface gráfica para facilitar a retenção de informação na memória de curta duração do usuário.

exemplos:

* Se uma lista contem mais do que $7 \pm 2$ itens, mostre as opções na tela.

se um texto contem mais do que duas sentenças, apresente-o visualmente ao usuário

Aplicação: Informações duplicadas foram tratadas, tanto na interface gráfica quanto na interação por voz. A aplicação utiliza interface gráfica e componentes de voz de maneira que os componentes de voz auxiliam no preenchimento da interface. Os textos foram dispostos na tela para que o usuário retenha informações que podem ser usadas posteriormente para preenchimento com voz

8) Consistência na interação. As Interfaces visuais e de voz devem compartilhar ao máximo as características comuns e devem se referenciar a uma tarefa com a mesma terminologia nas diferentes modalidades.

CheckList - A terminologia e os comandos são consistentes entre as interfaces, componentes e modalidades?

Guideline: Permita ao usuário falar palavras-chave ao invés de sentenças complexas. Coloque essas palavras nos prompts do sistema.

Aplicação: sim, os comandos são consistentes e as palavras que o usuário deve utilizar como respostas para o preenchimento da interface gráfica são simples e visíveis na interface. 
9) Retorno (feedback) Os usuários devem perceber que modalidades estão presentes em determinado momento da interação e devem perceber quais são os tipos de interação alternativas que estão presentes para executar uma tarefa.

CheckList - o usuário percebe o estado atual de uma tarefa e sabe quando a terminou?

Guideline: use saída de voz para informar ou comentar uma ação do usuário ou fornecer informação complementar.

Guideline: Apresente a(s) palavra(s) reconhecida(s) pelo ASR na forma visual, para que o usuário possa verificar se o que foi reconhecido está correto.

Guideline: Mostre uma lista n-best para habilitar a correção de erros de reconhecimento de fala

Guideline: Tempo de resposta deve ser menor que 5seg. Informe ao usuário quando houver demora em consultas de BD.

Guideline: Sempre mostre o status do sistema ao usuário. Indique o caminho percorrido na forma gráfica. e permita falas do tipo "Repita", "volte", "menu principal"

Aplicação: quando a aplicação inicia, é executada uma mensagem de voz de maneira evidenciando ao usuário a possibilidade de voz. As ações incorretas do usuário são comentadas. Há comentários para ocorrência de erros e possibilidade de voltar pelo caminho percorrido na interface.

10) Tratamento e prevenção de erros.

Os erros podem ser evitados e minimizados e o tratamento de erros pode ser melhorado quando a interface fornece claramente ao usuário quais saídas o sistema disponibiliza e permitindo que ele reverta ou recupere suas ações quando desejado. Os usuários novatos ocasionalmente podem não responder a um prompt de maneira adequada. A interface deve ser projetada para detectar tais erros e ajudar os usuários a se recuperarem naturalmente. As interfaces multimodais devem ajudar o usuário a aprender como usar as múltiplas modalidades para atingir os resultados desejados rápida e eficientemente.

CheckList - Existem informações duplicadas (texto e voz individualmente e separadamente) sendo apresentadas ao usuário?

CheckList - O sistema consegue tratar erros de reconhecimento, estouro de tempo sem fala, ajudar o usuário, repetir a ultima fala, voltar para um local seguro e conhecido pelo usuário? Guideline: Sempre forneça ajuda sensível ao contexto para cada ação. Princípio reflexivo. As pessoas tendem a responder de maneira parecida como são perguntadas. Perguntas longas serão respondidas com respostas longas. Trechos da pergunta freqüentemente são usados na resposta.

Guideline: O usuário tende a usar o mesmo modo no qual foi feita a pergunta para fornecer a resposta.

Aplicação: é feito verificações de erros nos campos obrigatórios, tanto pelo modo gráfico ou por voz voltando o foco no campo que apresentar erro. 


\section{Apêndice C. Exemplo de DR identificado em um estudo de caso}

Questão: A seleção por voz do campo "Type Car" deve filtrar a lista de carros exibidos no campo "List of cars". Assim, se o usuário optar por tipo de carro igual a "Van", apenas carros dessa categoria devem ser exibidos na lista. Como sincronizar esses dois eventos?

Posição Desenvolvedor 1: utilizar <select>

Argumento Desenvolvedor 1: Quando seleciono van, car ou motocycle eu gostaria que apresentasse uma lista com os respectivos veiculos de cada categoria. Eu estou utilizando o componente <select> só que eu não sei realizar um filtro e depois setar no select apenas os cars.. ou vans.. ou motocycles... Tentei fazer com <assign>, porem não consegui.

Posição Desenvolvedor 4: : o <assign> do vxml serviria para informar via JavaScript para o select quais veiculos mostrar.

\section{Argumento Desenvolvedor 4:}

<vxml:assign name="document.frm1.listcars.options[0]" expr="new

Option('Pontiac','Pontiac')"/>

<vxml:assign name="document.frm1.listcars.options[1]" expr="new Option('Buick','Buick')"/> a tag <assign> é vxml mas o conteudo dela é jscript.

Questão Desenvolvedor 1: esse comando ja cria uma option no select?

Posição Desenvolvedor 4: : não, vc tem que ter o form html pronto e o select com o nome listcars. E este select não está em branco, entende? Ele já contém já de ínicio no mínimo duas opções referentes ao tipo 'Car'. E caso anteriormente o usuário tenha escolhido o tipo 'Both', esse select está com quatro opções.

Questão Desenvolvedor 1: Então esse select no início está assim?

<select name="listcars" id="idlistcars" class="input-box2">

$<$ option value $=$ "Pontiac" $>$ Pontiac $</$ option $>$

$<$ option value $=$ "Buick" $>$ Buick $</$ option $>$

$</$ select $>$

Posição Desenvolvedor 4: Certo.

Daí os seguintes comandos removem as oções que estavam lá anteriormente. Se tinha duas, todas foram retiradas. Se tinham quatro, duas foram retiradas.

\section{Argumento Desenvolvedor 4:}

<vxml:assign name="document.frm1.listcars.options[1]" expr="null"/>

$<$ vxml:assign name="document.frm1.listcars.options[0]" expr="null"/>

\section{Argumento Desenvolvedor 3:}

Dependendo do tipo do carro que ele escolheu ('Car','Van' ou 'Both'). Colocamos novas opções no select. Para o caso do usuário ter escolhido 'Van', colocaríamos as opções de carros 'Pontiac Vibe' e 'Blazer' por meio dos comandos: 
$<$ vxml:assign name="document.frm1.listcars.options[0]" expr="new Option('Pontiac Vibe','Pontiac Vibe')"/>

<vxml:assign name="document.frm1.listcars.options[1]" expr="new Option('Blazer','Blazer')"/>

\section{Argumento Desenvolvedor 3:}

só que o nome dele tem que ser listcars, por causa do JavaScript:

document.frm1.listcars.options[0] e o seu form HTML tem que chamar "frm1" nesse caso, o atributo 'action' está vazio pois não estamos salvando a informação da reserva do carro em nenhum banco de dados. Já que isso não está no escopo do projeto atualmente. ou vc troca o nome no JavaScript.

*Solução adotada*: A sincronização é realizada utilizando o comando <assign>. Caso o usuário escolha a opção de "Car" é automaticamente selecionado no formulário html as opções [0] e [1]: 'Pontiac', 'Buick'. Se a opção for por "Van", os itens [0] e [1] setados no formulário são 'Pontiac Vibe' e 'Blazer'. Caso a opção seja "Both", as 4 opções anteriores são exibidas nas opções [0], [1], [2] e [3].

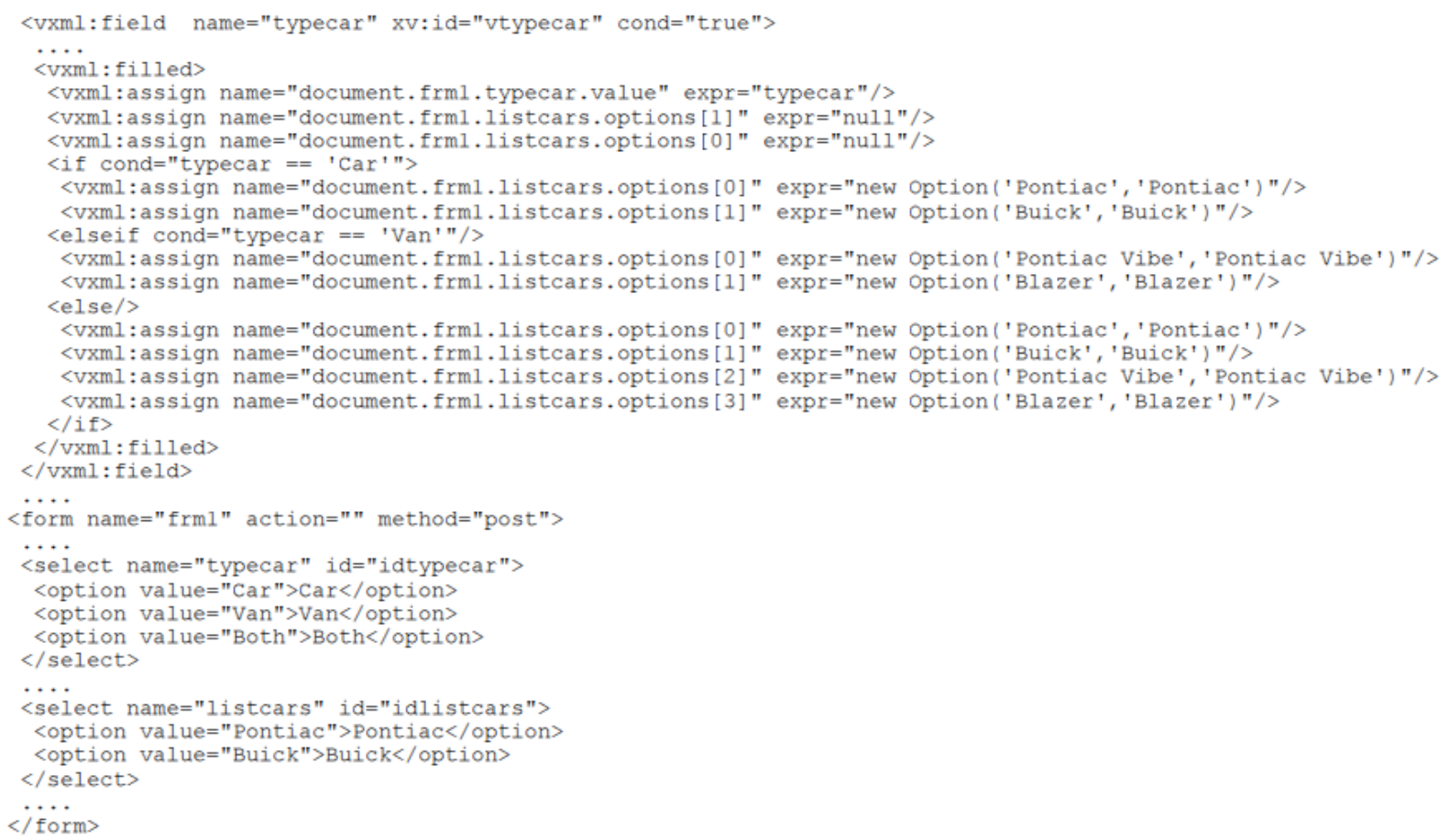




\section{Apêndice D. Questionário aplicado a um desenvolvedor que utilizou o MMWA-}

\section{ae}

O questionário a seguir, baseado no questionário SUMI ${ }^{14}$, foi aplicado a um dos desenvolvedores que utilizaram o MMWA-ae.

\begin{tabular}{|c|c|c|c|}
\hline & Concordo & Neutro & Discordo \\
\hline $\begin{array}{l}\text { Tanto a quantidade ou a qualidade das informações de ajuda varia dentro do } \\
\text { sistema. }\end{array}$ & & & $\mathrm{X}$ \\
\hline Este software responde muito lentamente às entradas & & & $\mathrm{X}$ \\
\hline Eu recomendaria esse software aos meus colegas. & $\mathrm{X}$ & & \\
\hline As instruções e mensagens de solicitação são úteis. & $\mathrm{X}$ & & \\
\hline O software "travou" inesperadamente. & & & $\mathrm{X}$ \\
\hline Aprender operar esse software inicialmente é cheio de problemas. & & & $\mathrm{X}$ \\
\hline $\begin{array}{l}\text { Às vezes eu não sei qual é a próxima ação a realizar na execução de uma } \\
\text { dada tarefa com esse software. }\end{array}$ & & & $\mathrm{X}$ \\
\hline Eu gosto de projetar interfaces com esse software. & & & $\mathrm{X}$ \\
\hline Eu acho que a informação de ajuda dada por esse software não é útil. & & & $\mathrm{X}$ \\
\hline Se esse software "trava", não é fácil de reiniciá-lo. & & $\mathrm{X}$ & \\
\hline A aprendizagem dos comandos desse software é muito lenta. & & & $\mathrm{X}$ \\
\hline Às vezes tenho dúvida se estou utilizando o comando correto. & & & $\mathrm{X}$ \\
\hline Projetar Interfaces com esse software é prazeroso. & & $\mathrm{X}$ & \\
\hline O modo que a informação do sistema é apresentada é claro e entendível. & $\mathrm{X}$ & & \\
\hline Eu me sinto mais seguro usando poucos comandos ou operações familiares. & & $\mathrm{X}$ & \\
\hline A documentação do software é bastante informativa. & & & $\mathrm{X}$ \\
\hline $\begin{array}{l}\text { Este software parece que rompe o modo que eu normalmente gosto de } \\
\text { realizar o meu trabalho. }\end{array}$ & & & $\mathrm{X}$ \\
\hline Utilizar esse software é mentalmente estimulante. & & $\mathrm{X}$ & \\
\hline Nunca há informação na tela quando é necessário. & & & $\mathrm{X}$ \\
\hline Eu me sinto no comando desse software quando estou usando o mesmo. & $\mathrm{X}$ & & \\
\hline Prefiro utilizar as funcionalidades que eu conheço melhor. & & $\mathrm{X}$ & \\
\hline Acho que esse software é inconsistente. & & & $\mathrm{X}$ \\
\hline Não gostaria de trabalhar com esse software todos os dias. & & & $\mathrm{X}$ \\
\hline Consigo entender e utilizar as informações fornecidas por esse software. & $\mathrm{X}$ & & \\
\hline Este software é ruim quando eu quero fazer algo que não seja simples. & & $\mathrm{X}$ & \\
\hline Há muito o que aprender antes de conseguir usar o software. & & $\mathrm{X}$ & \\
\hline $\begin{array}{l}\text { As tarefas podem ser realizadas de uma maneira bem direta usando esse } \\
\text { software. }\end{array}$ & $\mathrm{X}$ & & \\
\hline Usar esse software é frustrante. & & & $\mathrm{X}$ \\
\hline $\begin{array}{l}\text { O software me ajudou superar qualquer problema que eu tenha tido ao } \\
\text { utilizá-lo. }\end{array}$ & & $\mathrm{X}$ & \\
\hline
\end{tabular}

${ }^{14}$ http://sumi.ucc.ie/ 


\begin{tabular}{|l|l|l|l|}
\hline A velocidade desse software é rápida suficiente. & X & & \\
\hline Eu tenho que olhar as instruções para utilizar esse software. & X & \\
\hline $\begin{array}{l}\text { É óbvio que as necessidades dos usuários foram totalmente levadas em } \\
\text { consideração. }\end{array}$ & X & \\
\hline $\begin{array}{l}\text { Houve momentos durante a minha utilização do software que eu me senti } \\
\text { tenso. }\end{array}$ & & & \\
\hline $\begin{array}{l}\text { A organização dos menus ou das listas de informação parece ser bastante } \\
\text { lógica. }\end{array}$ & X & \\
\hline $\begin{array}{l}\text { O software permite que o usuário seja econômico em digitação ou cliques } \\
\text { de mouse. }\end{array}$ & $\mathrm{X}$ & & \\
\hline Aprender usar as funcionalidades é difícil. & & & $\mathrm{X}$ \\
\hline Há muitos passos que devem ser executados durante o trabalho & $\mathrm{X}$ & & \\
\hline Acho que esse software já me deixou confuso em certa ocasião. & & & $\mathrm{X}$ \\
\hline Mensagens de prevenção de erro não são adequadas. & & $\mathrm{X}$ & \\
\hline É fácil fazer o software realizar exatamente o que você deseja. & $\mathrm{X}$ & & \\
\hline Nunca aprenderei todas as funcionalidades que esse software oferece. & & & $\mathrm{X}$ \\
\hline O software nem sempre fez o que eu esperava. & & & $\mathrm{X}$ \\
\hline O software possui uma apresentação atraente. & $\mathrm{X}$ & & \\
\hline $\begin{array}{l}\text { Tanto a quantidade ou a qualidade das informações de ajuda varia dentro do } \\
\text { sistema. }\end{array}$ & & & $\mathrm{X}$ \\
\hline É relativamente fácil mover de uma parte da tarefa para a outra. & $\mathrm{X}$ & & \\
\hline É fácil de esquecer de fazer algumas coisas. & & & $\mathrm{X}$ \\
\hline Este software ocasionalmente se comporta de um modo que eu não entendo. & & & $\mathrm{X}$ \\
\hline Esse software é realmente muito difícil. & & & \\
\hline $\begin{array}{l}\text { É fácil de descobrir as opções disponíveis para cada estágio de execução de } \\
\text { uma tarefa. }\end{array}$ & $\mathrm{X}$ & \\
\hline $\begin{array}{l}\text { Eu preciso procurar por assistência a maioria das vezes que estou usando o } \\
\text { software. }\end{array}$ & & & \\
\hline
\end{tabular}




\section{Apêndice E. Trechos de artefatos desenvolvidos no EC1}

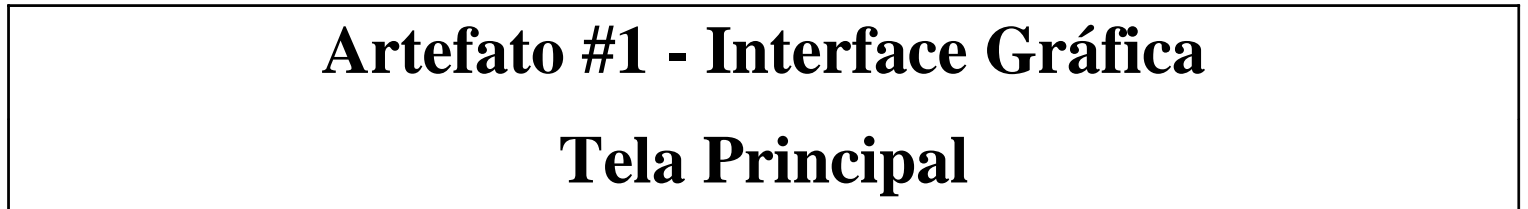

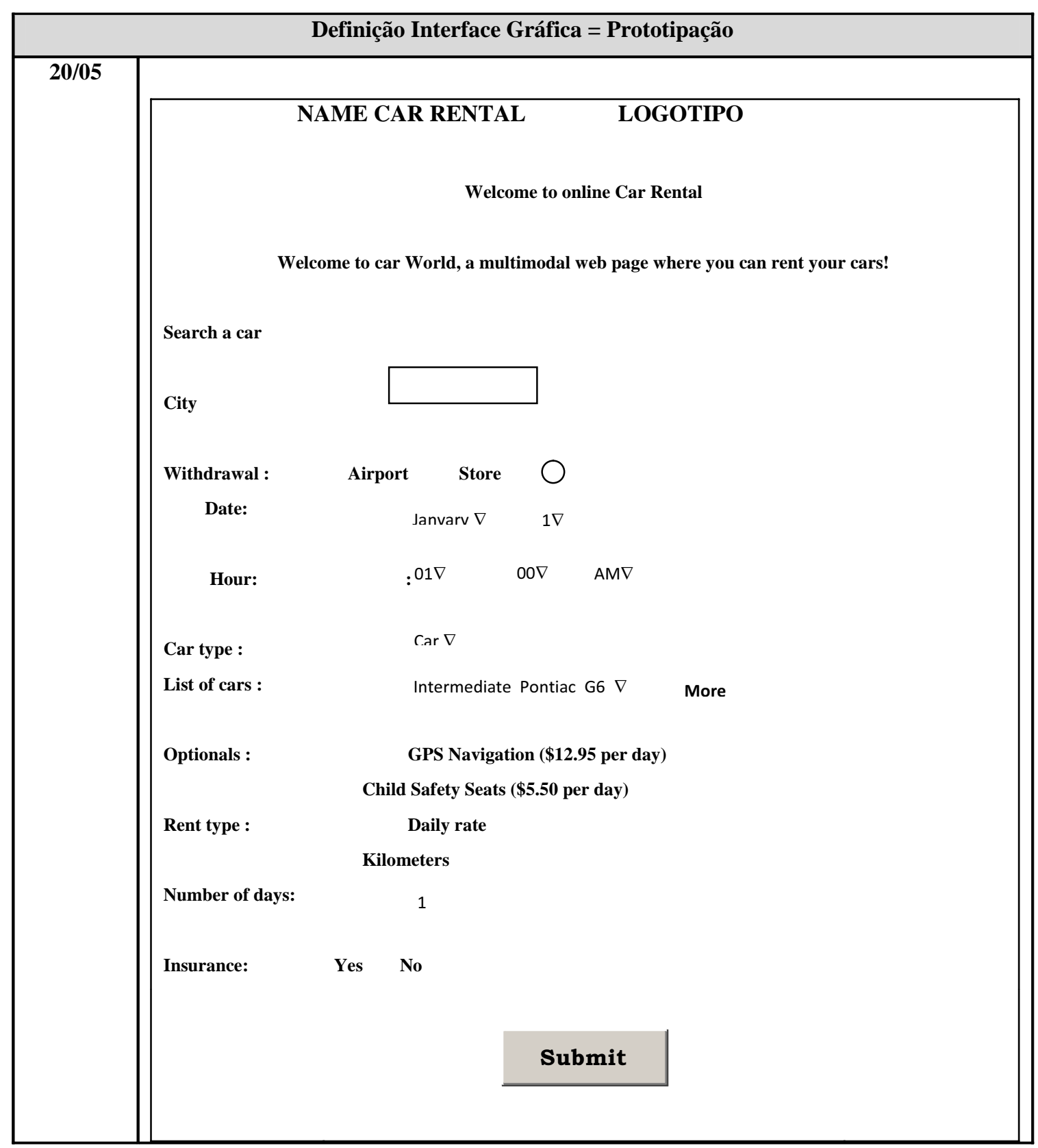


Apêndice E

\section{Artefato \#2 - Interface Gráfica Detalhes dos Carros}

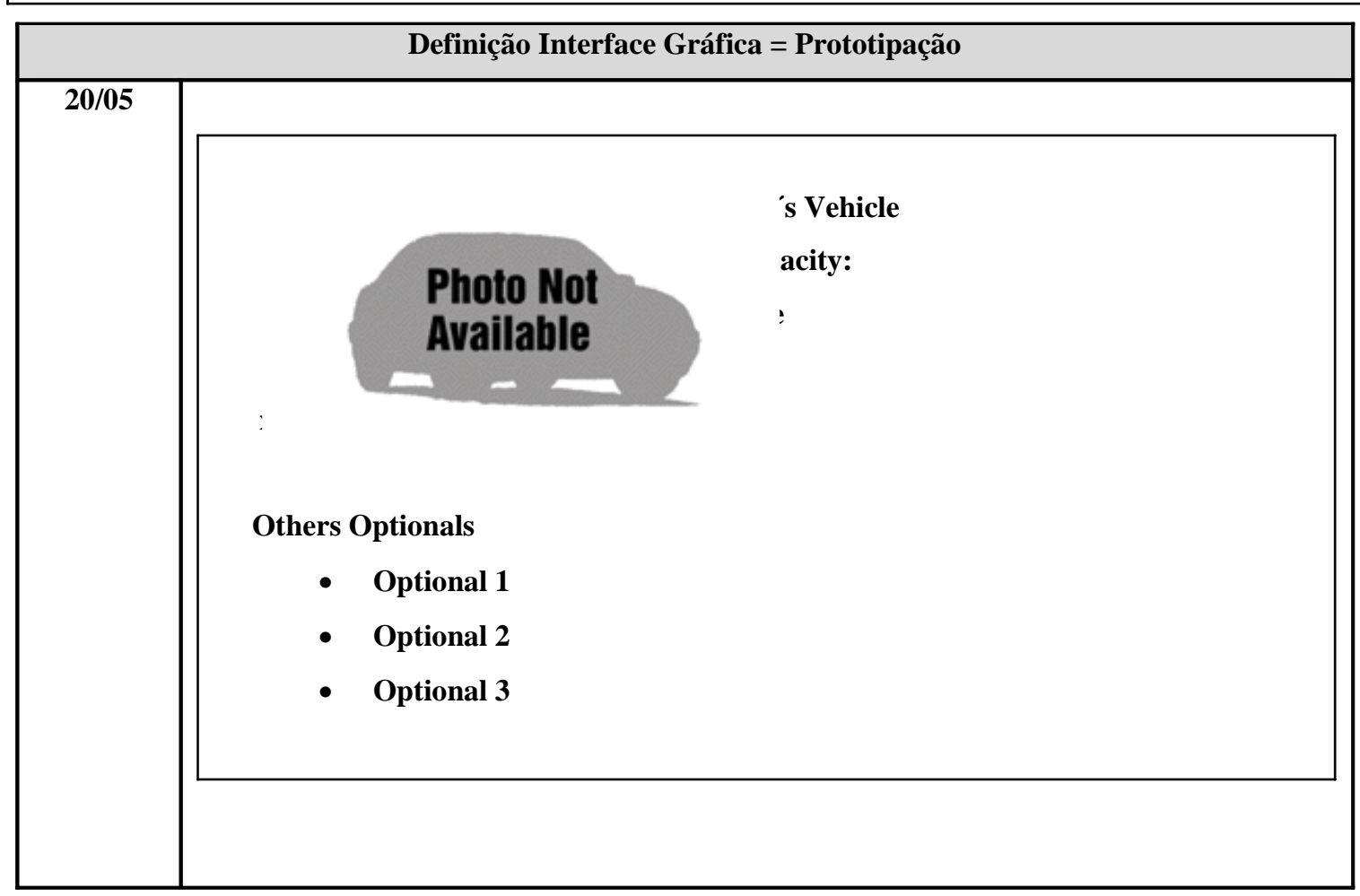




\section{Artefato \#3 : Interface + Voice + Sincronização}

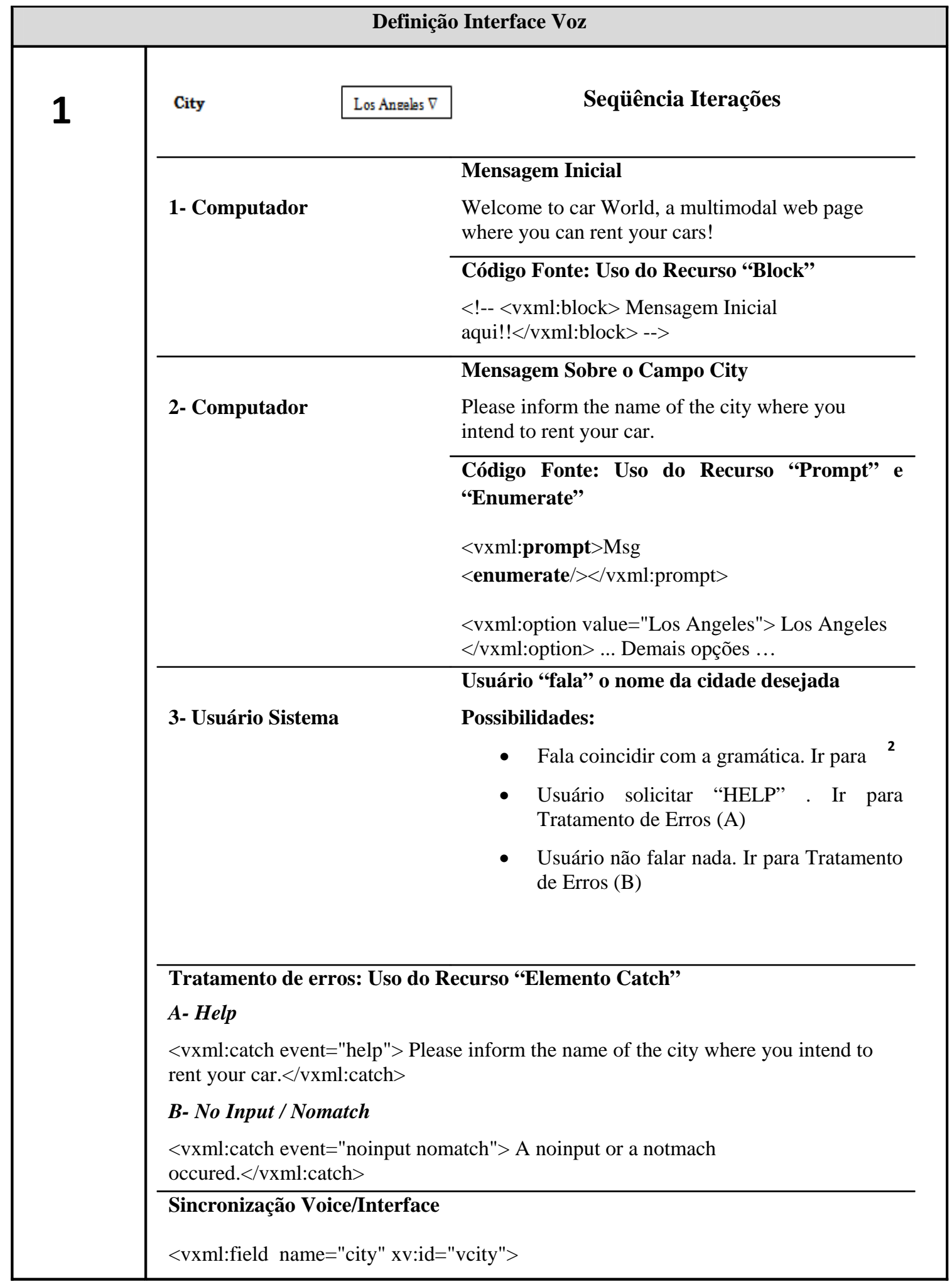


<vxml:assign name="document.frm1.city.value" expr="city"/>

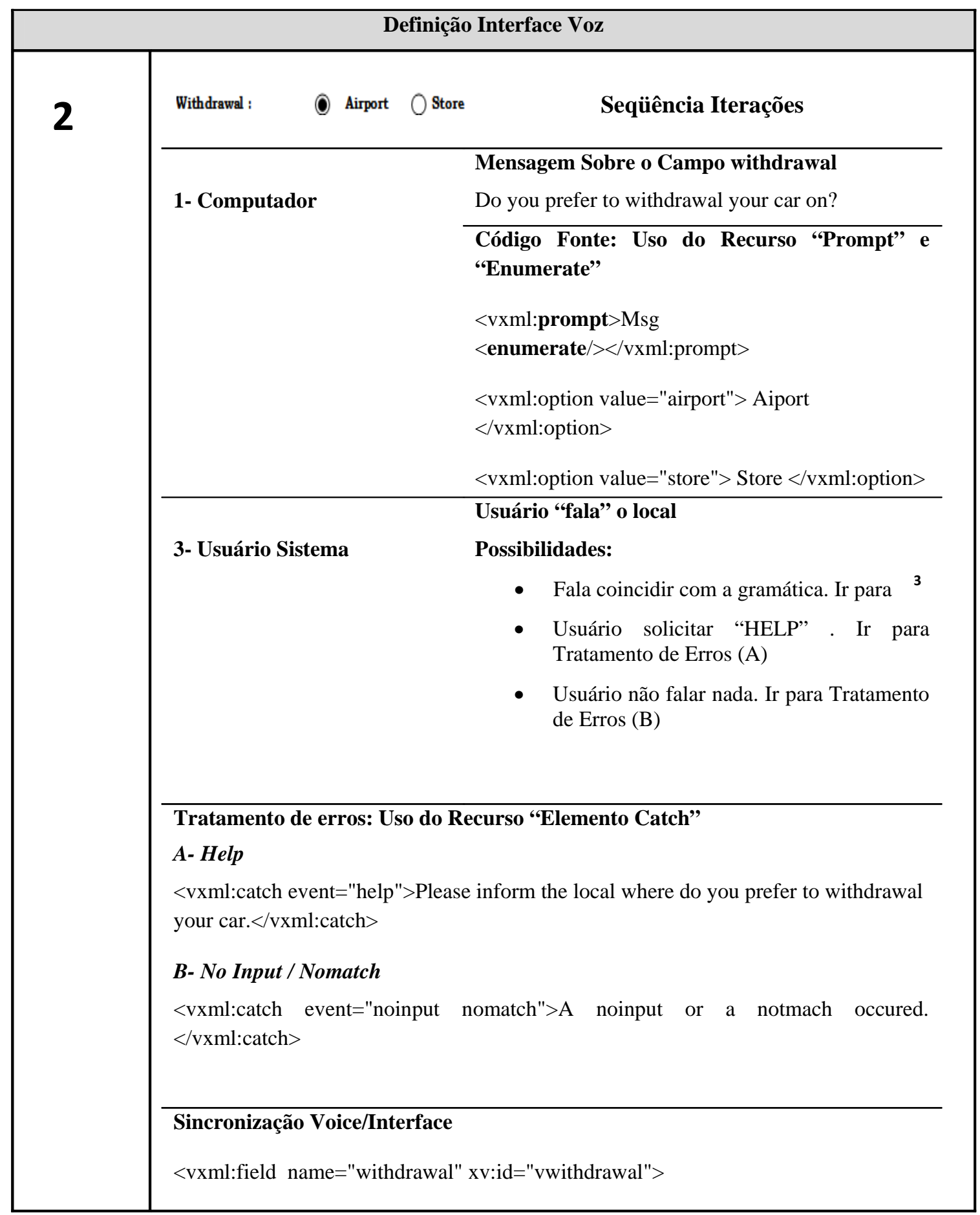




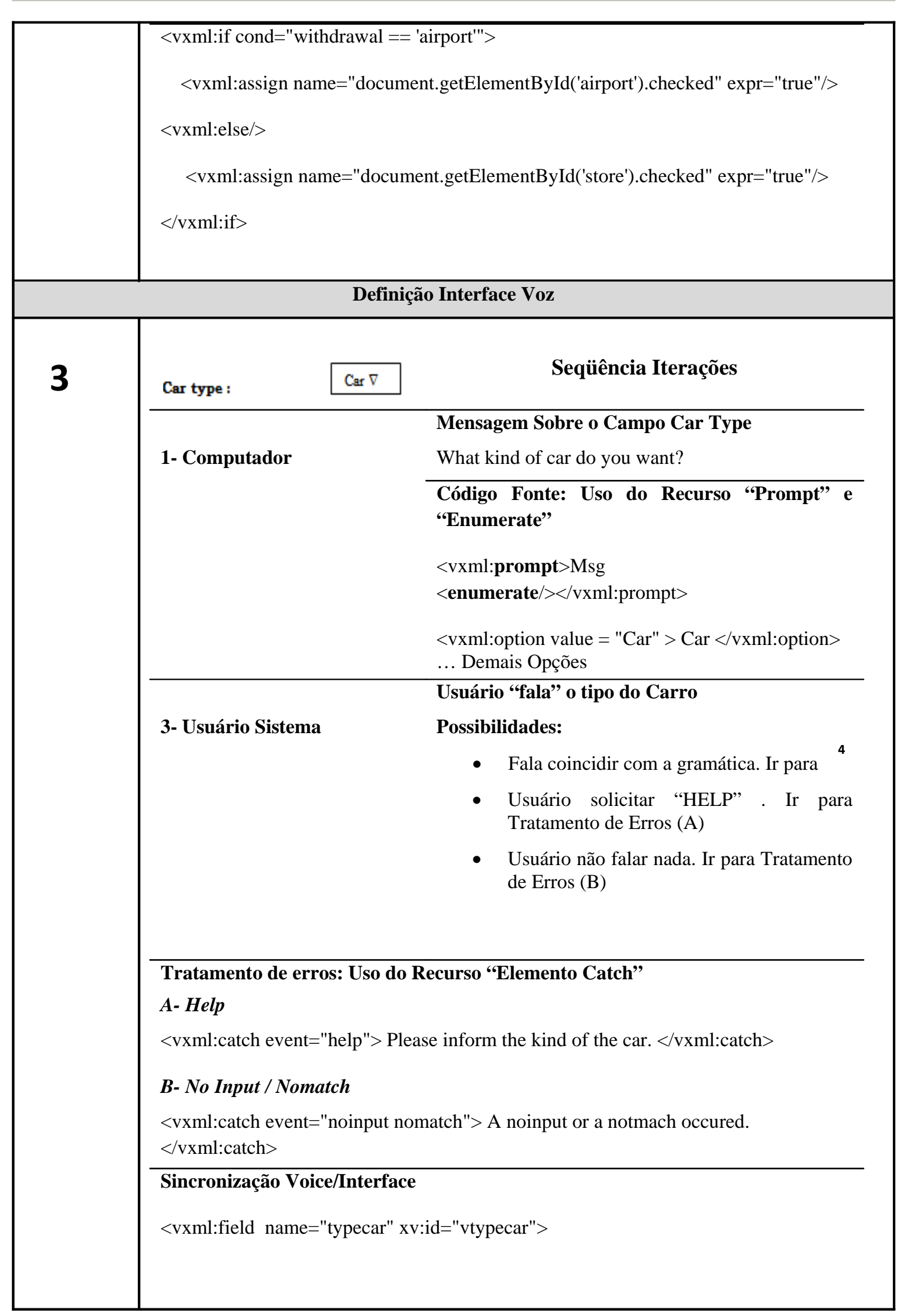




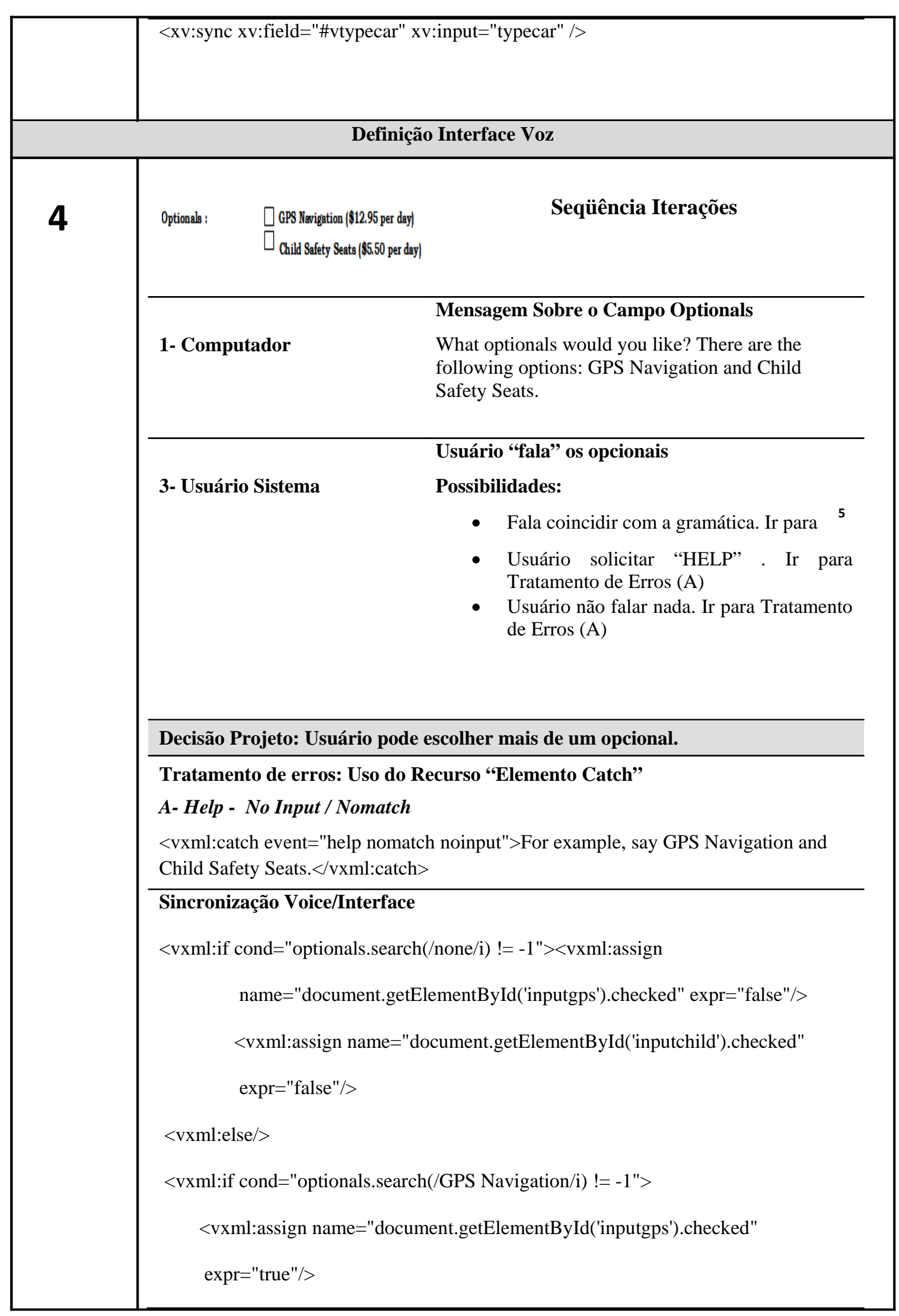




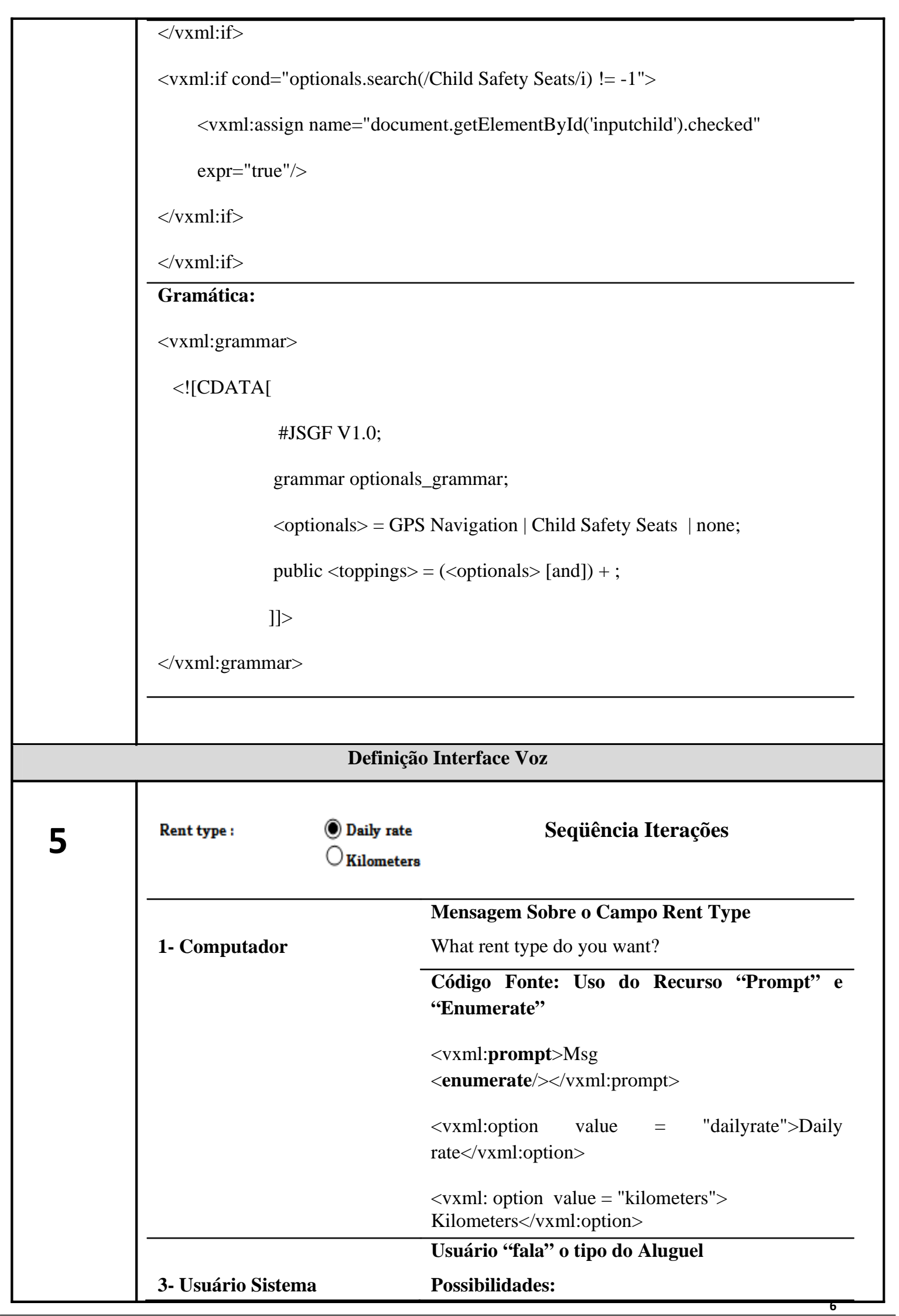




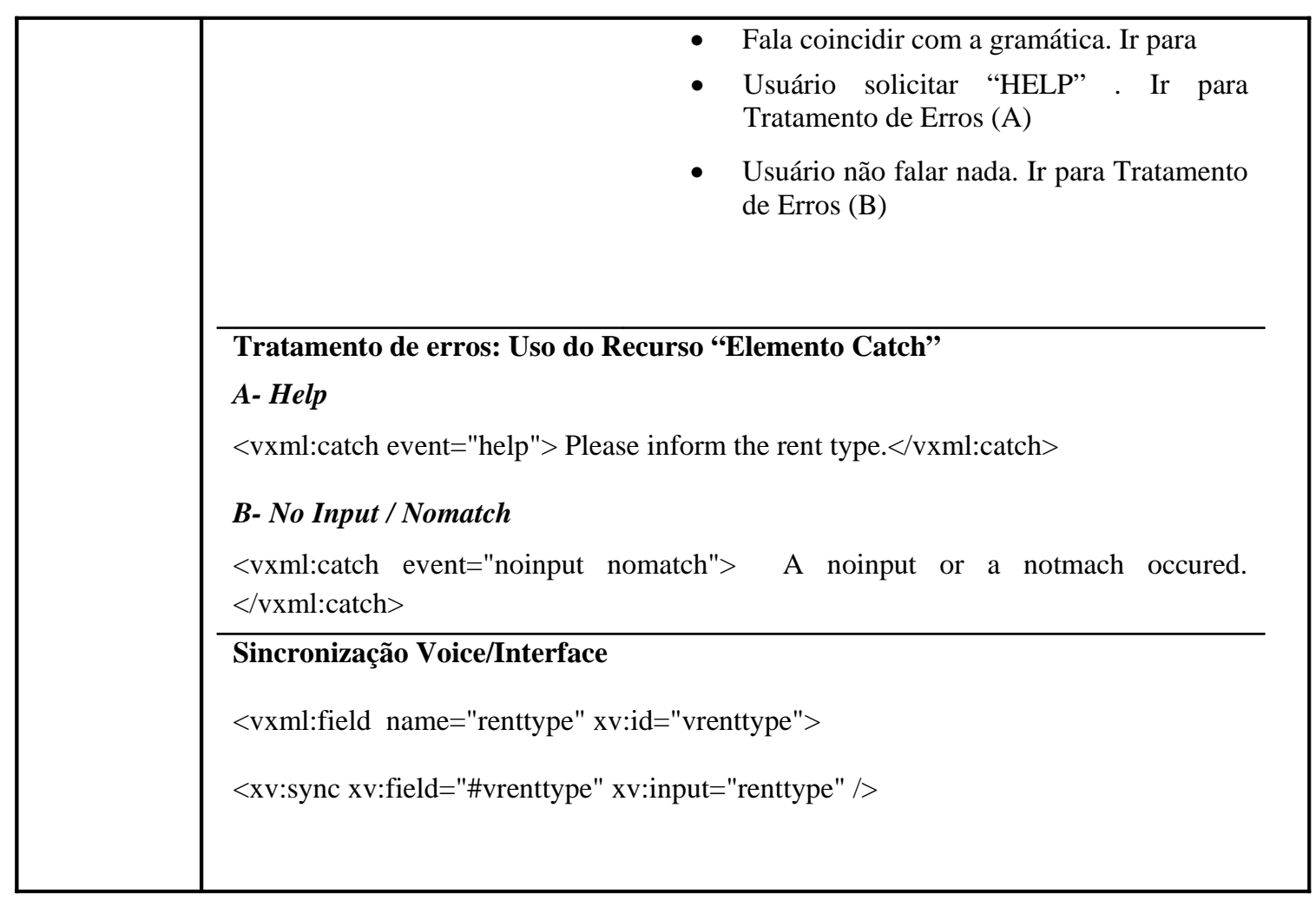

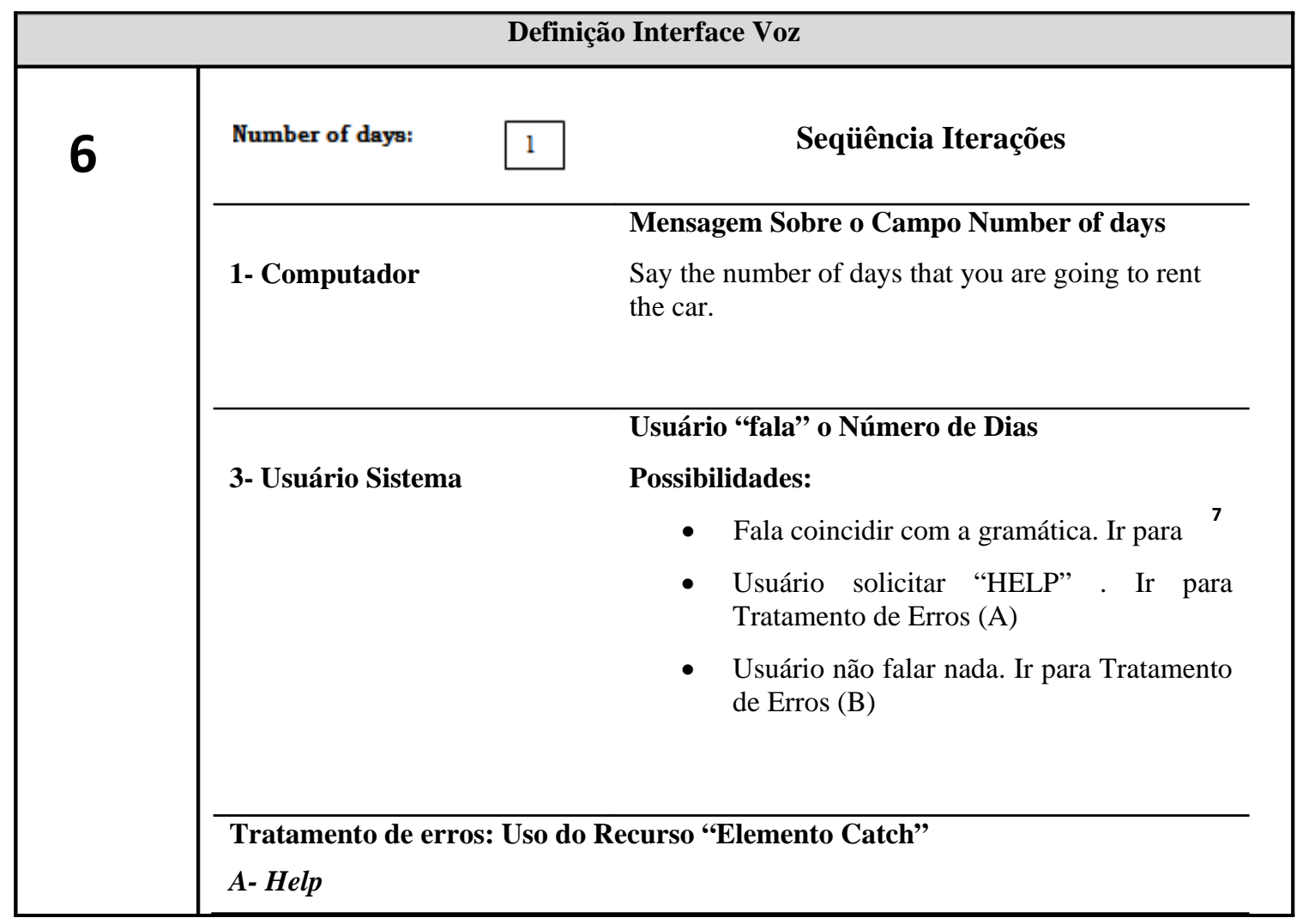


$<$ vxml:catch event="help"> Please inform the number of days that you are going to rent the car. </vxml:catch>

\section{B- No Input / Nomatch}

<vxml:catch event="noinput nomatch"> A noinput or a notmach occured. $</ v x m l$ catch $>$

\section{Sincronização Voice/Interface}

<vxml:field name="numberofdays" xv:id="vnumberofdays" type="digits">

<vxml:assign name $=$ "document.getElementById ('numberofdays'). value" expr="numberofdays"/>

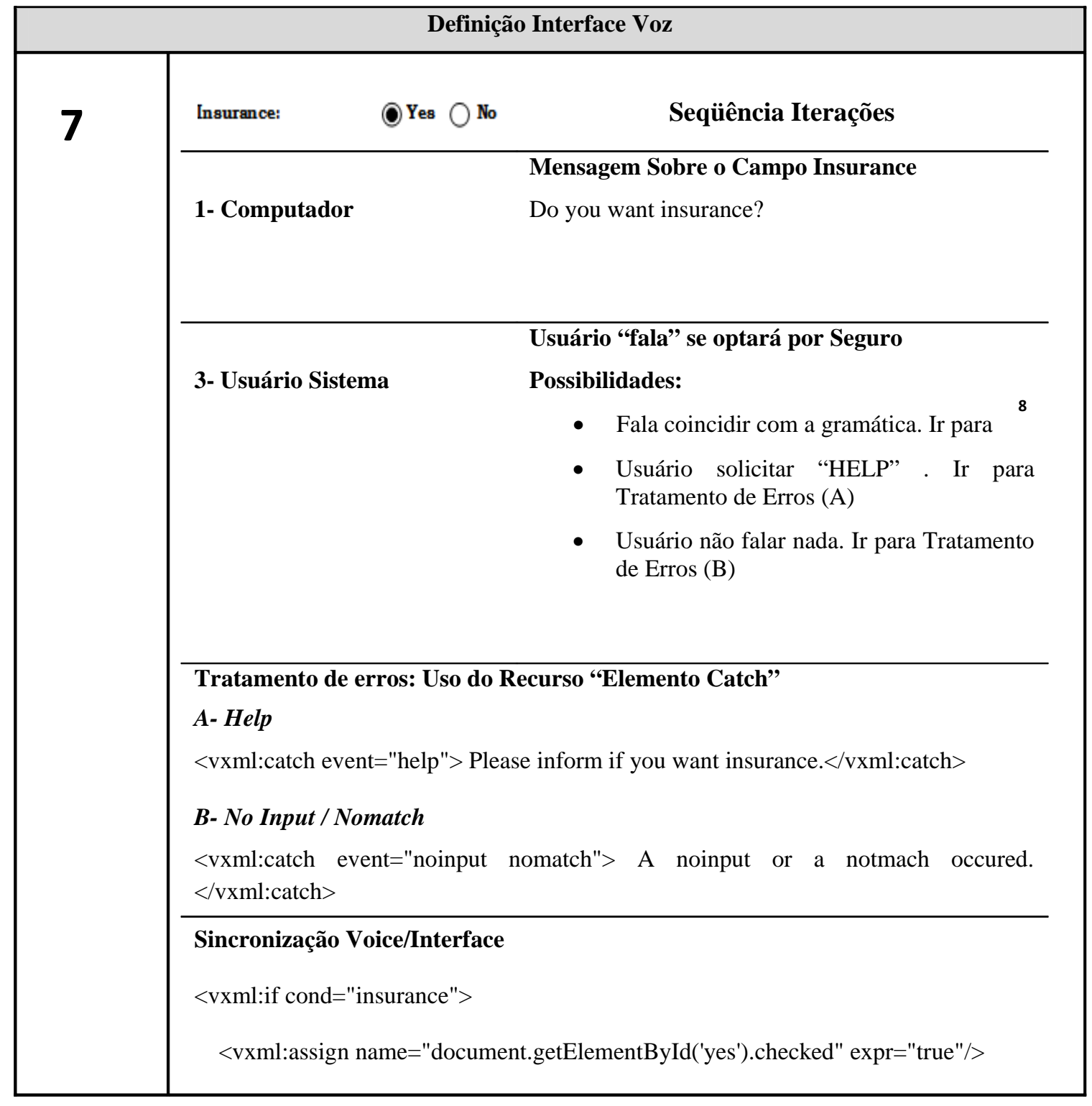


<vxml:else/>

<vxml:assign name="document.getElementById('no').checked" expr="true"/> $</ v x m l:$ if $>$

\begin{tabular}{|c|c|c|}
\hline \multicolumn{3}{|c|}{ Definição Interface Voz } \\
\hline \multirow[t]{9}{*}{8} & Submit & Seqüência Iterações \\
\hline & \multirow{4}{*}{ 1- Computador } & Mensagem Final de Confirmação \\
\hline & & $\begin{array}{l}\text { Computador repete todas as opções selecionadas } \\
\text { pelo usuário }\end{array}$ \\
\hline & & $\begin{array}{l}\text { Código Fonte: Uso do Recurso "Prompt" e } \\
\text { "Value Expr" }\end{array}$ \\
\hline & & $\begin{array}{l}\text { <vxml:prompt> You said <vxml: value } \\
\text { expr="city"/>, <vxml:value expr="withdrawal"/>, } \\
\text { <vxml:value expr="typecar"/>, <vxml: value } \\
\text { expr="optionals" />, <vxml: value expr="renttype" } \\
\text { />, <vxml: value expr="numberofdays"/> and } \\
\text { <vxml: value expr="insurance"/> to insurance. Is } \\
\text { this correct? </vxml:prompt> }\end{array}$ \\
\hline & \multirow{3}{*}{ 3- Usuário Sistema } & Usuário “confirma” ou "não confirma" \\
\hline & & $\begin{array}{l}\text { Possibilidades: } \\
\text { - Fala coincidir com a gramática do tipo } \\
\text { BOOLEAN } \\
\text { ○ Confirmação do Usuário: "Link" } \\
\text { para "Fechar". }\end{array}$ \\
\hline & & $\begin{array}{l}\text { ○ Não Confirmação do Usuário: } \\
\text { "Link para correção. }\end{array}$ \\
\hline & \multicolumn{2}{|c|}{$\begin{array}{l}\text { Sincronização Voice/Interface } \\
\text { <vxml:field name="confirm" type="boolean"> }\end{array}$} \\
\hline
\end{tabular}


Apêndice E

Legenda:

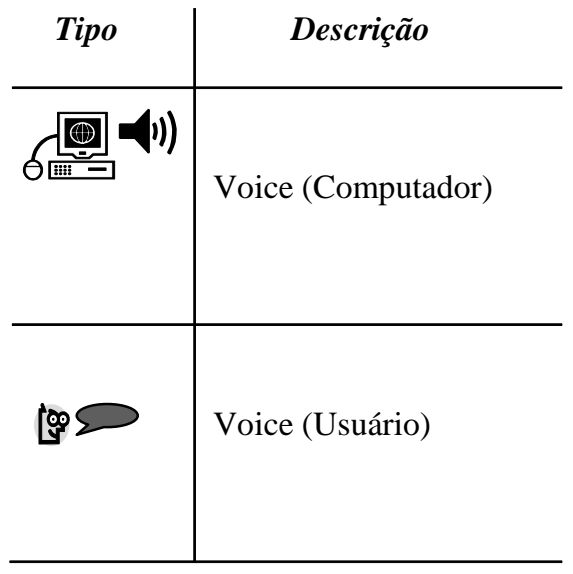

